\title{
Death Education: An Educational Approach to Death and Dying
}

\author{
PETER A. CLARK, PH.D, JENNIFER DONOHUE, DANIEL DISANDRO, DAVID GRANA, ANDREW MYERS, MICHAEL FONTANA, KEVIN \\ COONEY
}

pclark@sju.edu

Abstract: This paper explains the importance of education in the dying process and outlines a full curriculum to create a society more prepared for difficult end-of-life situations. This course is structured to be taught as a high school elective course in which the principles and approaches to death and dying are discussed in depth. For a high school student, death can be approached from diverse perspectives. Within these perspectives, there are several vital topics to understand in order to ensure a student's proper education on death. The complexity of death is represented by the titles of the nine chapters of the course. Chapter One, titled "Definition of Death, Consciousness, and Persistent Vegetative State," highlights the development of death throughout history, the general consensus about death today, and the morality of different levels of treatment for dying patients. Chapter Two, "End Stage Medical Conditions," outlines the most common end-of-life health conditions along with their symptoms and possible treatments. In Chapter Three, titled "Bad News and Communication," the course introduces patient-physician communication, the current shortcomings of medical education in this vital area, and the possible protocols for effectively conveying both truth and sup port to a patient. Chapter Four, labelled "Do Not Resuscitate Orders, Living Wills/Advance Directives, and Durable Powers of Attorney for Health Care," presents the appropriate options available to prepare for a patient's inability to make informed decisions autonomously. Chapter Five, "Ordinary vs. Extraordinary Means: The Issue of Tube Feedings," discusses the distinction between different types of end-of-life treatment and when certain treatments can be morally excused. Chapter Six, titled "Palliative Care and Hospice: A Paradigm for End-of-Life Care," gives effective options for terminally ill patients that ensure care is never stopped and a patient's dignity is never lost. Chapter Seven, "Pain Management," highlights the difficulties and recommendations for establishing proper pain management. Chapter Eight, entitled "Medical Futility," presents the debate surrounding patient autonomy with physician's beneficence and nonmaleficence, forgoing and requesting treatments, and the values associated with this issue. Finally Chapter Nine, titled "Spirituality and End of Life Care," emphasizes the inevitable linkage between healthcare, death, and spirituality and the benefits of proper support for a patient. This paper also highlights the ethical implications surrounding the death and dying process. The importance of this subject lies within the death-denying reality that society is today in which death is avoided and human dignity is increasingly sacrificed as a result. Discussions and education among society's youngest adults can improve general knowledge about the dying process and lead to overall better preparation for handling this inevitable stage of humanity.

*Address correspondence to: Peter A. Clark, S.J., Ph.D. Director-Institute of Clinical Bioethics Saint Joseph's University. 5600 City Avenue Philadelphia, Pennsylvania 19131. Email: pclark@sju.edu

+To cite this article: Clark, P., Donohue, J., DiSandro, D., Grana, D., Myers, A., Fontana, M., Cooney, K. “Death Education: An Educational Approach to Death and Dying". The Journal of Healthcare Ethics \& Administration Vol. 7, no. 1 (Winter 2021): 11-159, https://doi.org/10.22461/jhea.1.71627

This work is brought to you for free and open access by the Institute of Clinical Bioethics (ICB) at Saint Joseph's University, Philadelphia, PA, U.S.A. It has been accepted for inclusion in The Journal of Healthcare Ethics \& Administration by the editorial board and an authorized administrator of the JHEA. For more information, please contact support@jheaonline.org 


\section{THE JOURNAL OF HEALTHCARE ETHICS \& ADMINISTRATION}

Vol. 7 | No. 1 (Winter 2021)

\section{INTRODUCTION}

We are born, we live, and then we die. This is the natural cycle of life, with the inevitable fate of death. Death is often an emotionally heavy topic, and in the cycle of life "death is a rite of passage in which we all participate - as family member, provider, or, eventually patient - we understand little of what is valued at the end of life." In fact, for most of us, we seem to avoid mentioning death for fear that it might become a reality and we might have to face the inevitable with honesty.

The uncertainty surrounding death can be filled with grief, terror, unease, or a wide array of emotions. For a high school student, death can be approached from different and diverse perspectives, and can also be related to several different individuals. It is possible students have never taken the time to think about the realities of death. It is also possible that students have had real experiences with the death of a loved one. Either way, one thing is for certain - humans have a 100 percent mortality rate. This inevitably is frightening, which is a familiar response of a death-denying culture in America. Fear and trepidation can overwhelm the topic of death because conversations surrounding the end of life are often left undiscussed. Without an atmosphere of willingness to talk about topics surrounding the end of life, it is easy for fear of the unknown to take over. Avoiding the topic of death altogether is a symptom of the death-denying culture. Establishing an educational curriculum about the practical aspects of dying and death will help facilitate an atmosphere of approachability surrounding death and the dying process. Here, discussions and education can improve a student's knowledge about the dying process so they can better handle this inevitability in their personal and familial lives.

The culture of death has changed over the decades. In the twentieth century, most people died at home and their loved ones, primary physicians, and/or community assumed responsibility for their care. With the advent of technology and the cultural shift toward autonomy, our understanding of death and dying has changed. Physicians' use of the latest advances in medicine and technology have become responsible for maintaining the lives of millions of hospitalized individuals. According to the Centers for Disease Control and Prevention, "the percentage of deaths from all causes that occurred in a hospital decreased from $48.0 \%$ in 2000 to $35.1 \%$ in $2018 . .^{\prime 2}$ Also during that period, "the percentage of deaths that occurred in the decedent's home increased from $22.7 \%$ to $31.4 \%$, and the percentage that occurred in a long-term care facility (hospice, nursing home, long-term care) increased from $22.9 \%$ to $26.8 \% .^{\prime \prime 3}$ Throughout a patient's hospital stay and a physician's evaluations of health progress, a patient may be asked to make decisions in which they are uncertain of the consequences of particular medical actions/procedures. In particular, the request or decision to use all means necessary to maintain life. This is where education and intentional conversations about death and the dying process can help prepare individuals for what the dying process entails.

Instead of talking about death and dying honestly and allowing individuals to get their lives in order to prepare for the inevitable, today "death is viewed through the lens of biomedical explanation and is primarily defined as a physiological event." ${ }^{4}$ Three false gods have become prominent in contemporary American culture when it comes to any discussion on death and dying: "an unrealistic faith in technology; the view that death is always someone's failure; and a moral sense that pays little attention to clinical realities but becomes scrupulous." ${ }^{5}$ These false gods have caused us to avoid the inevitability of death, which has resulted in an unrealistic view of death and the false hope of avoiding it at all costs. The result has been that many individuals are dying without the dignity and respect they deserve. Instead of being surrounded by loved ones with their symptoms adequately assessed and managed, they are often dying alone, alienated, dehumanized, and connected to all types of sophisticated technology that is

\footnotetext{
${ }^{1}$ Steinhauser et al., "In Search of a Good Death: Observations of Patients, Families, and Providers." Annals of Internal Medicine 132, no. 10 (May 16, 2000): 825-832.

${ }^{2}$ National Vital Statistics System. Underlying cause of death data, 2000-2018. https://wonder.cdc.gov/ucd-icd10.html.

${ }^{3}$ Ibid.

${ }^{4}$ Steinhauser et al., "In Search of a Good Death:" 825-832.

${ }^{5}$ Sheehan, M. "A Great Comfort." America (October 7, 2000): 8-11.
} 


\section{THE JOURNAL OF HEALTHCARE ETHICS \& ADMINISTRATION}

Vol. 7 | No. 1 (Winter 2021)

burdensome and very expensive. The intention of the patient's family and physician is to give the best medical treatment available, but in reality, they are denying the patient the best care.

When a patient is dying, often there is a silence associated with the dying process. It is this silence that confronts us as we face the fear of the unknown. Instead of going deep within ourselves and confronting the fear and silence, we try to name the silence and even try to avoid it with the false hope of one last experimental medication or one more surgery or another round of chemotherapy or radiation therapy. Americans have become a "death-denying society," but the truth is that death is a reality that cannot be hidden, ignored, or conquered. It must be faced realistically. Death is frightening because we are dealing with a fear of the unknown, but it does not have to incapacitate us. If one faces death realistically, surrounded by family and friends, it has the potential of bringing about peace and a transformation for not only the patient but for all who are present.

Care for the dying has become a national priority according to many medical associations and the public in general. We now talk about what constitutes a "good death." What is a "good death?" Generally speaking, a "good death" should be one in which the patient and his or her loved ones feel empowered to participate in medical decision-making and do what they believe is in the best interest of the patient. According to studies, a "bad death frequently includes scenarios in which treatment preferences are unclear. Patients felt disregarded, family members felt perplexed and concerned about suffering, and providers felt out of control and feared that they were not providing good care. Decisions that had not previously been discussed usually had to be made during a crisis, when emotional reserves were already low." ${ }^{6}$ Unfortunately, this is the situation that many terminal patients and their families find themselves in today. Instead of allowing suffering and the dying process to form and inform us, we are allowing it to destroy us. "A good death, regardless of the circumstances, means putting medical care in proper perspective and not allowing it to dominate." This notion of a "good death" is not only important to the person who is dying but also for the patient's family and friends who survive this event. Therefore, all have a role to play in the dying process.

Dr. Elisabeth Kübler-Ross in the late 1960s formulated five stages that she believed people go through after the diagnosis of a terminal illness. The stages are denial, anger, bargaining, depression, and finally acceptance of their inevitable death. She recognized that not all people go through all five stages and some could become stuck at one stage. She also believed people could jump stages. She believed, however, that if one reached the final stage of acceptance, then it was likely that the person would die in peace, which would also give comfort to their family and loved ones. ${ }^{8}$

Understanding these stages and their implications helps not only the terminal patient but family members and even physicians to face death realistically. Patients have to be able to talk about their feelings and should feel comfortable allowing others to be with them as they go through the dying process. Family members and loved ones have to be present to the patient in both words and actions, have to respect the patient's feelings and values, and have to be open to learning from the experience. Physicians have the duty to be open and honest with their patients about end-of-life treatment and care, to be willing to hear and respect the patient's feelings and values, and to be there with the patient until the end.

There comes a point in every terminal situation when treatment options become limited or even nonexistent. When a physician can no longer cure, he or she still has the duty to provide care. No patient is ever beyond care. Allowing a patient to die with dignity not only respects that individual patient, but allows us, who are left behind, to learn from this experience so that we are better prepared to accompany others through the same process in the future. Accepting and understanding the dying process will allow patients to die with dignity and respect, will give family members the comfort of knowing that their loved one is at peace, and will give physicians the consolation of knowing that they acted in the best interest of their patient.

To help bring about this notion of a "good death" for all concerned, researchers have identified six components of a good death. These six components neither guarantee the "right way" to die nor offer a perfect solution, but they can be used as a framework for understanding what patients tend to value at the end of life. The six components are the following:

\footnotetext{
${ }^{6}$ Steinhauser et al., 827.

${ }^{7}$ Sheehan, “On Dying Well." America (July 29-August 5, 2000): 12-15.

${ }^{8}$ Kübler-Ross, E. On Death and Dying. New York: Macmillan, 1969.
} 


\section{THE JOURNAL OF HEALTHCARE ETHICS \& ADMINISTRATION}

Vol. 7 | No. 1 (Winter 2021)

1. Pain symptoms and management. Pain, more than dying itself, is often the cause of anxiety among patients and families

2. Clear decision making. Patients feel empowered by participating in their treatment decisions.

3. Preparation for death. Patients want to know what to expect as their illness progresses and to plan for what will follow their deaths.

4. Completion. Completion includes not only faith issues but also life review, resolving conflicts, spending time with family and friends, and saying goodbye.

5. Contribution to others. Patients nearing death often achieve clarity as to what is really important in life and are anxious to share that understanding with others.

6. Affirmation. Study participants emphasized the importance of being seen as a unique and whole person and being understood in the context of their lives, values, and preferences. ${ }^{9}$

These preferences show that end-of-life care should be holistic, involving not only the physiological but also the spiritual and psychosocial aspects of the process. The problem is that, for this to happen, family members and physicians must be aware of what can be done to help facilitate a "good death." Curricula in medical schools and residency programs often fail to incorporate the very practical knowledge physicians need to understand and communicate bad news and end-of-life treatment options to their patients and their families. This causes a lack of clarity for patients and decision-makers which makes family members helpless, confused, and in a state of despair. At a time when family members are called upon to be present to a loved one in a terminal condition in order to support them and assure them that they will die with dignity and respect, just the opposite happens. Due to their lack of medical knowledge and their feelings being overwhelmed by the complex world of medicine and technology, family members often feel paralyzed and guilty that they have abandoned their loved ones at the most crucial time. This is the state of medicine in American culture today.

This curriculum will attempt to address these complex and often confusing issues in a practical way so that patients and you, the family members have some guidance in dealing with end-of-life issues. The focus will be on doing what is medically and ethically appropriate and doing all of this in a timely manner. We hope that this effort will cause a paradigm shift in the care of the terminally ill so that all people may properly prepare for and experience the most dignified and peaceful death possible. This will start with you, the students, and it will become your responsibility to implement what you learn from this course during real-life experiences.

\section{CURRICULUM}

Outside of the realms of teachers and educators, the term "curriculum" may be understood in diverse and perhaps contradictory ways. Curriculum is certainly associated with education and learning, but this shallow grasp does not do the concept justice and fails to explain why it is so emphasized in the circles of education. The etymology of the word is revealing: curriculum is the original Latin term meaning "race" or "racecourse", which is itself derived from curro, the verb meaning "to run/proceed." ${ }^{10}$ This illuminates two key points of an educational curriculum. First, much like the ancient racecourses of the Roman charioteers, the educational curriculum must be established before the event itself can take place. An architect must plan the starting point, the duration, the materials used, and the final goal of the course. Similarly, an educator must establish a baseline and foundation of knowledge, set a pace of study, plan appropriate amounts of time for various topics, decide what texts, activities, and assessments will be used, and determine what standards are going to be addressed by the course of study. The second key similarity of the curriculum to the curriculum is the progressive nature of the course. The contender and the student are both required to move forward and stay true to the course in order to achieve their goals. Thus, a curriculum is ordered to facilitate movement from fundamentals to complexities, all being relevant to the learning standards being addressed.

\footnotetext{
${ }^{9}$ Steinhauser et al., 826-828

${ }^{10}$ Harper, Douglas. "Curriculum (n.)." Online Etymology Dictionary, https://www.etymonline.com/word/curriculum.
} 


\section{THE JOURNAL OF HEALTHCARE ETHICS \& ADMINISTRATION}

Vol. 7 | No. 1 (Winter 2021)

The practice of curriculum development and delivery is common because of the benefits that this practice provides for educators and students alike. For the teacher, a curriculum provides a comprehensive plan, establishing fundamentals and progressing in a logical sequence towards specific standards and goals. This benefits the students by giving them a clear direction for their efforts, rather than the disorder of lessons on varied topics without a cohesive purpose. A curriculum also enhances the transparency and accountability of the education process by laying out measurable goals that the teacher will address. Poor instruction by the teacher will become clear when the predetermined criteria for success are not being achieved by students.

Within the modern educational context, it is commonly recognized that curriculum is not limited to the explicit plans, materials, activities, projects, assessments, and lessons developed and delivered by the educator. The use of an explicit educational curriculum, named as such, can be documented as far in the past as the sixteenth century A.D., a time period when the loosely structured schools of the medieval period were being reordered by Renaissance ideals. ${ }^{11}$ More recently, curricula are written, purchased, and even mandated for use by governing agencies. However, the tangible curriculum is not the only course on which students embark; there is also the implicit curriculum that students experience through classroom dynamics, hierarchies, relationships, and attitudes. The implicit curriculum forms students' perceptions of social norms, modes of thought, and conceptions of what constitutes learning. The explicit and implicit curricula are not simply a culmination of the experienced and learned; what teachers decide to leave out of the curriculum can be just as important. Knowledge that is excluded from a curriculum can be important in shaping students' ideals, self-conceptions, and future opportunities. ${ }^{12}$

In American high schools, students are often mandated to embark on a multi-year curriculum of elective courses that may include foreign languages, physical education, human health and sexuality, music, arts, and other content areas that may enhance the life experiences and character formation of the student. Notably absent from such curricula are courses that specialize in the reality that all people are guaranteed to face: Death. If elective curricula are designed to holistically educate high school students, the topic of death must be addressed in a straightforward and nuanced manner. This curriculum proposes to plumb the depths of death and dying in the modern world through nine chapters, ranging in topics from definitions of death to medical practice to spirituality, as well as a brief introductory chapter. It is recommended that the course begins with the viewing of FRONTLINE's "Facing Death" as an introduction to the difficult reality of the topics introduced in this curriculum. This can be found in the Additional Resources section of the Introduction to the course.

Each chapter of this curriculum begins with a relevant quotation and thereafter lists what "students will be able to" (SWBAT) do after the chapter has been completed. The SWBAT list gives the curriculum a goal that is supported by the Pennsylvania State Common Core, a set of guidelines for student achievement and skills. The pertinent guidelines are listed with each chapter, giving the teacher discretion in terms of which standards to highlight. The sometimes-opaque language of the PA State CC is deconstructed and rewritten in a curriculum-specific form in the "Overarching Practical Goals of Curriculum" section, which is divided into three parts: The Basics, Preparation Techniques, and Communication. The Basics describe the literal, factual knowledge that students should extract from the chapter. The Preparation Techniques describe particular topics that the teacher should be aware of before teaching the chapter to the students and sometimes suggests an activity or resource that can mentally prepare students for the upcoming content. Finally, the Communication step is meant to extend the impact of this curriculum beyond the classroom by providing ways for students to bring their newfound knowledge into their familial and cultural context. After the Overarching Goals, a brief "Pre-Assessment Activity" is outlined that can be used to introduce the chapter's topic before the students are exposed to its content. The activity not only sparks students' interest, but also serves to illuminate the backg round knowledge or misconceptions that students bring with them, thereby helping the teacher know which topics should be emphasized in future lessons. Various chapters also contain "Do Now" activities that further serve to introduce students to the chapter as well as give teachers a gauge of students' baseline understanding.

Each text of each chapter is divided into subsections and important terms are bolded. This structure allows for pacing by section and the creation of a glossary of vocabulary. At the end of each chapter (except Chapter 2) there is a "Post-Chapter

\footnotetext{
${ }^{11}$ Hamilton, David. Towards a Theory of Schooling. Routledge, 2014.

12 Zamboni, Jon. "How Do Explicit \& Implicit Curriculum Differ?" The Classroom / Empowering Students in Their College Journey, Leaf Group Ltd., 10 Jan. 2019, https://www.theclassroom.com/explicit-implicit-curriculum-differ-11367407.html.
} 


\section{THE JOURNAL OF HEALTHCARE ETHICS \& ADMINISTRATION}

Vol. 7 | No. 1 (Winter 2021)

Assessment Activity" that can be used by the teacher in place of or in addition to another assessment technique to determine whether the students achieved the goals outlined at the beginning of the chapter. A list of recommended discussion questions is also included at the end of each chapter (except the Introduction); these questions may be used or modified for use in the Pre- or PostChapter Assessment Activities or incorporated into other assignments. Some chapters contain a "Closure" exercise, the basis of which is for the students to complete an exercise themselves that forces them to rehash a specific topic or area. Also, an "Exit Ticket" is present to complete most chapters that challenges students to answer a pertinent question in order to leave the classroom. Finally, most chapters have a "Further Reading" section or an appendix to supplement the chapter's content. Additional relevant resources and experiences (e.g., films, field trips, service activities, etc.) may be incorporated into the curriculum at the discretion of the teacher. At the very end, a culminating research paper will be due, which will entail research conducted in groups examining one of the seven end-stage conditions from Chapter 2.

\section{CHAPTER SUMMARIES}

In Chapter 1, the definition of death is explored. Prior to extreme advancements in technology, death was marked by the permanent and irreversible cessation of the circulatory and respiratory function - when the heart no longer beats and a person no longer breaths. However, these new technological improvements raised issues as they made the traditional concept of death obsolete, as improvements in resuscitative and supportive measures led to an increase in efforts to save patients who were gravely injured. As a result, two issues drove consensus toward a new "brain death" criteria: organ donation and allocation of medical resources. From this, multiple new definitions of death arose, but the one that gained general consensus was "whole brain death." The clinical criteria of this definition included: 1) unreceptivity and unresponsivity to externally applied stimuli and inner need;2) absence of spontaneous muscular movements or spontaneous respiration; 3) no electable brainstem reflexes; and 4) the presence of an EEG confirmatory value. In 1980, the National Conference of Commissioners on Uniform State Laws formulated the Uniform Determination of Death Act (UDDA), which legally defines death based on the whole-brain criterion as recommended by the President's Commission. Despite clear clinical criteria regarding brain death, there are groups who do not believe in the brain death criteria due to cultural or religious beliefs, such as Orthodox Judaism, and remain steadfast in their belief in traditional cardiopulmonary death. One aspect of "brain death" that causes great confusion is related to minimally conscious individuals and those in a persistent vegetative state (PVS). Minimally conscious patients, and those in a permanent vegetative state are not brain dead as they do not meet the whole-brain criterion. Patients in a minimally conscious state or in a persistent vegetative state are categorically distinct from those patients who meet the brain death standard. One is still alive and the other is clearly dead. This does not mean that those who are minimally conscious or in PVS have to be aggressively treated. After careful ethical discernment, which would include pertinent medical information and consideration of the patient's values and wishes, a decision to not initiate or to withdraw medical treatment would be medically appropriate and morally justified.

Chapter $\mathbf{2}$ looks to draw attention to and explain seven of the most common conditions people may face at the end of their life. Each section explains what the disease is, its causes, treatments, and known risk factors. The sections then provide suggested lifestyle changes that, may decrease the likelihood of developing the condition. The conditions outlined in this chapter are End Stage Renal Disease, HIV/AIDS, Cancer, Congestive Heart Failure and Heart Disease, Dementia and more specifically Alzheimer's, and Cerebrovascular Diseases. Due to the detail provided in this chapter, it allows the next chapters to address the ethical questions surrounding treatment options and care. The common themes of the coming chapters are the standards of care, physician and patient relationships, and responsible decision making.

Chapter $\mathbf{3}$ deals with the essential and inevitable aspect of medicine: communicating bad news. It is a topic that concerns both patients and physicians. And as technology continues to become more and more integrated into daily life, communication and the skills necessary to successfully comprehend nuances in conversation have become deemphasized. While the benefits of technology in medicine are undeniably tremendous, the value of human to human interaction cannot be replicated by any technology developed to date. This chapter discusses the death denying society that America has become, and the role that both the 


\section{THE JOURNAL OF HEALTHCARE ETHICS \& ADMINISTRATION}

Vol. 7 | No. 1 (Winter 2021)

physician and patient can play in reversing this reality. The chapter presents a series of six practical steps, called SPIKES, to assist physicians in the deliverance of "bad news." The first step includes setting up an interview to ensure privacy and confidentiality. Next, the physician should assess the patient's perception of his or her condition and situation by posing open-ended questions. The next step includes obtaining the patient's invitation to divulge information about his or her situation, as some do not want to know the specifics of the case. Presenting the information in a basic but compassionate manner is the next step in the process. Penultimately, addressing the patient's emotions with empathic response helps to show support and a willingness to walk with the patient in his or her situation. Finally, providing a clear plan and process for the future can help lower a patient's stress and anxiety. Overall, this chapter stresses the need for cultural, social, and spiritual sensitivity on part of the physician. This is an ongoing process of education that currently begins in medical school but needs to be initiated before and must be continued throughout residency programs and beyond.

Chapter 4 discusses the intersection between advances in technology in medicine and the ability of a physician to determine the correct ethical treatment for a patient. It primarily focuses on documents to assist physician-patient communication, namely DNR orders, Advance Directives/Living Wills and Durable Powers of Attorney for Health Care. A DNR order, which is consented to by a patient or surrogate and written by a physician, is a physician's order that tells health care professionals that if this particular patient suffers cardiopulmonary arrest, the patient should not be resuscitated. Other options for a patient include "full code" and "limited code," which means that only certain procedures will be done. This chapter stresses the need for education on "code status," because unless patients or surrogates understand the full implications of what "code status" entails, they cannot give informed consent. This chapter also highlights the contrast between DNRs and ANDs ("Allow Natural Death"), which generally involves a more comfortable experience for both the patient and family, and how and when to write a DNR/AND.

Next, the chapter covers Advance Directives, which indicate specific kinds of decisions an individual would make if he/she were unable to participate in the decision-making process, and Living Wills, which apply to more specific situations. The chapter outlines common terminology, requirements, and criteria for activating Living Wills. Lastly, Chapter 4 explains how to negate a Living Will as well as alternative options for End-of-Life decisions.

To conclude the section on Advance Directives, the chapter describes the Durable Power of Attorney for Healthcare, which explains who is assigned the duty of making decisions for a patient in the event that patient is incompetent or otherwise unable to make medical decisions for his/herself. The responsibilities of the Healthcare POA, recommendations for how to choose one, and the selection process are discussed therein. Decision-making hierarchy and other types of surrogate decision-makers are also discussed.

To end the chapter, the authors utilize their experience at an organ donation facility to discuss organ donation and the many popular myths surrounding the topic. The overall goal of the chapter is to educate everyone about the options available for patients who are near death or terminally ill because addressing these challenges will not only allow patients to die with dignity and respect, but will give family members the peace of mind of knowing that they made decisions in the best interest of their loved one.

Chapter 5 covers the concepts of ordinary and extraordinary means of treatment. The differences are based on the prudential, cautious judgement of the patient or the patient's decision maker on whether the techniques and resources used offer an equal amount of hope of benefit without causing excessive burdens to the overall quality of the patient's life. Until 2004, the concept of ordinary-extraordinary means allowed each individual the freedom to use his or her well-formed conscience to make judgments about what would be in his or her best interest as a whole person. This notion was applicable to medicine in many circumstances such as deciding whether a patient could refuse to start or withdraw ventilators, feeding tubes, dialysis, pacemakers, and so on. However, Pope John Paul II challenged this notion and sparked an ongoing debate when he proclaims that food and water represent a natural means of preserving life, and denying that idea is morally incorrect. The chapter highlights the development of the modern idea of ordinary-extraordinary means from the fourth century AD to Domingo Banez determining that a treatment or medical procedure was ordinary or extraordinary according to whether it was proportionate to one's condition or state in life. The complications of advanced technology, including artificial feeding and hydration, are also analyzed in this chapter. The last section of the chapter is devoted to Pope John Paul II's speech. It examines the questions raised, the resulting shift in 


\section{THE JOURNAL OF HEALTHCARE ETHICS \& ADMINISTRATION}

Vol. 7 | No. 1 (Winter 2021)

methodology and the role of conscience in the debate. Finally, the authors call for a simple solution: respect the traditional understanding of the ordinary-extraordinary means distinction that has served the Church and society well for centuries.

Chapter 6 outlines Palliative and Hospice Care. It primarily focuses on the unfortunate yet inevitable decision that many face life-prolonging treatment has been unsuccessful: how to reduce the suffering of an individual when death is imminent. The first option offered is palliative care, which is a form of medical care or treatment that concentrates on reducing pain and managing symptoms of a disease, rather than providing a cure. Palliative care is not restricted to end of life care, but rather can be utilized for any procedure. The three well-defined purposes of palliative care are pain management, symptom management, and the improvement of patient and family quality-of-life. The chapter then highlights hospice care as a part of the palliative care philosophy while also providing the history of hospice care in the world, as well as the more recent history within the United States. The chapter highlights the criteria for entering hospice, which requires that patients acknowledge they are in the dying process and are willing to forego insurance coverage for life prolonging treatments and that two physicians certify that the patient has a life expectancy of six months or less. The chapter provides abundant evidence that displays the benefits of palliative/hospice care, while also presenting the evident unawareness of the existence of such programs among Americans. Overall, despite providing some of the criticisms of hospice care, the chapter stresses the need for increased awareness and a shift in the perception of these programs. No longer should these programs be viewed as abandonment and giving up hope, but rather hospice and palliative care have to be seen as receiving the care that the patient and the family desperately need.

Chapter 7 examines pain management, specifically its history, issues surrounding the topic, the ethics associated with pain management, and recommendations for improving the state of pain management in the modern world of medicine. The history of pain management primarily centers around opiates, leading up to the current opioid crisis and the benefits and dangers of prescribing opioids. The chapter explains the complications with pain management and its reliance on each individual patient, detailing the three main types of pain: nociceptive, neuropathic, and incidental. The main purpose of this chapter is to high light the barriers to proper pain management and why innumerable patients have experienced unnecessary pain due to subpar pain management. The ethical nature of this issue centers mostly around respect for persons and the duty of a physician to do what is in the best interest of a patient. The chapter includes a case study to provide a tangible application of this information. Lastly, the chapter focuses on how to improve pain management in healthcare, specifically recommending that pain management becomes a top priority in hospitals with programs and teams assembled for its purpose. Overall, in order for this chapter to invoke real change, reforms are needed from various aspects of society. It is both the professional and ethical responsibility of healthcare professionals to see that these reforms are initiated and carried out so that the best interest of the patient remains at the forefront of the medical profession.

While Chapter 7 settled the controversy surrounding a patient's rights to refuse medical treatment, it started another about whether a patient also has a corresponding right to demand medical treatment. Chapter 8 covers the idea of medical futility, specifically the resurgence of the debate surrounding a patient's rights to dictate how they are treated. Ethically, patients argue that if they have the right to withhold or withdraw certain medical treatments this also gives them the right to request certain medical treatments because they know what is in their best interest. Physicians argue that many of these interventions are burdensome for the patient and medically inappropriate, citing misuse of medical equipment and resources. While this chapter details the debate and its legal implications, it also provides an ethical analysis of what is truly "futile" and what makes a life meaningful. The chapter highlights the types of futility, patient autonomy, and beneficence on the part of the physician. Lastly, the chapter provides recommendations for improving upon patient awareness of futile treatment, and several example policies related to the topic are included.

The final chapter of the curriculum parses out the role of spirituality at the end of life. It explains that many spiritual and religious convictions will form the foundation by which many patients base their decision making when confronted about lifesustaining decisions. This chapter also discusses the lack of awareness and comfortability that many physicians possess surrounding this topic. Chapter 9 first lays the groundwork for this topic by explicating the definition of spirituality. In short, the chapter defines it as our relationship to what we value most and with our commitment to live in a way that is consistent with what this value of love ultimately demands. While the chapter presents numerous studies focused on the intersection of prayer and medicine with 


\section{THE JOURNAL OF HEALTHCARE ETHICS \& ADMINISTRATION}

Vol. 7 | No. 1 (Winter 2021)

conflicting results, it presents spirituality as an essential part of a physician's empathizing with a patient. It also describes the importance of a patient's dependence on God and physician, as well as the importance of a patient's physician and family to be present and understanding. The role of ritual in the Christian tradition as well as the stages of grief are explained to finish the chapter.

\section{CONCLUSION}

Death is a guaranteed reality for all human beings. And yet, because of the death-denying culture in which we live, conversations and education on this inevitable topic are rarely discussed, if ever, before dire circumstances present themselves. In a world in which medical technology is rapidly advancing, the need to be educated on topics related to this stage in life is most paramount. Preparatory education and conversations on this widely avoided topic can lead to a drastic increase in patients and their loved ones dying with the dignity and respect that each person deserves. Therefore, this curriculum allows young people to enter their adulthood prepared with a background knowledge in the most prevalent topics surrounding death. We hope this is only the first step in a series of many that this country and world can take to better educate society. Yes, it is an "elective" class as it stands right now, but we regard this curriculum and the information contained therein as a requirement in order to advance toward a world more fully prepared to face life's guaranteed phenomenon. 


\section{APPENDIX I - CHAPTER 1: DEFINITION OF DEATH, CONSCIOUSNESS, AND PERSISTENT VEGETATIVE STATE}

Quote: "The boundaries which divide Life from Death are at best shadowy and vague. Who shall say where the one ends, and where the other begins?" - Edgar Allen Poe, The Premature Burial

Chapter Objectives: (SWBAT= Students will be able to..)

- SWBAT differentiate clinical death and brain death

- SWBAT differentiate whole brain death and higher brain death

- SWBAT know and understand three criteria necessary to diagnose Persistent Vegetative State (PVS)

- SWBAT comprehend the difficulties that are faced with treating patients diagnosed with PVS, locked-in syndrome, and other serious conditions.

Standards (derived from Common Core State Standards)

\section{CC.1.3.11-12.B}

Cite strong and thorough textual evidence to support analysis of what the text says explicitly as well as inferences and conclusions based on and related to an author's implicit and explicit assumptions and beliefs

\section{CC.1.5.11-12.A}

Initiate and participate effectively in a range of collaborative discussions on grade level topics, texts, and issues, building on others' ideas and expressing their own clearly and persuasively

\section{CC.1.2.11-12.H}

Analyze seminal texts based upon reasoning, premises, purposes, and arguments.

\section{Overarching Practical Goals of Curriculum:}

Step 1 - The Basics - Knowing the difference between clinical death, brain death, and Persistent Vegetative State.

Step 2 - Preparation Techniques - An acceptance that death is more complicated today due to advances in technology. Individuals must begin to recognize that these terms are not abstract and will impact their lives someday.

Step 3 - Communication - We ask that students question their parents or other trusted adults (aunts, uncles, etc.) about their personal definition of death and return to class next day with a few key words or sentences.

Pre-Assessment Activity: Students will work in small groups to compare and contrast the definitions of death their parents gave the previous night. From this discussion, they will form two definitions: one that reflects the collective definition of parents, and another that is what students think should be the definition of death. This discussion should be guided by some (or all) of the following questions:

- When you talk about death do you prefer saying someone "passed away" or someone "died" or no preference? Can you explain?

- How would you define death?

- Do you believe in life after death? What do you think it's like?

- Are you afraid to die? Can you explain?

- Is this a difficult conversation for you to have with me? Why or why not?

- What else would you like to say on the subject? 


\section{THE JOURNAL OF HEALTHCARE ETHICS \& ADMINISTRATION}

Vol. 7 | No. 1 (Winter 2021)

\section{Sections:}

\section{$\underline{\text { Introduction }}$}

When does a persons' life come to an end? Before advances in medical technology made prolonging life a reality, this question was answered rather easily. Death was marked by the permanent and irreversible cessation of the circulatory and respiratory function when the heart no longer beats and a person no longer breaths. This was known as "clinical death". This diagnosis was first described in medical literature in 1959 and was widely used over the next ten years, with the use of specific clinical criteria. ${ }^{1}$ This traditional concept of death was determined by physicians and was based on all vital signs that relate to cardio-pulmonary (heart and lung) function without much thought given to the role of the brain. Advances in medical technologies during the 1950's and 1960's (Iron lung, ventilation, CPR, dialysis, etc.) made prolonging life a distinct reality. However, these new technological improvements raised issues as they made the traditional concept of death, "clinical death", obsolete. Improvements in resuscitative and supportive measures led to an increase in efforts to save patients who were gravely injured. This resulted in cases where the patients were left with irreversible brain damage and loss of cognitive function.

\section{What is a Living Person?}

Historically, death was believed to be an event that coincided with clinical death. New technologies showed that death was a process, rather than an event. ${ }^{2}$ "In 1959, Mollaret and Goullon used the term dépassé, 'a state beyond coma," to describe a condition from which they believed recovery was not possible." ${ }^{3}$ This state of irreversible unconsciousness was verified by isoelectric Electroencephalogram (EEG) findings, a test that measures electrical activity in the brain. By traditional standards, a patient can appear to be alive when attached to a ventilator. The patient has a heartbeat, appears to be breathing, and maintains organ function. This raises the question of whether that patient is then a living person. Were these patients dependent on machines to live, or had they 'crossed the line' that separates life and death? ${ }^{4}$

\section{$\underline{\text { Reassessing Death - Brain Death }}$}

A growing need for the recovery of organs for transplantation was the motivation for a reassessment of the definition of death. Two issues drove consensus toward a new "brain death" criteria. "If patients were already dead, they would be ideal organ donors; and if they were dead, continuing life-sustaining treatment was a grave misuse of our medical prowess." ${ }^{5}$ Additionally, the brain death criteria was pushed due to the issue of just allocation of otherwise scarce medical resources. While it is possible to maintain patients on life support for extended periods of time, maintaining life support on a patient who is already dead would be a misuse of those medical resources.

The Ad Hoc Committee of the Harvard Medical school to Examine the Definition of Brain Death was the first group to address these issues. The goal was to determine the characteristics of irreversible coma and to clarify and standardize medical

\footnotetext{
${ }^{1}$ Lazar N., Shemie S., Webster, G. et al. "Bioethics For Clinicians" Brain Death," Canadian Medical Association Journal 164 (6) (March 20, 2001): 833-836 at 833. See also, Wertheimer P., Jouvet M., Descotes J. "A Propos du Diagnostic de la Mort du Système Nerveux les Comas Avec Arrêt Respiratoire Traités par Respiration Artificielle." Presse Med 67 (1959): 87-88.

2 Crippen D. "Brain Failure and Brain Death: Introduction," ACS Surgery Online, Critical Care (April 2005), Retrieved on 2007-01-09. http://www.acssurgery.com/abstracts/acs/acs0812.htm.

${ }^{3}$ Doig C. \& Burgess E. "Brain Death: Resolving Inconsistencies in the Ethical Declaration of Death," Canadian Journal of Anesthesia 50 (2003): $725-$ 731. http://www.cja-jca.org/cgi/content/full/50/7/725. See also, Powner DJ., Ackerman BM., Grenvik A. "Medical Diagnosis of Death in Adults: Historical Contributions to Current Controversies," Lancet 348 (1996): 1219-1223.

${ }^{4}$ Rubenstein, A., Cohen, E. \& Jackson, E. "The Definition of Dearth and the Ethics of Organ Procurement from the Deceased," Discussion paper for the President's Council on Bioethics, (September 2006): 1-35, at 7. http://bioethicsprint.bioethics.gov/background/runenstein.html.

${ }^{5}$ Rubernstein et al., at 7.
} 


\section{THE JOURNAL OF HEALTHCARE ETHICS \& ADMINISTRATION}

Vol. 7 | No. 1 (Winter 2021)

guidelines for the new definition of brain death. The committee argued that there were two reasons why a new definition was needed.

1) Improvements in resuscitative and supportive measures have led to increased efforts to save patients who are desperately injured. Sometimes these efforts only have partial success and while a patient's heart continues to beat, the brain is irreversibly damaged. This creates a burden on those patients who suffer the loss of brain function, their families, the hospitals, and those in need of beds occupied by comatose patients.

2) Obsolete criteria for the definition of death can lead to controversy in obtaining organs for transplantation. ${ }^{6}$

The Ad Hoc Committee of the Harvard Medical school to Examine the Definition of Brain Death published its report, "A Definition of Irreversible Coma," in 1968, proposing a brain death definition based on whole brain death. The clinical criteria of this definition included: 1) unreceptivity and unresponsivity to externally applied stimuli and inner need; 2) absence of spontaneous muscular movements or spontaneous respiration; 3) no electable brainstem reflexes; and 4) the presence of an EEG confirmatory value. Two separate examinations at least 24 hours apart would be conducted to confirm the diagnosis. ${ }^{7}$ The report stated that patients who passed these tests should be considered brain dead. Since they were dead, all treatment could be stopped and organs could be procured, even while the heart was still beating, including the heart itself. ${ }^{8}$ Between 1974 and 1978 , nearly half of the states enacted some form or legislation or judicial decisions establishing death based on the irreversible cessation of brain function. Issues arose as states were reaching these conclusions through different routes based on various legal and medical precedents. Other states held onto minority opinions concerning death such as the heart-lung definition, and some even advocated for a "higher-brain-oriented" criteria.

\section{The President's Commission on Brain Death}

To address these issues, Congress passed an Act in 1980 establishing the President's Commission for the Study of Ethical Problems in Medicine and Biomedical and Behavioral Research. The commission considered three possible definitions for death - a nonbrain definition, a whole-brain definition, and a higher-brain definition. The first definition, the nonbrain criterion, is consistent with the definition of death as the cessation of the flow of vital body fluids. The second definition, the whole-brain criterion, is consistent with the definition of death as the cessation of the function of the entire brain, and by extension the whole individual. The third definition of death, the higher-brain criterion, is consistent with the definition of death as the loss of what is essential to the nature of man, consciousness. ${ }^{9}$ The commission selected the whole-brain criterion and detailed a set of clinical guidelines and tests to determine brain death. ${ }^{10}$

1) Cessation of brain function is recognized when an evaluation discloses that cerebral functions are absent, and brain stem functions are absent.

\footnotetext{
${ }^{6}$ Ad Hoc Committee of the Harvard Medical School to Examine the Definition of Brain Death. "A Definition of Irreversible Coma," Journal of the American Medical Association 205 (1968): 337-340.

${ }^{7}$ Ad Hoc Committee of the Harvard Medical School to Examine the Definition of Brain Death, at 337-340.

${ }^{8}$ Rubenstein et al., at 8.

${ }^{9}$ Halevy A. \& Brody, B. "Brain Death: Reconciling Definitions, Criteria, and Tests," Annals of Internal Medicine 119 (6) (September 15, 1993): 519525, http://www.annals.org/cgi/content/full/119/6/519.

${ }^{10}$ President's Commission for the Study of Ethical Problems in Medicine and Biomedical and Behavioral Research. "Defining Death: A Report on the Medical, Legal and Ethical Issues in the Determination of Death," (Washington, D.C.: Government Printing Press, 1981).
} 


\section{THE JOURNAL OF HEALTHCARE ETHICS \& ADMINISTRATION}

Vol. 7 | No. 1 (Winter 2021)

2) Irreversibility is recognized when an evaluation discloses that the cause of coma is established and is sufficient to account for the loss of brain functions, the possibility of any recovery of brain function is excluded, and the cessation of all brain functions persists for an appropriate period of observation and/or trial of therapy. ${ }^{11}$

That year, the National Conference of Commissioners on Uniform State Laws formulated the Uniform Determination of Death Act (UDDA) which legally defines death based on the whole-brain criterion as recommended by the President's Commission. All fifty states either enacted or acknowledged in case law this federal legislation. The legal definition of the whole-brain death criterion states that "An individual who has sustained either 1 ) irreversible cessation of circulatory and respiratory functions, or 2 ) irreversible cessation of all functions of the entire brain, including the brain stem, is dead. A determination of death must be made in accordance with accepted medical standards."12 $T$ This has become the legal definition of death in all fifty states.

\section{Diagnosing Whole-Brain Death}

Clinical diagnoses of brain death generally vary between hospitals. However, after intoxication and hypothermia have been ruled out, a brain death diagnosis can be determined under the following guidelines:

1) Cessation of cerebral function is attested by deep coma without clinical response to any physical stimuli;

2) Brain stem function is assessed by testing for cranial nerve function, including papillary, corneal, oculocephalic, oculovestibular, and oropharyngeal reflexes;

3) Absence of spontaneous respiration as determined by an apnea test (patient is removed from ventilator to observe whether spontaneous breathing continues)'

4) And, following these clinical tests, laboratory tests will be performed to ascertain total lack of higher brain function. These laboratory tests include EEG, a brain stem evoked potentials study, or a cerebral blood study. ${ }^{13}$

Confirmatory tests are optional if each of the preceding clinical criteria are met. However, if the clinical tests cannot be reliably evaluated, tests are repeated between 6 and 24 hours later to ensure irreversibility, with life-sustaining measuring supplied in the interim. Determination of death has become a strict technical assessment done by physicians. ${ }^{14}$

\section{Exemptions from Whole-Brain Death Criteria}

Despite clear clinical criteria regarding brain death, there are groups who do not believe in the brain death criteria due to cultural or religious beliefs. "Various cultural and religious groups (e.g., some First Nation and Asian Countries, and Orthodox Judaism) do not accept that death has occurred until all vital functions have ceased." ${ }^{15}$ (i.e. pulmonary and circulatory functions). Orthodox Jews still abide by the heart-lung definition of death on religious grounds. Two states, New York and New Jersey have passed legislation that allow for groups to be exempt from the brain death criteria based on religious grounds." ${ }^{16}$ These laws recognize the difference between the "traditional cardio-pulmonary" criteria and the "modern neurological criteria", prohibiting a physician to declare death

\footnotetext{
${ }^{11}$ Medical Consultants on the Diagnosis of Death to the President's Commission for the Study of Ethical Problems in Medicine and Biomedical and Behavioral Research. "Guidelines for the Determination of Death." Journal of the American Medical Association 246, 19 (November 13, 1981): 2184-2186.

12 Uniform Definition of Death Act. 12 Uniform Laws Annotated 320 (1990 Supp). See also “Uniform Definition of Death Act, “Journal of the American Medical Association 246 (19) (November 13, 1981): 2184-2186.

${ }^{13}$ Halevy \& Brody, at 520.

${ }^{14}$ Freer J. "Brain Death," Ethics Committee Core Curriculum, University of Buffalo Center for Clinical Ethics and Humanities in Health Care, (December 14, 2001): 1-2. http://wings.buffalo.edu/faculty/research/bioethics/man-deth.html.

${ }^{15}$ Lazar et al., at 834 .

${ }^{16}$ Freer, at 1 .
} 


\section{THE JOURNAL OF HEALTHCARE ETHICS \& ADMINISTRATION}

Vol. 7 | No. 1 (Winter 2021)

using the latter criteria if he or she believes it would violate the religious beliefs of the patient. Despite the widely-accepted use of the brain death criteria, there are still families who demand life sustaining treatments despite the determination of death, because of grief, denial, or the fact that their loved one appears to look no differently today than he or she did the day before death was determined. Explanations about neurologic and brain stem functions do not make sense to some who still see a warm body and a beating heart. The issue of brain death has become more complicated because physicians often fail to correct misconceptions by families concerning the brain death criteria, or even mistakenly give them (the family) the impression that it is their decision to decide whether the patient is dead or alive.

\section{What Causes the Confusion Surrounding Brain Death?}

"Brain death" is a complex term as it has medical, legal, ethical, and even religious implications. If those in the medical profession are confused by the complexity of the term, it is easy to see how it is confusing for lay people. One major area of confusion centers on how families often use the term "brain death" to include patients who are minimally conscious, severely brain damaged, or in a persistent vegetative state. Minimally conscious patients, and those in a permanent vegetative state are not brain dead as they do not meet the whole-brain criterion. This point is controversial as consciousness and the ability to relate to others and the wider world have been defining characteristics of what it means to be a human person. ${ }^{17}$ William James defined consciousness in 1890 as awareness of the self and the environment. Going deeper, consciousness has two dimensions: wakefulness and awareness. Unconsciousness implies total unawareness and is characteristic of both coma and the persistent vegetative state. Patients in a coma are unconscious because they lack both wakefulness and awareness. Patients in a persistent vegetative state are unconscious because, although they are wakeful, they lack awareness. ${ }^{18}$ The term persistent vegetative state was coined by Jennet and Plum in 1972 to describe a condition of severe damage in which the patient in a coma has progressed to a state of wakefulness without detectable awareness. ${ }^{19}$ According to the American Academy of Neurology, about 10,000 to 25,000 adults and 6,000 to 10,000 children are diagnosed as being in a persistent vegetative state. ${ }^{20}$ The leading neurological authorities define a persistent vegetative state as "a clinical condition of complete unawareness if the self and the environment accompanied by the sleep-wake cycles with either complete or partial preservation of hypothalamic and brainstem functions." ${ }^{21}$

\section{$\underline{\text { Diagnosing PVS }}$}

In 1991, the Multi-Society Task Force on PVS, comprised of experts from organizations such as the American Academy of Neurology, Child Neurology Society, etc., gathered and analyzed all data on PVS. The clinical criteria they established for the diagnosis of PVS uses the following:

1) No evidence of awareness of self or environment and an inability to interact with others;

2) No evidence of sustained, reproducible, purposeful, or voluntary behavioral responses to visual, auditory, or tactile, or noxious stimuli;

3) No evidence of language comprehension or expression

\footnotetext{
${ }^{17}$ Lazar et al., at 834 .

${ }^{18}$ Multi-Society Task Force on PVS. "Medical Aspects of the Persistent Vegetative State-First of Two Parts," New England Journal of Medicine 330 (1994a): 1499-1508.

${ }^{19}$ Jennett B. \& Plum F. "Persistent Vegetative State After Brain Damage: A Syndrome in Search of a Name," Lancet 1 (1972): $734-737$.

${ }^{20}$ Quality Standards Subcommittee of the American Academy of Neurology. "Practice Parameters: Assessment and Management of Patients in a Persistent Vegetative State," Neurology 45 (1995): 1015-1018.

${ }^{21}$ Quality Standards Subcommittee, 1015-1018; Multi-Society Task Force 1994a, at 1499; and Working Group of the Royal College of Physicians.

"The Permanent Vegetative State," Journal of the Royal College of Physicians 30 (1996): 119-121.
} 


\section{THE JOURNAL OF HEALTHCARE ETHICS \& ADMINISTRATION}

Vol. 7 | No. 1 (Winter 2021)

4) Intermittent wakefulness manifested by the presence of sleep-wake cycles;

5) Sufficiently preserved hypothalamic and brainstem autonomic functions to permit survival with medical and nursing care;

6) Bowel and bladder incontinence;

7) Variably preserved cranial nerve (papillary, oculocephalic, corneal, vestibule-ocular, gag) and spinal reflexes. ${ }^{22}$

A person can be defined as being in a persistent vegetative state at one month after acute traumatic or non-traumatic brain injury (where traumatic is the result of some outside force such as a blow to the head and non-traumatic is due to another cause such as a stroke or meningitis), and manifest for at least one month in degenerative/metabolic disorders or developmental malformations. ${ }^{23}$

The diagnosis of PVS on clinical grounds can be made with a high degree of medical certainty in most adults and pediatric patients after careful, repeated neurologic examinations. This diagnosis ought to be made by physicians who, by reason of training and experience, are competent in neurologic function, assessment, and diagnosis. ${ }^{24}$ Neurologists often face criticism as there is not definitive test for PVS. It can be difficult to identify if a patient is PVS or in a low awareness state or suffers from locked-in syndrome.

\section{Minimally Conscious and Locked-In Syndrome}

According to the Aspen criteria, patients who are in a low awareness state or minimally conscious have definite but limited and fluctuating awareness of self and the environment. These patients may be able to follow simple commands, give appropriate yes or no responses to questions, make intelligible verbalizations, or move or feel in response to external stimuli: avoiding physical obstacles in a wheelchair, crying in response to the emotional content of language, pursuing moving objects with their eyes, or responding to threatening gestures. ${ }^{25}$ Locked-in syndrome is a condition in which consciousness and cognition are retained, but movement and communication are impossible due to severe paralysis of the voluntary motor system. ${ }^{26}$ These patients are aware of self and environment, retain cognitive functions, but are unable to move or speak. The American Academy of Neurology gives three lines of evidence based on careful clinical and laboratory studies to support the conclusion that patients in PVS are unaware of themselves and their environment:

\footnotetext{
${ }^{22}$ Quality Standards Subcommittee, at 1016-1017.

${ }^{23}$ Acute traumatic and nontraumatic brain injury: PVS usually evolves within one month of injury from a state of eyes-closed coma to a state of wakefulness without awareness with sleep-wake cycles and preserved brainstem functions.

Degenerative and metabolic disorders of the brain: Many degenerative and metabolic nervous system disorders in adults and children inevitably progress toward an irreversible vegetative state. Patients who are severely impaired but retain some degree of awareness may lapse briefly into a vegetative state from the effects of medication, infection, superimposed illnesses, or decreased fluid and nutritional intake. Such temporary encephalopathy must be corrected before establishing that the patient is in PVS. If the vegetative state persists for several months, recovery of consciousness is unlikely.

Severe developmental malformations of the nervous system: The developmental vegetative state is a form of PVS that affects some infants and children with severe congenital malformations of the nervous system. These children do not acquire awareness of the self or the environment. This diagnosis can be made at birth only with infants with anencephaly. For children with other severe malformations who appear vegetative at birth, observations for 3 to 6 months is recommended to determine whether these infants acquire awareness. The majority of such infants who are vegetative at birth remain vegetative; those who acquire awareness usually recover only to a severe disability. See, Quality Standards Subcommittee, 1016-1017.

24 "Reliable criteria do not exist for making a diagnosis of PVS in infants under 3 months old, except in patients with anencephaly. Other diagnostic studies may support the diagnosis of PVS, but none adds to diagnostic specificity with certainty." Quality Standards Subcommittee, at 1016

${ }^{25}$ Editor. "Emerging Scientific Knowledge About Minimally Conscious States," Initiatives 22 (October 2004): at 5.

${ }^{26}$ Ethics and Humanities Subcommittee of the American Academy of Neurology. "Certain Aspects of Care and Management of Profoundly and Irreversibly Paralyzed Patients with Retained Consciousness and Cognition," Neurology 43 (1993): 222-223.
} 


\section{THE JOURNAL OF HEALTHCARE ETHICS \& ADMINISTRATION}

Vol. 7 | No. 1 (Winter 2021)

1) Motor or eye movements and facial expressions in response to various stimuli occur in stereotyped patterns that indicate reflexive responses integrated at deep subcortical levels rather than learned voluntary acts. The presence of these response is consistent with complete unawareness.

2) Positron-emission tomographic (PET Scan) studies of regional cerebral glucose metabolism show levels far lower than those in patients who are unaware or in a locked in state. These lower metabolic rates are comparable to those reported during deep general anesthesia in normal subjects whom all would agree are unaware and insensate.

3) All available neuropathological examinations of the brains of patients with a clinical diagnosis of a persistent vegetative state show lesions so sever and diffuse that awareness would have been highly improbable, given our biologic understanding of how the anatomy and physiology of the brain contribute to consciousness. ${ }^{27}$

Essentially, the evidence points to responses to stimuli as reflexes rather than a deliberate, cognitive function, lower metabolic rate in the brain consistent with normal patients who have been intentionally induced to an unconscious state, and brain tissue so widely damaged that consciousness and awareness is unlikely. With that said, an accurate diagnosis is critical for determining PVS. Neurological authorities agree that errors in diagnosis have occurred because of confusion about terminology used to describe patients in this condition, the inexperience of the examiner/physician, or an insufficient period of observation and examination. However, if neurologists are aware of the potential problems in the clinical diagnosis of PVS, are precise and careful when applying the suggested clinical criteria, and the patient has been in a vegetative state for three months after a non-traumatic injury and 12 months after a traumatic brain injury, the diagnosis of PVS can be made with a high degree of clinical certainty that the chance of a patient regaining consciousness is exceedingly small. ${ }^{28}$

\section{$\underline{\text { Prognosis for PVS }}$}

Prognosis for recovery can be classified as recovery of consciousness and recovery of function. "Recovery of consciousness can be verified when a patient shows reliable evidence of awareness of self and the environment, consistent appearance of voluntary behavioral responses to visual and auditory stimuli, and interaction with others. Recovery of functions occurs when a patient becomes mobile and is able to communicate and learn, perform adaptive skills and self-care, and participate in recreational and vocational activities." ${ }^{29}$ To determine recovery of function, the Glasgow Outcome Scale is used. This scale classifies outcomes into 5 categories:

1) Good Recovery: these patients have the capacity to resume normal occupational and social activities, although there may be minor physical or mental deficits or complaints.

2) Moderate Recovery: these patients are independent and can resume almost all activities of daily living. They are, however, disabled, as they can no longer participate in a number of social and work activities.

3) Severe Disability: these patients are no longer capable of resuming most previous personal, social, and work activities. These patients have limited communication skills and abnormal behavioral and emotional responses. They are partially or totally dependent on others for their activities of daily living.

4) PVS: clinical condition of complete unawareness of the self and the environment

5) Death. $^{30}$

\footnotetext{
${ }^{27}$ Multi-Society Task Force, Part I, 1994, at 1499-1508.

${ }^{28}$ Multi-Society Task Force, Part I, 1994, at 1499-1508; Jennett B. The Vegetative State: Medical Facts, Ethical and Legal Dilemmas. (Cambridge: Cambridge University Press, 2002).

${ }^{29}$ Quality Standards Subcommittee, 1995.

${ }^{30}$ Quality Standards Subcommittee, 1995.
} 


\section{THE JOURNAL OF HEALTHCARE ETHICS \& ADMINISTRATION}

Vol. 7 | No. 1 (Winter 2021)

One of the most definitive studies on recovery from PVS was done by the Multi-Society Task Force on PVS in 1994. "The Task Force concluded from analyses of 754 cases that the vegetative state could reasonably be declared permanent 3 months after nontraumatic damage and 12 months after head injury in both children and adults. ${ }^{31}$ However, due to the substantial recovery rate for vegetative patients a month after acute brain damage, some optimism is justified in the first 3 months. ${ }^{32}$ Life spans of children and adults in PVS is substantially reduced, ranging from 2-5 years. Survival beyond 10 years is unusual, and survival beyond 15 years is between $1 / 15,000$ and $1 / 75,000 .{ }^{33}$ Since recovery of consciousness from a post-traumatic PVS is unlikely after 12 months and recovery from a non-traumatic PVS after 3 months is exceedingly rare in both children and adults, one can determine with a high degree of medical certainty the diagnosis and prognosis of a patient in PVS after 12 months.

\section{Pain and PVS}

Issues of pain and suffering in PVS patients have been raised by those with concerns about foregoing artificial nutrition and hydration. Neurological studies based on extensive clinical experience, the results of positron-emission tomographic (PET) studies, and neuropathologic examinations support the belief that patients in a PVS are unaware and insensate and therefore lack the cerebral-cortical capacity to be conscious of pain. Nearly all patients have some degree of motor activity and eye movement that would be capable of signaling conscious perception of pain and suffering if such conditions existed." ${ }^{34}$ Therefore, since PVS patients feel no pain, this concern of added pain and suffering with the foregoing of artificial nutrition and hydration is not an issue.

\section{Care for Patients in PVS}

Therapies aimed at ameliorating or reversing PVS have been unsuccessful. ${ }^{35}$ There have been some reports of benefits from drugs such as dopamine agonists or dextroamphetamine, but the benefits have been modest at best, and to date there have been no placebo-controlled or double blinded studies. ${ }^{36}$ When families accept the diagnosis of PVS, physicians have the responsibility of working with families to determine appropriate levels of care for the patient. There are four levels of treatment:

1. High technology "rescue" treatments, such as mechanical ventilation, dialysis, and cardiopulmonary resuscitation

2. Medications and other commonly ordered treatments, including antibiotics and supplemental oxygen

3. Hydrations and nutrition

4. And nursing and home care to maintain personal dignity and hygiene. ${ }^{37}$

A rough approximation of the total cost in the United States for the care of adults and children in PVS is between \$1billion and \$7 billion. ${ }^{38}$ However, when surrogate decision makers believe that aggressive treatment is in the best interest of the patient, or the patient has an advance directive that states no aggressive treatment including artificial nutrition and hydration if in a PVS, then surrogates have the right to forego all such treatments medically, legally, and ethically. Physicians have the duty to respect the wishes of the patient/surrogate medically, legally, and ethically.

\footnotetext{
31 Jennett, 2002, at 61-62.

${ }^{32}$ For a more detailed analysis of data on recovery from a persistent vegetative state, see Jennett, 2002, at 57-72.

${ }^{33}$ Quality Standards Subcommittee, 1995.

${ }^{34}$ Multi-Society Task Force of the American Academy of Neurology. "Medical Aspects of the Persistent Vegetative State-Second of Two Parts." New England Journal of Medicine 330 (1994b): 1572-1779.

${ }^{35}$ Multi-Society Task Force, Part II, 1994b, at 1572-1579.

${ }^{36}$ Haig AS \& Ruess JM. "Recovery From Vegetative State of Six Months' Duration Associated With Sinemet (levodopa/carbidopa)," Archives of Physical Medicine and Rehabilitation 7 (1990): 1081-1083.

${ }^{37}$ Multi-Society Task Force, Part II, 1994b, at 1572-1579.

${ }^{38}$ Multi-Society Task Force, Part II, 1994b, at 1572-1579.
} 


\section{THE JOURNAL OF HEALTHCARE ETHICS \& ADMINISTRATION}

Vol. 7 | No. 1 (Winter 2021)

\section{Conclusion}

Brain death is a concept that may appear to have clear clinical criteria but in reality, the clinical criteria is not universally understood and/or applied correctly by medical professionals. The concept of brain death is even less understood by the general public. ${ }^{39}$ Defining death is complex and will remain a debatable concept. "Confronted with individuals in this seemingly in-between state, we seem to need a 'concept' of death to guide experience; and we seem to need an expertise about the body - standards, tests, protocols, criteria - to discern whether death has occurred in particular cases." ${ }^{40}$ The whole-brain death standard is the best criteria we have to determine death. To expand these criteria to include severely neurologically damaged individuals or those in a persistent vegetative state would open the slippery slope to possibly allow for the harvesting of organs from living human beings or to a subtle form of active euthanasia. Patients in a minimally conscious state or in a persistent vegetative state are categorically distinct from those patients who meet the brain death standard. One is still alive and the other is clearly dead. This does not mean that those who are minimally conscious or in PVS have to be aggressively treated. After careful ethical discernment, which would include pertinent medical information and consideration of the patient's values and wishes, a decision to not initiate or to withdraw medical treatment would be medically appropriate and morally justified.

Post-Chapter Assessment Activity: Students will re-form their groups and critique their definitions of death that they made before this lesson.

Discussion Questions (done in small groups followed by sharing with the class):

1. Clinical death was long determined by physicians using a set of common criteria. Describe how a physician in the 1940 's would have determined death and what the hallmarks of death were before brain death criteria.

2. Examine one of the technologies of the 1950 s such as the Iron lung, ventilation, CPR, dialysis, etc... Why did these new technologies add to the confusion of death?

3. Compare and contrast the two definitions of brain death presented by the President's Commission for the Study of Ethical Problems in Medicine and Biomedical and Behavioral Research. Which of these definitions is more precise? Do you have any ethical or legal concerns surrounding these definitions?

4. What religious group is exempt from brain death criteria? How is death determined by doctors for members of this group?

5. Defend what you think is the best diagnosis of Persistent Vegetative State. What do you value you in this method of diagnosis?

\section{Further Reading:}

1. DeGrazia, David, "The Definition of Death", The Stanford Encyclopedia of Philosophy (Spring 2017 Edition), Edward N. Zalta (ed.)

2. Jonsen, A.R., Bioethics Beyond the Headlines: Who Lives? Who Dies? Who Decides?, Rowman \& Littlefield, 2005, Pages 26-34

3. Sarbey, Ben, Definitions of death: brain death and what matters in a person, Journal of Law and the Biosciences, Volume 3, Issue 3, 1 December 2016, Pages 743-752

\footnotetext{
${ }^{39}$ Doig et al., at 728. See also Younger SJ, Landefeld CS, Coulton CJ et al., "'Brain Death' and Organ Retrieval: A Cross Sectional Survey and Concepts Among Health Professionals," Journal of the American Medical Association 261 (1989): 2205-2210.

${ }^{40}$ Rubenstein, at 28.
} 


\section{THE JOURNAL OF HEALTHCARE ETHICS \& ADMINISTRATION}

Vol. 7 | No. 1 (Winter 2021)

\section{APPENDIX II - CHAPTER 2: END STAGE MEDICAL CONDITIONS}

Quote: "The good physician treats the disease; the great physician treats the patient who has the disease" - William Osler

Chapter Objectives: (SWBAT= Students will be able to..)

- SWBAT distinguish among the seven common end stage medical conditions' causes, treatments, and risk factors.

- SWBAT formulate original solutions to preventing these conditions and how to change the current culture that promotes these diseases.

- SWBAT communicate the risks of these end stage conditions to family members.

Standards (derived from Common Core State Standards)

\section{CC.1.2.11-12A}

Determine and analyze the relationship between two or more central ideas of a text, including the development and interaction of the central ideas; provide an objective summary of the text.

\section{CC.1.2.11-12.J}

Acquire and use accurately general academic and domain-specific words and phrases, sufficient for reading, writing, speaking, and listening at the college and career readiness level; demonstrate independence in gathering vocabulary knowledge when considering a word or phrase important to comprehension or expression.

\section{CC.1.2.11-12.K}

Determine or clarify the meaning of unknown and multiple-meaning words and phrases based on grade-level reading and content, choosing flexibly from a range of strategies and tools.

\section{CC.1.3.11-12.B}

Cite strong and thorough textual evidence to support analysis of what the text says explicitly, as well as inferences and conclusions based on and related to an author's implicit and explicit assumptions and beliefs.

\section{CC.1.4.11-12.A}

Write informative/explanatory texts to examine and convey complex ideas, concepts, and information clearly and accurately

\section{CC.1.4.11-12.J}

Create organization that logically sequences claim(s), counterclaims, reasons, and evidence; use words, phrases, and clauses as well as varied syntax to link the major sections of the text to create cohesion and clarify the relationships between claim(s) and reasons, between reasons and evidence, and between claim(s) and counterclaims; providing a concluding statement or section that follows from and supports the argument presented

\section{CC.1.5.11-12.C}

Integrate multiple sources of information presented in diverse formats and media (e.g., visually, quantitative, orally) in order to make informed decisions and solve problems, evaluating the credibility and accuracy of each source and noting any discrepancies among the data.

\section{CC.1.5.11-12.D}

Present information, findings, and supporting evidence, conveying a clear and distinct perspective; organization, development, substance, and style are appropriate to purpose, audience, and task. 


\section{THE JOURNAL OF HEALTHCARE ETHICS \& ADMINISTRATION}

Vol. 7 | No. 1 (Winter 2021)

\section{Overarching Practical Goals of Curriculum:}

Step 1 - The Basics: This chapter should inform readers about seven common end-stage conditions. The most practical aspects of this chapter offer potential treatment plans and measures to limit the probabilities of inheriting these conditions.

Step 2 - Preparation Techniques: Students may want to consider small lifestyle changes to begin preventing some of these conditions.

Step 3 - Communication: No matter the context, students will be able to communicate the risk factors of several of these diseases with family and friends. They may be able to recognize these risk factors in their loved ones and address small changes.

Do Now: (5 minutes) Students will journal what they know or think they know about end stage diseases.

Pre-Assessment: Divide the students into groups of four or five. Give each group one of the following topics:

- Marijuana legalization

- Smoking at 18

- Drinking at 21

- $\quad$ Exercising over 60 minutes at a given time

- "Clean eating"/vegan/vegetarian

- Unprotected intercourse

- $\quad$ Same sex marriage

Allow students to discuss the pros and cons. Is there anything wrong with the above list, especially if it is legal? At what point does it become something to worry about? Does it ever become something to worry about? For example, what if "clean eating" is the start of an eating disorder known as "Orthorexia Nervosa," which is "an obsession with eating foods that one considers healthy; a medical condition in which the sufferer systematically avoids specific foodsin the belief that they are harmful." Over exercising is a way that bulimics choose to purge. Pot may be legal in many states, but many medical professionals still consider it a gateway drug.

One spokesperson per group reports out to the class.

\section{Sections:}

\section{$\underline{\text { Introduction }}$}

This chapter looks to draw attention to and explain seven of the most common conditions people may face at the end of their life. Each section explains what the disease is, its causes, treatments, and known risk factors. Each section then provides suggested lifestyle changes that may decrease the likelihood of developing the condition.

\section{End Stage Renal Disease (ESRD)}

End Stage Renal Disease (ESRD) is the final stage of Chronic Kidney Disease (CKD) in which kidney functions drops below $15 \% .{ }^{1}$ At this point, the kidneys are unable to adequately filter out toxins and excess fluid from the blood, balance $\mathrm{pH}$, and produce certain hormones. This leads to the buildup of fluid in an individual's body, as the kidneys cannot process the fluid and electrolytes. The

\footnotetext{
${ }^{1} \mathrm{NIH}$ - National Institute of Diabetes and Digestive Kidney Disease. (2018, January 23). End Stage Renal Disease (ESRD). Retrieved from PubMed Health: https://www.ncbi.nlm.nih.gov/pubmedhealth/PMHT0028184/
} 


\section{THE JOURNAL OF HEALTHCARE ETHICS \& ADMINISTRATION}

Vol. 7 | No. 1 (Winter 2021)

only treatments for this condition include renal dialysis or a kidney transplant. Forgoing treatment leads to death in a matter of days to weeks. ${ }^{2}$

There are several conditions that left untreated evolve into CKD and eventually ESRD. Among these, the two most common include diabetes mellitus (Type 1 and 2 diabetes) and high blood pressure. Other causes include certain autoimmune diseases such as systemic lupus erythematous (SLE) and IgA nephropathy (Berger's disease). Lupus is an autoimmune disease in which the immune system attacks the body's own tissues while Berger's disease is caused by a buildup of antibodies in the kidneys. This response from the immune system hinders the kidneys' abilities to perform their necessary functions. Other causes of ESRD include genetic diseases like polycystic kidney disease. This condition is responsible for the formation of clusters of cysts on the kidneys, causing swelling and decreased kidney function. General urinary tract problems and urinary tract infections (UTIs) are also linked to ESRD. However, having one of these conditions does not necessarily mean you will develop ESRD if the condition is properly managed. ESRD is also caused by acute kidney injuries and acute renal failure. These conditions result from heart attacks, drug use, and lack of blood flow. These conditions are not always permanent but should be addressed immediately. ${ }^{3}$

Symptoms occur as the condition progresses from CKD to ESRD. At this point, the kidneys have already been extensively damaged. These symptoms include itching, muscle cramps, nausea and vomiting, lack of appetite, swelling in the feet and ankles, lack of urination or frequent urination, trouble catching breath, and trouble sleeping. Acute renal failure presents with different symptoms, but can also lead to ESRD. These symptoms include back pain, diarrhea, fever, nosebleeds, rash, and vomiting. ${ }^{4}$

When exploring treatment options, ESRD has no quick fix. Treatments include regular hemodialysis, a process in which your blood is filtered through a dialysis machine, or a kidney transplant. ${ }^{5}$ While treatment options may be limited, there are preventative measures that can be taken to avoid developing this condition. Healthy lifestyle choices including a healthy and balanced diet, adequate amounts of exercise, proper hydration, and avoiding alcohol and tobacco all lower an individual's risk of developing this disease, as well as many others. ${ }^{6}$

\section{HIV and AIDS}

Human Immunodeficiency Virus, or HIV, is a retrovirus that attacks the body's immune system, hindering its ability to fight off infections. Acquired Immunodeficiency Syndrome, or AIDS is the final stage of HIV in which the body's CD4 blood cell count drops below 200. The CD4 cell is a blood cell of the immune system responsible for activating other immune cells when the body faces infections. With so few CD4 cells in the body, fighting off infections becomes a challenge. Opportunistic infections such as cancers or bacterial infections ravage the body as the immune system struggle to fight them off. The exact origins of the virus are unknown, but scientists suggest the virus was transferred to humans from chimpanzees in Central Africa after hunters consumed or handled infected meat. The disease then arrived in the United States in the 1970s. ${ }^{7}$

HIV is transmitted through specific body fluids including blood, semen, vaginal fluid, and breast milk. The virus cannot be transmitted through kissing, hugging, hand shaking, or sharing food and water. While there is no cure for HIV and AIDS, the condition can be managed through antiretroviral drug therapies (ARTs). This is a class of drugs that specifically targets retroviruses like HIV. On this medication, an infected individual may show undetectable viral loads in their body, reducing the rate of infection,

\footnotetext{
${ }^{2}$ American Kidney Fund. (2018, January 23). Kidney Failure/ESRD. Retrieved from American Kidney Fund Website: http://www.kidneyfund.org/kidney-disease/kidney-failure/?referrer=https://www.google.com/

${ }^{3}$ Ibid.

${ }^{4}$ Ibid.

${ }^{5}$ Ibid.

${ }^{6}$ The Mayo Clinic. (2017, August 9). End-stage renal disease. Retrieved from The Mayo Clinic Website:https://www.mayoclinic.org/diseasesconditions/end-stage-renal-disease/symptoms-causes/syc-20354532

${ }^{7}$ The Center for Disease Control and Prevention. (2017, May 30). About HIV/AIDS. Retrieved from Center for Disease Control and Prevention Website: https://www.cdc.gov/hiv/basics/whatishiv.html
} 


\section{THE JOURNAL OF HEALTHCARE ETHICS \& ADMINISTRATION}

Vol. 7 | No. 1 (Winter 2021)

and drastically increasing life span. On ARTs, an individual may experience only a slightly shorter life span than that of a noninfected individual. ${ }^{8}$

The CDC highlights the following three specific stages of the disease: acute HIV infection, clinical latency, and acquired immunodeficiency syndrome (AIDS). The first stage, acute HIV infection, occurs between 2 and 4 weeks after an individual is infected. Those infected experience flu-like symptoms for up to a few weeks. Moreover, as a large amount of the viral genome infects an individual's blood, the virus is highly contagious during this stage. Blood testing is required to diagnose this disease. ${ }^{9}$

The second stage of HIV infection is clinical latency, also called asymptomatic HIV infection. In this stage, the HIV virus is still alive, but reproduces at a very low rate so that infection is almost unnoticeable. Although asymptomatic, the virus can still be transmitted. Those without medication can be in this stage for over a decade; those taking antiretroviral medication can be in this stage for several decades. At the end of this stage, the CD4 cell count drops below 200 and the viral count increases as the disease progresses to AIDS. ${ }^{10}$

The final stage of the diseases, acquired immunodeficiency syndrome or AIDS is the result of a severely damaged immune system. During this stage, opportunistic infections such as tuberculosis, cryptococcal meningitis, bacterial infections, and cancers such Kaposi's Sarcoma may afflict the infected individual. ${ }^{11}$ Other symptoms associated with AIDS include chills, fever, sweats, swollen lymph glands, weakness, and weight loss. Individuals with AIDS can have a very high viral load increasing the virus's ability to infect another individual. Without treatment, patients can live about three years. ${ }^{12}$ It is worth noting that patients do not necessarily die from AIDS itself. Rather, patients die from the compounding opportunistic infections that take advantage of the body's weak immune system.

Putting HIV and AIDS into perspective, about 36.7 million people globally were living with HIV in 2016 with 1.8 million new infections. Roughly 1 million people died in 2016 worldwide from HIV related causes. ${ }^{13}$ The WHO highlights certain demographic populations that are at a higher risk of contracting the virus, including IV drug users, men engaging in sexual intercourse with other men, people in prisons, sex workers and their clients, and transgender people. These groups often have social and legal issues that increase vulnerability and limit access to screenings and treatment. However, between 2000 and 2016, rates of HIV infections fell by $30 \%{ }^{14}$

\section{Cancer}

Cancer is a group of diseases characterized by uncontrolled cell growth that spreads into surrounding tissue. Cancer occurs when old or abnormal cells do not die to make room for new cells. Rather the old and/or abnormal continue to replicate, sometimes rapidly, and can form cancerous tissue called tumors. While many cancers can form tumors, not all do. Leukemia, for example, is a form of blood cancer in which bone marrow produces abnormal white blood cells that cannot fight off infections. ${ }^{15}$ Cancerous, or malignant tumors can invade surrounding tissue or enter the bloodstream, forming new tumors in other parts of the body in a process called metastasis. Benign tumors, on the other hand, differ from malignant tumors; a benign tumor will not grow back when removed and does not spread into surrounding tissue. ${ }^{16}$

\footnotetext{
${ }^{8}$ lbid.

${ }^{9}$ Ibid.

${ }^{10}$ Ibid.

11 The World Health Organization. (2017, November). HIV/AIDS Fact Sheet. Retrieved from The World Health Organization Website: http://www.who.int/mediacentre/factsheets/fs360/en/

${ }^{12}$ The Center for Disease Control and Prevention. (2017, May 30). About HIV/AIDS. Retrieved from Center for Disease Control and Prevention Website: https://www.cdc.gov/hiv/basics/whatishiv.html

${ }^{13}$ The World Health Organization HIV/AIDS Fact Sheet

${ }^{14}$ Ibid.

15 Leukemia and Lymphoma Society. (2012). Understanding Leukemia. Retrieved from Leukemia and Lymphoma Society Website: https://www.lls.org/sites/default/files/file_assets/understandingleukemia.pdf

16 NIH - National Cancer Institute. (2017, February 13). Common Cancers. Retrieved from National Cancer Institute Website: https://www.cancer.gov/types/common-cancers
} 


\section{THE JOURNAL OF HEALTHCARE ETHICS \& ADMINISTRATION}

Vol. 7 | No. 1 (Winter 2021)

There are several key differences between cancer cells and normal cells. In general, cancer cells are less specialized compared to normal cells. Without a highly specific role to play, unspecialized cells are at a greater risk for continued cell division without stopping. Moreover, cancer cells ignore the body's signals to stop dividing through a process of programmed cell death called apoptosis. Without those signals, the cells continue to divide. Cancer cells are also able manipulate surrounding cells, creating structures like blood vessels to bring nutrients and remove waste, feeding the tumor's growth. Lastly, cancer cells are able to evade the body's immune system, making it more difficult to fight off the infection. ${ }^{17}$

Cancer arises from a combination of genetic and environmental factors. Genetically, certain genes essential to cell function have mutated. These changes are either inherited from a parent or caused by external environmental factors such as chemicals, tobacco smoke, radiation, and the sun's ultraviolet rays. What makes cancer difficult to treat is the unique combination of genetic change in each cancer. As the cancer grows, the genetic changes may continue to occur. The genetic change between various cancer cells may be different between cells in the same tumor. The genes concerned with cell division and DNA repair are typically the agents responsible for cancer growth. ${ }^{18}$

As previously mentioned, cancer cells can enter the bloodstream or surrounding tissues to form new tumors in a process called metastasis. When cancer of the lung spreads to the liver, medical professionals call it "metastatic lung cancer", not liver cancer. Metastatic cancer cells are often very similar to the original cancer cells. ${ }^{19}$

It is important to consider that not all changes in tissue are necessarily cancer. However, if left untreated, certain conditions have a higher likelihood of developing into cancer. Hyperplasia is characterized by an increased number of cells in a specific tissue, while dysplasia is characterized by the presence of immature or abnormal cells. While these conditions are not necessarily cancer, they are precursors.

New breakthroughs in cancer research have ushered in a new wave of treatment options for a patient diagnosed with cancer. With over 100 types of cancer that affect different cells in different tissues treatment is highly specific. Treatment depends on the type and severity of the cancer. Options include surgery for removal of the cancer, radiation therapy that targets cancerous cells, chemotherapy that consists of anti-cancer drugs, immunotherapy to boost the body's immune response in fighting cancer, targeted therapy to interfere with cancer cell growth, hormone treatment to slow the growth of cancer cells, stem cell transplant to help the body produce new, healthy cells, and precision medicine which takes into account an individual patient's genes, medical history, environment, and lifestyle. ${ }^{20}$

17 NIH - National Cancer Institute. (2015, February 9). About Cancer. Retrieved from National Cancer Institute Website: https://www.cancer.gov/about-cancer/understanding/what-is-cancer

${ }^{18} \mathrm{NIH}$ - About Cancer

${ }^{19} \mathrm{Ibid}$.

20 NIH - National Cancer Institute. (2017, April 6). Types of Cancer Treatment. Retrieved from National Cancer Institute Website: https://www.cancer.gov/about-cancer/treatment/types 
THE JOURNAL OF HEALTHCARE ETHICS \& ADMINISTRATION

Vol. 7 | No. 1 (Winter 2021)

\begin{tabular}{|l|l|}
\hline Most Common Types of Cancer & Lung* \\
\hline Bladder & Melanoma \\
\hline Breast* & Non-Hodgkin Lymphoma \\
\hline Colorectal & Pancreatic \\
\hline Endometrial & Prostate \\
\hline Kidney & Thyroid \\
\hline Leukemia & \\
\hline Liver & \\
\hline
\end{tabular}

*Breast cancer and lung cancer are the first and second most common types of cancer respectively. The NIH estimated in

2017 , there will be roughly 252,710 cases of breast cancer and 222,500 cases of lung cancer. ${ }^{21}$

\section{Congestive Heart Failure/Heart Disease/Myocardial Infarction}

Heart disease is a general term for conditions and disease that affect the heart and cardiovascular system and is caused by various infections and congenital conditions. Specific symptoms depend on which part of the cardiovascular system is affected, and typically have different manifestations between men and women. In general, men are more likely to have chest pain, whereas women are more likely to have shortness of breath, nausea and vomiting, and fatigue. Heart disease most commonly affects the valves of the heart and arteries/blood vessels near the heart. This category of disease includes arrhythmias and other congenital defects. Some examples include congestive heart failure and coronary artery disease. ${ }^{22}$

Congestive Heart Failure (CHF), also known as heart failure, occurs when the heart is unable to pump blood as well as it should. Over time, certain conditions weaken the heart muscle, negatively affecting its ability to pump blood. These conditions include but are not limited to high blood pressure, and coronary artery disease in which fatty plaque deposits build up in arteries near the heart.

CHF develops after other conditions weaken the heart muscle. In some instances, the heart's ventricles become stiff and unable to pump efficiently, causing a loss of function. The heart is then unable to keep up with the necessary demand. When the heart is unable to pump blood, other organs like the kidneys and liver may be damaged. Contributing factors include high blood pressure, faulty heart valves, cardiomyopathy or heart tissue damaged from prior infection, substance abuse, chemotherapy, or genetic factors, swelling of the heart or surrounding muscles, and arrhythmia. Symptoms manifest in shortness of breath, fatigue and weakness, swelling in legs and feet, rapid or irregular heartbeat, reduced ability to exercise, coughing and wheezing, excessive urination at night, swelling of the abdomen, weight gain, difficulty concentrating, and chest pain. ${ }^{23}$

Myocardial Infarctions (MI), commonly known as a heart attack, occurs when blood flow to certain sections of the heart is blocked and the tissue begins to die. This is usually the result of plaque build-up in the arteries near the heart. Symptoms include

\footnotetext{
${ }^{21} \mathrm{NIH}$ - About Cancer

22 The Mayo Clinic. (2017, October 6). Heart Disease. Retrieved from The Mayo Clinic Website: https://www.mayoclinic.org/diseasesconditions/heart-disease/symptoms-causes/syc-20353118

23 The Mayo Clnic. (2017, December 23). Heart Failure. Retrieved from The Mayo Clinic Website: https://www.mayoclinic.org/diseasesconditions/heart-failure/symptoms-causes/syc-20373142
} 


\section{THE JOURNAL OF HEALTHCARE ETHICS \& ADMINISTRATION}

Vol. 7 | No. 1 (Winter 2021)

chest pain, pain in the arms and upper body, and shortness of breath. This condition is fatal if medical intervention is not immediately sought. ${ }^{24}$

\section{Alzheimer's and Dementia}

Dementia is a broad term characterized by overall decline in mental and cognitive functions. There are several different forms, but Alzheimer's disease, sometimes called senile dementia, is the most common and comprises about $60-80 \%$ of cases. Vascular dementia, which may occur after an individual suffers a stroke, is the second most common form. This disease can be mentally and emotionally taxing on both caretakers and family members of the individual exhibiting systems. While onset is typically later in life, there are instances of early-onset cases. ${ }^{25}$

Symptoms of dementia may vary between forms, but at least two of the following functions must be impaired to constitute dementia. These functions include memory, communication and language, ability to focus and pay attention, reasoning and judgement, and visual perception. Individuals suffering from dementia also face short term memory loss. These symptoms gradually get worse as the disease progresses. ${ }^{26}$

Dementia is caused by damage to brain cells from which the cells cannot effectively communicate. The varying forms of dementia result from the different types of brain cells damaged and the location of these brain cells. Cells in the hippocampus, the region of the brain responsible for learning and memory, are usually the first to be damaged. Certain conditions such as depression, medication side effects, alcohol use, thyroid problems, and vitamin deficiencies can further exacerbate some of the cognitive impairments associated with dementia. ${ }^{27}$

While physicians can diagnose dementia with a high degree of certainty, diagnosing which specific form of dementia a patient has is far more difficult. Diagnosis comes after various lab tests, cognitive examinations, and a review of a patient's past medical history. There is no cure for dementia, but drug therapies help to alleviate some of the symptoms. There are a plethora of clinical trials currently underway to find new drugs and treatment options. While genetic factors are out of one's control when considering the likelihood of developing dementia, certain lifestyle factors such as a healthy diet, exercise, and good cardiovascular health reduce the chance of developing this disease.

Alzheimer's disease is the most common form of dementia. It makes up $60 \%$ to $80 \%$ of cases. Contrary to popular belief, the decline in memory and cognitive function associated with Alzheimer's is not a normal part of aging. However, age is an important factor in the development of Alzheimer's. This disease progresses over time and is the sixth leading cause of death in the United States. Early symptoms include short-term memory loss and difficulty remembering new information. As the disease progresses, other symptoms emerge such as mood and behavior changes, agitation and suspicion of family members and friends, disorientation to time and place, and lastly, difficulty walking, speaking, and swallowing. The disease progresses until an individual is no longer able to eat, drink, or swallow. While a definitive answer is still unclear, Alzheimer's disease is thought to be caused by buildups of amyloid plaque and protein fiber tangles within brain cells. The buildup of plaque and protein tangles kill brain cells thereby impairing cognitive function. ${ }^{28}$

\footnotetext{
$24 \mathrm{NIH}$ - National Heart, Lung, and Blood Institute. (2018). Myocardial Infarction (Heart Attack). Retrieved from PubMed Health: https://www.ncbi.nlm.nih.gov/pubmedhealth/PMHT0021982/

25 Alzheimer Association. (2018). What is Alzheimer's. Retrieved from Alzheimer Association Website: https://www.alz.org/alzheimers_disease_what_is_alzheimers.asp

${ }^{26} \mathrm{Ibid}$.

${ }^{27}$ Ibid.

${ }^{28}$ Ibid.
} 


\section{THE JOURNAL OF HEALTHCARE ETHICS \& ADMINISTRATION}

Vol. 7 | No. 1 (Winter 2021)

\section{Cerebrovascular Diseases}

Cerebrovascular disease, also known as cerebrovascular accidents, or strokes, are a complex of symptoms that occur when blood flow is cut off from a region of the brain. Depending on the location of the stroke, the severity of the bleed, and how quickly the stroke is addressed, the damage can have far reaching implications across various body systems. Stroke are caused either by ischemia, a lack of blood flow to an area of the brain causes by a blockage like plaque, or a hemorrhage in which a blood vessel ruptures. Most strokes are ischemic in nature; approximately $80 \%$ are caused by blocked arteries in the brain. ${ }^{29}$ Transient ischemic attacks, or "mini-strokes" are ischemic attacks in which blood flow is partially cut off to a region of the brain. Symptoms are like that of an ischemic attack, but are usually less severe. ${ }^{30}$

There are certain factors that increase the likelihood of having a stroke, namely heart conditions. High blood pressure, valvular dysfunction, coronary artery disease, and a history of myocardial infarctions increase the risk of strokes. Symptoms may vary depending on which specific region of the brain is affected. However, some general symptoms include partial paralysis, facial weakness and drooping, numbness, difficulty speaking, vertigo, trouble swallowing, double vision, and partial or total blindness. ${ }^{31}$

Treatment of a stroke seeks to stabilize the patient and address the problems that caused the initial stroke to prevent further strokes from occuring. ${ }^{32}$ Nearly 1 in 5 stroke survivors are left with some sort of physical or cognitive impairment - distorted ambulation, short term memory loss, or loss of vision. ${ }^{33}$ Furthermore, suffering a stroke also increases one's likelihood of developing vascular dementia. In the five years following a stroke, the mortality rate for survivors is about $50 \%{ }^{34}$

Certain factors increase an individual's odds of having a stroke. High blood pressure, cardiovascular disease, high cholesterol, tobacco smoke, age, race (African Americans are more likely to suffer a stroke), and sex. While males usually have more strokes than females, strokes tend to be more fatal in females than males. Lifestyle changes can decrease one's likelihood of having a stroke. These include avoiding smoking or excessive alcohol, eating a healthy, balanced diet, regular exercise, controlling diabetes and high cholesterol, and addressing any sleep apnea problems. ${ }^{35}$

Now that seven common diseases and conditions that are prevalent in individuals facing the end of life have been described and discussed, the next chapters will address the ethical questions surrounding treatment options and care. The common themes to be aware of in the coming chapters are the standards of care, physician and patient relationships, and responsible decision making.

\section{Discussion Questions:}

1. What is one of the common threads that connects the potential causes of all of these end stage conditions? Can you identify any other similar risk factors?

2. In your opinion, what is more connected to disease? - Genetics or environment? Explain your answer. Does it vary with each end stage condition?

\footnotetext{
${ }^{29}$ Good, D. C. (1990). Cerebrovascular Disease. In H. W. Walker HK, Clinical Methods: The History, Physical, and Laboratory Examinations. 3rd edition ( $p$. Chapter 55). Boston: Butterworths.

30 The Mayo Clinic. (2017, November 11). Stroke. Retrieved from The Mayo Clnic Website: https://www.mayoclinic.org/diseasesconditions/stroke/symptoms-causes/syc-20350113

${ }^{31}$ Good et. al.

32 Ibid.

33 The Mayo Clinic. (2018). Neurology Research - Cerebrovascular Diseases. Retrieved from The Mayo Clninc Research Website: http://www.mayo.edu/research/departments-divisions/department-neurology/cerebrovascular-diseases

${ }^{34}$ Good, et. al.

${ }^{35}$ The Mayo Clinic: Strokes
} 


\section{THE JOURNAL OF HEALTHCARE ETHICS \& ADMINISTRATION}

Vol. 7 | No. 1 (Winter 2021)

3. Develop a response to someone who refuses to acknowledge the connection between smoking and heart disease. In your response be respectful but assert some of the medical facts that connect the behavior with the disease. An internet search may be helpful.

Closure: Students will summarize, in their own words, some notes that they took during the class.

\section{FINAL PAPER ASSIGNMENT:}

- Seven groups will form to research one of the seven end stage conditions or one of their choosing in greater detail than the class is addressing as a whole.

- Students will individually write a 12-15 page research paper on the end stage condition of their choosing.

- One inch margins, Times New Roman font 12 (or school's standard formatting guidelines)

- Some class time should be set aside on occasion for groups to collaborate; however, students may not copy work from one another or the work will be disqualified for plagiarism and must be redone with another topic to be selected by the instructor.

- Students will not receive a "0" for incomplete work. Instead, a redo is demanded in order to pass the class to encourage students to actually finish the paper.

- $\quad$ Due at the end of the course.

Exit Ticket: What was the muddiest point of the lesson? Write your answer on a $3 \times 5$ card and turn it in at the door as you leave.

\section{Further Reading:}

1. Kalanithi, Paul. When Breath Becomes Air. Thorpe, Isis, 2018. 


\section{THE JOURNAL OF HEALTHCARE ETHICS \& ADMINISTRATION \\ Vol. 7 | No. 1 (Winter 2021)}

\section{APPENDIX III - CHAPTER 3: BAD NEWS AND COMMUNICATION}

Quote: "The most important thing in communication is hearing what isn't said." -Peter Drucker

Chapter Objectives: (SWBAT= Students will be able to..)

- SWBAT present an explicit guide for navigating tough conversations and how to deliver bad news.

- SWBAT recognize that each person has different preferences for the disclosure of medical information; some may want to know all information, while others desire a limited amount.

- SWBAT propagate the message that more training on communication skills is desperately needed in medical school residency programs.

Standards (derived from Common Core State Standards)

\section{CC.1.2.11-12.A}

Determine and analyze the relationship between two or more central ideas of a text, including the development and interaction of the central ideas; provide an objective summary of the text.

\section{CC.1.4.11-12.C}

Develop and analyze the topic thoroughly by selecting the most significant and relevant facts, extended definitions, concrete details, quotations, or other information and examples appropriate to the audience's knowledge of the topic; include graphics and multimedia when useful to aiding comprehension.

\section{CC.1.4.11-12.G}

Write arguments to support claims in an analysis of substantive topics.

\section{CC.1.5.11-12.A}

Initiate and participate effectively in a range of collaborative discussions on grade-level topics, texts, and issues, building on others' ideas and expressing their own clearly and persuasively.

\section{Overarching Practical Goals of Curriculum:}

Step 1 - The Basics - Students should recognize that communication and open conversation with physicians is critical for successfully treating illnesses.

Step 2 - Preparation Techniques - Practice careful listening.

Step 3 - Communication - Students will inform parents that finding the correct balance of autonomy and paternalism is the best way to customize the physician-patient relationship.

Do Now: Make a list of 25 ways that you communicate. This can be with anyone.

Pre-Assessment Activity: First Exam (Excerpt from “The Doctor," YouTube, 3:37, https://youtu.be/YZsfdYBllao . After watching clip, students will discuss in groups of four what they observed in both doctors' behavior. Groups will report out. 


\section{THE JOURNAL OF HEALTHCARE ETHICS \& ADMINISTRATION}

Vol. 7 | No. 1 (Winter 2021)

\section{Sections:}

This chapter serves as an introduction to a matter that concerns both physicians and patients. As technology continues to become more and more integrated into daily life, communication and the skills necessary to successfully comprehend nuances in conversation have become deemphasized. While the benefits of technology in medicine are undeniably tremendous, the value of human to human interaction cannot be replicated by any technology developed to date.

\section{America's Death Denying Culture}

What has become evident is that the process of aging and even dying has changed greatly over the last two decades due to advancements in medicine and technology, but the health care system and health care professionals have not kept pace with these changes. Instead of dying at home, the elderly are transitioning to assisted living facilities or nursing homes because their families no longer feel the responsibility of caring for them. Advanced treatments lead to longer lives and more hospital admissions. "The price of longer lives is longer, slower deaths. People rarely die quickly anymore. They decline and live years with debilitating, isolating incurable diseases." ${ }^{1}$ Honoring the wishes of patients at the end of life has become problematic because in many instances family members and primary care physicians do not know what the patient would want when confronted with these end-of-life situations. Conversations about end-of-life treatments are not taking place between patient and physician or between patient and families because we are living in a "death denying culture." We hide from death, attempt to ignore death and are even so arrogant to think we can conquer death. It has become quite evident that Americans are still uncomfortable and even unrealistic about death and dying. This culture must be reversed if we are to face death with dignity and incorporate it as a part of life. Conversation is the first step to undoing the death denying culture.

Physicians need to be trained not only to be honest with their patients but to feel comfortable with them as they face terminal illness. Those physicians who are comfortable in giving "bad news" view this process as attempting to achieve four essential goals. "The first is gathering information from the patient. This allows the physician to determine the patient's knowledge and expectations along with her readiness to hear bad news. Forming a relationship based on trust is the first step in gathering meaningful background information from patients. The second goal is to provide intelligible information in accordance with the patient's needs and desires. The third goal is to support the patient by employing skills to reduce emotional impact and isolation experienced by the recipient of bad news. The final goal is to develop a strategy in the form of a treatment plan with the input and cooperation of the patient." ${ }^{2}$ Finding the correct balance between patient autonomy and physician expertise in each individual situation will help this strategy be the most efficient plan possible

To accomplish these goals, a series of six practical steps have been designed to help physicians to deliver "bad news." The following paragraphs are based on SPIKES - A Six Step Protocol for Delivering Bad News, a breakthrough article in undesirable information disclosure. We have adapted these six steps to best fit any end of life situation.

\section{Setting Up the Interview}

The time and place of a meeting designed to disclose unfavorable news is important for successful dialogue and reception. Arrange for some privacy, involve significant others, sit down with the patient and family, and manage time constraints and interruptions. Privacy can eliminate any pressures or anxiety the patient may face in the context of the hospital. Finding an appropriate room during a convenient time of day, not in the early morning or late at night is advised. Listening to the patient disclose personal

1 Vitz M. "Let Us Not Forsake The Dying, Says Pa. Report," Philadelphia Inquirer (February 5, 2007$)$ : $1-2$ at 1. http://www.philly.com/mld/inquirer/16623894.htm?template=contentModules/printstory.jsp

${ }^{2}$ For a more detailed evaluation of SPIKES, see Baile et al. "SPIKES - A Six-Step Protocol for Delivering Bad News: Application to the Patient with Cancer." 


\section{THE JOURNAL OF HEALTHCARE ETHICS \& ADMINISTRATION}

Vol. 7 | No. 1 (Winter 2021)

information even if it is not directly pertinent to the medical situation will help set the tone of the meeting as an open discussion. It is recommended that the physician either mutes or shuts down all pagers, phones, and other electronic devices to remove any unnecessary interruptions.

\section{Assessing the Patient's Perception}

Before discussing the medical findings, the physician should use open-ended questions to create a reasonably accurate picture of how the patient perceives the medical situation - what it is and whether it is serious or not. It may seem obvious, but communicating with a patient who is in the early stages of dementia is much different than someone who currently works in the health profession. Furthermore, obtaining the interpretation of a minor's perception of her diagnosis is much different than an adult because her legal guardian is the direct line of communication.

\section{Obtaining the Patient's Invitation}

While the majority of patients express a desire for full knowledge about their diagnosis, prognosis, and details of their illness, some patients do not. If patients do not want to know details, offer to answer any questions they may have in the future or offer to talk to a relative or friend. Some patients may say that they want whatever the physician thinks is in their best interest. In this situation, having a strong relationship with the patient is very important so their family situation, social history, and economic state can all be considered. Hopefully the patient will eventually disclose some treatment preferences, and the physician must be alert of any small signals of preference displayed by the patient.

\section{Giving Knowledge and Information to the Patient}

Warning patients that bad news is coming may lessen the shock that can follow the disclosure of bad news and may make it easier to process that news. When giving medical facts, start at the level of comprehension and vocabulary of the patient. The authors recommend using a fifth-grade level of vocabulary; try to use non-technical terms. Avoid excessive bluntness as it is likely to leave the patient isolated and later angry, with a tendency to blame the messenger of the bad news. To ensure the patient is comprehending the information, periodically ask them to recite back the information as a list of bulleted points. Give information in small chunks. Using this strategy allows the physician to explain any information that the patient did not grasp while saving time by preventing unnecessary reiteration. Finally, when the prognosis is poor, above everything else, avoid using phrases such as "There is nothing more we can do for you." Care can always be given to a patient no matter their condition.

\section{Addressing the Patient's Emotions With Empathic Responses}

When patients receive bad news, their emotional reaction is often an expression of shock, isolation, and grief. In this situation, the physician can offer support and solidarity to the patient by offering an empathic response. It may be easier to respond with a claim of false hope, but this is more detrimental than anything. Showing support and a willingness to walk alongside the patient throughout their illness is much more important.

\section{Strategy and Summary}

Patients who have a clear plan for the future are less likely to feel anxious and uncertain. Before discussing the treatment plan, it is important to ask if the patient is ready at that time for such a discussion. Clinicians are often uncomfortable when they must discuss diagnosis and treatment options with a patient whose prognosis is unfavorable. There are various reasons for this, including 


\section{THE JOURNAL OF HEALTHCARE ETHICS \& ADMINISTRATION}

Vol. 7 | No. 1 (Winter 2021)

uncertainty about the patient's expectations, fear of destroying the patient's hope, and fear of their own inadequacy in the face of uncontrollable disease. To overcome these fears, two strategies can be employed: first, exploring the patient's knowledge, expectations, and hopes will allow the physician to understand where the patient is and to start the discussion from that point. Second, understanding the important specific goals that many patients have, such as symptom control and making sure they receive the best possible treatment and continuity of care, will allow the physician to frame hope in terms of what it is possible to accomplish. ${ }^{3}$ A cure is not always the goal of patients; some may simply wish to remain symptom and pain free or live long enough to say goodbye to loved ones.

Physicians need to have the necessary communication skills to give their patients the information they need in order to make informed decisions, but they also need to have the ability to be a source of support for their patients as they move toward the end of life. Patients want and deserve the truth about their medical conditions, but they want it in a way that fosters confidence, cooperation, and compassion. Basic communication courses in medical school are not enough to address these issues. What is also needed is cultural, social, and spiritual sensitivity on part of the physician. This is an ongoing process of education that currently begins in medical school but needs to be initiated before and must be continued throughout residency programs and beyond.

\section{Additional Resource (optional):}

- “Being Mortal” (FRONTLINE, Season 2015, Episode 3, 54:11, https://www.pbs.org/video/frontline-being-mortal/)

Post-Chapter Assessment Activity: Have students either develop their own strategy for delivering bad news or search for techniques that have not been included in this chapter. A discussion that incorporates these solutions into the strategy used to close physicianpatient communication gap can further the discussion started by this chapter.

\section{Discussion Questions:}

1. What would be your top two pieces of advice for a recent medical school graduate who is caring for their first patient that is at the end stages of a terminal condition? From who would you recommend the young doctor seek guidance in this situation?

2. Describe the setting of an ideal family meeting or discussion that is necessary for discussion goals of care and the disclosure of bad information. Support your description with a reason why you personally think at least one particular aspect of this setting is necessary.

3. Within this chapter there is a section titled Giving knowledge and information to the patient which discusses the steps physicians should use to disclose bad news. Defend the authors' suggestion to warn patients before bad news is delivered. Why do you think it is recommended that the conversation is held using technical terms not beyond on a fifth-grade level of comprehension?

Closure: Taking the User's Perspective (Excerpt from The Doctor, 1991, 2:44, https://www.youtube.com/watch?v=mSnhY5Bb6el)

Exit Ticket: What are your feelings about the YouTube clip? Explain.

\footnotetext{
${ }^{3}$ Ibid., 6-10.
} 


\section{THE JOURNAL OF HEALTHCARE ETHICS \& ADMINISTRATION}

Vol. 7 | No. 1 (Winter 2021)

\section{Further Reading:}

1. Badruddin, S., Ethics of Breaking Sad News to Patient by Health Care Professionals: Pakistan Perspective. J Clinical Research Bioethics, 2016; 7:261.

2. Førde R., Vandvik, I.H., Clinical ethics, information, and communication: review of 31 cases from a clinical ethics committee, Journal of Medical Ethics 2005;31:73-77.

3. Gawande, Atul. Being Mortal. Anchor Canada, 2017. 


\section{APPENDIX IV - CHAPTER 4: DO NOT RESUSCITATE ORDERS, LIVING WILLS/ADVANCE DIRECTIVES \& DURABLE POWERS OF ATTORNEY FOR HEALTH CARE}

Quote: "The price of longer lives is longer, slower deaths. People rarely die quickly anymore. They decline and live years with debilitating, isolating incurable diseases." ${ }^{1}$

Chapter Objectives: (SWBAT= Students will be able to..)

- SWBAT create opinions regarding their experience with death through understanding base concepts such as living wills, DNR Orders, etc.

- SWBAT analyze why people are living longer and why there has been a shift toward chronic diseases as common causes of death.

- SWBAT fluently discuss with peers, parents, and guardians the differences between DNR orders, Living Wills, and Durable Powers of Attorney for Health Care.

- SWBAT define Living Wills and express what should and should not be included in a sample Living Will.

- SWBAT discern between the different types of "codes" and explain the faults in each.

Standards (derived from Common Core State Standards)

\section{CC.1.2.11-12.K}

Determine or clarify the meaning of unknown and multiple-meaning words and phrases based on grade-level reading and content, choosing flexibly from a range of strategies and tools.

\section{CC.1.3.11-12.B}

Cite strong and thorough textual evidence to support analysis of what the text says explicitly, as well as inferences and conclusions based on and related to an author's implicit and explicit assumptions and beliefs.

\section{CC.1.5.11-12.C}

Integrate multiple sources of information presented in diverse formats and media (e.g., visually, quantitative, orally) in order to make informed decisions and solve problems, evaluating the credibility and accuracy of each source and noting any discrepancies among the data.

\section{CC.1.5.11-12.D}

Present information, findings, and supporting evidence, conveying a clear and distinct perspective; organization, development, substance, and style are appropriate to purpose, audience, and task.

\section{Overarching Practical Goals of Curriculum:}

Step 1 - The Basics: This chapter should inform readers about three aspects of end-of-life care: DNR Orders, Living Wills, and Durable Powers of Attorney for Health Care. The most practical aspects of this chapter are what DNR Orders truly involve and the hierarchy for health care decision makers.

\footnotetext{
${ }^{1}$ Vitz M. “Let Us Not Forsake The Dying, Says Pa. Report," Philadelphia Inquirer (February 5, 2007): 1-2 at 1. http://www.philly.com/mld/inquirer/16623894.htm?template=contentModules/printstory.jsp
} 


\section{THE JOURNAL OF HEALTHCARE ETHICS \& ADMINISTRATION}

Vol. 7 | No. 1 (Winter 2021)

Step 2 - Preparation Techniques: Students should decide their code statuses. At the minimum, each student should appoint a Durable Power of Attorney for Health Care if they are over the age of 18, fill out a POLST form, and complete the " 5 wishes" paperwork.

Step 3 - Communication: Students should discuss their religious beliefs, treatment preferences, and other wishes with their parents/guardians. This conversation will help the parents determine their own wishes. Students should press their parents to evaluate code status and complete documents for Living Wills and Advance Directives.

Do Now: What do you know about DNR's?

\section{Pre-Chapter Assessment Activity:}

Have students fill out a DNR/DNI order. If they choose to fill one out, have them explain why they chose to do so. If the students do not wish to fill out a DNR/DNI form, have them explain what they would want done in the event they went into cardiac arrest.

Lesson: As a supplement to the written content, consider displaying one (or all) of these clips:

- $\quad$ https://youtu.be/zc51XEy8Hk0 When CPR Doesn't “Work” Explained by Paramedic 11:09

- $\quad$ https://youtu.be/ksVakjS6-54 Mock Code Training Video 13:21

- $\quad$ https://youtu.be/4EEKnP34elg How Hospital Reacted to Man's ‘Do Not Resuscitate’ Tattoo 4:28

\section{Sections:}

Aging By the Numbers

"In the year 1900, 4.1 percent of the population of America was over the age of 65. By mid-century, this number rose to 8.1 percent. In 2000, 35.0 million people were over 65 which was 12.4 percent of the population; this number is projected to rise to 71.5 million $(19.6 \%)$ by 2030 . In 1900 , the usual place of death was at home; in 2000 , it was the hospital. In 1900, most people died from accidents or infections without suffering a long period of disability. In 2000, people suffered, on average, two years of severe disability on the way to death. Acute causes of death (such as pneumonia, influenza, and septicemia) are in decline; prolonged causes of death from age-related degenerative diseases (such as Alzheimer's, Parkinson's, and emphysema) are on the rise." ${ }^{2}$ Joanne Lynn, who has studied disability and aging in America argues, "Most Americans die with failure of a major organ (heart, lungs, kidneys, or liver), dementia, stroke, or general frailty of old age. . . [T] [Tese conditions lead to long periods of diminished function and involve multiple unpredictable and serious exacerbations of symptoms. ${ }^{3}$ Fewer Americans were affected by these degenerative diseases in the past because they did not live long enough to acquire these diseases or conditions. Because of this, different treatments are performed on patients who may be better served with less aggressive forms of care. Medicine is adapting slowly to the new technologies that are available today. Although it seems like physicians know how to treat most conditions, the proper knowledge for treatment takes time to acquire and is adaptable as new information becomes available. Before we learn more about treating the causes of death that are becoming increasingly prevalent in society, one way to ensure patients are being treated ethically is the use of Do Not Resuscitate Orders, Living Wills, and Advance Directives.

\footnotetext{
2 President's Council on Bioethics. Taking Care: Ethical Caregiving in Our Aging Society Chapter 1 (September 2005): www.bioethics.gov ; Older Americans 2004: Key Indicators of Well-Being, Federal Interagency Forum on Aging-Related Statistics. Available online at http://www.agingstats.gov

${ }^{3}$ Lynn J. Sick to Death And Not Going to Take It Anymore! (Berkeley, CA: University of California Press, 2004$)$ : at 21.
} 


\section{THE JOURNAL OF HEALTHCARE ETHICS \& ADMINISTRATION}

Vol. 7 | No. 1 (Winter 2021)

\section{Decision Makers}

With these prolonged periods of disability, questions have arisen about the appropriateness of certain aggressive medical treatments. A few of these questions you may wish to think about as you read this chapter include the following:

- Do patients want aggressive medical treatment when they have an end-stage medical condition?

- Are these treatments in the best interest of the patient?

- Do we know the wishes of patients regarding end-of-life treatment?

- Are physicians and family members listening to the wishes of patients regarding end-of life medical treatment?

"In the last three decades of the twentieth century, a series of court cases-Karen Ann Quinlin (1976), Brother Fox (1979), Claire Conroy (1985), Nancy Cruzan (1990), and Nancy B (Canada, 1992) attempted to deal with these questions. In each of these cases, self-determination was affirmed. The individual patient or the patient's surrogate is the ultimate decision-maker concerning possible treatment options." ${ }^{4}$ The patient or patient's surrogate decides which treatments are beneficial and ordinary and which treatments are extraordinary means that prolong life. This concept was explained in the previous chapter, and its application will become apparent as this chapter progresses. However, since the 1990s with advancements in medicine and technology medical decision making has become even more complex.

\section{Documents to Assist Physician-Patient Communication}

There is a need to develop a systematic way that these vital conversations can be initiated so that when treatment decisions need to be made at the end of life and the patient is no longer competent, both the primary care physician and the family know the values and wishes of the patient in these circumstances and are willing to carry them out. Three documents in particular can assist patients, family members and physicians in both the initiation of a conversation about end-of-life treatment and care and the fulfillment of a person's wishes. These documents can also serve to assure patients that they will die in comfort when a cure is no longer possible and that they will die with dignity and respect. This chapter will discuss DNR orders, Advance Directives/Living Wills and Durable Powers of Attorney for Health Care. These documents are often misunderstood, often confused with one another and often never discussed, initiated or followed. Each document will be explained, discussed and analyzed and sample copies of each document will be included.

\section{DNR (Do Not Resuscitate Orders)}

\section{CPR - A Supportive Therapy}

It is estimated every year in the United States, that more than a million people suffer cardiac arrest. About half of these people $(515,000)$ die as a result. More than 250,000 of these coronary heart disease deaths occur without the victim ever reaching the hospital. ${ }^{5}$ Cardiopulmonary Resuscitation (CPR) is a specific set of medical procedures designed to establish circulation and breathing in a patient who has suffered an arrest of both. CPR is a supportive therapy, designed to keep blood and other necessary fluids flowing to vital organs while attempts are made to restore spontaneous breathing and cardiac rhythm. ${ }^{6}$ CPR may involve simple efforts such as mouth-to-mouth resuscitation and external chest compressions or advanced efforts such as electric shock,

\footnotetext{
${ }^{4}$ Miller M. "Making Decisions About Advance Health Care Directives," in Making Health Care Decisions: A Catholic Guide (Ed. Ron Hamel) (Missouri: Liguori, 2006): 91-108 at 91.

5 Editor. "MCW Researchers Identify Steps To Improve CPR Survival," Medical College of Wisconsin (2004): $1-2$ at 1. http://healthlink.mcw.edu/article/1031002362.html

6 Editor. "Do Not Resuscitate Orders," Ethics In Medicine University of Washington School of Medicine (1998): 1-4. http://eduserver.hscer.washington.edu/bioethics/topics/dnr.html.
} 


\section{THE JOURNAL OF HEALTHCARE ETHICS \& ADMINISTRATION}

Vol. 7 | No. 1 (Winter 2021)

insertion of a tube to open the patient's airway, injection of medications directly into the heart, and in extreme cases open chest massage. It should be made clear that CPR is a temporary procedure that can be used to maintain some blood flow to the brain, heart and other vital organs until trained medical personnel are available to provide more advanced treatment.

\section{CPR and Network Television}

"Studies have found that CPR is most effective when trained medical personnel arrive within 8 to 12 minutes of the arrest. Cardiopulmonary resuscitation should be performed only by persons trained in the technique because specific CPR recommendations vary depending on the patient's age and the cause of the arrest." ${ }^{7}$ The problem is that two studies have found that even well-trained providers do not perform CPR according to the guidelines set forth by the American Heart Association and the International Liaison Committee on Resuscitation. ${ }^{8}$ Even though the public has the perception that CPR is quite effective, mainly because of television shows like "ER" and "Grey's Anatomy," the survival rates remain relatively low. "Despite decades of efforts to promote CPR science and education, the survival rate for out-of-hospital cardiac arrest remains low worldwide, averaging $6 \%$ or less." ${ }^{\prime 9}$ Those taken to the hospital with a cardiac arrest, it is estimated that the likelihood of surviving to leave the hospital ranges from $2 \%$ to $30 \%$. For the average elderly person this number hovers around $5 \%$ based on medical literature. Hospitalized patients who suffer cardiac arrest fare even worse, as these patients are usually sicker with other comorbidities. Only an estimated $2 \%$ to $15 \%$ survive to discharge. ${ }^{10}$ According to a Canadian study "survival following cardiopulmonary resuscitation in hospital does not appear to have changed markedly in 40 years." ${ }^{11}$ The basic problem is that when patients or surrogates are approached by a physician regarding "code status" (if you go into cardiac or respiratory arrest do you wish to be resuscitated) they often times are not told the survival rate or even what a "code" would entail. This violates the patient's right of informed consent.

\section{What is a DNR Order?}

Any patient who does not wish to undergo life saving treatment in the event of cardiac or respiratory arrest can request a "Do Not Resuscitate" order. The DNR order was first described in the United States in the 1960s when defibrillation allowed the reversal of cardiac arrest. Even though defibrillation allows the reversal of cardiac arrest, many times the patient is only revived for a very short time. $^{12}$

A DNR order is also referred to as the "code status" of a patient. A patient can be a "full code" when all life-sustaining measures will be attempted on the patient in the event that the patient goes into cardiac or respiratory arrest. A patient can be a "no code" or what we refer to as having a DNR order written on his or her chart. [Appendix A \& B] A DNR order, which is consented to by a patient or surrogate and written by a physician, is a physician's order that tells health care professionals that if this particular patient suffers cardiopulmonary arrest, the patient should not be resuscitated. It should be noted that some states require one or two witnesses attesting to the fact that the patient is of sound mind, and under no duress, fraud or undue influence when this decision is made and paperwork is signed.

\footnotetext{
${ }^{7}$ Ringold S. \& Glass T. “Cardiopulmonary Resuscitation (CPR)," Journal of the American Medical Association 293 (January 19, 2005$): 388$.

${ }^{8}$ Wik L., Kramer-Johasen J., Myklebust H. et al. "Quality of Cardiopulmonary Resuscitation During Out-of-Hospital Cardiac Arrest," Journal of the American Medical Association 293 (January 19, 2005): 299-304; and Abella B., Alvarado J., Myklebust H. et al. "Quality of Cardiopulmonary Resuscitation During In-Hospital Cardiac Arrest," Journal of the American Medical Association 293 (January 19, 2005): 305-310.

${ }^{9}$ Hazinski MF., Nadkarni V., Hicket R. et al. "Major Changes in 2005 AHA Guidelines for CPR and ECC," Circulation 112 (2005): IV-206 - IV -211. http://circ.ahajournals.org/cgi/content/full/112/24 suppl/IV-206

10 Christopoulos K. "Doctors Hope To Push CPR to New Level," New York Times (March 15, 2005): 1-3 at 1. http://www.nytimes.com/2005/03/15/health/policy/15cpr.html?pagewanted=printer\&position

${ }^{11}$ Brindley P., Markland D., Mayers I. et al. "Predictors of Survival Following in-Hospital Adult Cardiopulmonary Resuscitation," Canadian Medical Association Journal 167 (4) (2002): 1-9 at 2. http://www.cmaj.ca/cgi/content/full/167/4/343

${ }^{12}$ Brindley et al. at 2-3.
} 


\section{THE JOURNAL OF HEALTHCARE ETHICS \& ADMINISTRATION}

Vol. 7 | No. 1 (Winter 2021)

Limited Codes, Chemical Codes, and Futility

A patient can be a "limited code" which means that only certain procedures will be done, such as allowing for chest compressions and antiarrhythmic drugs (to prevent or relieve cardiac arrhythmia) but no endotracheal intubation or mechanical ventilation. ${ }^{13}$ [Appendix C] Limited codes, under most circumstances are not medically appropriate. Limited codes are sometimes referred to as chemical codes. The problem is that if a person wants antiarrhythmic drugs but no chest compressions then the drugs are injected but are not circulated and thus they give no benefit to the patient. The drug sits in the body but is not circulated to take full effect. Under most circumstances, "limited codes" are written because patients or surrogates fail to understand the full dimensions of a DNR order or fear the patient will be "abandoned." So why do these types of codes exist if medical literature shows they are not effective? The confusion or lack of understanding surrounding code status is due to the failure of physicians to explain DNR orders correctly. Unless patients or surrogates understand the full implications of what "code status" entails they cannot give informed consent. To give informed consent the patient or surrogate should understand the survival rate, the trauma that is involved in a "code" and the quality of life that might result even if the code is successful.

There is also something called a "slow code" or what has been referred to as a partial, show, light blue or Hollywood code. This is when a patient is either a full code or a limited code and the medical professionals make a deliberate decision not to attempt aggressively to resuscitate a patient. This is a half-hearted attempt where the full range of pharmacologic and mechanical interventions is not used, or because the length of the effort is shortened so that a full attempt at resuscitation is not made. ${ }^{14} \mathrm{~A}$ "slow code" is unethical and illegal because it undermines the patient's right to self-determination and also violates the patient's trust in the medical professionals to abide by the agreed upon wishes of the patient or surrogate.

\section{DNRs and Other Treatments}

The patient or surrogate should also understand that a DNR order is only a decision about CPR and does not relate to other treatments. Often even medical professionals misunderstand a DNR order to mean the foregoing of aggressive treatment in general. This is absolutely false. A patient can have a DNR order and still receive aggressive treatment for their medical condition. A patient can have a DNR order and still be in an Intensive Care Unit (ICU).

\section{DNR or AND: Terminology Makes a Difference}

Another problem associated with DNR orders is that the terminology "do not resuscitate" seems very harsh, cold and even cruel. "Do Not Resuscitate" is often understood by patients and surrogates as "do nothing," and thus the abandonment of the patient. To address this issue a number of states are considering legislation to change the terminology in their relevant state codes from DNR to "Allow Natural Death" (AND). [Appendix D] Many might argue that using the terminology DNR or AND is basically a matter of semantics. This may be true, but when talking with a patient or family about code status, AND sounds "softer, more comforting, warmer even though it contains a form of the " $D$ " word (death). It says that the team cares and will continue to care for the family member." ${ }^{15}$ Basically what AND does is allow the physician to explain that in the event of a cardiac arrest the medical team will do everything possible to make the patient comfortable, but will allow the patient to die naturally and peacefully. This may seem like semantics, but we have found in practice that patients and family members react very positively to this terminology and it then allows the physician, when appropriate, to initiate a conversation about comfort measures, palliative care and in some instances even hospice care. Do you think the wording would influence your decision? Instead of a using DNR which conveys a negative action

\footnotetext{
${ }^{13}$ The drugs used in cardiac arrest depend on what rhythm the patient is in at that moment. If in asystole, the drug of choice is epinephrine; for bradycardia it is atropine; for ventricular tachycardia one would use lidocaine. Other medications approved are procainamide, amiodarone, etc.

${ }^{14}$ Sounding Board. "The Slow Code-Should Anyone Rush To Its Defense?" New England Journal of Medicine 338, 7 (February 12, 1998): 467-469 at 467.

${ }^{15}$ Cohen, at 49.
} 


\section{THE JOURNAL OF HEALTHCARE ETHICS \& ADMINISTRATION}

Vol. 7 | No. 1 (Winter 2021)

using AND conveys comfort and peace. It is possible that this small change may help society discuss this matter more openly and comfortably.

How and When is a DNR/AND Order Written?

DNR orders are written for patients in a hospital setting, nursing home or even, in some states, for patients at home. To be valid there may be a specific form that must be filled out with the signature of the physician and in some cases the patient or surrogate. The exact rules for obtaining and for emergency personnel accepting the validity of a DNR order vary widely according to jurisdiction. In many states, such as Pennsylvania, every time a patient moves from one institution (nursing home) to another (hospital) the DNR order must be rewritten to be valid. This is done to allow patients and surrogates the opportunity to reevaluate and even revise the code status when there is a change in the patient's medical condition. The problem that often happens is that an unconscious patient is rushed to an Emergency Department in the middle of the night and it is hard to contact the patient's surrogate to confirm the code status. When this occurs, the patient automatically becomes a full code until the physician can obtain consent from the surrogate. Another example of a complication is when a terminal patient who is on home hospice with a DNR order goes into cardiac arrest and a family member becomes anxious and calls 911. The Emergency Medical Technicians (EMTs) or the paramedics arrive at the home and if the person's heart or breathing has stopped they will initiate treatment to restart the heart or breathing. EMTs must perform life sustaining treatments when they are called into the field even if the patient has a legitimate DNR order. To eliminate this problem, some states, like Pennsylvania, have adopted "Out-of-Hospital Do Not Resuscitate Orders."

\section{Out-of-Hospital DNR Orders}

On November 29, 2006, Pennsylvania enacted a statute (P.L. 1484, No. 169) that repealed the "DNR Act" and replaced it with the "Out-of-Hospital Nonresuscitation Act" (20 Pa. C.S. 5481-5488). The Act empowers a person who is competent and 18 years of age or older with an end-stage medical condition to secure an out-of-hospital DNR order and, at the person's option either a bracelet or necklace that indicates they have an out-of-hospital DNR order. These necklaces and bracelets can be obtained from the Pennsylvania Department of Health. The out-of-hospital DNR order is a written order that is issued by the person's attending physician that directs Emergency Medical Service (EMS) personnel to withhold CPR from the person in the event of the person's cardiac or respiratory arrest. [Appendix E]

The effectiveness of a DNR order depends on the hospital in which the cardiopulmonary event occurs and the terms laid out in the specific DNR. If a patient has a DNR order neither cardiopulmonary resuscitation nor intubation will be performed, but treatment for infections or other treatable conditions, intravenous feeding and fluids, pain management and comfort care are generally continued. To violate a DNR order is both illegal and unethical because it violates the person's right to self-determination.

\section{Advance Directives/Living Wills}

The History of Advance Directives and Living Wills - The Federal Patient Self-Determination Act

The origin of Advance Directives and Living Wills can be traced back to the beginnings of the euthanasia movement in the United States. "Some people wanted their written wishes, such as to be euthanized when they were no longer competent, to be legally binding . . . The difficulty of making decisions for noncompetent patients, however, opened up the possibility of using a similar kind of document to guide treatment decisions, particularly at the end of life." ${ }^{16}$ These documents became legal on November 5 , 1990 when the United States Congress passed the "Federal Patient Self-Determination Act" (PSDA). This act became effective on December 1, 1991. The PSDA requires healthcare providers to give adults certain information about their rights under state laws

\footnotetext{
${ }^{16}$ Miller, at 92.
} 


\section{THE JOURNAL OF HEALTHCARE ETHICS \& ADMINISTRATION}

Vol. 7 | No. 1 (Winter 2021)

governing advance directives when they are admitted or enrolled at the facility. Some of the rights that must be disclosed include the right to make decisions concerning medical care, the right to accept or refuse medical/surgical treatment, and the right to have advance directives. The PSDA also states that information must be given about how to utilize these rights and the act prohibits discrimination against patients who do have advance directives.

Even though polls show that patients and physicians strongly support advance directives and living wills, the medical literature consistently shows that only 15 to $20 \%$ of patients complete these forms. The other problem is that of those completed physicians often do not honor them and patients with advance directives or living wills receive no measurably different care than patients without them at the end of life. ${ }^{17}$ In this section we will explore how advance directives improve patient self-determination through written communication with physicians and loved ones.

\section{Defining Advance Directives}

An Advance Directive is a document which indicates specific kinds of decisions an individual would like made should he/she be unable to participate in the decision-making process. In some cases, this document may spell out specific decisions, such as in a Living Will. An advance directive does not need to be specific, it may only designate a specific person to make health care decision for them, which is called a Durable Power of Attorney for Health Care. It can also a combination document that includes both specific statements about treatment options and designated decision makers. ${ }^{18}$ As you can see, the term "advance directive" is somewhat of an umbrella term that covers many different types of documents surrounding end-of-life decisions.

\section{Living Wills Are More Specific}

A Living Will is a document that allows individuals to describe their wishes and values about the initiation or discontinuance of death-delaying procedures in the event that they are incompetent and either in a terminal, end-stage state or permanently unconscious. There are stringent rules as to when and how living wills can be enacted because they must be followed once they are activated.

\section{The Importance of Durable Powers of Attorney for Health Care}

The Durable Power of Attorney for Health Care is a specific document that allows an individual, also known as the principal, to appoint a particular person or persons, also known as a surrogate or proxy, to direct health care decisions should the principal be unable to do so. This surrogate or proxy should know the principal's values and wishes and have discussed what the principal would want in the event he or she is incompetent and terminal or in an end stage condition or permanently unconscious. This document will be explained in much more detail in the following section, but it should be noted that this document eliminates a lot of confusion in emergency settings.

There is no universal, standard form for Advance Directives, Living Wills or Durable Power of Attorney for Health Care. It is basically a written form expressing the wishes of an individual regarding the initiation, continuation, withholding or withdrawing of life-sustaining treatment and may include other specific directions. Depending on the individual state some may need to be witnessed or in some cases notarized, some place a time limit on the document and some allow refusal of treatment resulting in death only under certain circumstances. ${ }^{19}$ This is a legal document but there is no need to have it written by legal counsel. Most

\footnotetext{
${ }^{17}$ Shaw J. "POLST: Honoring Wishes at the End of Life," Health Care Ethics USA 15, 1 (Winter 2007): 1-17 at 8. See also The SUPPORT Principle Investigators. "A Controlled Trial to Improve Care for Seriously III Hospitalized patients: A Study to Understand Prognoses and Preferences for Outcomes and Risks of Treatments (SUPPORT)," Journal of the American Medical Association 274 (4) (November 22-29, 1995): 1591-1598.

18 Editor. "Do Not Resuscitate Orders," Ethics In Medicine (University of Washington School of Medicine, 1999): $1-4$ at 3. http://eduserv.hscer.washington.edu/bioethics/topics/dnr.html.

${ }^{19}$ Miller, at 97-98.
} 


\section{THE JOURNAL OF HEALTHCARE ETHICS \& ADMINISTRATION}

Vol. 7 | No. 1 (Winter 2021)

state legislatures have made the process citizen-friendly so that all people can easily write such a document. To assist individuals with these forms, the U. S. Living Will Registry's website lists links to each state so that individuals can down load the specific forms proposed by each of the 50 states [http://www.uslivingwillregistry.com/forms.shtm].

Even though there are no universal forms for these documents, the requirements are rather standard in each state. The state of Pennsylvania recently passed a new law, Act 169 "Health Care Power of Attorney/Living Will Act" that went into effect January 29, 2007. Before the requirements are discussed, some basic terminology from Act 169 regarding advance directives will be explained. The following table contains terms that are commonly used in advance directives and your understanding of these terms will improve your medical competency and prepare you to be an informed decision-maker. You will want to discuss these terms with parents, guardians, and loved ones so they understand the legal ramifications of these documents.

\section{Table 1: Common Terms Seen in Advance Directives}

\begin{tabular}{|c|c|}
\hline $\begin{array}{l}\text { Advance Health Care } \\
\text { Directive }\end{array}$ & $\begin{array}{l}\text { A health care power of attorney, living will or a written combination of a health care power } \\
\text { of attorney and living will. }\end{array}$ \\
\hline Attending Physician & The physician who has primary responsibility for the health care of a principal or patient. \\
\hline Competent & $\begin{array}{l}\text { A condition in which an individual, when provided appropriate medical information, } \\
\text { communication supports and technical assistance, is documented by a health care provider } \\
\text { to DO ALL OF THE FOLLOWING: } \\
\text { (1) Able to understand the potential material benefits, risks and alternatives } \\
\text { involved in a specific proposed health care decision. } \\
\text { (2) Able to make that health care decision on his own behalf. } \\
\text { (3) Able to communicate that health care decision to any other person. } \\
\text { This term is intended to permit individuals to be found competent to make some health care } \\
\text { decisions, but incompetent to make others. It is also useful to add to this definition that the } \\
\text { person is alert and oriented himself/herself, to the time and date, and to his/her location. }\end{array}$ \\
\hline $\begin{array}{l}\text { End-stage } \\
\text { condition }\end{array}$ & $\begin{array}{l}\text { An incurable and irreversible medical condition in an advanced state caused by injury, } \\
\text { disease or physical illness that will, in the opinion of the attending physician to a reasonable } \\
\text { degree of medical certainty, result in death despite the introduction or continuation of } \\
\text { medical treatment. Except as specifically set forth in an advance healthcare directive, the } \\
\text { term is not intended to prevent treatment of a disease, illness or physical, mental, cognitive } \\
\text { or intellectual condition, even if incurable and irreversible and regardless of severity, if both } \\
\text { of the following apply: } \\
\text { (1) The patient would benefit from the medical treatment, including palliative care. } \\
\text { (2) Such treatment would not merely prolong the process of dying. }\end{array}$ \\
\hline Health care & $\begin{array}{l}\text { Any care, treatment, service or procedure to maintain, diagnose, treat or provide for physical } \\
\text { or mental health, custodial or personal care, including any medication program, } \\
\text { therapeutical and surgical procedure and lifesustaining treatment. }\end{array}$ \\
\hline Health care agent & An individual designated by a principal in an advance health care directive. \\
\hline
\end{tabular}




\section{THE JOURNAL OF HEALTHCARE ETHICS \& ADMINISTRATION}

Vol. 7 | No. 1 (Winter 2021)

\begin{tabular}{|c|c|}
\hline Health care decision & $\begin{array}{l}\text { A decision regarding an individual's health care, including, but not limited to, the following: } \\
\text { (1) Selection and discharge of a health care provider. } \\
\text { (2) Approval or disapproval of a diagnostic test, surgical procedure or program of } \\
\text { medication. } \\
\text { (3) Directions to initiate, continue, withhold or withdraw all forms of life-sustaining } \\
\text { treatment, including instructions not to resuscitate. }\end{array}$ \\
\hline $\begin{array}{l}\text { Health care power of } \\
\text { attorney }\end{array}$ & $\begin{array}{l}\text { A writing made by a principal designating an individual to make health care decisions for the } \\
\text { principal. }\end{array}$ \\
\hline Health care provider & $\begin{array}{l}\text { A person who is licensed, certified or otherwise authorized by the laws of the } \\
\text { Commonwealth of Pennsylvania to administer or provide health care in the ordinary course } \\
\text { of business or practice of a profession. }\end{array}$ \\
\hline $\begin{array}{l}\text { Health care } \\
\text { representative }\end{array}$ & $\begin{array}{l}\text { An individual authorized under the Health Care Agents and Representatives Act to make } \\
\text { health care decisions for a principal, provided that conditions set forth in section IV (b) (iii) of } \\
\text { this policy have been met. }\end{array}$ \\
\hline Incompetent & $\begin{array}{l}\text { A condition in which an individual despite being provided appropriate medical information, } \\
\text { communication supports and technical assistance, is documented by a health care provider } \\
\text { to be: } \\
\text { (1) unable to understand the potential material benefits, risks and alternatives } \\
\text { involved in a specific proposed health care decision; or } \\
\text { (2) unable to make that health care decision on his own behalf; or } \\
\text { (3) unable to communicate that health care decision to any other person. } \\
\text { The term is intended to permit individuals to be found incompetent to make some health } \\
\text { care decisions, but competent to make others. }\end{array}$ \\
\hline $\begin{array}{l}\text { Life-sustaining } \\
\text { treatment }\end{array}$ & $\begin{array}{l}\text { Any medical procedure or intervention that, when administered to a patient or principal who } \\
\text { has an end-stage medical condition or is permanently unconscious, will serve only to prolong } \\
\text { the process of dying or maintain the individual in a state of permanent unconsciousness. In } \\
\text { the case of an individual with an Advance Directive the term includes nutrition and hydration } \\
\text { administered by gastric tube or intravenously or any other artificial or invasive means if the } \\
\text { advance health care directive so specifically provides. }\end{array}$ \\
\hline Living will & $\begin{array}{l}\text { A writing made in accordance with the Living Will Act that expresses a principal's wishes and } \\
\text { instructions for health care and health care directions when the principal is determined to be } \\
\text { incompetent and has an end-stage medical condition or is permanently unconscious. }\end{array}$ \\
\hline $\begin{array}{l}\text { Permanently } \\
\text { unconscious }\end{array}$ & $\begin{array}{l}\text { A medical condition that has been diagnosed in accordance with currently accepted medical } \\
\text { standards and with reasonable medical certainty as total and irreversible loss of } \\
\text { consciousness and capacity for interaction with the environment. The term includes, without } \\
\text { limitation, an irreversible vegetative state or irreversible coma. }\end{array}$ \\
\hline Person & $\begin{array}{l}\text { Any individual, corporation, partnership, association or other similar entity, or any Federal, } \\
\text { State or local government or governmental agency. }\end{array}$ \\
\hline
\end{tabular}




\section{THE JOURNAL OF HEALTHCARE ETHICS \& ADMINISTRATION}

Vol. 7 | No. 1 (Winter 2021)

\begin{tabular}{|l|l|}
\hline Principal & $\begin{array}{l}\text { An individual who executes an advance health care directive, designates an individual to act } \\
\text { or disqualifies an individual from acting as a health care representative or an individual for } \\
\text { whom a health care representative acts in accordance with this chapter. }\end{array}$ \\
\hline Reasonably available & $\begin{array}{l}\text { Readily able to be contacted without undue effort and willing and able to act in a timely } \\
\text { manner considering the urgency of the individual's health care needs. }\end{array}$ \\
\hline
\end{tabular}

The Fine Print of Living Wills

The requirements for writing a Living Will are that an individual must be of sound mind, 18 years of age or older, or has graduated from high school, has been married or is an emancipated minor (has ever been pregnant, been in the military, or has been emancipated by a judge). The Living Will must be dated and signed by the principal with a signature or by another individual on behalf of the principal if the principal is unable to sign the document. The Living Will must also be witnessed by two individuals, each of whom is 18 years of age or older. It is also stipulated that an individual who signs a living will on behalf of the principal may not witness the living will. In addition, a health care provider (hospital, nursing home, etc.) and its agents may not sign a living will on behalf of a principal if the health care provider or agent provides health care services to the principal. This is because there may be a conflict of interests. Once the living will is completed, the principal should give copies of it to those individuals who present it to the attending physician or the health care provider when it is appropriate. ${ }^{20}$ The principal should also sit down with these individuals and review the Advance Directive/Living Will with them to help eliminate any ambiguity about intention, wording or wishes.

\section{What to Included in a Living Will}

There are no specific guidelines for what the content of a Living Will should include. Bioethicist Mark Miller recommends three essential things that should be included in a Living Will/Advance Directive. "First, if you are dying (and unable to make your own decisions), ask for palliative or hospice care, which is treatment appropriate for the dying. Second, it is important to make a statement about your most fundamental beliefs. Third, it is helpful to put a 'safety valve' statement into one's Advance Directive/Living Will. A sample 'safety valve' statement would be: 'If you do not know what my condition is, please treat me until you do know; then follow my wishes-make me better if you can, or allow me to die according to my instructions."'21 Miller also believes there are certain specific issues that need to be considered concerning end-of-life choices: use of a ventilator, cardiopulmonary resuscitation (code status), surgery or aggressive medical interventions, and artificial hydration and nutrition. ${ }^{22}$ All of these issues need to be considered, but it is important to state that one cannot cover every issue or condition that could arise. Making a Living Will/Advance Directive clear and specific to avoid ambiguity is good but these documents are not foolproof.

\section{Activating the Living Will}

For the living will to become operative first a copy of the document must be given to the attending physician and placed on the principal's chart. Second, the attending physician must certify in writing that the principal is "incompetent" and has either an "end stage medical condition" or is permanently unconscious. Finally, once it is determined that the living will is operative, the attending physician and other health care providers will act in accordance with its provisions. A surrogate, proxy, or Durable Power of Attorney for Health care CANNOT override a Living Will/Advance Directive if it has been declared operative.

\footnotetext{
${ }^{20}$ Pennsylvania Legislature, Section 5442.

${ }^{21}$ Miller, at 100.

${ }^{22}$ Miller, at 101-106.
} 


\section{THE JOURNAL OF HEALTHCARE ETHICS \& ADMINISTRATION}

Vol. 7 | No. 1 (Winter 2021)

If an attending physician or health care provider are unable in good conscience to comply with the provisions of the living will they are required to make every reasonable effort to assist in the transfer of the principal to another physician or health care provider who can comply with the living will.

There are two exceptions to complying with a living will that has been activated. The first is if 911 is activated and the principal does not have an out-of-hospital DNR order, the EMS personnel will give emergency treatment. Second, the law mandates life-sustaining medical treatment must be given to an incompetent pregnant woman unless life-sustaining treatment will: (1) not maintain the pregnant woman in such a way as to permit the continuing development and live birth of the unborn child; (2) be physically harmful to the woman; or (3) cause pain to the woman that cannot be alleviated by medication. These determinations must be made to a reasonable degree of medical certainty and certified by the woman's attending physician and an obstetrician who has examined the woman. Act 169 requires the state to pay for life-sustaining care provided to a pregnant woman under this provision. ${ }^{23}$

\section{Altering or Cancelling a Living Will}

A patient may amend an advance directive or living will only if the patient is of sound mind. An amendment must conform to the requirements for executing an advance directive or living will. In the case of multiple advance directives or living wills the latest directive prevails. An advance directive or living will may be revoked at any time and in any manner by the principal regardless of the mental and physical condition of the principal. The attending physician or health care provider must immediately note in the principal's medical record that the living will has been revoked. ${ }^{24}$ Many people in Pennsylvania question why the legislators allow for incompetent people to revoke their living will. The only possible explanation is that they are protecting the person's right of selfdetermination. This appears to be an extreme measure and not prudent under most circumstances.

\section{Other Forms Available for End-of-Life Decisions}

A form known as the POLST form originated in Oregon in the late 1990s. This form called for a standardization of physician-orderfor-life-sustaining treatment (POLST). ${ }^{25}$ "The POLST form allows persons with serious medical conditions to document their advance decisions for life-prolonging treatments as clear, specific written medical orders, which will be honored in all settings." ${ }^{26}$ The first version of the form was implemented in 1995. [Appendix H] "By 1998, early research confirmed that patients with POLST forms received the care they wanted and did not receive the care they did not want. In a study of 180 nursing home residents requesting comfort care measures only, transfer to hospital only if comfort measures fail, and do not resuscitate (DNR) orders, only $2 \%$ were hospitalized to extend their lives, and none were resuscitated against their wishes. ${ }^{27}$ The reason the POLST form is so important is that it provides for the continuity of care, especially in regards to DNR orders and other life-sustaining treatment orders, from one setting to another. So that, if a patient is transferred from a nursing home to a hospital, the POLST form is transferred with the patient to assure that each person's difficult decisions regarding end-of-life care are honored and are not dishonored by misplaced or delayed paperwork. The POLST form is currently being considered by an advisory committee of the Pennsylvania Department of Health.

\footnotetext{
${ }^{23}$ Pennsylvania Legislature, Section 5443-5446. See also Pennsylvania Medical Society." Advance Health Care Directives and Health Care Decisionmaking for Incompetent Patients: A Guide to Act 169 of 2006 for Physicians and Other Health Care Providers," (Pennsylvania, Pennsylvania Medical Society, 2006): 1-13, at 11. www.pamedsoc.org

24 Pennsylvania Legislature, Section 5444; Pennsylvania Medical Society, at 2-3.

${ }^{25}$ Pennsylvania Medical Society, at 1.

${ }^{26}$ Shaw, at 8 .

${ }^{27}$ Shaw, at 8. See also Tolle SW et al. "A Prospective Study of the Efficacy of the Physician Order Form for Life-Sustaining Treatment," Journal of the American Geriatrics Society 46, 9 (September 1998): 1097-1102.
} 


\section{THE JOURNAL OF HEALTHCARE ETHICS \& ADMINISTRATION}

Vol. 7 | No. 1 (Winter 2021)

Another type of Advance Directive/Living Will is a form called "Five Wishes." The Five Wishes document is unique among other living will forms because it looks at the total needs of the person: medical, personal, emotional and spiritual. It allows you to choose the person you want to make medical decisions for you in the event that you become incompetent. Anyone 18 years of age and older who is competent can write Five Wishes. The following five wishes allow your surrogate, family members and physicians know what you would want in the event that you become incompetent:

1) Which person you want to make health care decisions for you when you can't make them

2) The kid of medical treatment you want or don't want.

3) How comfortable you want to be.

4) How you want people to treat you.

5) What you want your loved ones to know.

It is estimated that nearly six million copies of this document are circulating throughout the United States. Presently, Five Wishes meets the legal requirements under the health decisions statutes of 36 states and the District of Columbia. Unfortunately, this form does not legal statutes in Alabama, Indiana, Kansas, Kentucky, Nevada, New Hampshire, Ohio, Oklahoma, Oregon, South Carolina, Texas, Utah, Vermont, or Wisconsin.

Living Wills/Advance Directives might make medical decision-making at the end-of-life any easier for loved ones. No matter how specific one might be in writing an Advance Directive/Living Will these documents will always be ambiguous to a certain degree and can always be misinterpreted. That is why these documents should be written in combination with the appointment of a Durable Power of Attorney for Health Care. Appointing a person who knows the patient's values and wishes and will be able to carry out those wishes in the best interest of the patient can help to lighten the burden of end-of-life decision-making for everyone involved. The next section will explain the significance of appointing a Durable Power of Attorney for Health Care.

Durable Power of Attorney for Health Care

The final aspect to advance directives is deciding who should make decisions for a patient in the event that patient is incompetent or otherwise unable to make medical decisions for his/herself. Assigning a substituted decision maker allows for smoother processing of information and decisions are able to be made more rapidly at the benefit of the patient. When a person is no longer competent, the patient's wishes are expressed by a substitute decision maker that is someone who knows the patient's wishes and values and makes medical decisions based on what he or she believes the patient would want if the patient were competent. These substitute decision makers are known as a durable power of attorney for health care, proxy, health care agent, surrogate, next of kin, etc. Each of these terms allow a person to make a substituted judgment for a patient but the one with the most legal standing is the Durable Power of Attorney for Health Care.

It should be noted that there are different types of Powers of Attorney (POA). There have been situations in the hospital in which an individual identifies himself or herself as the POA for the patient and wants to make medical decisions for that individual, but in reality they are the POA only for financial matters. It is imperative that if someone identifies himself or herself as the Durable Power of Attorney for Health Care that this particular individual produce the proper document with the necessary signatures appointing him or her to this position. This document should then be placed on the patient's chart.

\section{How to Appoint a Durable Power of Attorney for Health Care}

In the state of Pennsylvania, any individual of sound mind can appoint a Durable Power of Attorney if the individual is 18 years of age or older; has graduated from high school, has been married; or is an emancipated minor. The Health Care Power of Attorney (POA) form must be signed by the principal by a signature or by another person on behalf of the principal if the principal is unable to sign. It must also be witnessed by two individuals 18 years of age or older [Appendix I]. Like the Living Will form, an individual who 


\section{THE JOURNAL OF HEALTHCARE ETHICS \& ADMINISTRATION}

Vol. 7 | No. 1 (Winter 2021)

signs a health care power of attorney on behalf of or at the direction of a principal may not witness the health care power of attorney. A health care provider and its agents may not sign a health care power of attorney on behalf of or at the direction of a principal if the health care provider or its agents provide health care services to the principal for the same fear of conflicts of interest as previously mentioned in the Living Will section. ${ }^{28}$ In the state of Pennsylvania a Health Care POA cannot be the principal's attending physician, health care provider or the owner, operator or employee where a principal is receiving care unless related to the principal by blood, marriage or adoption.

\section{Who Should be Your Health Care POA?}

In choosing a Health Care POA two things are essential. First, choose someone who knows your wishes and values. Second, choose someone who you know is able to carry out your instructions if you should become incompetent. It is also imperative to communicate to your physician and family the name of this person so that all parties know a decision-maker is in place when a crisis arises. ${ }^{29}$ Make sure the person that is appointed is willing to make all medical decisions. This means he/she would be willing to consent to simple things such as blood transfusions to more serious issues such as ventilators and DNR orders. The principal can give a Health Care POA authority as broad as the patient would have if competent. In contrast to living wills, Health Care POA's are not restricted to end-of-life decision making. Although they are usually given authority only when the patient is incompetent, a principal may invest a Health Care POA with authority even when the patient is competent. The Health Care POA document only becomes operative when a copy is provided to the attending physician and the attending physician determines that the principal is incompetent. A copy of the Health Care POA document should be placed in the principal's medical record. ${ }^{30}$

\section{Responsibilities of the Durable Power of Attorney for Health Care}

The duty of a Health Care POA is to gather information about the principal's diagnosis, prognosis and acceptable medical alternatives regarding diagnosis, treatments and supportive care. The Health Care POA should make medical decisions in accordance with the POA's understanding and interpretation of the instructions given by the principal at a time when the principal had capacity to make and communicate such decisions. In the absence of such instructions the Health Care POA should make medical decisions for the principal that conform with the principal's preferences and values, including religious and moral beliefs. If the principal's preferences are unknown, the Health Care POA should take into account what he or she knows of the principal's values and beliefs and assess what is in the principal's best interest. Then the Health Care POA should decide, taking into consideration, the following goals: the preservation of life; the relief of suffering; and the preservation and restoration of functioning. The Health Care POA should consider any concurrent diseases, illness or physical, mental, cognitive or intellectual conditions that may have predated the principal's end stage medical condition. The Health Care POA is permitted to consent to treatments based on his/her good faith in keeping to the religious beliefs of the principal and can also withhold health care that is contrary to the religious beliefs of the principal. The Health Care POA has the same rights and limitations as the principal to request, examine, copy and consent to the disclosure of medical or other health care information.

The Principal Can Change His/Her Durable Power of Attorney for Health Care

A principal of sound mind may modify or revoke a Durable Power of Attorney for Health Care in writing or by orally informing the attending physician or health care provider. The law also states, that regardless of the patient's mental or physical capacity, a principal may countermand the decision of a Health Care POA that would withhold or withdraw life-sustaining treatment, by personally informing the attending physician. If it is determined by a judge that a Durable Power of Attorney is not acting in the

\footnotetext{
${ }^{28}$ Pennsylvania Medical Society, at 3-5.

${ }^{29}$ Miller, at 98.

${ }^{30}$ Pennsylvania Medical Society, at 3; Pennsylvania Legislature, Section 5456.
} 


\section{THE JOURNAL OF HEALTHCARE ETHICS \& ADMINISTRATION}

Vol. 7 | No. 1 (Winter 2021)

best interest of the patient, said judge can remove the Durable Power of Attorney and appoint a guardian ad litem for the patient. ${ }^{31}$ This means the state intervenes and assigns a special guardian that makes medical decisions for the patient.

\section{Hierarchy of Decision Makers}

In the absence of a Health Care POA or if the POA is not reasonably available the following classes may act as the patient's proxy in the state of Pennsylvania: 1) the spouse, unless an action for divorce is pending, and the adult children of the patient who are not the children of the spouse; 2) an adult child; 3) a parent; 4) an adult brother or sister; 5) an adult grandchild; 6) an adult who has knowledge of the patient's preferences and values, including but not limited to, religious and moral beliefs, to assess how the patient would make health care decisions. If none of these individuals can be reasonably located then the patient's health care provider must seek a legal guardian from the courts. This list is a hierarchy; only when nobody from a higher level can be id entified should an attempt be made to appoint someone from a lower level. The Pennsylvania law stipulates that if there is more than one member of a class who assumes authority and the members do not agree, the decision is made by the majority members of the class. If the members of the class are evenly divided no decision shall be deemed acceptable until such time when the parties resolve their disagreement. Usually, two hours is an acceptable amount of time to permit the parties to come to agreement. If the disagreement seems unable to be resolved, the health care provider can refer the situation to the courts to have a guardian appointed. It should be stated that if the patient's Living Will is operative, a durable Power of Attorney for Health Care cannot countermand the wishes of a patient stipulated in a Living Will. If the attending physician or health care provider cannot in good conscience comply with the decision of the Health Care POA, the attending physician must inform the POA and then assist the POA in the transfer of the principal to another physician or health care provider who can comply with the wishes of the POA. If transfer is impossible the attending physician will not be subject to civil or criminal liability or administrative sanction. Physicians are protected in Pennsylvania under the Pennsylvania Health Care Act. ${ }^{32}$

\section{Other Surrogate Types}

It should be noted that Pennsylvania's new "Health Care Agents and Representatives Act" also gives patients the flexibility to appoint a health care agent by any signed written document or by verbally telling the patient's health care provider or attending physician who the patient authorizes to make health care decisions on behalf of the patient should the patient become incompetent. $^{33}$ The State recognizes the importance of Advance Directives, Living Wills and Durable Powers of Attorney for Health Care but it also recognizes that if an individual fails to have these documents, it is vital that an individual appoint a health care agent so that attending physicians, health care providers and family members know to the best of their ability, the wishes of the individual. If it is the case that a patient does not have a Durable Power of Attorney for Health Care but wishes to appoint somebody, the title given to this person is the Health Care Representative. Pennsylvania legislators went out of their way to make this process as simple as possible for its citizens so that in the event that a person becomes incompetent all parties concerned will act in the best interest of the person.

\section{Organ Donation}

The authors of this curriculum had the unique opportunity to spend a day shadowing the Gift of Life Donors' Program Facilities in Philadelphia, PA to gain an insider's perspective on organ donation and to debunk many of the myths surrounding organ donation. We have chosen to include this topic in this chapter because it is yet another decision that can be made at any point of life; furthermore, this decision may be able to save the lives of others under certain circumstances. All major religions including Baptists,

\footnotetext{
${ }^{31}$ Pennsylvania Medical Society, at 3-6; Pennsylvania Legislature, Section 5459.

32 Pennsylvania Medical Society, at 8-10.

${ }^{33}$ Pennsylvania Legislature, Subchapter C, Sections 5451-5465.
} 


\section{THE JOURNAL OF HEALTHCARE ETHICS \& ADMINISTRATION}

Vol. 7 | No. 1 (Winter 2021)

Buddhism, Catholicism, Hinduism, Islam, Judaism, Mormons, and Presbyterians either view organ and tissue donation as an act of self-sacrifice and charity or a personal decision with which they do not have any prohibitions against. The choice to become an organ donor is thus an individual choice that all should consider.

Many myths surround organ donation. One of the most common myths is that doctors and emergency response units do not work as hard to save the lives of organ donors if they know the individual is a registered organ donor. This is false. Medical teams are morally and legally obligated to do everything in their power to treat individuals whether they are donors or not. There is no difference. Also, the team that is responsible for the recovery of a donor's organs is separate from the medical teams in hospitals who treat the patient until the said patient passes. This ensures there isn't any conflict of interests.

As previously mentioned, all major religions not only support organ donation, but view it as a great giving of life. Also, many people fear they are too sick old to be organ and tissue donors. Once again, this is false. Age and past medical history do not affect one's ability to register to be an organ and tissue donor. With such great demand for major organs, any viable organs are accepted. Organs that are accepted include the following: heart, lungs, kidney, liver, intestine, pancreas. Tissues that are accepted include the cornea, tendons, valves, veins, skin, and bones. All of organs and tissues are entered into a nationwide data base to find potential matches between the donor and recipient. Race, gender, income, and social status are never considered. With over 200,000 individuals waiting for kidney and liver transplants alone, the choice to become an organ and tissue donor is up to you.

\section{Conclusion}

In the end, medical treatment decisions will never be made into a perfect science for those who are incompetent and have endstage medical conditions. Rather, the goal is to do the best we can with the tools that have been given to us. DNR orders, Advance Directives/Living Will and Durable Powers of Attorney for Health Care are all tools that direct physicians and family members to make medical decisions for patients that are in their best interest and comply with their values and wishes. Terminally ill patients and their family members and caregivers deserve a system better than the one currently available. "They depend on the health care system to serve their needs and certainly not to add to the burden of their or a loved one's final days." 34

Meeting the needs of patients and family members will require initiating conversations about end-of-life treatment and care, understanding and respecting the values and wishes of the patient, confronting the barriers to respecting the patient's values and wishes, and developing new tools and policies to change the present health care system. Addressing these challenges will not only allow the terminally ill patient to die with dignity and respect but will give family members the peace of mind of knowing that they made decisions in the best interest of their loved one.

\section{Post-Chapter Assessment Activity:}

Distribute the DNR/DNI forms students filled out before the chapter. Give students the opportunity to make any changes now that they have been informed about ordinary-extraordinary means and how they apply to end-of-life care. Have students write reflections on their views and why they either changed or stayed the same.

\footnotetext{
${ }^{34}$ Lynn J. and Adamson D. "Living Well at the End of Life: Adapting Health Care to Serious Chronic Illness in Old Age," (Washington, D.C., Rand, 2003): 1-21 at 18. www.rand.org/pubs/white papers/WP137/index.html
} 


\section{THE JOURNAL OF HEALTHCARE ETHICS \& ADMINISTRATION}

Vol. 7 | No. 1 (Winter 2021)

\section{Discussion Questions:}

1. Compared to network television, what are the actual statistics of cardiac arrest and CPR success rates? Do you think more people would elect to have DNR orders if they knew these statistics?

2. What is informed consent? Do you think the general public has informed consent of what CPR and intubation involves?

3. Explain the significance of out-of-hospital DNRs.

4. Describe a good candidate to elect as a Durable Power of Attorney for Healthcare. What is the confusion with this term?

5. Is a living will reversible? Who can reverse it? Under what circumstances?

Closure: Distribute the DNR/DNI forms students filled out before the chapter. Give students the opportunity to make any changes now that they have been informed about ordinary-extraordinary means and how they apply to end-of-life care. Have students write reflections on their views and why they either changed or stayed the same.

Exit Ticket: Write three-five sentences about your reaction to one of the video clips you saw today.

\section{Further Reading:}

1. Jalal, Safwan. "A Loss of Character: Dementia and Advance Directives | Princeton Journal of Bioethics." Princeton University, The Trustees of Princeton University, 15 Aug. 2016, pjb.mycpanel2.princeton.edu/wp/index.php/2016/08/15/a-loss-ofcharacter-dementia-and-advance-directives/.

2. "Advance Directives and Outcomes of Surrogate Decision Making before Death | NEJM." New England Journal of Medicine, www.nejm.org/doi/full/10.1056/NEJMsa0907901.

3. "Advance Directives for Medical Care - A Case for Greater Use I NEJM." New England Journal of Medicine, www.nejm.org/doi/full/10.1056/NEJM199103283241305. 


\section{Appendix A: Sample State of Illinois DNR Order Sheet}

Do Not Resuscitate (DNR) Order

I, (print full name) DO NOT AUTHORIZE CARDIOPULMONARY RESUSCITATION. I (or my legal representative) understand that this order remains in effect until revoked by me (or my legal representative) or the attending physician. I (or my legal representative) acknowledge that cardiopulmonary resuscitation (CPR) will not be performed if breathing or heart beat stops. (The signatures of [a] the patient OR legal representative, [b] the physician and [c] two witnesses are required.)

Printed name of patient Signature of patient Date

Printed name of physician Signature of physician Date

Effective date

Legal Representative's Signature of Consent for Patient Lacking Decision Making Capacity

(If the patient lacks decision making capacity, then a signature in this section is required.)

Printed name of (circle appropriate title) legal guardian Street Address

OR durable power of attorney for health care agent

OR surrogate decision maker

City, State, ZIP

Signature of legal representative

Date

Printed name of witness Signature of witness Date 


\section{THE JOURNAL OF HEALTHCARE ETHICS \& ADMINISTRATION}

Vol. 7 | No. 1 (Winter 2021)

Address of witness

Printed name of witness Signature of witness Date

Address of witness

Illinois Department of Public Health

535 W. Jefferson St.

Springfield, IL 62761

217-785-2080,

TTY (hearing impaired use only)

800-547-0466

Reproduce on brightly colored orange paper 


\section{Appendix B: Sample DNR Order Sheet}

\section{DO-NOT-RESUSCITATE ORDER}

I request that in the event my heart and breathing should stop, no person shall attempt to resuscitate me. This order is effective until it is revoked by me.

Being of sound mind, I voluntarily execute this order, and I understand its full import.

(Declarant's signature and Date)

(Type or print declarant's full name)

(Signature of person who signed for declarant, if applicable and Date)

(Type or print full name)

\section{ATTESTATION OF WITNESSES}

The individual who has executed this order appears to be of sound mind, and under no duress, fraud, or undue influence. Upon executing this order, the individual has (has not) received an indentification bracelet.

(Witness signature) (Date)

(Type or print witness's name)

(Witness signature) (Date)

(Type or print witness's name)

THIS FORM WAS PREPARED PERSUANT TO, AND IN COMPLIANCE WITH, THE MICHIGAN DO-NOT-RESUSCITATE PROCEDURE ACT. 
Appendix C: Sample DNR Order Sheet that would allow for a Limited Code Status:

PHYSICIAN ORDERS SHEET

\section{CARDIOPULMONARY RESUSCITATION ORDER SHEET}

— No Cardiopulmonary Resuscitation/continue comfort measures

_ Limited Cardiopulmonary Treatment (specify)

_ withhold antiarrhythmic drugs

_ withhold cardioversion/defibrillation/external pacing

_ withhold chest compressions

_ withhold intravenous vasopressor drugs

_ withhold endotracheal intubation

_ withhold mechanical ventilation

\section{Procedures:}

Discussed treatment and potential choices with patient and/or family/guardian

Discussed with 


\section{THE JOURNAL OF HEALTHCARE ETHICS \& ADMINISTRATION}

Vol. 7 | No. 1 (Winter 2021)

Documented discussion in progress notes

Date

Signature of Attending Physician/Designee 
Appendix D: Sample AND/DNR Order Sheet

\section{CARDIOPULMONARY RESUSCITATION ORDER SHEET}

Code Status:

[ ]

A.N.D. - Allow Natural Death / DNR (Do Not Resuscitate)/Continue

Comfort Measures, No Cardiopulmonary Resuscitation/No Intubation

Or Mechanical Ventilation

[ ] Perform Basic Cardiopulmonary Resuscitation/Withhold Endotracheal Intubation/Mechanical Ventilation

[ ] Full Cardiopulmonary Resuscitation

Discussion/Content:

[ ] Discussed treatment and potential choices with patient and/or authorized representative of the patient

[ ] Documented discussion in Progress Notes. Date: 
Signature of Attending Physician/Designee:

Date:

Date:

N.B. Re-evaluate prior to and after going to the OR or Cathlab. 


\section{Appendix E: Sample Emergency Medical Prehospital DNR Form:}

\section{EMERGENCY MEDICAL SERVICES PREHOSPITAL DO NOT RESUSCITATE (DNR) FORM}

\section{An Advance Request to Limit the Scope of Emergency Medical Care}

I,

$$
\text { request limited emergency care as herein }
$$

(Print patient's name and medical record number)

described.

I understand DNR means that if my heart stops beating or if I stop breathing, no medical procedure to restart breathing or heart functioning will be instituted.

I understand this decision will not prevent me from obtaining other emergency medical care by pre-hospital emergency medical care personnel and/or medical care directed by a physician prior to my death.

I understand I may revoke this directive at any time by destroying this form and removing any "DNR" medallions.

I give permission for this information to be given to the prehospital emergency care personnel, doctors, nurses or other health personnel as necessary to implement this directive.

I hereby agree to the "Do Not Resuscitate" (DNR) order.

Date

Patient/Surrogate

Signature

Print Surrogate's name Relationship to Patient Surrogate's phone number

By signing this form, the surrogate acknowledges that this request to forego resuscitative measures is consistent with the known desires of and with the best interest of the individual who is the subject of this form. 


\section{THE JOURNAL OF HEALTHCARE ETHICS \& ADMINISTRATION}

Vol. 7 | No. 1 (Winter 2021)

I affirm that this patient/surrogate is making an informed decision and that this directive is the expressed wish of the patient/surrogate. A copy of this form is in the patient's permanent medical record.

In the event of cardiac or respiratory arrest, no chest compressions, assisted ventilations, intubation, defibrillation, or cardiotonic medications are to be initiated.

Physician Signature Date

Print

Name

California License number

THIS FORM WILL NOT BE ACCEPTED IF IT HAS BEEN AMENDED OR ALTERED IN ANY WAY

\section{PREHOSPITAL DNR REQUEST FORM}

Original is to be kept by patient Submit a copy to be kept in patient's permanent medical record If an authorized DNR medallion is desired, submit a copy of this form, with Medic Alert enrollment form, to Medic Alert Foundation, 2323 Colorado Avenue, Turlock, CA 95381. To obtain the Medic Alert enrollment form, call 1-800-432-5378 An Advance Request to Limit the Scope of Emergency Medical Care 


\section{Appendix F: Sample Pennsylvania Out-Of-Hospital Resuscitation Order}

\section{OUT-OF-HOSPITAL DO-NOT-RESUSCITATE ORDER}

\section{Patient's Name:}

\section{A. Attending Physician Statement:}

I, the undersigned, state that I am the attending physician of the patient named above. The above-named patient, or the patient's surrogate or other person by virtue of that person's legal relationship to the patient, has requested this order, and I have made a determination that this patient is eligible for an order and satisfies one of the following: (1) the patient has an end-stage medical condition; (2) the patient is in a terminal condition; (3) the patient is permanently unconscious and has a living will directing that no cardiopulmonary resuscitation be provided to the patient in the event of the patient's cardiac or respiratory arrest; or (4) the patient is permanently unconscious and has a living will authorizing the surrogate or other person named below to request an out-ofhospital do-not-resuscitate order for the patient. I direct any and all emergency medical services personnel, commencing on the date of my signature below, to withhold cardiopulmonary resuscitation, (cardiac compression, invasive airway techniques, artificial ventilation, defibrillation and other related procedures) from the patient in the event of the patient's respiratory or cardiac arrest. If the patient is not yet in cardiac or respiratory arrest, I further direct such personnel to provide to the patient other medical interventions, such as intravenous fluids, oxygen or other therapies necessary to provide comfort, care or to alleviate pain, unless directed otherwise by the patient or the emergency medical services provider's authorized medical command physician.

Signature of Physician:

Printed:

Date:

Emergency Telephone Number:

Bracelet issued: Yes No Necklace issued: Yes No

\section{B. Attending Physician Statement for Patient Pregnant When Order Issues (in addition to above statement):}

I, the undersigned, certify that an obstetrician has examined the patient named above and that the obstetrician and I have certified in the patient's medical record as required by law that life-sustaining treatment, nutrition, hydration and cardiopulmonary resuscitation will have one of the following consequences if provided to this pregnant patient: (1) they will not maintain the pregnant patient in such a way as to permit the continuing development and live birth of the unborn child; or (2) they will be physically harmful to the pregnant patient; or (3) they will cause pain to the pregnant patient which cannot be alleviated by medication.

Signature of Physician: Printed:

Date:

\section{A. Patient's or Surrogate's Statement:}

I, the undersigned, hereby direct that in the event of my cardiac and/or respiratory arrest efforts at cardiopulmonary resuscitation not be initiated and that they may be withdrawn if initiated. I understand that I may revoke these directions at any time by giving verbal instructions to the emergency medical services providers, by physical cancellation or destruction of this form or my bracelet or necklace or by simply not displaying this form or the bracelet or the necklace for my EMS caregivers. 
Date

Signature of Patient

(If patient qualified to sign)

\section{B. Surrogate's/other Person's (by virtue of relationship to patient) Statement:}

I, the undersigned, hereby certify that I am legally authorized to execute this order on the patient's behalf by virtue of having been designated as the patient's surrogate and/or by virtue of my relationship to the patient (specify relationship: ). I hereby direct that in the event of the patient's cardiac and/or respiratory arrest, efforts at cardiopulmonary resuscitation not be initiated and be withdrawn if initiated.

Date

Signature of Surrogate/Other Person by Virtue of Relationship to Patient

(If patient not qualified to sign)

\section{Out-Of-Hospital Do-Not-Resuscitate Order Information}

Authority: Out-of-Hospital No resuscitation Act (Act), P.L. 1484, No. 169 (20 Pa.C.S. §§ 5481-5488), effective January $28,2007$.

When Order is Effective: An out-of-hospital do-not-resuscitate (DNR) order is effective when it is signed by the attending physician. The attending physician signs last. It remains in effect until the death of the patient or the order is revoked.

Implementation: Emergency medical services (EMS) providers are obligated to honor an out-of-hospital DNR order when displayed with the patient or the patient is wearing an out-of-hospital DNR bracelet or necklace. Patient interventions indicated and not indicated under out-of-hospital DNR order:

Shall not be provided if patient is in cardiac or respiratory arrest:

CPR

Endo-tracheal intubation

Bag valve mask

Defibrillation

Common medications used during resuscitation efforts

Shall be provided if patient is not yet in cardiac or respiratory arrest*:

Oxygen

Suctioning

Medications and other interventions within scope of practice and as authorized by protocols or medical command orders, to provide 
comfort, care or alleviate pain

*These interventions are not to be provided if the patient or a medical command physician directs otherwise.

Pregnant patient: Statement 2B on the reverse side needs to be completed only if the patient is a woman and the physician diagnoses the woman to be pregnant at the time the out-of-hospital DNR order is issued.

Revocation: The out-of-hospital DNR order may be revoked by destroying or not displaying the order, bracelet, and necklace, or by conveying the decision to revoke the order verbally or otherwise at the time the patient experiences cardiac or respiratory arrest. If the patient obtained the out-of-hospital DNR order, only the patient may revoke it. If a surrogate/other person by virtue of relationship to the patient obtained the out-of-hospital DNR order, the patient or a surrogate/other person by virtue of relationship to patient may revoke the order. Neither the patient's mental or physical condition limits the patient's right to revoke an out-ofhospital DNR order.

\section{Definitions:}

Out-of-hospital DNR patient: A patient for whom an attending physician has issued an out-of-hospital DNR order.

Surrogate: A "health care agent" or a "health care representative" as those terms are defined in 20 Pa.C.S. § 5422.

Attending physician: A physician who has primary responsibility for the medical care and treatment of a patient. A patient may have more than one attending physician.

End-stage medical condition: An incurable and irreversible medical condition in an advanced state caused by injury, disease or physical illness which will, in the opinion of the attending physician, to a reasonable degree of medical certainty, result in death despite the introduction or continuation of medical treatment.

EMS provider: An ambulance attendant, first responder, EMT, paramedic, pre-hospital registered nurse, health professional physician, medical command physician, advanced life support service medical director, medical command facility medical director, medical command facility, ambulance service and quick response service as defined in regulations adopted under the Emergency Medical Services Act, and an individual who is given good Samaritan civil immunity under 42 Pa.C.S. § 8331.2 (when using an automated external defibrillator).

Out-of-hospital DNR order: A written order that is issued by an attending physician and directs EMS providers to withhold or withdraw CPR from the patient in the event of cardiac or respiratory arrest. The form for the physician's order is supplied by the Department of Health or its designee.

Permanently unconscious: A medical condition that has been diagnosed in accordance with currently accepted medical standards and with reasonable medical certainty as total and irreversible loss of consciousness and capacity for interaction with the environment. The term includes, without limitation, an irreversible vegetative state or irreversible coma.

Terminal condition: An incurable and irreversible medical condition in an advanced state caused by injury, disease or physical illness which will, in the opinion of the attending physician, to a reasonable degree of medical certainty, result in death regardless of the continued application of life-sustaining treatment. 


\section{Appendix G: Sample Living Will}

\section{HEALTH CARE TREATMENT INSTRUCTIONS IN THE EVENT \\ OF END-STAGE MEDICAL CONDITION OR \\ PERMANENT UNCONSCIOUSNESS}

(LIVING WILL)

The following health care treatment instructions exercise my right to make my own health care decisions. These instructions are intended to provide clear and convincing evidence of my wishes to be followed when I lack the capacity to understand, make or communicate my treatment decisions:

IF I HAVE AN END-STAGE MEDICAL CONDITION (WHICH WILL

RESULT IN MY DEATH, DESPITE THE INTRODUCTION OR CONTINUATION OFMEDICAL TREATMENT) OR AM PERMANENTLY UNCONSCIOUS SUCH AS ANIRREVERSIBLE COMA OR AN IRREVERSIBLE VEGETATIVE STATE AND THERE IS NOREALISTIC HOPE OF SIGNIFICANT RECOVERY, ALL OF THE FOLLOWING APPLY (CROSS OUT ANY TREATMENT INSTRUCTIONS WITH WHICH YOU DO NOT AGREE):

1. I direct that I be given health care treatment to relieve pain or provide comfort even if such treatment might shorten my life, suppress my appetite or my breathing, or be habit forming.

2. I direct that all life prolonging procedures be withheld or withdrawn.

3. I specifically do not want any of the following as life prolonging procedures: (If you wish to receive any of these treatments, write "I do want" after the treatment)

heart-lung resuscitation (CPR)

mechanical ventilator (breathing machine)

dialysis (kidney machine)

surgery

chemotherapy

radiation treatment

antibiotics

Please indicate whether you want nutrition (food) or hydration (water) medically supplied by a tube into your nose, stomach, intestine, arteries, or veins if you have an end-stage medical condition or are permanently unconscious and there is no realistic hope of significant recovery. 


\section{(Initial only one statement.)}

\section{TUBE FEEDINGS}

I want tube feedings to be given

OR

NO TUBE FEEDINGS

I do not want tube feedings to be given.

HEALTH CARE AGENT'S USE OF INSTRUCTIONS (INITIAL ONE OPTION ONLY).

My health care agent must follow these instructions.

OR

These instructions are only guidance. My health care agent shall have

final say and may override any of my instructions. (Indicate any exceptions)

If I did not appoint a health care agent, these instructions shall be followed.

\section{LEGAL PROTECTION}

Pennsylvania law protects my health care agent and health care providers from anylegal liability for their good faith actions in following my wishes as expressed in this form or in complying with my health care agent's direction. On behalf of myself, my executors and heirs, I further hold my agent's health care agent and my health care providers harmless and indemnify them aga inst any claim for their good faith actions in recognizing my health care agent's authority or in following my treatment instructions. 


\section{ORGAN DONATION (INITIAL ONE OPTION ONLY.)}

I consent to donate my organs and tissues at the time of my death for the purpose of transplant, medical study or education. (Insert any limitations you desire on donation of specific organs or tissues or uses for donation of organs and tissues.)

OR

I do not consent to donate my organs or tissues at the time of my death. Having carefully read this document, I have signed it ___ this day of ___ 20_ revoking all previous health care powers of attorney and medical health care treatment instructions.

Having carefully read this document, I have signed this day of 20 , revoking all previous health care powers of attorney and medical health care treatment instructions.

WITNESS:

Address of Witness:

WITNESS:

Address of witness:

Two witnesses at least 18 years of age are required by Pennsylvania law and should witness your signature in each other's presence. A person who signs this document on behalf of and at the direction of a principal may not be a witness. (It is preferable if the witnesses are not your heirs, nor your creditors, nor employed by any of your health care providers.) 


\section{THE JOURNAL OF HEALTHCARE ETHICS \& ADMINISTRATION}

Vol. 7 | No. 1 (Winter 2021)

\section{NOTARIZATION (OPTIONAL)}

(Notarization of document is not required by Pennsylvania law, but if the document is both witnessed and notarized, it is more likely to be honored by the laws of some other states.)

On this___ day of , 20 before me personally appeared the aforesaid declarant and principal, to me known to be the person described in and who executed the foregoing instrument and acknowledged that he/she executed the same as his/her free act and deed.

IN WITNESS WHEREOF, I have hereunto set my hand and affixed my official seal in the County of State of the day and year first above written. 


\section{Appendix H: Sample POLST Form}

\section{Physician Orders for Life-Sustaining Treatment}

\section{Last Name}

(POLST) First follow these orders, then contact physician or NP.

First Name/ Middle Initial

This is a Physician Order Sheet based on the person's medical condition and wishes. Any section not completed implies full treatment for that section. Everyone shall be treated with dignity and respect.

\section{Date of Birth}

\section{A}

Check

One

CARDIOPULMONARY RESUSCITATION (CPR): Person has no pulse and is not breathing. Resuscitate/CPR Do Not Attempt Resuscitation (DNR/no CPR) When not in cardiopulmonary arrest, follow orders in B, C and D.

B

Check

One

(C) CENTER FOR ETHICS IN HEALTH CARE, OHSU Form developed in conformance with Oregon Revised Statute 127.505 et seq September 2004

C

Check

One

ANTIBIOTICS No antibiotics. Use other measures to relieve symptoms. Determine use or limitation of antibiotics when infection occurs. Use antibiotics if life can be prolonged. Additional Orders:

D

Check

One

Additional Orders: No artificial nutrition by tube. Defined trial period of artificial nutrition by tube. Long-term artificial nutrition by tube. ARTIFICIALLY ADMINISTERED NUTRITION: Always offer food by mouth if feasible.

\section{E SUMMARY OF MEDICAL CONDITION AND SIGNATURES}

Discussed with: Patient Parent of Minor

Health Care Representative Court-Appointed 
Guardian Other:

Summary of Medical Condition

Print Physician/ Nurse Practitioner Name

MD/DO/NP Phone Number

Office Use Only

Physician/ NP Signature (mandatory) Date

SEND FORM WITH PERSON WHENEVER TRANSFERRED OR DISCHARGED

(c) CENTER FOR ETHICS IN HEALTH CARE, Oregon Health \& Science University, 3181 Sam Jackson Park Rd, UHN-86, Portland, OR 97239-3098 (503) 494-3965

This POLST form is provided as a sample only and is not to be reproduced for patient use.

HIPAA PERMITS DISCLOSURE OF POLST TO OTHER HEALTH CARE PROFESSIONALS AS NECESSARY

\section{Signature of Person, Parent of Minor, or Guardian/Health Care Representative}

Significant thought has been given to life sustaining treatment. Preferences have been expressed to a physician and/or health care professional(s). This document reflects those treatment preferences. (If signed by surrogate, preferences expressed must reflect patient's wishes as best understood by surrogate.)

Signature (optional)

Name (print)

Relationship (write "self"if

patient)

Contact Information

Surrogate (optional)

Relationship

Phone Number

Health Care Professional

Preparing Form

(optional) Preparer Title

Phone Number 
Date Prepared

Directions for Health Care Professionals Completing POLST Must be completed by a health care professional based on patient preferences and medical indications. POLST must be signed by a physician or nurse practitioner to be valid. Verbal orders are acceptable with follow-up signature by physician or nurse practitioner in accordance with facility/community policy. Use of original form is strongly encouraged. Photocopies and FAXes of signed POLST forms are legal and valid. Using POLST Any incomplete section of POLST implies full treatment for that section. No defibrillator (including AEDs) should be used on a person who has chosen "Do Not Attempt Resuscitation." Oral fluids and nutrition must always be offered if medically feasible. When comfort cannot be achieved in the current setting, the person, including someone with "Comfort Measures Only," should be transferred to a setting able to provide comfort (e.g., treatment of a hip fracture). IV medication to enhance comfort may be appropriate for a person who has chosen "Comfort Measures Only." Treatment of dehydration is a measure which prolongs life. A person who desires IV fluids should indicate "Limited Interventions" or "Full Treatment." A person with capacity, or the surrogate of a person without capacity, can request alternative treatment. Reviewing POLST This POLST should be reviewed periodically and if: (1) The person is transferred from one care setting or care level to another, or (2) There is a substantial change in the person's health status, or (3) The person's treatment preferences change. Draw line through sections A through E and write "VOID" in large letters if POLST is replaced or becomes invalid.

The POLST program was developed by the Oregon POLST Task Force. The POLST program is administratively housed at Oregon Health \& Science University's Center for Ethics in Health Care. Research about the safety and effectiveness of the POLST program is available online at <www.polst.org > or by contacting the Task Force at <polst@ohsu.edu>. The Oregon POLST Task Force

\section{SEND FORM WITH PERSON WHENEVER TRANSFERRED OR DISCHARGED}

MEDICAL INTERVENTIONS: Person has pulse and/or is breathing. Comfort Measures Only Use medication by any route, positioning, wound care and other measures to relieve pain and suffering. Use oxygen, suction and manual treatment of airway obstruction as needed for comfort. Do not transfer to hospital for life-sustaining treatment. Transfer if comfort needs cannot be met in current location. Limited Additional Interventions Includes care described above. Use medical treatment, IV fluids and cardiac monitor as indicated. Do not use intubation, advanced airway interventions, or mechanical ventilation. Transfer to hospital if indicated. Avoid intensive care. Full Treatment Includes care described above. Use intubation, advanced airway interventions, mechanical ventilation, and cardioversion as indicated. Transfer to hospital if indicated. Includes intensive care. Additional Orders: 


\section{Appendix I: Sample Durable Power of Attorney for Health Care Form}

\section{DURABLE HEALTH CARE POWER OF ATTORNEY}

I, _ of___ County,

Pennsylvania, appoint the person named below to be my health care agent to make health and personal care decisions for me. Effective immediately and continuously until my death or revocation by a writing signed by me or someone authorized to make health care treatment decisions for me, I authorize all health care providers or other covered entities to disclose to my health care agent, upon my agent's request, any information, oral or written, regarding my physical or mental health, including, but not limited to, medical and hospital records and what is otherwise private, privileged, protected or personal health information, such as health information as defined and described in the Health Insurance Portability and Accountability Act of 1996 (Public Law 104-191, 110 Stat. 2024 1936), the regulations promulgated there under and any other State or local laws and rules. Information disclosed by a health care provider or other covered entity may be redisclosed and may no longer be subject to the privacy rules provided by 45 C.F.R. Pt. 164.The remainder of this document will take effect when and only when I lack the ability to understand, make or communicate a choice regarding a health or personal care decision as verified by my attending physician. My health care agent may not delegate the authority to make decisions.

MY HEALTH CARE AGENT HAS ALL OF THE FOLLOWING POWERS SUBJECTTO THE HEALTH CARE TREATMENT INSTRUCTIONS THAT FOLLOW IN PART III (CROSS OUT ANY POWERS YOU DO NOT WANT TO GIVE YOUR HEALTH CARE AGENT):

1. To authorize, withhold or withdraw medical care and surgical procedures.

2. To authorize, withhold or withdraw nutrition (food) or hydration (water) medically supplied by tube through my nose, stomach, intestines, arteries or veins.

3. To authorize my admission to or discharge from a medical, nursing, residential or similar facility and to make agreements for my care and health insurance for my care, including hospice and/or palliative care.

4. To hire and fire medical, social service and other support personnel responsible for my care.

5. To take any legal action necessary to do what I have directed.

6. To request that a physician responsible for my care issue a do-not-resuscitate (DNR)

order, including an out-of-hospital DNR order, and sign any required documents and consents. 


\section{APPOINTMENT OF HEALTH CARE AGENT}

I appoint the following health care agent:

HEALTH CARE AGENT:

(Name and relationship)

Address:

Telephone Number: Home Work

E-MAIL:

IF YOU DO NOT NAME A HEALTH CARE AGENT, HEALTH CARE PROVIDERS WILLASK YOUR FAMILY OR AN ADULT WHO KNOWS YOUR PREFERENCES AND VALUESFOR HELP IN DETERMINING YOUR WISHES FOR TREATMENT. NOTE THAT YOUMAY NOT APPOINT YOUR DOCTOR OR OTHER HEALTH CARE PROVIDER ASYOUR HEALTH CARE AGENT UNLESS RELATED TO YOU BY BLOOD, MARRIAGE OR ADOPTION.

If my health care agent is not readily available or if my health care agent is my spouse and an action for divorce is filed by either of us after the date of this document, I appoint the person or persons named below in the order named. (It is helpful, but not required, to name alternative health care agents.)

First Alternative Health Care Agent:

(Name and relationship)

Address:

Telephone Number: Home Work

E-MAIL:

Second Alternative Health Care Agent:

(Name and relationship)

Address:

Telephone Number: Home Work

E-MAIL: 


\section{THE JOURNAL OF HEALTHCARE ETHICS \& ADMINISTRATION}

Vol. 7 | No. 1 (Winter 2021)

\section{APPENDIX 5 - CHAPTER 5: ORDINARY VS. EXTRAORDINARY MEANS: THE ISSUE OF TUBE FEEDINGS}

Quote: "Whatever requires an undue amount of thought or trouble or involves a large expenditure of effort and causes our whole life to revolve, as it were, around the solicitude for the flesh must be avoided by Christians." -St. Basil the Great in Long Rules (Question 55)

Chapter Objectives: (SWBAT= Students will be able to..)

- SWBAT analyze the differences between extraordinary and ordinary means through case studies and discussions.

- SWBAT discern the different forms of extraordinary and ordinary means through discussion and peer collaboration.

- SWBAT elaborate and reflect on the meaning of case studies presented.

Standards (derived from Common Core State Standards)

\section{CC.1.2.11-12A}

Determine and analyze the relationship between two or more central ideas of a text, including the development and interaction of the central ideas; provide an objective summary of the text

\section{CC.1.2.11-12.B}

Cite strong and thorough textual evidence to support analysis of what the text says explicitly as well as inferences and conclusions based on and related to an author's implicit and explicit assumptions and beliefs

\section{CC.1.2.11-12.D}

Evaluate how an author's point of view or purpose shapes the content and style of a text

\section{CC.1.2.11-12.H}

Analyze seminal texts based upon reasoning, premises, purposes, and arguments.

\section{CC.1.2.11-12.J}

Acquire and use accurately general academic and domain-specific words and phrases, sufficient for reading, writing, speaking, and listening at the college and career readiness level; demonstrate independence in gathering vocabulary knowledge when considering a word or phrase important to comprehension or expression.

\section{CC.1.2.11-12.K}

Determine or clarify the meaning of unknown and multiple-meaning words and phrases based on grade-level reading and content, choosing flexibly from a range of strategies and tools.

\section{CC.1.2.11-12.L}

Read and comprehend literary non-fiction and informational text on grade level, reading independently and proficiently.

\section{CC.1.4.11-12.A}

Write information/explanatory texts to examine and convey complex ideas, concepts, and information clearly and accurately

\section{CC.1.4.11-12.B.}

Write a sharp and distinct focus identifying topic, task, and audience 


\section{THE JOURNAL OF HEALTHCARE ETHICS \& ADMINISTRATION}

Vol. 7 | No. 1 (Winter 2021)

\section{CC.1.4.11-12.C}

Develop and analyze the topic thoroughly by selecting the most significant andm relevant facts, extended definitions, concrete details, quotations, or other information and examples appropriate to the audience's knowledge of the topic; include graphics and multimedia when useful to aiding comprehension

\section{CC.1.4.11-12.D}

Organize complex ideas, concepts, and information so that each new element builds on that which precedes it to create while; use appropriate and varied transitions and syntax to line the major sections of the text; provide a concluding statement or section that supports the information presented; include formatting when useful to aiding comprehension

\section{CC.1.4.11-12.F}

Demonstrate a grade appropriate command of the conventions of Standard English grammar, usage, capitalization, punctuation, and spelling

\section{CC.1.4.11-12.G}

Write arguments to support claims in an analysis of substantive topics

\section{Overarching Practical Goals of Curriculum:}

Step 1 - The Basics: Students will be able to decide for themselves what they would consider to be extraordinary means.

Step 2 - Preparation Techniques: Students will be able to understand the Church's position on end-of-life care obligations. This will be applied to Advance Directives in the next chapter.

Step 3 - Communication: This chapter should spark conversations about personal preferences. Hopefully this will create an atmosphere in which people are comfortable discussing "how far" they wish to be treated and translate these preferences into legal documents.

Do Now: What is your understanding of "extraordinary means?"

Pre-Chapter Assessment Activity: How would you like to be taken care of if you knew you were ill? (This would be in the form of a small sheet of paper collected anonymously then discussed as a whole class.)

\section{Sections:}

\section{Introduction}

For five hundred years, the Catholic Church's position on the ordinary-extraordinary means distinction has been the basis for moral decision making when determining if certain medical treatments or procedures were morally obligatory or nonobligatory for individuals. The differences were based on the prudential, cautious judgement of the patient or the patient's decision maker on whether the techniques and resources used offered an equal amount of hope of benefit without causing excessive burdens to the overall quality of the patient's life. There is no set category of ordinary or extraordinary treatments. Instead, the concept of ordinary-extraordinary means allows each individual the freedom to use his or her well-formed conscience to make judgments about what would be in his or her best interest as a whole person. This notion is applicable to medicine in many circumstances such as deciding whether a patient could refuse to start or withdraw ventilators, feeding tubes, dialysis, pacemakers, and so on. 


\section{THE JOURNAL OF HEALTHCARE ETHICS \& ADMINISTRATION}

Vol. 7 | No. 1 (Winter 2021)

The standard of ordinary-extraordinary means was challenged in 2004 by John Paul II's speech, "Care For Patients In A Permanent Vegetative State" presented to The International Congress on Life-Sustaining Treatment and Vegetative State: Scientific Advances and Ethical Dilemmas. This single talk opened a debate about the ordinary-extraordinary means distinction that could have consequences that change modern bioethics. The core of John Paul II's position is that "the administration of water and food, even when provided by artificial means, always represents a natural means of preserving life, not a medical act." ${ }^{1}$ This means that artificial nutrition and hydration for those in a permanent vegetative state is always morally obligatory because Pope John Paul II's declared those mean ordinary. If artificial nutrition or hydration is not provided in these cases it would be considered death by starvation or dehydration, and if done willingly it could be considered "euthanasia by omission." 2

The dilemma is that this single speech may change the 500-year-old ordinary-extraordinary means distinction that has guided medical professionals, ethicists and patients in making well-reasoned moral decisions. Instead of bringing clarity to this issue, this speech has caused a crisis for Catholic healthcare. Numerous questions are now being asked. Some that you may want to keep in mind while reading this chapter include the following:

1. Who was the Pope referring to when he applied his ordinary-extraordinary distinction?

2. Does this statement imply that Catholics may not refuse artificial nutrition and hydration if they have a terminal condition?

3. If a patient or surrogate wishes to withdraw artificial nutrition and hydration would the patient either not be accepted in a Catholic facility or have to be transferred to another facility?

4. If a physician continues to provide artificial nutrition and hydration against the wishes of the patient could the physician be accused of battery or be sued for malpractice?

5. How might the Pope's speech impact palliative care programs and hospice programs in Catholic health care facilities?

6. Might insurance companies refuse to pay for what they may deem to be futile treatment?

7. Would families have to absorb some or most of the costs of prolonged care?

These questions raised show the complexity of this issue and the confusion that has resulted. To address these questions and to give clarity to patients and surrogates we will first explore how history has led us to our current understanding of ordinaryextraordinary means. Then, we will examine Pope John Paul II's speech on the subject and how it has challenged the Church's longstanding position. Finally, the role of conscience in decision making will be explained so all decisions surrounding medical treatments are made morally.

\section{Historical Background of the Ordinary-Extraordinary Means Tradition Saint Basil the Great Hints at Extraordinary}

The history of the ordinary-extraordinary means distinction has its origin in the Roman Catholic Church and many scholars believe that its origin dates back to the $16^{\text {th }}$ century Dominican moralists. There are however, some who believe it may go back to the fourth century A.D. when St. Basil the Great wrote the following in his Long Rules (Question 55), "Whatever requires an undue amount of thought or trouble or involves a large expenditure of effort and causes our whole life to revolve, as it were, around the solicitude for the flesh must be avoided by Christians. . Therefore, whether we follow the precepts of the medical art or decline to have recourse to them. . . we should hold to our objective of pleasing God and see to it that the soul's benefit is assured, fulfilling thus the Apostle's precept: 'Whether you eat or drink or whatsoever else you do, do all to the glory of God'" (1 Corinthians 10:31). ${ }^{3}$

\footnotetext{
1John Paul II. “Care for Patients in a Persistent Vegetative State," Origins 33 (2004): 739-752, no.4 at 739.

2 John Paul II, no. 4, p. 740.

3 Sulmasy D. "Are Feeding Tubes Morally Obligatory?" St. Anthony Messenger (January 2006): 1-7, at 2. http://www.americancatholic.org/Messenger/Jan2006/Feature1.asp.
} 


\section{THE JOURNAL OF HEALTHCARE ETHICS \& ADMINISTRATION}

Vol. 7 | No. 1 (Winter 2021)

St. Basil highlights that there is some distinction between experiences, procedures, or medicines that cause an "undue amount of trouble" and ones that do not. He explains that as humans we can choose to pursue these or decline to move forward with such treatments as long as we are attempting to please God and taking our whole self into consideration when making these decisions.

\section{Thomas Aquinas Judges Burdens}

Other scholars argue that the ordinary-extraordinary terminology goes back to Thomas Aquinas (1225-1274), a Dominican Friar and Doctor of the Roman Catholic Church. Thomas judged all human activity based on whether it leads to God, the final end. Thus, if something was "too difficult" or "too burdensome" he implied that it might make loving God too difficult. ${ }^{4}$ So Thomas believes there is a limit to the general obligation to preserve life. This is influenced by Thomas' concept of God's dominion over the gift of human life..$^{5}$ Thomas' influence on ordinary-extraordinary means is clearly present, but it is the three Dominican moralists--Francisco De Vitoria, Domingo Soto and Domingo Banez--who are credited with the foundation of the ordinary-extraordinary means distinction.

\section{Dominican Moralists De Vitoria, Soto, and Banez Develop the Modern Definition}

Francisco De Vitoria (1486-1546) examined the limits of treatment in regards to nourishment and medicinal drugs. In his seminal work Relectiones Theologicae ${ }^{6}$ he states:

If a sick man can take food or nourishment with a certain hope of life, he is required to take food as he would be required to give it to one who is sick. However, if the depression of spirits is so severe and there is present grave consternation in the appetitive power so that only with the greatest effort and as though through torture can the sick man take food, this is to be reckoned as an impossibility and therefore, he is excused, at least from mortal $\sin ^{7}$

De Vitoria is not condoning suicide here. A healthy person may not starve him-herself because life is problematic. If the means are effective and not burdensome then the person has a moral obligation to seek nourishment. However, if the person is so sick or depressed that eating may become a grave burden, then the person is not morally obliged to eat and does not commit a sin. The essential point here is that De Vitoria recognizes and includes both psychological and physiological illness as possible burdens.

Francisco De Vitoria also examined the use of medicinal drugs and the requirements individuals have when deciding to use them. In summary, De Vitoria concludes that one is not obliged to sacrifice one's whole means of subsistence, nor one's general lifestyle, nor one's homeland in order to acquire a cure or obtain optimum health. ${ }^{8}$ In present day, this idea is expressed as the reasonable person standard. De Vitoria believed means that offer a reasonable hope of benefit in regard to cure and return to health must be used when available. Excessive burdens in terms of financial costs or inconvenience of lifestyle are also measured by "the semi-objective standard of the common person," or what we refer to as the "reasonable person standard." ${ }^{9}$ If the means used

\footnotetext{
${ }^{4}$ Atkinson G. "Theological History of Catholic Teaching on Prolonging Life," in D. McCarthy \& A. Moraczewski (Eds.), Moral Responsibility In Prolonging Life Decisions (St. Louis: Pope John Center, 1981).

${ }^{5}$ Aquinas T. Summa Theologica A. Ross \& PG Walsh (Eds), Blackfriars edition (New York: McGraw Hill, 1966).

${ }^{6}$ The Relectio was a lecture that De Victoria, the preeminent theologian at the University of Salamanca, Spain, would give at the beginning of each school year. These lectures treated some difficult, contemporary dilemma. One can presume that the question of prolonging life must have been a disputed topic at the time.

7 De Vitoria F. "Relectio IX: de Temperentia," Relectiones Theologicae Lugdini, 1587. cf Relecciones Theologicas, edition critica, (Madrid: Imprenta La Rafa, Volume III., 1933-1935).

${ }^{8}$ De Vitoria, 1933-35; Sparks R. To Treat or Not To Treat (NewYork: Paulist Press, 1988): at 95.

${ }^{9}$ Sparks, at 96.
} 


\section{THE JOURNAL OF HEALTHCARE ETHICS \& ADMINISTRATION}

Vol. 7 | No. 1 (Winter 2021)

to prolong life were ineffective, if the effect was doubtful, or if it involves a grave burden for the person in question, then the treatment is not morally required.

\section{Amputations in the $15^{\text {th }}$ and $16^{\text {th }}$ Century and Domingo Soto}

How were concepts practically applied to medicine in the $15^{\text {th }}$ century? Prior to the development of modern anesthesia, surgical procedures, especially amputations, were quite painful. Domingo Soto (1494-1560) reasoned that surgery such as amputation of a limb, because of the excessive pain, ought to be considered categorically optional. He argued that such torture was beyond the limits that the "common man" ought to be obliged to suffer for the sake of one's bodily health. Such pain can make a beneficial surgery "morally impossible" to bear. ${ }^{10}$ Besides the question of pain, Soto also recognizes the role that emotions of fear and disgust could play. ${ }^{11}$ Soto incorporates the dimension of optional versus obligatory, adding if a procedure or treatment was too painful or burdensome, it would be morally optional.

\section{Coining "Ordinary versus Extraordinary"}

In 1595, Domingo Bañez (1528-1604) was the first to articulate the terms "ordinary" and "extraordinary" means of preserving life. He argued that if preserving life was reasonable it was obligatory but insisted that one is "not bound to extraordinary means but to common food and clothing, to common medicines, to certain common and ordinary pain; not, however, to certain extraordinary and horrible pain, nor to expenses which are extraordinary in proportion to the status of this man."12 One determined if a treatment or medical procedure was ordinary or extraordinary according to whether it was proportionate to one's condition or state in life. The cultural and socio-economic factors were also weighed when facing these questions. "Thus, if something were very costly or burdensome or if it did not offer substantial benefit to the patient, there was no moral obligation to use it. This standard applied to even life-saving measures."13 Jesuit moralists and Dominican moralists agreed with Bañez and confirmed the tradition of the Church that states human life is a good but not an absolute good. As a relative good, one's duty to preserve it is a limited duty. While a person has freedom over his or her life, one is never permitted to directly take one's life. The issue then is to what extent is one obligated to preserve one's life?

\section{Technology in the mid-1900s Challenges the Definitions of Ordinary and Extraordinary}

The traditional understanding of ordinary-extraordinary means remained basically unchallenged until the mid-1900s when advances in medicine and technology introduced new concerns surrounding treatments. Issues applying the early distinction of ordinaryextraordinary means to matters like oxygen and feeding tubes, especially with permanently unconscious patients became hotly debated as early as the 1950s. Jesuit moralist Gerald Kelly was one of the first to examine this issue. He defined ordinary means of preserving life as "all medicines, treatments, and operations, which offer a reasonable hope of benefit for the patient and which can be obtained and used without excessive expense, pain, or other inconvenience." Extraordinary means would be "all medicines, treatments, and operations, which cannot be obtained or used without excessive expense, pain, or other inconvenience, or which, if used, would not offer a reasonable hope of benefit." ${ }^{14}$

\footnotetext{
${ }^{10}$ Soto D. De Justitia et Jure, Lib. 5, question 2, article 1. (Venice, Italy, 1568); see also Sparks, at 96.

${ }^{11}$ Wildes K. "Ordinary and Extraordinary Means and the Quality of Life," Theological Studies 57 (1996): 500-512 at 504.

12 Bañez D. Scholastica Commentaria in Partem Angelici Doctoris S. Thomae Tom. IV, "Decisiones de Jure et Justitia," II, II ae, Question 65, Article 1. (Duaci, 1614-1615).

${ }^{13}$ Paris J \& McCormick R. "The Catholic Tradition on the Use of Nutrition and Fluids," America 156 (1987): 256-361, at 358.

${ }^{14}$ Kelly G. Medico-Moral Problems (St. Louis: The Catholic Health Association of the United States and Canada, 1957$):$ at 129.
} 


\section{THE JOURNAL OF HEALTHCARE ETHICS \& ADMINISTRATION}

Vol. 7 | No. 1 (Winter 2021)

The distinctive element of Kelly's interpretation is that it is a patient-centered, quality-of-life approach and that it is consistent with the $16^{\text {th }}$-century-Dominican moralists view. According to Kelly, no person is morally obligated to use any means that do not offer a reasonable hope of relieving the patient's condition.

Many believe that the most influential historical study on this topic was done by Daniel Cronin in his 1958 doctoral dissertation at the Gregorian University in Rome entitled, "The Moral Law in Regard to the Ordinary and Extraordinary Means of Preserving Life." After a review of over 50 moral theologians dating from Aquinas to those writing in the early 1950's Cronin concludes that the Church's teaching is consistent in its view: "Even natural means, such as taking of food and drink, can become optional if taking them requires great effort or if the hope of beneficial results (spes salutis) is not present." For a patient whose condition is incurable, he writes, "even ordinary means, according to the general norm, have become extraordinary [morally dispensable] for the patient [so] the wishes of the patient, expressed or reasonably interpreted, must be obeyed." ${ }^{15}$ The importance of Cronin's position is that no means-even food and water-can ever be classified as absolutely obligatory regardless of the patient's condition. Cronin's work exemplifies that there is no set category of treatments or medications that someone must always accept. Instead, it is up to the person to determine how those treatments or medicines would affect them by weighing the benefits and burdens.

However, some moralists disputed this fact and claimed that food and water were absolutely ordinary and even tried to say that was what the tradition taught. Despite pushback by some moralists, Pope Pius XII gave a talk to the International Congress of Anesthesiologists that echoed the Church's 500 year-old distinction on the subject. Pius XII upholds the traditional ordinaryextraordinary means distinction that "involves patient-centered judgments about the quality of life, which must take into account the usefulness of the treatment, one's understanding about death and dying, and the repugnance one may have toward one's life after subjection to a particular medical treatment. ${ }^{16}$ It is also important to note that Pius XII emphasized the importance of viewing the person holistically. Viewing the person holistically is critical because preserving life at all costs is to risk idolatry and would lead a person away from the higher spiritual good which is eternal life.

\section{A Contemporary Definition of Ordinary-Extraordinary}

The 1980 Sacred Congregation for the Doctrine of the Faith produced a document entitled Declaration on Euthanasia. The congregation rejects euthanasia but also elaborates on distinctions between euthanasia and natural death and physician assisted suicide. Euthanasia and physician assisted suicide will be discussed in an upcoming chapter. The document does remind us of the duty one has to care for one's own life and to seek such care for others but that there are limits to this obligation. The Declaration explains that one needs to judge the means used by "studying the type of treatment to be used, its degree of complexity or risk, its cost and the possibilities of using it, and comparing these elements with the result that can be expected, taking into account the state of the sick person and his or her physical and moral resources." ${ }^{17}$ The Declaration goes on to give four examples:

1. Patients are permitted to use experimental, advanced medical techniques, which may be a service to humanity.

2. Patients may interrupt treatments if they fall short of expectations.

3. The refusal of a technique that is in use and carries a risk or is burdensome is not equivalent to suicide.

4. When death is imminent in spite of the means used, it is permitted in conscience to make the decision to refuse forms of treatment that would only secure a precarious and burdensome prolongation of life, so long as the normal care due to the sick person in similar cases is not interrupted. ${ }^{18}$

\footnotetext{
${ }^{15}$ Cronin D. The Moral Law in Regard to Ordinary and Extraordinary Means of Conserving Life (Rome: Gregorian, 1958); Paris and McCormick, at 360.

${ }^{16}$ Wildes, at 512.

${ }^{17}$ Congregation for the Doctrine of the Faith. "Declaration on Euthanasia" Part IV, Origins 10 (1980): 154-157.

${ }^{18}$ Congregation for the Doctrine of the Faith, at Part IV.
} 


\section{THE JOURNAL OF HEALTHCARE ETHICS \& ADMINISTRATION}

Vol. 7 | No. 1 (Winter 2021)

These examples attempt to clarify the otherwise vague distinction between ordinary-extraordinary.

\section{Artificial Nutrition and Hydration}

Even after the Declaration on Euthanasia was published, some moralists continue to argue that artificial nutrition and hydration are basic care, and therefore always ordinary and morally obligatory, as long as an immediate death is not expected. Those who argue this position maintain that patients in a persisted vegetative state must be given nutrition and hydration, because these are basic to human life, aspects of normal care, and far from burdensome. They argue that failure to give these patients this basic care results in a new pathology which is starvation or dehydration which leads to death by omission. Their position is that artificial nutrition and hydration is normal care, beneficial, and a failure to supply it to patients is intentional killing. This argument is a complete revision of the Catholic tradition dating back to the $16^{\text {th }}$ century. Traditional moralists made a clear distinction between allowing to die and direct killing or euthanasia. The former was always morally permissible; the latter was forbidden. Allowing to die included the refusal of nutrition and hydration if they were considered burdensome and non-beneficial to the patient. This was a broad interpretation of the understanding of benefits and burdens as opposed to the more restrictive interpretation being proposed by the recent revisionists.

It is into this mix of recent revisions that Pope John Paul II's 2004 speech regarding tube feedings for PVS patients has raised medical, ethical, legal and even financial implications for Catholic health care. In the next section, we will break down Pope John Paul II's statement and analyze the effects it has had on end-of-life care.

Implications of Pope John Paul II's Allocution

Hopefully, the last section made it apparent that the Catholic Church has a long history of documents outlining its position on ordinary-extraordinary means surrounding end-of-life care. Most scholars, priests, and popes agree on a patient-centered, qualityof-life approach to the topic that extends from De Vitoria's notion of ordinary-extraordinary means. For many years, Catholic health care was guided by these definitions. If a patient or a patient's decision maker decided, all things considered, that it was in the best interest of the patient to not initiate means such as artificial feeding at the end of life, then the Church agreed that not only was there no sin, but it was the morally justified course of treatment.

\section{A Shift in Methodology}

The reason Pope John Paul II's statement has caused such a debate and a real sense of moral confusion, is that there appears to be a distinct shift in methodology regarding the traditional understanding of the ordinary-extraordinary means distinction. This excerpt from his speech illustrates the shift.

I should like particularly to underline how the administration of water and food, even when provided by artificial means, always represents a natural means of preserving life, not a medical act. Its use, furthermore, should be considered in principle ordinary and proportionate, and as such morally obligatory insofar as and until it is seen to have attained its proper finality, which in the present case consists in providing nourishment to the patient and alleviation of his suffering (emphasis added). He continues, Death by starvation or dehydration is in fact the only possible outcome as a result of their withdrawal. In this sense it ends up becoming, if done knowingly and willingly, true and proper euthanasia by omission. ${ }^{19}$

\footnotetext{
${ }^{19}$ John Paul II, at 739.
} 


\section{THE JOURNAL OF HEALTHCARE ETHICS \& ADMINISTRATION}

Vol. 7 | No. 1 (Winter 2021)

The medical condition of the patient appears not to be relevant because the Pope declares artificial nutrition and hydration ordinary care that is beneficial. As you can see, many questions come from this statement. People now feared that decision makers were actively committing sin by omitting treatments and killing patients. Pope John Paul II's statements shift the principles of ordinary-extraordinary means from a patient-determined judgement to a finite declaration as to which procedures are always morally obligated. He constitutes artificial nutrition and hydration as always proportionate natural means of preserving life. The Pope weighs societal circumstances and the patient's personal preferences only minimally.

\section{Three Distinctions Made by Pope John Paul II's Statement "Medical Act" or "Normal Care" ?}

The recent statement of the Pope appears to impact the traditional understanding of the ordinary-extraordinary means distinction in three ways. First, the Pope declares artificial nutrition and hydration for PVS patients as "not a medical act" but "normal care." No one is disputing that all people who are ill, whether in a PVS or a terminal condition must be cared for in ways that respect their inherent dignity. The Pope's statement differs from tradition because it claims food and fluids must always be provided. ${ }^{20}$

Feeding tubes are used when patients have difficulty in swallowing, diminished consciousness, or need to supplement eating or drinking to maintain health or sustain life. There are a variety of types of feeding tubes such as nasogastric feeding tubes, gastrostomy tubes (G tubes), and Jejunostomy tubes (J tubes). Each of these tubes either involves some surgical procedure to place into the patient or some form of invasive entry such as the nostrils of the patient. ${ }^{21}$ These are medical procedures, which carry certain risks to the patient. However, Pope John Paul II claims that these are not a medical act or treatment. This is illogical. In addition, it does not make sense for the Pope to consider food and hydration as basic care and not include oxygen. Classifying artificial nutrition and hydration as basic care and not oxygen, which is even more basic to our survival, is not only illogical but is irrational.

\section{Euthanasia by Omission?}

Second, the Pope declares that ending or interrupting artificial nutrition or hydration leads to death by starvation or dehydration. The Pope declares that the intention of the surrogate is the direct killing of the patient - euthanasia by omission. When a patient needs artificial nutrition and hydration it is usually as a result of a serious head injury, coma, PVS, or some other neurologic condition, such as a stroke or brain tumor, that prevents swallowing. In these situations, death comes from the underlying pathology that placed the person in the condition. The issue here is that foregoing artificial nutrition and hydration from a PVS patient does not cause a second pathology-starvation/dehydration-- but allows the original pathology to take its natural course. The intention is not to end the life of the patient but to forego a burdensome treatment and allow the patient to die from the original pathology. The Pope himself states clearly that euthanasia must be distinguished from the decision to forego "aggressive medical treatment." He states: "Medical procedures which no longer correspond to the real situation of the patient, either because they are by now disproportionate to any expected results or because they impose an excessive burden on the patient and his family. ${ }^{22}$ For the decision maker of a PVS patient, the intention is "to recognize that either the proposed intervention is not useful in helping to restore the patient to health or that the patient is dying or in a condition that will lead to death and that the moral obligation is to accompany this person on his or her final journey." ${ }^{23}$ These patients will not be abandoned. Instead they will be cared for lovingly, kept warm and clean and treated with the utmost dignity and respect. It should also be noted that according to the American Academy of Neurology, patients in a PVS do not feel pain, therefore, the withdrawal of nutrition and hydration is not a painful death.

\footnotetext{
${ }^{20}$ Hamel and Panicola, at 9.

${ }^{21}$ Sheehan M. "Feeding Tubes: Sorting Out The Issues," Health Progress 6 (2001): 22-27, at 23-24.

22 John Paul II, Evangelium Vitae, no. 65.

${ }^{23}$ Shannon T. \& Walter J. “Artificial Nutrition, Hydration: Assessing Papal Statement," National Catholic Reporter 4 (2004): 1-4, at 2.
} 


\section{THE JOURNAL OF HEALTHCARE ETHICS \& ADMINISTRATION}

Vol. 7 | No. 1 (Winter 2021)

\section{Restricting the Duty to Preserve Life}

Third, the Pope introduces a more limited view of the duty to preserve life. The traditional interpretation was a more holistic standard based on the benefits and burdens relative to the person. Any means of preserving life must be subject to a benefit-burden analysis. The Pope appears to have reinforced a more restrictive standard based on recent revisions of the traditional teaching by groups like the U. S. Bishop's Pro-Life Committee. This interpretation understands the benefits and burdens narrowly. It looks at the situation apart from relative factors, and it also gives nutrition and hydration special moral classification. ${ }^{24}$ Traditionally, the benefit of a medical procedure was determined by the patient, who considered how a particular treatment or procedure would impact his or her life. Benefits and burdens were never judged abstractly. For DeVitoria and other traditional moralists, the mere preservation of life and vital physiological functions was not sufficient in itself to oblige someone to use a certain means, including food and fluids. ${ }^{25}$ Benefits were judged much more holistically.

The potential harms of tube feedings should also be noted. There are side effects like terminal pulmonary edema, nausea, diarrhea, abdominal swelling and impaired consciousness. There are other side effects such as pneumonia, infections at the site of the insertion of the tube, and often patients have to be physically restrained from pulling out the tubes. ${ }^{26}$ Patients should have the correct medical knowledge to make value-judgements surrounding treatment.

Pope John Paul II does not consider the potential burden of cost when delineating ordinary-extraordinary means. The Declaration on Euthanasia states that a treatment may be judged to be too burdensome if it imposes an excessive expense on the family or the community. ${ }^{27}$ The American Medical Association estimates that the cost of aggressively treating patients in a PVS is anywhere from \$1-\$7 billion a year. Approximately 47 million people are uninsured and millions more are underinsured in the United States. These costs may be a disproportionate expense for the individual, family and society, when the medical authorities believe there is almost no possibility of recovery after a year.

The traditional understanding of ordinary-extraordinary means was based on treating the whole person, not one part of the person. Just because a treatment could prolong a life did not mean that a particular treatment was a benefit. Benefits must be considered worthwhile both in quality and duration. In the Catholic moral tradition, a medical treatment was beneficial if it restored a patient to a relative state of health. Failure to receive a meaningful benefit from a treatment makes the treatment not morally obligatory.

An initial reading of the Pope's speech on tube feedings for PVS patients appears to have introduced a shift concerning the Church's tradition on the ordinary-extraordinary means distinction. The purpose behind this statement was to counter the "culture of death" and the attitude of relativism that seems apparent in Western culture. This culture is based on a utilitarian calculus where human worth is weighed on what a person can achieve. It does not consider the human as a person. ${ }^{28}$ While the intention of the pope's statement is good, the means to bring about this good may have serious implications that in the long-run could cause the "culture of death" to be advanced rather than be reversed.

\section{The Role of Conscience in Moral Decision Making}

In the last section, the Pope's statement was examined and was compared to historical understanding of ordinary-extraordinary means. The Pope's statement does seem to narrow the traditional understanding of the ordinary-extraordinary means distinction as applied to artificial nutrition and hydration for PVS patients. However, upon a more careful analysis, one might interpret this speech

\footnotetext{
${ }^{24}$ Hamel and Panicola, at 12.

${ }^{25}$ Hamel and Panicola, at 9.

${ }^{26}$ Lynn J. \& Childress J. "Must Patients Always be Given Food and Water?" in J. Howell and W. Sale (Eds.) Life Choices (Washington, D.C.: Georgetown University Press, 1995): 201-213.

${ }^{27}$ Congregation for the Doctrine of the Faith, Part 4.

${ }^{28}$ Place M. "Thoughts On the Papal Allocution," Health Progress 85 (2004): 6, 60.
} 


\section{THE JOURNAL OF HEALTHCARE ETHICS \& ADMINISTRATION}

Vol. 7 | No. 1 (Winter 2021)

differently. It could be understood as "a theoretical clarification." ${ }^{29}$ The reason for this is twofold: first, there are different levels of authority of Church teachings-infallible statements, conciliar documents, encyclicals, congregation documents, apostolic exhortations, allocutions, etc. The type of document determines the weight of authority the statement holds. For example, a conciliar document such as the Pastoral Constitution on the Church in the Modern World or an encyclical like Evangelium Vitae would carry more authority than an allocution. There have only been a handful of infallible statements made by popes in the history of the church, but almost every pope has presented multiple allocutions throughout his papacy. The Pope's recent speech is classified as an allocution. Instead of reading allocutions as the Church's final position on a subject, they should be read in the light that popes present them to specific groups of people to discuss particular issues. These issues typically are not part of major political shifts but are usually subject to interpretation by moral theologians. ${ }^{30}$

Thus, the present allocution does not appear to be a teaching of a general moral principle but a practical application of the Pope's statement in Evangelium Vitae: "In such situations, when death is clearly imminent and inevitable, he can in conscience refuse forms of treatment that would only secure a precarious and burdensome prolongation of life." ${ }^{31}$ Teachings of general moral principles carry more weight than a proposal for its practical application. So, theologians and ethicists have more room to interpret this speech and it does not carry as much influence compared to other Church documents.

\section{Examining the Pope's Wording}

In addition, if one reads the allocution carefully, the Pope does not completely depart from the traditional understanding of ordinary-extraordinary means by making their use an absolute requirement with no exceptions. It seems clear that the Pope is talking exclusively about PVS patients which were the focus of the Congress to which the Pope read this allocution. As a result, Hamel and Panicola argue, "we may be left with a presumption in favor of providing nutrition and hydration to all patients. But nutrition and hydration can be withheld or withdrawn when they do not attain their proper finality, which for patients in general can be decided on traditional grounds (i.e., holistic benefit-burden calculus) and for patients in a PVS on the more limited grounds set by the Pope (i.e., nourishment and the alleviation of suffering)." ${ }^{32}$ If the Pope meant this to be an absolute requirement he would not have used words such as "insofar" which indicate there is a limit to which nutrition and hydration are absolutely required. This may be true, but because this is an application of a general principle, one could in good conscience, apply the traditional benefit-burden calculus to determine whether to withhold or withdraw artificial nutrition and hydration even for PVS patients. This is accepting the limits of human life, "that a person has come to the end of his or her pilgrimage and should not be impeded from taking the final step." ${ }^{33}$

\section{In Good Conscience}

Second, as with all Church teachings that are not infallible statements, one has the right, with a well-formed conscience, to do what one believes is morally right. The Catholic ethical tradition has always viewed conscience as the ultimate subjective norm of human action. To have a well-formed conscience one has the obligation to search for the truth in a situation by consulting the sources of moral wisdom (scripture, tradition church teaching, reason and experience) and seeking guidance and instruction from those who have knowledge about the particular issue. It is clear from the best neurological authorities that recovery of consciousness for post-

\footnotetext{
${ }^{29}$ Place, at 6.

30 Walter and Shannon, at 19; O'Rourke K.\& Boyle P. "Tissue Transplantation," in Medical Ethics: Sources of Catholic Teachings (3 ${ }^{\text {rd }}$ Ed) (Washington, D.C.: Georgetown University Press, 1999): 286-287.

31 John Paul II, Evangelium Vitae, No. 65.

${ }^{32}$ Hamel and Panicola, at 12.

33 Texas Catholic Bishops and the Texas Conference of Catholic Health Care Facilities. "On Withdrawing Artificial Nutrition and Hydration," Origins 20 (1990): 53-55.
} 


\section{THE JOURNAL OF HEALTHCARE ETHICS \& ADMINISTRATION}

Vol. 7 | No. 1 (Winter 2021)

traumatic PVS is unlikely after 12 months for adults and children and recovery from non-traumatic PVS after three months is exceedingly rare for both adults and children.

In the event that this diagnosis is confirmed medically, and the surrogate or the patient's advance directive states clearly that the patient would not want extraordinary-disproportionate means used, which includes artificial nutrition and hydration, then in light of a broad interpretation of the benefit-burden calculus, the treatment could be witheld or withdrawn as a matter of conscience. Allowing a patient to die by foregoing aggressive, non-beneficial treatments is not only morally permissible, but it is treating the patient with dignity and respect.

\section{Physician-Assisted Suicide (PAS)}

Although this curriculum is intended as a comprehensive death and dying curriculum that includes, moral, ethical, philosophical, religious, and medical interpretations of the dying process, the authors have decided to include a short section on physician-assisted suicide to inform students of an alternative some individuals choose at the end of their lives. This concept is not supported by the authors, but knowledge of this topic will give students a more complete understanding of death and dying.

Currently, Oregon has the Death With Dignity Act which is a statewide act that legalizes physician-assisted suicide. A link to the act will be included in the further reading section of this chapter, but a brief outline of the act follows. To qualify as an individual legally allowed to request for medication to end one's life in a "Humane and Dignified Manner" one must be an adult resident of Oregon and who has been determined by an attending physician and consulting physician to be suffering from a terminal disease. The individual must voluntarily express the wish to die. This request must be witnessed by two individuals. This person's physician must inform the patient of his or her medical diagnosis, prognosis, the potential risks of taking the lethal medication, the result, and the alternatives such as hospice or pain management care. Only after many more steps is it legal for the physician to prescribe a lethal dose of medication for the individual. It is then the responsibility of the individual to fill the prescription and take the medication. $^{34}$

There are two arguments in favor of physician-assisted suicide. One is the argument for compassion and the other is the autonomy argument or the right to control one's destiny. The compassion argument begs that a physician is both a healer and a reliever of pain and suffering, and there are cases of such existential pain that are intractable and intolerable. Therefore it is the role of the physician to assist a terminally ill patient, at their request, with the skills and resources for their termination. The argument for autonomy states that every individual has the right to control his or her life, and that a physician is bound to respect the wishes of his or her patients. Thus, at the request of a competent patient, a physician must assist in the termination of a terminally ill patient's life.

Opposing these arguments, there are three arguments against physician-assisted suicide. Theologically, there is a prohibition against direct killing. It is morally wrong and illegal to kill another person deliberately, and physician-assisted suicide is direct killing. Therefore, it is morally wrong. Secondly, the American Medical Association Code of Ethics claims PAS violates the professional role of the physician. Treatment designed to cause death is not a medical treatment. It is central to the meaning of being a physician to protect and preserve human life, and PAS contradicts this norm. Finally, there is a slippery slope argument against PAS that claims it has the potential to lead to genocide and mass killing, so it must be prevented to avoid worse consequences.

\footnotetext{
34 "MenuSite Navigation Oregon Revised Statute." Oregon Health Authority : Oregon Revised Statute : Death with Dignity Act : State of Oregon, www.oregon.gov/oha/PH/PROVIDERPARTNERRESOURCES/EVALUATIONRESEARCH/DEATHWITHDIGNITYACT/Pages/ors.aspx.
} 


\section{THE JOURNAL OF HEALTHCARE ETHICS \& ADMINISTRATION}

Vol. 7 | No. 1 (Winter 2021)

\section{Conclusion}

The recent Papal allocution has caused a serious debate both within the Church and in society as a whole regarding the ordinaryextraordinary means distinction and how it relates to the use of artificial nutrition and hydration. This debate has been instructive not only because death and dying are being openly discussed in a society that avoids such discussions but also because the Pope's concern about moral relativism and a "culture of death" are being examined and critiqued. People are struggling with end-of-life decisions daily and they are in desperate need of guidance. Unfortunately, the media has presented this issue as a Papal mandate that is being imposed on all Catholics and as a result, this has caused much confusion, pain, and even guilt. Some have questioned past decisions to forego artificial nutrition and hydrations and have even wondered if they have committed a sin. End-of-life decisions are difficult enough for individuals and families without adding to their pain and suffering. And Catholic health care facilities are struggling with numerous medical and financial dilemmas without adding another of this magnitude.

At the present moment, our concern must focus on the moral relativism in society and the present trend toward a "culture of death." This can be done by respecting the traditional understanding of the ordinary-extraordinary means distinction that has served the Church and society well for centuries. It can also be done by improving end-of-life care by advocating for better pain management, more palliative care centers and earlier referrals to hospice. The fear is, if the traditional understanding of ordinaryextraordinary means is abandoned, then instead of advocating for a "culture of life," we may end up driving more people toward a "culture of death"--euthanasia and physician-assisted suicide. This would not only be medically irresponsible but would be morally objectionable.

\section{Post-Chapter Assessment Activity:}

Students form groups and analyze case study of their choice to be turned in as summative assessment.

\section{Discussion Questions:}

1. When was the distinction between ordinary and extraordinary treatments first made?

2. When the Pope made his allocution, what was the shift in methodology?

3. Argue the Pope's limited perspective on the duty to preserve life against the former stricter duty. How did the Pope use his interpretation to change the Church's stance on artificial nutrition and hydration?

4. What are the connections between benefits, burdens, ordinary, and extraordinary?

5. Explain what euthanasia by omission is and how this is different from physician-assisted suicide.

Closure: Report out

Exit Ticket: Turn in case study analysis

\section{Further Resources:}

1. Documentary on PAS: "How to Die in Oregon." How to Die in Oregon, www.howtodieinoregon.com/.

2. Oregon Health Authority : Oregon Revised Statute : Death with Dignity Act : State of Oregon, www.oregon.gov/oha/PH/PROVIDERPARTNERRESOURCES/EVALUATIONRESEARCH/DEATHWITHDIGNITYACT/Pages/ors.aspx 


\section{APPENDIX 6 - CHAPTER 6: PALLIATIVE CARE AND HOSPICE: A PARADIGM FOR END-OF-LIFE CARE}

Quote: "Death is not the ultimate tragedy of life. The ultimate tragedy is depersonalization-dying in an alien and sterile area, separated from the spiritual nourishment that comes from being able to reach out to a living hand, separated from a desire to experience the things that make life worth living, separated from hope." ${ }^{1}$

Chapter Objectives: (SWBAT...)

- SWBAT identify the goals of palliative care and hospice care.

- SWBAT distinguish between the philosophies of palliative medicine and hospice care and determine when each is appropriate.

- SWBAT identify common concerns of the terminally ill and acknowledge the potential fears expressed by patients and the families of patients entering hospice.

- SWBAT recognize the cost-effectiveness of palliative care and hospice and how this is rooted in a just allocation of medical resources.

- SWBAT analyze the Aetna Open Access Experiment and form opinions on the future of hospice and healthcare.

Standards (derived from Common Core State Standards)

\section{$\underline{\text { CC.1.2.11-12A }}$}

Determine and analyze the relationship between two or more central ideas of a text, including the development and interaction of the central ideas; provide an objective summary of the text

\section{CC.1.2.11-12.B}

Cite strong and thorough textual evidence to support analysis of what the text says explicitly as well as inferences and conclusions based on and related to an author's implicit and explicit assumptions and beliefs

\section{CC.1.2.11-12.J}

Acquire and use accurately general academic and domain-specific words and phrases, sufficient for reading, writing, speaking, and listening at the college and career readiness level; demonstrate independence in gathering vocabulary knowledge when considering a word or phrase important to comprehension or expression.

\section{CC.1.2.11-12.K}

Determine or clarify the meaning of unknown and multiple-meaning words and phrases based on grade-level reading and content, choosing flexibly from a range of strategies and tools.

\section{CC.1.2.11-12.L}

Read and comprehend literary non-fiction and informational text on grade level, reading independently and proficiently.

\section{CC.1.3.11-12.B}

Cite strong and thorough textual evidence to support analysis of what the text says explicitly as well as inferences and conclusions based on and related to an author's implicit and explicit assumptions and beliefs

${ }^{1}$ Cousins, N. Anatomy of an IIIness as Perceived by the Patient: Reflections on Healing and Regeneration, (New York: Norton, 1979$): 133$. 


\section{THE JOURNAL OF HEALTHCARE ETHICS \& ADMINISTRATION}

Vol. 7 | No. 1 (Winter 2021)

\section{CC.1.3.11-12.J}

Acquire and use accurately general academic and domain specific words and phrases, sufficient for reading, writing, speaking, and listening at the college and career readiness level; demonstrate independence in gathering vocabulary knowledge when considering a word or phrase important to comprehension or expression

\section{Overarching Practical Goals of Curriculum:}

Step 1 - The Basics: This chapter aims to separate palliative care and hospice care as two separate entities. These two services often work side-by-side, but it is important for students to recognize their stark differences in philosophy.

Step 2 - Preparation Techniques: Besides knowing the differences between the two services, this chapter should prepare students to be open to palliative care in the future and to be advocates for its implementation as an essential service in the care of loved ones.

Step 3 - Communication: Should students come across an advertisement for an independent hospice whether it be while driving, watching television, or in a printed source, they should start a discussion with family members that quickly debunks some of the myths of hospice care.

Do Now: Have you or your family ever had a discussion regarding hospice care for a relative or friend? Explain that experience. If you have not, what thoughts do you have about why this issue has not come up.

Pre-Chapter Assessment Activity: Brainstorm what you know about hospice care. Perhaps you know someone who has had this service. What are your thoughts, feelings, experiences?

\section{Sections:}

\section{$\underline{\text { Introduction }}$}

Traditionally, in medical care there are two mutually exclusive goals: either to cure disease and prolong life or to provide comfort care. In some cases, this creates a conflict in decision making. The decision to focus on reducing suffering is usually only made after life-prolonging treatment has not been successful and death is imminent. By imminent, only days or hours are expected. ${ }^{2}$ As a result, two of the best kept secrets in a hospital today in the United States are palliative care and hospice care. We estimate that of the 2.4 million Americans that die each year, about $80 \%$ end their lives in hospitals attached to the latest advances in technology and only 300,000 die at home under hospice care. ${ }^{3}$ The reasons why more people do not receive palliative or hospice care range from the patient's fear of abandonment and the unknown, the family's denial of the inevitability of death of their loved one, and physician's denial of medicine's limitations. Unless the options of palliative or hospice care are given to patients the fears that people have of dying--fear of dying alone and fear of dying in pain--will continue to make the dying process one that lacks dignity and respect.

\section{The Philosophy of Palliative Care}

Palliative care comes from the Latin word palliare which means to cloak. It is a form of medical care or treatment that concentrates on reducing the severity of the symptoms of a disease, or to slow the disease progress, rather than provide a cure. Occasionally, it can be used with a curative therapy, providing that the curative therapy will not cause additional morbidity. The goal is to relieve suffering and improve the quality of life for patients with chronic illnesses and their families through scientific knowledge and skills, including communication with patients and family members; management of pain and other symptoms; psychosocial, spiritual, and

\footnotetext{
${ }^{2}$ Morrison RS \& Meier D. “Palliative Care," New England Journal of Medicine 350, 25 (June 17, 2004): 2582-2590 at 2582.

${ }^{3}$ Editor. "Hospice Facts \& Statistics," Hospice Association of America (Washington, D.C.: 2010): 1-11. http://www.nahc.org/assets/1/7/HospiceStats10.pdf
} 


\section{THE JOURNAL OF HEALTHCARE ETHICS \& ADMINISTRATION}

Vol. 7 | No. 1 (Winter 2021)

bereavement support; and coordination of many medical and social services. ${ }^{4}$ The World Health Organization (WHO) in 1990 defined palliative care as "the active care of patients whose disease is not responsive to curative treatment." This definition stresses the terminal nature of the disease, but this does not mean a patient must have an end-stage condition to receive palliative care. ${ }^{5}$ This is one of the biggest myths in the care and treatment of patients. Palliative care has three well-defined purposes:

1. Pain management

2. Symptom management

3. Improve patient and family quality-of-life

An example of a patient who would see great benefit from a palliative care consult, but does not have a diagnosed endstage condition is someone who has sickle cell disease or chronic COPD. A person can live and cope with these conditions for many years, but may experience extreme pain during chronic episodes or exacerbations. Without "giving-up" the palliative care team can counsel a patient on how to manage and identify symptoms of these diseases to prevent future crises. The palliative care team also could manage the patient's medical regimen to personalize and perfect it. With palliative care, the patient receives extra attention from a specialized team; it does not necessarily mean that she/he is dying or even near death. Please do not confuse palliative care services with hospice care services. While palliative care is a philosophy that is incorporated into hospice care, it is also its own entity and serves a completely separate purpose for many cases of illness and disease. Think of it as hospice care always incorporates palliative medicine, but palliative care does not require hospice services or end-stage documentation.

\section{$\underline{\text { Hospice Care }}$}

Hospice care is viewed as part of the philosophy that we call palliative care. Hospice is a centuries old idea coming from the Latin word hospes meaning guest. Originally, it referred to the offering of a place of shelter and rest or what we refer to as "hospitality" to weary and sick travelers on a long journey. Over the centuries, it developed into a philosophy of care that recognizes death as the final stage of life and seeks to enable patients to continue an alert, pain-free life and to manage other symptoms so that their last days may be spent with dignity and quality, surrounded by their loved ones. Hospice care like palliative care affirms life and neither hastens or postpones death. The focus of hospice and palliative care is to treat the whole person rather than the disease; it emphasizes quality rather than quantity or length of life. ${ }^{6}$ In addition, emphasis is placed not only on the well-being of the patient but also on the well-being of the family caregivers. Hospice personnel provide care for the patient and the family 24 hours a day, 7 days a week.

\section{History of Hospice}

The history of hospice and palliative care dates back to ancient times. Some say the first hospice experience appears in the New Testament with the parable of the Good Samaritan (Luke 10: 29-37). The Good Samaritan bandaged the wounds of the man beaten and lying along the roadside, then took him to the closest inn and paid to have the man ministered to by the innkeeper. Others believe the first recorded hospice opened in 475 AD in Syria by Fabiola, a Roman woman and follower of St. Jerome, as a place of rest for the traveler, the sick and the dying. During the next 1500 years, hospices, provided care for those on a journey. In the $19^{\text {th }}$ century a religious order established hospices for the dying in Ireland and London. " "Until the $20^{\text {th }}$ century, most people spent their last days at home, surrounded, cared for, and comforted by family and friends. That tradition faded as hospitals became places of

\footnotetext{
${ }^{4}$ Morrison \& Meier, at 2583.

${ }^{5}$ World Health Organization. "Definition of Palliative Care," (World Health Organization: 1990). http://www.who.int/cancer/paliative/definition/en/) Retrieved on December 12, 2006.

${ }^{6}$ Editor. "What is Hospice?" American Cancer Society (August 2004): 1-4 at 1. http://www.cancer.org/docroot/eto/content/eto 2 $5 \mathrm{x}$ what is hospice care.asp?

${ }^{7}$ Taylor P. "Hospice: Caring When There Is No Cure," Advance For Nurses (February 1, 1999): 20.
} 


\section{THE JOURNAL OF HEALTHCARE ETHICS \& ADMINISTRATION}

Vol. 7 | No. 1 (Winter 2021)

healing in many Western countries." ${ }^{8}$ The modern notion of hospice began in 1967 when Dr. Cicely Saunders founded St. Christopher's Hospice in London. She is regarded as the founder of the modern hospice movement. As a physician, Saunders dedicated her life to the care of the dying and planned a model hospice that would provide exemplary palliative care and would incorporate teaching and research programs. She avowed the regular giving of strong narcotics, including heroin and the Brompron cocktail mixture of morphine and gin, as the proper regimen to ensure that a pain-free patient could maintain quality of life in the last days.

\section{$\underline{\text { Hospice in the United States }}$}

The hospice movement in the United States began in the 1960s but the first hospice to provide services was the Connecticut Hospice in March 1974. "In 1982, Congress created the Medicare hospice benefit, reserving such services for terminally ill Medicare beneficiaries with life expectancies of six months or less 'if the disease runs its normal course.' Hospice benefits were divided into the following benefit periods: 1) an initial 90-day period; 2) a subsequent 90-day period; and 3) an unlimited number of subsequent 60-day benefit periods as long as the patient continued to meet program eligibility requirements. Beneficiaries must be re-certified as terminally ill at the beginning of each benefit period." ${ }^{9}$ The relatively generous Medicare reimbursement for hospice treatment has increased hospice usage in the United States. The 1989 Congressional mandate increased reimbursement rates by $20 \%$ and tied future increases to the annual increase in the hospital market basket. The first hospital-based palliative care program in the United States began in 1989 at the Cleveland Clinic, in response to the recognition that restrictions on hospice eligibility imposed by the Medicare Hospice Benefit prevented adequate care for seriously ill and dying patients in acute care hospitals. In response, there has been a dramatic increase in hospital-based palliative care programs, now numbering more than $1200 .^{10}$

Hospice programs provide services in various settings: the home, hospice centers, hospitals, or skilled nursing facilities. The number of hospice programs in the United States has continued to increase from the first program in 1974 to more than 4,100 programs today. ${ }^{11}$ The majority of the growth is in small free-standing programs. $93 \%$ of agencies reported that they are Medicare certified; nearly 3 out of 4 hospice programs are accredited by either the Joint Commission on Accreditation of Healthcare Organizations (JCAHO), Community Health Accreditation Program (CHAP), Accreditation Commission for Healthcare (ACHC), or other accrediting agencies. $67.6 \%$ of programs reported nonprofit (501c3) status while $27.2 \%$ reported for-profit status. Government-run programs account for $5.2 \%$ of all programs. ${ }^{12}$

\section{Criteria for Entrance into Hospice Care}

The criteria for hospice care under the Medicare benefit requires that patients acknowledge they are in the dying process and are willing to forego insurance coverage for life prolonging treatments and that two physicians certify that the patient has a life expectancy of six months or less. Studies have shown that referral to palliative care programs and hospice results in beneficial effects on patients' symptoms, reduced hospital costs, greater likelihood of death at home, and a higher level of patient and family satisfaction that does conventional care. ${ }^{13}$

\footnotetext{
8 Mayo Clinic Staff. "Hospice Care: An Option for People with Terminal Illness," Mayo Clinic (April 17, 2006): 1-4 at 1. http//www.mayoclinic.com/health/hospice-care/HQ00860

${ }^{9}$ Editor, "Hospice Facts \& Statistics," at 1.

${ }^{10}$ Center to Advance Palliative Care. "A Guide to Building a Hospital-Based Palliative Care Program," (2006). www.capc.org.

${ }^{11}$ Centers for Disease Control and Prevention, "Hospice Care," July 6, 2016. https://www.cdc.gov/Other/plugins/\#pdf.

12 Editor. "NHPCO's Facts and Figures - 2005 Findings," National Hospice and Palliative Care Organization (November 2006 ): $1-3$ at 1. www.nhpco.org/files/public/2005-facts-and-figures.pdf

${ }^{13}$ Morrison \& Meier, at 2586.
} 


\section{THE JOURNAL OF HEALTHCARE ETHICS \& ADMINISTRATION}

Vol. 7 | No. 1 (Winter 2021)

The principles that make up the National Hospice Organization's "Philosophy of Hospice" include:

1) Hospice implies acceptance of death as a natural part of the cycle of life.

2) When death is inevitable, hospice will neither seek to hasten it nor to postpone it.

3) Patients, their families and loved ones are the unit of care.

4) Psychological and spiritual pain are as significant as physical pain, and addressing all three requires the skills and approach of an interdisciplinary team.

5) Pain relief and symptom control are appropriate clinical goals; the goal of all intervention is to maximize the quality of remaining life through the provision of palliative therapies.

6) Care is provided regardless of ability to pay. ${ }^{14}$

The principles of hospice and palliative care are based on a shift in the patient's treatment from curative to palliative care. This shift rarely takes place at a specific moment. "Just as the disease treatment is a process, so to is preparing a patient for the time when treatment for cure is no longer an option. Preparing a patient begins with an honest discussion of the disease and its outcomes." ${ }^{15}$ Physicians have the ethical responsibility to be honest with their patients about their medical condition. When there are no further treatments to cure the disease, the patient must be informed of this fact but must also be given the option of palliative care and hospice care as a treatment. "Presenting hospice as a medical option for treating a terminal illness can help with many unknowns-'fears of uncontrollable pain, nausea, vomiting, embarrassment and especially abandonment' that often accompany end stage diseases." ${ }^{16}$ The focus of hospice is to provide services to both patients and their families to assist and support them during the dying process. The family of the patient and others involved with the patient can be crucial in any hospice discussion and care plan. In many cases the patient may be ready to accept hospice care but family members and friends are not. At times, they can even coerce the patient into continuing aggressive treatment even though the burdens outweigh the benefits. That is why the family should be included in these discussions whenever possible but always with the patient's consent. Many times all the family needs to hear is that the patient has accepted the diagnosis of the terminal condition and that it is his or her choice to accept hospice care. ${ }^{17}$ Hospice treats the patient and the family as a unit and unless both parties understand the principles and the goal of hospice, the services offered will fail to be beneficial.

Hospice services are offered by a multidisciplinary team whose emphasis is to maximize comfort for the terminally ill patient and support the family members and other loved ones. The hospice team consists of physicians, nurses, health care aides, spiritual counselors, social workers, volunteers, ancillary therapists and bereavement counselors. The services offered by the hospice team include: pain and symptom support, spiritual care, home care and inpatient care, respite care, family conferences, bereavement care [Examples can be found in Appendix A, B, C, D]. The services offered are extensive and wide-ranging. For example, hospice care integrates complementary therapies with conventional care such as relaxation therapy, massage therapy, music therapy and acupuncture to relieve symptoms and other causes of pain. Trained bereavement counselors offer support and guidance for patients and family members. This support continues for up to a year after the death of the patient. The most common concerns found among those in a terminal condition are: fear of pain, loss of independence, worries about family and feeling like a burden. The hospice team provides comprehensive palliative care aimed at relieving symptoms, treating depression in patients and giving social, emotional and spiritual support to both the patient and the family.

\footnotetext{
${ }^{14}$ Ackerman F. "Goldilocks and Mrs. Ilych: A Critical Look at the 'Philosophy of Hospice,'” Cambridge Quarterly of Health Care Ethics 6 (1997): $314-$ 324 at 314; and Manard B. and Perrone C. Hospice Care: An Introduction and Review of Evidence (Arlington, Va.: National Hospice Organization, 1994): 4.

${ }^{15}$ National Hospice and Palliative Care Organization. Hospice Care: A Physician's Guide, (Alexandria, Va.: 1998$)$ : at 9.

${ }^{16}$ National Hospice and Palliative Care Organization, Hospice Care, at 10-11.

${ }^{17}$ National Hospice and Palliative Care Organization, Hospice Care, at 11.
} 


\section{THE JOURNAL OF HEALTHCARE ETHICS \& ADMINISTRATION}

Vol. 7 | No. 1 (Winter 2021)

\section{Factual Implications of Palliative Care and Hospice:}

Only about a third of the 2.5 million people who died in this country on 2014 were in hospice care despite all of the great services that are offered by hospice. In 2014, an estimated 1.6 to 1.7 million patients received services from hospice. About $80 \%$ ended their lives in hospitals connected to the latest in medical technology. However, perhaps twice as many patients should have been in hospice programs, according to specialists in the field. In 2014, approximately $84 \%$ of hospice patients were 65 years of age or older with $41.1 \%$ being 85 years of age or older. More than half of hospice patients are female (53.7\%) with $46.3 \%$ being male. When hospice care in the United States was established in the 1970s, the largest percentage of patients had cancer as a diagnosis when admitted. In 2014, less than half of the patients admitted were diagnosed with cancer. The majority of deaths were due to other terminal diseases. The top four non-cancer diagnoses for patients admitted to hospice were dementia (14.8\%), heart disease $(14.7 \%)$, lung disease $(9.3 \%)$, and stroke or coma $(6.4 \%){ }^{18}$

\section{Pediatric Hospice}

Pediatric patients account for less than $1 \%$ of patients. Pediatric palliative care programs are increasing with $20 \%$ of hospice programs actively providing or developing pediatric palliative care programs. ${ }^{19}$ In the last decade about 40 perinatal hospice programs have been started in the United States. Perinatal hospices are for those families who give birth to babies with fatal anomalies. Statistics show that $20 \%$ to $40 \%$ of parents given a diagnosis of a fatal fetal condition do not opt to abort the fetus but to carry the fetus to term. Perinatal hospices help families gain control over an event that could be devastating. In general, parents allow these babies to die without aggressive medical intervention. They allow for medications to ease the child's discomfort. Most of these children die within hours of birth but about $30 \%$ go home with their families where they eventually die. ${ }^{20}$

In 2014, the median length of service was 17.4 days, a decrease from 18.5 in 2013 . This means that about half the hospice patients received care for fewer than 17 days and half received care for more than 17 days. The average length of service decreased from 72.6 days in 2013 to 71.3 in 2014. In 2014, larger proportions of hospice patients (approximately 35.5\%) died or were discharged within seven days of admission when compared to 2013 (34.5\%) In addition, larger proportions of patients died or were discharged within 14 days of admission when compared to 2013 ( $50.3 \%$ and $48.8 \%$ respectively). ${ }^{21}$ Very little comfort and support can be given to patients and family members in such a short period of time. This is frustrating not only for the patient and family but also for the hospice personnel.

Another interesting statistic is that only one in five patients admitted to hospice care is a minority. $76.0 \%$ of hospice patients are white, 7.6\% African American, Hispanic/Latino 7.1\% and $13.1 \%$ other. The percentage of minority patients accounted for about one quarter of hospice patients in $2014 .^{22}$ There are many reasons for the low number of minorities ranging from mistrust of the medical profession dating back to the historical atrocities when Black Americans were denied adequate health care or were used as laboratory guinea pigs without their knowledge as in the Tuskegee Syphilis Study ${ }^{23}$; to not wanting strangers in their homes,

\footnotetext{
${ }^{18}$ Editor, "NHPCO Facts and Figures-Hospice Care in America," 2015 at pp.3-6.www.nhpco.org/nds.

${ }^{19}$ Editor, "NHPCO's Facts and Figures-Hospice Care in America," 2015 at 6.

20 Banerjee N. "A Place to Turn When a Newborn Is Fated to Die," New York Times (March 13, 2007 ): 1-6. http://www.nytimes.com/2007/03/13/health/13hospice.html? $r=1 \&$ th=\&oref=slogin\&emc

${ }^{21}$ Editor, "NHPCO's Facts and Figures-Hospice Care in America," 2015 at 5.

22 Editor, "NHPCO's Facts and Figures-Hospice Care in America," 2015 at 7.

${ }^{23}$ In 1932 the United States Public Health Service initiated a study on African American men with syphilis in Macon County, Alabama, to determine the natural course of untreated, latent syphilis in black males. The study comprised 399 syphilitic men as well as 201 uninfected men who served as the control group. These subjects were recruited from churches and clinics throughout Macon County and were led to believe they would receive free meals and "special free treatment" for what was called "bad blood," and burial insurance. In reality, they were enrolled in this study without informed consent. These men were deceived in that the infected were never told they had syphilis, which was known to cause mental illness and death. In fact, the infected were never treated for the disease. To determine the natural course of syphilis, the researchers withheld the standard treatment of mercury and arsenic compounds from the subjects. In 1947 when penicillin was determined to be an effective treatment for syphilis, this too was withheld. The treatment these men actively received came in the form of placebos. The Tuskegee Syphilis Study was a covert medical
} 


\section{THE JOURNAL OF HEALTHCARE ETHICS \& ADMINISTRATION}

Vol. 7 | No. 1 (Winter 2021)

to their spiritual tradition that believes God not a doctor determines who lives and who dies; to their belief in miracles. Many African Americans will opt to die in a hospital because they believe only there will they get all the treatment the medical profession has to offer like the whites receive.

\section{National Spending On Hospice}

In 2015, the United States health care spending increased $5.8 \%$ to reach $\$ 3.2$ trillion or $\$ 9,990$ per person. The percentage of patients covered by the Medicare Hospice Benefit (versus other payment sources) increased to $85.5 \%$ in 2014 . The percentage of patient days covered by the Medicare hospice benefit versus other sources was $90.3 \%$. In addition to Medicare and Medicaid funding, the other sources of hospice revenue are private insurance companies, and community donations and grants. It is believed that due to our aging population and an increasing interest and concern for end-of-life care and rising health care costs, the need for Medicare-certified hospices will continue to grow. ${ }^{24}$ Despite these costs, hospice care is still more cost-effective than hospital and skilled nursing care facilities. There have been various studies on the cost-effectiveness of hospice care, both federally and privately sponsored, which provide strong evidence that hospice is a less costly approach to care for the terminally ill.

One of the biggest deterrents for individuals in regard to hospice is that most individuals with a terminal condition who wish to enter hospice care must forego advanced medical treatment to qualify for hospice care. This means cancer patients, under most circumstances unless it is for palliative care, must pass up chemotherapy; and patients with kidney failure must abandon dialysis. This either-or decision has caused some patients who would greatly benefit from hospice care to opt for aggressive treatments in the hospital which are far more costly.

\section{Aetna's Open Access Experiment}

Recently, some hospice programs and private health insurers have initiated a new approach called "open access" to encourage patients to get on hospice for their last months of life. This new approach allows hospice programs to offer advanced medical treatment even when they are not paid more to do so. Proponents argue that it is an example of the efforts of some insurers and health care providers to try to fix specific problems in the nation's medical system. Insurers like Aetna and United Health are allowing some patients to have potentially life-prolonging medical treatment while on hospice. Physicians argue that the either-or approach is less valid today in that continued advances in medicine are allowing even patients with very advanced diseases to benefit from new treatments. The Aetna experiment allows 40,000 of its roughly 15 million insured members to be eligible for these services. The initial results have shown that people will take advantage of hospice care if they do not have to give up other treatments to prolong their life. In the long run this will be cost effective and it allows patients more time to take advantage of

research study. It was widely known in medical circles due to published articles in major medical journals. As late as 1969, a committee at the federally operated CDC examined the study and agreed to allow it to continue. Not until 1972, when the first accounts of this study appeared in the press, did the Department of Health, Education and Welfare (HEW) terminate the experiment. At that time, seventy-four of the test subjects were still alive; at least twenty-eight, but perhaps more than one hundred, had died directly from advanced syphilitic lesions. For a more detailed analysis see: Allen B. "Racism And Research: The Case Of The Tuskegee Syphilis Study," Hastings Center Report 8 (December 1978): 21; Ad Hoc Advisory Panel, Department of Health, Education and Welfare, "Final Report Of The Tuskegee Syphilis Study," (Washington, D.C.: Government Printing Office, 1973); Caplan A. "When Evil Intrudes," Hastings Center Report 22 (November-December 1992): 29-32; Harold E. "Outside The Community," Hastings Center Report 22 (November-December 1992): 32-35; King PA. "The Dangers of Difference," Hastings Center Report 22 (November-December 1992): 35-38; Jones JH. "The Tuskegee Legacy: AIDS And The Black Community," Hastings Center Report 22 (NovemberDecember 1992): 38-40 and Jones J H. Bad Blood: The Tuskegee Syphilis Experiment-A Tragedy Of Race And Medicine (New York: The Free Press, 1981).

${ }^{24}$ Editor, "NHPCO's Facts and Figures-Hospice Care in America," 2015 at 10. 


\section{THE JOURNAL OF HEALTHCARE ETHICS \& ADMINISTRATION}

Vol. 7 | No. 1 (Winter 2021)

hospice benefits.. Aetna plans to continue this experiment, because in the first year the average length of stay in hospice increased to 34 days up from 27 days. Aetna may in fact end up extending its coverage to more of its insured members. ${ }^{25}$

Most hospices are run by nonprofit, independent organizations. Some are affiliated with hospitals, nursing homes or home health care agencies, and there are some that are for-profit organizations. Determining which hospice would be best for a patient may take some research. Most patients and families hear about hospice from their physician or nurse or social worker. One can also find information about hospices from the National Hospice and Palliative Care Organization [http://www.nhpco.org/templates/1/homepage.cfm ], state hospice organizations, or the state health department. The telephone number for state hospice organizations and health departments can be found in the state government section of the local telephone directory. The Medicare hotline can also answer general questions about Medicare benefits and coverage and can refer people to their regional home health intermediary for information about Medicare-certified hospice programs. The toll-free telephone number is 1-800-MEDICARE (1-800-633-4227). Deaf and hearing impaired callers with TTY equipment can call 1-877-486-2048. The booklet Medicare Hospice Benefits is the official publication for Medicare hospice benefits. The booklet, which outlines the type of hospice care under Medicare and provides detailed information about hospice coverage, is available at http://www.medicare.gov/Publications/Pubs/pdf/02154.pdf on the Internet. Information about Medicaid benefits can be accessed at http://cms.hhs.gov/medicaid on the Internet. ${ }^{26}$ It is recommended that when evaluating hospice programs the following questions should be addressed:
1) Is the hospice Medicare-certified?
2) What services are available to the patient?
3) What services are offered to the family?
4) What bereavement services are available?
5) How involved are the family members?
6) How involved is the doctor?
7) Who makes up the hospice care team, and how are they trained and screened?
8) How will the individual's pain and symptoms be managed?
9) If circumstances change, can services be provided in different settings? Does the hospice have contacts with local nursing homes? Is residential hospice available?
10) Is the program reviewed and licensed by the state or certified in some other way?
11) Are all costs covered by insurance? ${ }^{27}$

Finding the right hospice for a patient is essential. It is important that patients and family members examine the available options and select the hospice that is the most advantageous for the particular individual in his or her condition.

\section{Criticisms of Hospice}

The general consensus is that hospice care is very beneficial for both patients and family members but it is not without its critics. Felicia Ackerman argues that some of the principles of hospice care depend on a highly questionable ideology that while valuable to some terminally ill patients, can be reasonably rejected by others. She uses as an example the fact that hospice is not religiously based, but she argues that it does seem to have a religious foundation. Although serenity in the face of impending death is reasonable for those who are confident of the afterlife, she asks why should those individuals who believe their death will be the unequivocal and permanent end of their existence expect such serenity. Ackerman questions whether such expectations constitute

\footnotetext{
25 Abelson R. "A Chance to Pick Hospice, and Still Hope to Live," New York Times (February 10, 2007$)$ : 1-5. http://www.nytimes.com/2007/02/10/business/10hospice.html

${ }^{26}$ National Cancer Institute, "Hospice Care," 2012. https://www.cancer.gov/about-cancer/advanced-cancer/care-choices/ho....

${ }^{27}$ Editor. MayoClinic "Hospice Care," at 3.
} 


\section{THE JOURNAL OF HEALTHCARE ETHICS \& ADMINISTRATION}

Vol. 7 | No. 1 (Winter 2021)

an attempt to export religious based attitudes. Ackerman also argues that "when its principles are fully scrutinized and understood, hospice care will be seen, not as 'the most effective route to a dignified death,' but as just one option for the terminally ill, whose other options should include experimental attempts at a cure, high-tech life-prolongation, and perhaps even assisted suicide." ${ }^{28}$ This position is based on giving all terminally ill patients the right to choose any option of treatment. What Ackerman fails to consider is that some of these options are neither in the best interest of the patient nor in the best interest of society as a whole. Medical resources are limited and using these resources on patients who will not benefit from them violates both the ethical principle of beneficence and the principle of justice because this is not a just allocation of resources.

\section{$\underline{\text { Conclusion }}$}

Despite all the services that hospice offers to patients and families, it is still one of the best kept secrets in hospitals, nursing homes and among those who are terminally ill. There are many reasons for this ranging from the patient's fear of accepting death, to the family's pressure on the patient not to give up hope, to physician's denial that there is nothing more that can be done for the patient clinically. However, there seems to be a trend in the United States that as more patients and families become educated about the benefits of hospice and palliative care it is becoming more of a viable option than dying in a hospital attached to the latest advances in technology. Hospitals and nursing homes need to initiate Palliative Care Policies not only to benefit patients but to encourage physicians, nurses and social works to make palliative and hospice care a priority for all terminal patients [Appendix E: Sample Palliative Care Policy]. For hospice and palliative care to become a viable option for the terminally ill, physicians, nurses and social workers need to initiate conversations about the benefits of these programs at the appropriate time. When a patient has been diagnosed with a terminal condition and further medical treatment would appear not to be beneficial, that is the time to begin the conversation. Patients and family members often need time to digest the fact that the disease process has moved from a curative mode to a palliative mode of care. Besides initiating such a conversation, physicians also need to take the time to listen to patients and their loved ones so that they truly comprehend how much the patient and family members understand and what are the values that are forming their decision-making. Physicians need to help patients walk their final journey with dignity, peace and compassion, as well as supporting their loved ones throughout the process. ${ }^{29}$ Recent studies have shown "lower morbidity and mortality and better emotional support among surviving family members of hospice patients than among family members of patients who did not receive hospice services, although it is uncertain whether this difference reflects the nature of families who elect hospice care rather than the effects of the intervention. ${ }^{30}$ The advantages of hospice and palliative care have been shown to benefit not only patients and family members but also society as a whole. Until health care professionals, patients and families become more comfortable talking about the death and dying process, the fear is that hospice and palliative care will remain marginalized as an excellent option for accessing supportive services during an extremely difficult time. ${ }^{31}$ Hospice and palliative care can no longer be viewed as abandonment and giving up hope; instead it has to be seen as getting the care that the patient and the family desperately need.

\section{Palliative Care and Hospice in Developing Nations:}

In the United States and in most Developed Nations, Palliative Care and Hospice, when utilized in a timely manner, offer great advantages to patients and their loved ones in end-of-life care. In many ways, hospice does more for families and friends of the patient then it does for the patient. The patient has his/her symptoms managed and their quality of life is of the highest caliber, but family and friends are often over looked at this crucial time. Hospice provides the needed support and counseling for loved ones so

\footnotetext{
${ }^{28}$ Ackerman, at 315-321

${ }^{29}$ Mulvihill, N. “Giving Patients a 'Good Death,'” Health Progress 85 (4) (July-August 2004): 23-26.

${ }^{30}$ Morrison \& Meier, at 2586. See also, Christakis NA and Iwashyna TJ. "The Health Impact of Health Care on Families: A Matched Cohort Study of Hospice Use by Decedents and Mortality Outcomes in Surviving, Widowed Spouses," Social Science Medicine57 (2003): $465-475$ and Teno JM, Clarridge BR, Casey V. et al. "Family Perspectives on End-Of-Life Care At the Last Place of Care," Journal of the American Medical Association 291 (2004): 88-93.

${ }^{31}$ Editor. Hospice Facts \& Statistics, at 11.
} 


\section{THE JOURNAL OF HEALTHCARE ETHICS \& ADMINISTRATION}

Vol. 7 | No. 1 (Winter 2021)

that they can continue be present to the patient, But more importantly, hospice helps loved ones to face the inevitability of death in a realistic and loving way. This support and counseling continues for at least 6 months after the death of their loved one.

Palliative care and hospice in the United States can serve as a paradigm for developing nations. Understanding the challenges that are faced in the United States can better prepare other nations to overcome the negative aspects and concentrate more on the positive aspects. Many of the challenges faced in the United States will be present in other nations. Death and dying has social, cultural and religious dimensions among all types of peoples. Lessons learned in the United States can be adapted to other cultures and religions and many of the challenges faced in the United States can be overcome by preparing people to face dying and death realistically and providing comfort measures as an integral part of end-of-life care. With the proposed implementation of Palliative Care and Hospice Care in developing nations, the dignity and respect of all human life, even in its last moments, would be protected and the greater good would be promoted.

Post-Chapter Assessment Activity: Break students up into pairs of groups of three or four. Pose the following questions. Have students discuss as a group and formulate one response from the group.

In your opinion, why is there such a general misunderstanding of hospice and palliative care in the public? Now that you have a greater understanding of the two services, formulate a brief ( 3 to 4 sentence) explanation of why these two services are so useful and widely underused by patients. (This comes from the questions posed at the end of the chapter.)

Closure: Have groups report out

Exit Ticket: Compare and contrast palliative care vs. hospice care. 


\section{THE JOURNAL OF HEALTHCARE ETHICS \& ADMINISTRATION \\ Vol. 7 | No. 1 (Winter 2021)}

\section{Appendix A: General Guidelines When Taking Medication}

1. Always read directions on the label carefully. Contact your nurse or pharmacist for clarification if you have any questions.

2. Do not mix different medications in one container. Keep medicine in original container with label from the pharmacy.

3. Do not store medicines for long periods of time. Most should be discarded after 6 months if not in use.

4. Do not stop taking any medication without first consulting with your doctor or nurse, unless a specific time limit was given when the medication was ordered.

5. On the Hospice medication information forms some abbreviations are used:
$\mathrm{N} / \mathrm{V}$ =nausea, vomiting
$\mathrm{N} / \mathrm{V} / \mathrm{D}$ =nausea, vomiting
$\mathrm{W} / \quad=$ with
$\mathrm{BM}=$ bowel movement
$\mathrm{GI}=$ gastrointestinal

6. Many patients experience no side effects(s) but all medications have the potential for producing some degree of side effect(s) and can be experienced in varying degrees.

If a side effect(s) is pronounced or very uncomfortable, report this to your nurse or physician.

7. Some medications do not absorb well if there is food or antacids in the stomach and must be taken on an empty stomach. Read the label carefully. Contact your nurse or pharmacist if the direction is unclear.

8. DO NOT cut, crush, or dissolve medications without checking with your nurse or pharmacist. If there is difficulty swallowing, a medication may be available in liquid form. Contact your nurse.

9. Be sure to let your nurse know if you are taking any medication which can be obtained without a prescription such as Tylenol or Aspirin.

10. Wash your hands before and after handling medications.

11. Wear gloves when administering suppositories or creams.

12. Don't store medications in a moist area such as the bathroom.

13. Prescription Refill Information

You may call the pharmacy to arrange for prescription refills provided that there are refills left on the prescription.

- Check the label on the bottle to make sure you have refills available.

- Give the pharmacy the prescription number for the medication(s) that you want refilled. 


\section{THE JOURNAL OF HEALTHCARE ETHICS \& ADMINISTRATION}

Vol. 7 | No. 1 (Winter 2021)

If you do not have any refills left on your prescription you will need to contact hospice nurse or your physician to arrange for a medication renewal.

Please, do not allow yourself to run out of medication - especially heading into a weekend or holiday. We recommend that you get into a routine or habit of checking all medications on Thursdays to make sure you have enough.

This allows for sufficient time to contact the doctor, if needed, before the weekend.

14. Dispose of all unused controlled substances only in the presence of the Hospice nurse when the patient no longer requires such medications. 


\section{THE JOURNAL OF HEALTHCARE ETHICS \& ADMINISTRATION}

Vol. 7 | No. 1 (Winter 2021)

\section{Appendix B: What To Do When Breathing Is Very Difficult:}

\section{ELEVATE HEAD}

Upright positions if best (raise head of bed or sit in chair).

\section{USE A FAN}

Place fan so it is directed to blow on face, across cheeks.

\section{USE OXYGEN}

Oxygen by nasal tips can be used at 1 to 3 liters per minute. Use the oxygen as long as needed. When you begin to feel more comfortable, you may decrease the flow rate to 1 or 2 or remove the oxygen for brief periods. If your nose becomes dry use KY jelly to lubricate or ask your nurse for suggestions. DO NOT USE VASELINE or petrolatum products. Your doctor may order a different flow rate.

The nurse will write in this flow rate:

If you do not have oxygen, CALL THE HOSPICE NURSE ANY TIME OF NIGHT OR DAY. While waiting for delivery, keep head elevated, use a fan, and ask someone to sit with you. Try to minimize activity and exertion.

\section{USE MEDICATIONS}

1. ROXANOL:

Enhances relaxation/rest, relieves the sense of difficult breathing. Can be mixed with a small amount of juice or water if too bitter. If there is difficulty swallowing, or produces nausea, it can be placed under the tongue.

\section{NEBULIZER TREATMENT}

The medication is placed in the small jar and the "Neb machine" creates a mist. As you hold the mouth piece and breathe in your usual way the medicated mist travels into the airway passages opening the passageways. Treatment time is approximately 10 minutes. This helps to relieve congestion and wheezing.

Your nurse will write in any other instructions: 


\section{Appendix C: Coordination of Care for Early, Middle, and Late Stages of Serious Chronic Illnesses.*}

\begin{tabular}{|c|c|c|c|}
\hline Palliative Care Services & Early Stage & Middle Stage & Late Stage \\
\hline Goals of care & $\begin{array}{l}\text { Discuss diagnosis, } \\
\text { prognosis, likely course of } \\
\text { the illness and disease- } \\
\text { modifying therapies; talk } \\
\text { about patient- centered } \\
\text { goals, hopes, and } \\
\text { expectations for medical } \\
\text { treatments. }\end{array}$ & $\begin{array}{l}\text { Review patient's } \\
\text { understanding of prognosis; } \\
\text { review efficacy and benefit-to- } \\
\text { burden ratio for disease- } \\
\text { modifying treatments; re } \\
\text { assess goals of care and } \\
\text { expectations; prepare patient } \\
\text { and patient's family for a shift } \\
\text { in goals; encourage paying } \\
\text { attention to important tasks, } \\
\text { relationships, and financial } \\
\text { affairs. }\end{array}$ & $\begin{array}{l}\text { Assess patient's } \\
\text { understanding of diagnosis, } \\
\text { disease course, and } \\
\text { prognosis; } \\
\text { appropriateness of disease- } \\
\text { goals of care and recommend } \\
\text { appropriate shifts; help } \\
\text { patient explicitly plan for a } \\
\text { peaceful death; encourage } \\
\text { completion of important task } \\
\text { increased attention to } \\
\text { relationships and financial } \\
\text { affairs. }\end{array}$ \\
\hline Programmatic support & $\begin{array}{l}\text { Advise patient to sign up } \\
\text { for visiting nurse and home } \\
\text { care services and case } \\
\text { management services } \\
\text { (if available) }\end{array}$ & $\begin{array}{l}\text { Advise patient to sign up for } \\
\text { visiting nurse and home care } \\
\text { services; consider palliative } \\
\text { care program in hospital or at } \\
\text { home, hospice, subacute } \\
\text { rehabilitation case- } \\
\text { Management services and } \\
\text { PACE. }\end{array}$ & $\begin{array}{l}\text { Advise patient to sign up for } \\
\text { palliative care program in } \\
\text { hospital or at home, case- } \\
\text { management services, } \\
\text { hospice, PACE; consider } \\
\text { nursing home placement with } \\
\text { hospice or palliative care if } \\
\text { patient's home caregivers are } \\
\text { overwhelmed. }\end{array}$ \\
\hline Financial Planning & $\begin{array}{l}\text { Advise patient to seek help } \\
\text { in planning for financial, } \\
\text { long term care, and } \\
\text { insurance needs and to } \\
\text { begin transfer of assets if } \\
\text { patient is considering a } \\
\text { future Medicaid } \\
\text { application, refer patient } \\
\text { to a lawyer who is } \\
\text { experienced in health } \\
\text { issues. }\end{array}$ & $\begin{array}{l}\text { Advise patient to reassess } \\
\text { adequacy of planning for } \\
\text { financial, medical home care, } \\
\text { prescription, long-term care, } \\
\text { and family-support needs; } \\
\text { consider hospice referral and } \\
\text { Medicaid eligibility. }\end{array}$ & $\begin{array}{l}\text { Advise patient to review all } \\
\text { financial resources and needs } \\
\text { inform patient and family } \\
\text { about financial options for } \\
\text { personal and long-term care } \\
\text { (e.g., hospice and Medicaid) if } \\
\text { resources are inadequate to } \\
\text { meet needs; explicitly } \\
\text { recommend hospice and } \\
\text { review its advantages; } \\
\text { consider Medicaid eligibility. }\end{array}$ \\
\hline Family support & $\begin{array}{l}\text { Inform patient and family } \\
\text { About support groups; ask } \\
\text { About practical support } \\
\text { Needs (e.g., transportation, } \\
\text { prescription-drug coverage, }\end{array}$ & $\begin{array}{l}\text { Encourage support or } \\
\text { counseling for family } \\
\text { caregivers; ensure that care- } \\
\text { givers have information about } \\
\text { practical resources, stress }\end{array}$ & $\begin{array}{l}\text { Encourage out-of-town family } \\
\text { to visit refer caregivers to } \\
\text { disease-specific support } \\
\text { groups or counseling inquire } \\
\text { routinely about health, well- }\end{array}$ \\
\hline
\end{tabular}




\section{THE JOURNAL OF HEALTHCARE ETHICS \& ADMINISTRATION}

Vol. 7 | No. 1 (Winter 2021)

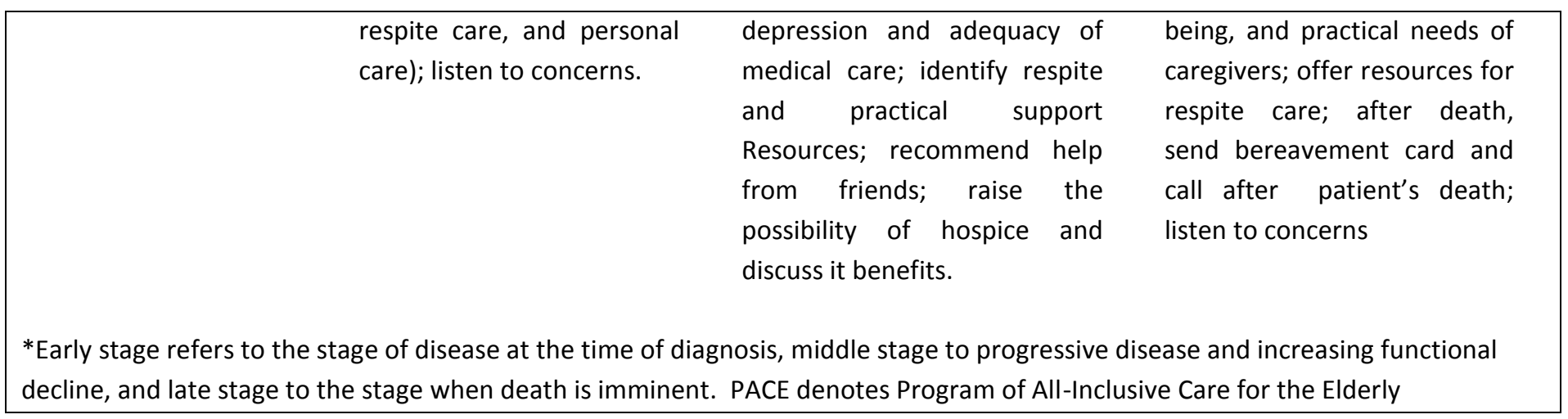


Drug Name

1.Captopril

(Capoten)

\section{Cipro}

(Cirpofloxacin)

3.Didanosine

(Videx, ddi)

\section{Flagyl}

\section{Indinavir}

(Crixivan)

\section{Monoamine Oxidase Inhibitors \\ Phenelzine (Nardil) \\ Tranlcypromine (Parnate)}

\section{Recommendation}

Take 1 hour before or 2 hours after a meal.

Avoid taking large amounts of drinks with caffeine like coffee, tea, some drinks (Mello Yello, Mountain Dew, Kick, Colas, Dr. Pepper, Mr. PIBB) and chocolate products.

Take on an empty stomach Drug should be taken 1 or 2 hours after a meal is eaten. If taken too close to a meal, take with an antacid. Tablets should not be swallowed whole. They are to be chewed well or crushed and mixed with at least an ounce of water.

Take with food avoid alcohol (including (Metronidazole) cough syrups with alcohol.

Take on an empty stomach 1 hour before or 2 hours after a meal or take with low-fat, low protein snack. Drink at least six (8oz.) glasses of water every day.

Avoid foods and drinks with tyramine or tryptophan while taking MAOI's and for 2 weeks after stopping this drug. These foods and drinks include alcoholic beverages, especially wine (Chianti and Champagne) and beer; alcohol-free beer, cheeses (strong, aged or processed types); bananas; raisins; sour cream, yougurt; pickled herring; liver (chicken liver) dry sausage (including hard salami and pepperoni); canned figs; avocados; soy sauce; yeast extracts; papaya products including certain meat tenderizers fava beans; and broad bean pods. Large amounts of caffeine and chocolate should be avoided as well.

\section{Reason}

Eating can lower $(\downarrow)$ drugs effect.

This drug with caffeine can make you more nervous, unable to sleep and have a fast heart beat.

Food in the stomach will $(\downarrow)$ how well drug works.

Taking with food will lower $(\downarrow)$ stomach Do not consume alcohol for at least one full day after drug is stopped. Upset. Use of alcohol may cause a fast heart beat, chest pains, flushing.

High fat/high protein foods can lower $(\downarrow)$ how well the drug works. Drinking six ( $8 \mathrm{oz}$.) glasses of water may help to lower the chance of forming a kidney stone by "flushing" the drug through the kidneys.

Eating tyramine or trytophan foods can cause fatal increase( $\uparrow$ )in blood pressure. Symptoms include severe headache, neck stiffness and soreness, nausea/vomiting, sweating, visual changes, chest pain and changes in heart rate. 


\section{THE JOURNAL OF HEALTHCARE ETHICS \& ADMINISTRATION}

Vol. 7 | No. 1 (Winter 2021)

\section{Phenytoin Suspensions}

(Dilantin) \& Tube Feeding

\section{Tetracycline}

(Sumycin, Achromycin

Panmycin)

\section{Warfarin}

(Coumadin)
Hold tube feeding for 1 hour before and 1 hour after taking Dilantin suspension

Take 1 hour before or 2 hours after a meal or dairy food. Avoid use of tetracyclines with antacids, laxatives, dairy products or iron pills If an antacid must be taken, take 2-3 hours before or after tetracycline. Take with a full glass of water.

Eat a steady amount of food containing Vit. K. Foods high in Vit. K. include: soybean oil, beef liver, chicken liver, port liver, green tea, broccoli, green cabbage, chickpeas (garbanzo beans), lentils, mung beans, seaweed, nettle leaves, spinach, green tomato, turnip greens. You do not have to avoid these foods. Consult doctor or dietitian before making major diet changes.
Tube feedings lower $(\downarrow)$ Dilantin's effect

Drinking a full glass of water can avoid stomach upset. Taking with food, milk or antacids can lower $(\downarrow)$ drug effect.

Changes in the amount of Vit. K. you eat may affect the way the drug works. Eating too much or too little Vit. K. will affect how fast your blood will clot. 


\section{THE JOURNAL OF HEALTHCARE ETHICS \& ADMINISTRATION}

Vol. 7 | No. 1 (Winter 2021)

\section{Appendix E: Sample Palliative Care Policy}

\section{PURPOSE}

The purposes of this policy are to:

- Clarify the meaning of palliative care, often referred to as "comfort care."

- Promote comprehensive and consistent palliative care.

- Establish a process for determining appropriate palliative care for individual patients.

\section{$\underline{\text { POLICY }}$}

The Health System recognizes that in the care of patients with advanced disease it is medically appropriate and ethically acceptable to shift the primary goal of treatment to palliative care if this is judged to be medically appropriate by the patient's physician and consistent with the wishes of the patient or the patient's surrogate.

\section{Definition}

Palliative care consists of all treatments and services aimed at alleviating physical symptoms and addressing the psychological, social and spiritual needs of the patients and their families so as to enhance patients' and families' quality of life to the greatest degree possible.

Palliative Care:

. affirms life and regards dying as a normal process;

- implies the cessation of all diagnostic measures and all life-sustaining and other therapeutic treatments that do not directly contribute to the patient's comfort or to patient and family goals;

consists of active management of pain and other distressing symptoms. In the relief of pain, it is ethically permissible to administer analgesics, in sufficient amounts, to control the patient's pain even if this has the unintended effect of depressing the patient's respiratory function

is multidisciplinary in order to address the physical, psychosocial, and spiritual needs of patient and family. 


\section{THE JOURNAL OF HEALTHCARE ETHICS \& ADMINISTRATION}

Vol. 7 | No. 1 (Winter 2021)

\section{Procedure}

A. A discussion should be initiated between the attending physician and the patient and/or the patient's family about the appropriateness of shifting goals of treatment to palliative care.

B. The attending physician and other members of the healthcare team should develop a palliative care plan with the patient and/or the patient's family (usually in the context of a family conference), taking into account their particular goals and needs. Special attention should be given to:

- what therapies and procedures should be continued, discontinued or initiated;

- $\quad$ symptom control, especially the management of pain and anxiety;

- the most appropriate setting for the patient's death to occur, including the appropriateness of hospice care.

C. The physician should document the patient's and/or family's agreement with the plan in the medical record.

D. The physician should complete the "Palliative Care Order Form." A general order like "comfort care only" is not acceptable.

E. A regular review of the palliative care plan should occur and adjustments made as the patient's condition changes.

\section{ADULT PALLIATIVE CARE ORDER FORM}

DATE:

TIME:

\section{RESUSCITATION STATUS}

This patient is no-CPR. In the event of cardiac or respiratory arrest, cardiopulmonary resuscitation will not be attempted. No "code blue" should be called.

2. INITIATE THE FOLLOWING ORDERS TO PROVIDE COMFORT: 


\section{THE JOURNAL OF HEALTHCARE ETHICS \& ADMINISTRATION}

Vol. 7 | No. 1 (Winter 2021)

Pain/air hunger:

Anxiety/delirium:

Sleep:

Constipation:

Diarrhea:

Nausea/vomiting:

Thirst:

Fever:

Other:

3. The following therapies may not contribute to providing comfort. If this patient is currently receiving any of these, please indicate below if they are to be continued or discontinued.

IV hydration

Diagnostic procedures

ECG and $\mathrm{O} 2$ sat monitoring

Supplemental O2

Parenteral and/or enteral nutrition

Arterial lines

Central venous lines

Peripheral venous lines

PT/OT

Blood products

Radiation therapy

Dialysis (Please notify

nephrologist Dr.

Blood draws for standing

laboratory orders

$\begin{array}{ll}\text { Continue } & \text { Discontinue } \\ \text { Continue } & \text { Discontinue } \\ \text { Continue } & \text { Discontinue } \\ \text { Continue } & \text { Discontinue } \\ \text { Continue } & \text { Discontinue } \\ \text { Continue } & \text { Discontinue } \\ \text { Continue } & \text { Discontinue } \\ \text { Continue } & \text { Discontinue } \\ \text { Continue } & \text { Discontinue } \\ \text { Continue } & \text { Discontinue } \\ \text { Continue } & \text { Discontinue } \\ \text { Continue } & \text { Discontinue }\end{array}$




\section{THE JOURNAL OF HEALTHCARE ETHICS \& ADMINISTRATION}

Vol. 7 | No. 1 (Winter 2021)

4. Please discontinue the following medications:

5. Consult Pastoral Care and Social Work Departments.

6. Hospice Department to evaluate patient for appropriateness of hospice care.

Transfer orders: 


\section{THE JOURNAL OF HEALTHCARE ETHICS \& ADMINISTRATION}

Vol. 7 | No. 1 (Winter 2021)

\section{APPENDIX 7 - CHAPTER 7: PAIN MANAGEMENT}

Quote: "Patients should be kept as free of pain as possible so that they may die comfortably and with dignity, and in the place where they wish to die." ${ }^{1}$-Bishops of the United States in the Ethical and Religious Directives for Catholic Health Care Services

Chapter Objectives: (SWBAT= Students will be able to..)

- SWBAT recall the basic history of pain and comment on its relevance today

- SWBAT form educated opinions on the Opioid Epidemic that is ravaging the United States, and develop potential strategies to curb the suffering.

- SWBAT distinguish between the categories of pain.

- SWBAT explain why there is often a communication gap between physicians and patients surrounding pain assessment.

\section{Standards (derived from Common Core State Standards)}

\section{CC.1.2.11-12.A}

Determine and analyze the relationship between two or more central ideas of a text, including the development and interaction of the central ideas; provide an objective summary of the text.

\section{CC.1.4.11-12.G}

Write arguments to support claims in an analysis of substantive topics.

\section{CC.1.4.11-12.I}

Distinguish the claim(s) from alternate or opposing claims; develop claim(s) and counterclaims fairly and thoroughly, supplying the most relevant evidence for each while pointing out the strengths and limitations of both in a manner that anticipates the audience's knowledge level, concerns, values, and possible biases.

\section{CC.1.2.11-12.J}

Acquire and use accurately general academic and domain specific words and phrases, sufficient for reading, writing, speaking, and listening at the college- and career- readiness level; demonstrate independence in gathering vocabulary knowledge when considering a word or phrase important to comprehension or expression.

\section{Overarching Practical Goals of Curriculum:}

Step 1 - The Basics: Have students understand a brief history of pain management, the classification of pain, and why pain can always be justifiably treated.

Step 2 - Preparation Techniques: Have students develop their own subjective pain chart, and see how they differ. [Appendix A] Step 3 -Communication: Students can have mock hospital situations where one student plays a patient in pain and the other is a physician who must communicate she/he is responsible for understanding and caring for the pain.

Do Now: What is the worst pain you've ever experienced? Write about it. Share with a partner or group.

\footnotetext{
${ }^{1}$ National Conference of Catholic Bishops, Ethical and Religious Directives for Catholic Health Care Services (Washington, D.C.: United States Catholic Conference, Inc., 1995): \# 61, at 23.
} 


\section{THE JOURNAL OF HEALTHCARE ETHICS \& ADMINISTRATION}

Vol. 7 | No. 1 (Winter 2021)

Pre-Chapter Assessment Activity: Multiple groups will be formed in the classroom. With the smiley face pain scale often seen in pediatrician offices in mind, each group will be responsible for developing a level of the pain scale and describe what categorizes this level of pain. The scale is 1-10 so groups may have to assess the scale for multiple levels depending on class size. Share out. Do students agree with the scale?

\section{Sections:}

\section{Introduction to the History of Pain}

Humankind has always been trying to understand pain. "The philosophical, political, and religious meaning of pain defined the suffering of individuals for much of human history. Pain is the central metaphor of Judeo-Christian thought: the test of pain in the story of Job, the sacrificial redemption of the crucifixion. From the utilitarian perspectives of the $18^{\text {th }}$ and $19^{\text {th }}$ centuries, pleasure was balanced against pain to determine the good of society." ${ }^{2}$ Pain has also obviously been a medical problem that has a close relationship with the end of life. Physicians in Europe relieved pain in patients through the common use of opium as early as the $15^{\text {th }}$ century. Attitudes toward pain changed in the 1800 s with the utilitarian emphasis on reducing pain for the greatest number of people and the new philosophy of individual rights. On October 16, 1846, William T.G. Morton an American dentist gave a demonstration of anesthesia with ether, and in 1848 a British obstetrician named James Young proposed the use of chloroform for childbirth and surgery to alleviate pain. The introduction of surgical anesthesia was a pivotal point in modern medicine. However, this advancement did not come about without significant debate and controversy. The debates ranged from the ethics of operating on an unconscious patient to the possibility that the relief of pain might actually retard the healing process. Even some religious writers questioned whether anesthesia might be a violation of God's law, because they believed that God inflicted pain to strengthen faith individuals. Despite this controversy, surgeons used anesthesia to perform longer and more complex procedures, but for much of the $19^{\text {th }}$ century it was not a universal practice. The gradual acceptance of surgical and obstetrical anesthesia promoted a general consensus that the relief of bodily pain was a positive good and also a form of curative therapy. ${ }^{3}$

\section{$19^{\text {th }}$ and $20^{\text {th }}$ Century Medicine}

Throughout the $19^{\text {th }}$ century, opiates were the standard treatment for acute pain from injuries and for recurrent pain such as headache or toothache. Morphine was industrially produced in Germany in the 1820s and in the United States a decade later. Opium and alcohol-based compounds, in the form of liquids, pills, and "headache powers," were unregulated and available over the counter in local pharmacies. By the 1870s physicians began to express concerns about "the morphine habit" or "narcomania." In 1898, the Bayer Company of Germany introduced diacetylated morphine under the trade name of heroin as a cough remedy. It was less habit-forming than morphine. In 1899, Bayer introduced a new compound called aspirin, which proved to be remarkably safe and well tolerated by patients and highly effective as an analgesic and antipyretic. However, for severe pain, opiates remained essential. ${ }^{4}$ Throughout the $19^{\text {th }}$ century physicians advocated the use of analgesics in seriously ill and dying patients. However, this was not universal because of fears regarding addiction. The conflict between the physician's desire to relieve pain and fear of inducing addiction persisted in medicine throughout the $20^{\text {th }}$ century. There exists even today during the wake of an opioid epidemic, the fear of giving liberal amounts of narcotics for fear of drug addiction. Some physicians even advise that every effort

\footnotetext{
${ }^{2}$ Meldrum, M. “A Capsule History of Pain Management," Journal of the American Medical Association 290, 18 (November 12, 2003): $2470-2475$ at 2470.

${ }^{3}$ Meldrum, at 2470.

${ }^{4}$ Meldrum, at 2471; See also Ballantyne J and Mao J. "Opioid Therapy for Chronic Pain," New England Journal of Medicine 349 (2003): $1943-1953$.
} 
should be made to put off narcotic use until all other measures have been exhausted and the patient's life can be measured in weeks. "Research in the last 30 years has developed a variety of alternatives or adjuncts to opiates for chronic pain, including neuroactive medications, counter stimulation methods, and cognitive behavioral therapies." ${ }^{6}$ The advancements in pain research and analgesic developments have not altered the truth of one clinical fact: "no one treatment works for every patient, even for pain of the same type and etiology. . . the meanings of pain-cognitive, affective, behavioral-are different for each individual and shape the pain experience and response to therapy. . . The most important treatment factor contributing to outcome was 'the intensive involvement of a single physician,' and why, with many new resources available, pain management remains a challenge for the clinician." ${ }^{7}$

\section{Assessing Pain Today}

The effective assessment and management of pain is a central goal of medicine. From the time of Hippocrates ${ }^{8}$ to the present-day Code of Medical Ethics of the American Medical Association, ${ }^{9}$ the assessment and management of a patient's pain has been the primary responsibility of every physician. However, due to various barriers, many patients today are not having their pain effectively assessed or managed. The 1995 SUPPORT study found that 50\% of Intensive Care Unit (ICU) patients suffered from moderate to severe pain during their last days of life. This study also found that pain assessment and management was not an institutional priority in most acute care facilities. ${ }^{10}$ "Dr. Russell K. Portenoy, chairman of pain medicine and palliative care at the Beth Israel Medical Center in New York, cites surveys estimating that as many as 6 to 10 percent of Americans suffer from chronic, disabling pain. He estimates that 1 in 10 of them could benefit from long-term, high dose treatment." ${ }^{11}$ These studies only confirm a long series of articles in the medical literature documenting the widespread and significant undertreatment of pain. ${ }^{12}$ All patients have the right to appropriate assessment and management of pain.

\section{Problems Related to Pain Assessment and Management Classifying Pain}

Pain is an unpleasant sensory and emotional experience. ${ }^{13}$ It is recognized as a complex phenomenon derived from sensory stimuli and modified by individual memory, expectations, and emotions. ${ }^{14}$ Since there are no objective biological markers of pain, the most accurate evidence of pain and its intensity is based on the patient's description and reporting. Pain affects every person from the tiniest neonate to the elderly. ${ }^{15}$ Pain can be classified into three categories, each of which can be acute or chronic. First, nociceptive pain is that generated by somatic or visceral tissue damage; this pain can be caused by cancer cells growing and interrupting normal nervous system function but does not have to be caused by cancer cells. Somatic pain is generated by nociceptors in skin and

\footnotetext{
${ }^{5}$ Meldrum, at 2470-2471.

${ }^{6}$ Meldrum, at 2474.

${ }^{7}$ Meldrum, at 2474.

${ }^{8}$ Hippocrates. "The Art," reprinted in S.J. Reiser, A.J. Dyck, \& W.J. Curran, eds. Ethics In Medicine (Cambridge, MA.: MIT Press, 1977).

${ }^{9}$ American Medical Association, Code Of Medical Ethics (Chicago: American Medical Association, 1997), 2:20.

${ }^{10}$ The SUPPORT Principal Investigators, "A Controlled Trial To Improve Care For Seriously III Hospitalized Patients," Journal of the American Medical Association 274 (1995): 1591-1598.

11 Satel A. "Doctors Behind Bars: Treating Pain Is Now Risky Business," New York Times (October 19, 2004$)$ : $1-3$ at 1. http://www.nytimes.com/2004/10/19/health/policy/19essa.html.

${ }^{12}$ Rich B. "An Ethical Analysis Of The Barriers To Effective Pain Management," Cambridge Quarterly of Healthcare Ethics 9 (2000): 54-70. See also, Marks RM \& Sachar EJ. Undertreatment of Medical Inpatients With Narcotic Analgesics," Annals of Internal Medicine 78 (1973): $173-181$.

${ }^{13}$ Merskey H \& Bogduk N. eds. Classification Of Chronic Pain $2^{\text {nd }}$ Ed. (Seattle: WA.: IASP Press, 1994), xi.

${ }^{14}$ Sternbach RA. “Clinical Aspects Of Pain,” in R. A. Sternbach, ed. The Psychology of Pain (New York, New York: Raven Press, 1978).

${ }^{15}$ Recent research suggests that infants may be more vulnerable to the negative effects of pain, which may later affect their neurological development, including the reaction to pain. See, Larsson BA. “Pain Management in Neonates," Acta Paediatr 88 (1999): $1301-1310$.
} 


\section{THE JOURNAL OF HEALTHCARE ETHICS \& ADMINISTRATION}

Vol. 7 | No. 1 (Winter 2021)

deeper tissues, such as in the musculoskeletal system, and is described as gnawing, cramping, and throbbing. Visceral pain results from stimulation of the nociceptors in the cardiovascular, gastrointestinal, genitourinary, and respiratory systems. It is described as deep, aching, squeezing, or as pressure. It is poorly localized. Second, neuropathic pain usually is described as constant, burning, shooting, or lancinating pain (eg., radiculopathies). Third, incidental pain is pain secondary to associated conditions such as positioning or constipation. ${ }^{16}$ Acute pain is pain that lasts or is anticipated to last a short period of time, typically $<1$ month. It is often associated with anxiety and with hyperactivity of the sympathetic nervous system. Chronic pain is usually defined broadly and arbitrarily as pain persisting $>1$ month beyond the resolution of an acute tissue injury, pain persisting or recurring for $>3$ months, or pain associated with tissue injury that is expected to continue or progress.

\section{The Cost of Pain}

Unrelieved pain is one of the greatest fears of people suffering from illnesses, especially terminal illness. Families of the suffering patient are in great distress, as well. Undertreatment of pain and unrelieved pain is also costly for patients, families, institutions and society as a whole. ${ }^{17}$ A 2003 study by Stewart et al. reported that between August 2001 and July 2002, an estimated 12.7\% of the total U.S. workforce lost productive time over a 2-week period because of pain, including headache (5.4\%), back pain (3.2\%), arthritis pain $(2.0 \%)$, and other musculoskeletal conditions $(2.0 \%)$. Of interest is that $80 \%$ of the lost productive time was explained by the reduced performance of work, not absence from work. In total, lost productive time cost employers an estimated $\$ 61.2$ billion annually. ${ }^{18}$ The reasons why pain has been undertreated or untreated are varied and numerous, but there are certain well-defined barriers that can be identified.

\section{Barriers to Pain Management}

The barriers to effective pain assessment and management fall under four distinct categories. First, the failure of health care professionals to identify pain as a priority in patient care. ${ }^{19}$ The failure of health care professionals to adequately treat pain is the result of an old conviction in medicine that separated physical and mental aspects of pain. Pain is the body's reaction to disease and suffering is the person's reaction to pain. Bodies are the site of disease, but persons undergo the experience of illness. Suffering is personal matter; it is as much a function of the value of individuals as it is of its physical causes. Suffering is more global than pain and is synonymous with a reduced quality of life. ${ }^{20}$ This split has allowed medical professionals to claim that their sole responsibility is the treatment of the physical and biological domain of illness. Physicians thus surrender the role of treating suffering to clinical psychologists, social workers, or pastoral counselors. The result of separating the objective dimension of disease from the subjective dimension of the person has been that the whole person's response to the experience of illness has suffered. ${ }^{21}$ Pain management is a priority in the care of every patient and has deep roots in the medical profession. Patients have a responsibility to make their physicians aware of the nature, severity, and duration of their pain to the best of their ability. The key is communication. The best way to assess pain is to ask the patient. Since pain cannot be objectively quantified, physicians should believe their patients. Patients need to be aware of the fact that they need not suffer because their pain can be and should be managed. Unless there is open and

\footnotetext{
${ }^{16}$ Cutson TM. “Management Of Cancer Pain,” Primary Care 25 (1998): 407-421.

${ }^{17}$ Effective pain management has been shown to shorten hospital stays and reduce costs. For a more detailed analysis see, Slack J. and FautCallahan M. "Pain Management," Clinical Nursing in North America 26 (1991): 463-476.

${ }^{18}$ Stewart WF, Ricci JA, Chee E. et al. "Lost Productive Time and Cost Due to Common Pain Conditions in the US Workforce," Journal of the American Medical Association 290 (2003): 2443-2454.

${ }^{19}$ Rich, at 54.

${ }^{20}$ Task Force on Pain Management-Catholic Health Association, "Pain Management: Theological And Ethical Principles Governing The Use Of Pain Relief For Dying Patients," Health Progress (January-February 1993): 30-39, 65.

${ }^{21}$ Rich, at 56.
} 


\section{THE JOURNAL OF HEALTHCARE ETHICS \& ADMINISTRATION}

Vol. 7 | No. 1 (Winter 2021)

honest dialogue between the patient and his or her physician, the covenant that binds them will be compromised due to lack of trust.

Second, there is insufficient knowledge among clinicians regarding the assessment and management of pain. ${ }^{22} \mathrm{~A}$ major issue causing this barrier is the lack of education in medical schools regarding a pain evaluation and management. A recent survey reported that the average amount of time spent teaching pain management in American medical schools was one hour, and for nursing schools it was four hours. ${ }^{23}$ In addition, they receive one course in pharmacology, which cannot properly prepare them for what they will face once they leave the security of medical school. One begins to wonder if pain management is a priority for physicians. One way to bring this issue to the forefront is the regular charting of a patient's pain as the "fifth vital sign." This is one way to enhance the clinical competency of physicians in pain assessment and management and to ensure patients that their fear of untreated pain will not become a reality.

Third, there is a fear of regulatory scrutiny of prescribing practices for opioid analgesics. ${ }^{24}$ Physicians are very open about the fact that they will under-prescribe opioid analgesics to avoid regulatory scrutiny. Physicians fear not only government agencies such as the Drug Enforcement Administration (DEA) but also their own medical licensing boards. This fear among physicians is not only wide-spread it is also based on factual evidence. It appears that the DEA has set the tone that drives physicians' perceptions about the legal risks associated with prescribing Schedule 2 drugs (potentially addictive drugs with critical medical uses) for seriously ill and dying patients. As a result, the covenant between physician and patient can be fractured as the basic trust that held the covenant together dissolves. Both the state medical licensing boards and the federal government need to re-evaluate and revise their present regulations regarding opioid analgesics.

These antiquated regulations are causing patients to suffer needlessly, are raising the anxiety levels among those nearing death that the dying process will be cruel and full of excruciating pain, and are leading the American public toward the slippery slope of physician-assisted suicide. Instead of playing into this antiquated system of regulations, medical professionals should take the initiative to advocate for comprehensive new regulations.

In addition, there are economic barriers to proper pain management. With the advent of managed care, there has been a greater inattention to pain assessment and management. Lower staffing levels, with fewer nurses having responsibility for a larger number of patients, deceases the likelihood that even a persistent patient will succeed in securing the required pain relief. The reluctance of physicians to prescribe and the lack of an adequate staff to monitor and evaluate patients will only lead to further barriers to pain relief for patients. ${ }^{25}$

Fourth, among health care professionals there are persistent unsound beliefs and unsubstantiated fears about addiction, tolerance, dependence, and adverse side effects of opioid analgesics. ${ }^{26}$ The major problem here is the lack of knowledge concerning the difference between addiction to narcotics and psychological dependence on opioid analgesics for relief of severe and persistent pain. The medical literature confirms that the majority of patients who receive large and extended doses of opioid analgesics for the management of their pain are not and rarely become addicts. ${ }^{27}$ "Physical dependence occurs in almost everyone who takes narcotic medication regularly for at least two weeks. Addiction is a craving for the drug and its compulsive use to regulate one's mood. With dependence, the body adapts physiologically to the drug, and if it is stopped abruptly, withdrawal symptoms occur. Tapering medications prevents nausea, vomiting, diarrhea and cramping of withdrawal. Tolerance and physical dependence are normal and reflect the pharmacologic properties of opiates. People who are addicted to narcotics are generally dependent and tolerant, but dependence and tolerance only sometimes indicate addiction. ${ }^{28}$ It seems obvious that many physicians and nurses are not being

\footnotetext{
${ }^{22}$ Rich, at 56.

${ }^{23}$ Rich BA. “Pain Management: Legal Risks And Ethical Responsibilities," Journal of Pharmaceutical Care in Pain Symptom Control 5 (1997): 5-20.

${ }^{24}$ Rich B., at 54.

${ }^{25}$ Rich B., at 63.

${ }^{26}$ Rich B., at 54.

${ }^{27}$ Porter J. \& Jick H. “Addiction Rare In Patients Treated With Narcotics," New England Journal of Medicine 320 (1980): 123.

${ }^{28}$ Satel, at 2.
} 


\section{THE JOURNAL OF HEALTHCARE ETHICS \& ADMINISTRATION}

Vol. 7 | No. 1 (Winter 2021)

exposed to this important medical information in their training. As a result, patients are being forced to endure unnecessary pain and suffering due to misinformation and ignorance. At the end of this chapter there is a chart that lists the standard doses of commonly used opioids. [Appendix B] These guidelines have been established, and as long as a physician is acting in good faith and following the standard of care addiction should not become an issue.

Issues of patient tolerance to opioid analgesics are also based on myths and misinformation. The need for higher doses is almost always related to a progression of the underlying disease producing the pain. Patients whose disease is stable do not necessarily require an increase in dosage once an effective level of analgesic is achieved and maintained. ${ }^{29}$ Finally, the issue of side effects from the sustained use of opioid analgesics has been greatly exaggerated according to pain management experts. The most common side effects of the drugs recommended for moderate to severe pain that persists are constipation, sedation, and respiratory depression. Prevailing clinical practice guidelines offer a range of effective means of managing these side effects without compromising the goal of pain relief. ${ }^{30}$

There are clear barriers to the assessment and management of pain that are complex. These barriers need to be challenged medically and ethically. If medicine is a moral enterprise then there is not only a medical reason to challenge these barriers but also an ethical reason.

\section{Ethical Analysis}

Failure to treat a patient's pain not only has medical implications but impacts on the deepest ethical roots of the medical profession. The primary responsibility of a physician is to do what is in the best interest of his or her patient. Not to treat the pain and suffering of a patient is to deny the patient the basic dignity deserved as a human person. Failure of physicians to assess and adequately manage pain violates the basic ethical principles of respect for the human person, beneficence, nonmaleficence and justice.

\section{$\underline{\text { Respect for Persons }}$}

Respect for persons incorporates two ethical convictions: first, that individuals should be treated as autonomous agents; and second, that persons with diminished autonomy are entitled to protection. The principle of respect for persons thus divides into two separate moral requirements: the requirement to acknowledge autonomy and the requirement to protect those with diminished autonomy. ${ }^{31}$ The physician-patient relationship is a covenant that is based on mutual trust. It is a relationship that is based on honesty. Ethicists Edmund Pellegrino and David Thomasma, who have written extensively in this area, argue that among the obligations that arise from the physician-patient relationship is technical competence: "the act of the medical professional is inauthentic and a lie unless it fulfills the expectation of technical competence." ${ }^{32}$ This means that patients can expect their physicians to have the technical skills to assess and manage their pain. Unfortunately, most patients believe that the pain medications they are receiving are all the pain relief that can be safely and effectively administered. Therefore, their continued pain and suffering can be attributed to the inherent limitations of medical science and technology. ${ }^{33}$ This directly relates to the issue of informed consent. Patients have a right to be informed about the advantages and disadvantages of any treatment, as well as any viable alternatives. Patients cannot give informed consent because in most cases they have not been given all the options available to manage their pain.

\footnotetext{
${ }^{29}$ Editor. "New Medication For Cancer Breakthrough Pain," at 1.

${ }^{30}$ Rich B., at 65. See also, Agency of Health Care Policy and Research, Management of Cancer Pain (Washington, D.C.: Agency of Health Care Policy and Research, 1994), 61-65.

${ }^{31}$ National Commission for the Protection of Human Subjects of Biomedical and Behavioral Research, The Belmont Report: Ethical Principles And Guidelines for the Protection of Human Subjects of Research (Washington, D.C.: U. S. Government Printing Office, 1979 ): B-1.

${ }^{32}$ Pellegrino ED \& Thomasma DC. A Philosophical Basis of Medical Practice (New York: Oxford University Press, 1981 ), at 213.

${ }^{33}$ Rich B., at 62.
} 


\section{THE JOURNAL OF HEALTHCARE ETHICS \& ADMINISTRATION}

Vol. 7 | No. 1 (Winter 2021)

One of the basic aspects of the principle of respect for persons is that a person should never be treated simply as a means, but always as an end. To undertreat a patient because of fear of regulatory scrutiny in prescribing opioid analgesics or out of misguided beliefs concerning addiction, dependence, and tolerance, is to use patients as a means rather than an end. Due to a basic lack of education, widespread misinformation, and unnecessary fear among physicians, patients are suffering needlessly, their autonomy is compromised, and the basic respect they deserve as human persons is violated because they are allowed to endure pain which can be alleviated. This violates the right of patients to be informed about their treatment options and to remain involved in the decision-making process.

\section{Beneficence}

Beneficence involves the obligation to prevent and remove harms and to promote the good of the person by minimizing possible harms and maximizing possible benefits. Beneficence includes nonmaleficence, which prohibits the infliction of harm, injury, or death upon others. In medical ethics this principle has been closely associated with the maxim Primum non nocere: "Above all do no harm." Allowing a person to endure pain when said pain can be managed and relieved violates the principle of beneficence because one is not preventing pain and therefore not acting in the best interest of the patient. It also violates the principle of nonmaleficence because it is causing harm and even injury to the person. Prescribing lower doses of effective analgesics because the physician fears regulatory scrutiny or failing to prescribe adequate doses of opioid analgesics because of misinformation about addiction, tolerance, and adverse side effects, places the patient in a situation in which his or her pain is either undertreated or not treated at all. This comes very close to willfully inflicting pain. It is true that most pain technologies also have risks of side-effects associate with them. Therefore, the physician must balance the pain relief potential with the potential harm. This can be done through dialogue with the patient and/or surrogates. The impact on the caregivers should also be considered in terms of physical and psychological burdens. ${ }^{34}$

\section{Voluntary Suffering?}

Some Christians believe that suffering can have spiritual value because they believe uniting one's suffering with Christ's is redemptive. However, to endure unnecessary pain and suffering is not only useless it is also a misrepresentation of the Christian position. ${ }^{35}$ The Bishops of the United States in the Ethical and Religious Directives for Catholic Health Care Services are quite clear that a patient's pain should always be managed effectively. "Patients should be kept as free of pain as possible so that they may die comfortably and with dignity, and in the place where they wish to die." ${ }^{36}$

\footnotetext{
${ }^{34}$ Farrell BR. “Cost Issues Surrounding The Treatment Of Cancer Related Pain," Journal of Pharmaceutical Care for Pain Symptom Control 1 (1993): 9-23.

${ }^{35}$ Illinois Bishops, "Facing The End Of Life, “ Origins 31 (June 21, 2001): 106-109.

${ }^{36}$ National Conference of Catholic Bishops, Ethical and Religious Directives for Catholic Health Care Services (Washington, D.C.: United States Catholic Conference, Inc., 1995): \# 61, at 23.
} 
A Case Study:

Principle of Double Effect in Pain Management - Morphine

The use of morphine and the principle of double effect are two very important issues for patients and families in this area of pain management. Often in the hospital a patient or family member will express concern about the use of morphine because it could "kill" the patient.

One major criticism of using morphine as a painkiller is that physicians often do not adequately explain to patients or their appropriate surrogate decision-makers how morphine works and what are its side-effects. This is because many physicians are not adequately trained in the art of pain management. Instead of referring the terminal patient to a palliative care team which has expertise in pain management, the physician writes an order for morphine and the family is left to watch their loved one die. In many instances patients and families are ill-prepared emotionally and clinically to make these decisions concerning the use of morphine. The result is that either the patient's pain is not managed adequately, or the families are left with feelings of guilt that they may have hastened the death of the patient. Family members may carry these feelings of guilt and frustration with them for a lifetime. Ethically, similar situations have led many health care professionals and non-health care professionals to question the use of morphine as an effective way to manage pain in terminal patients.

The use of morphine is not only medically appropriate it is also ethically and morally acceptable. The principle of double effect is a fundamental principle in Roman Catholic moral theology. As the name implies it refers to one action with two effects. One effect is intended and morally good; the other is unintended and morally evil. It is an efficient guide to prudent moral judgment in solving difficult moral dilemmas. ${ }^{37}$ The principle of double effect specifies four conditions that must be fulfilled for an action with both a good and a bad effect to be morally justified.

1) The action, considered by itself and independently of its effects, must not be morally evil. The object of the action must be good or indifferent.

2) The evil effect must not be the means of producing the good effect.

3) The evil effect is sincerely not intended, but merely tolerated.

4) There must be a proportionate reason for performing the action, in spite of its evil consequence. ${ }^{38}$

The use of morphine to manage pain effectively is ethically justified because it meets the four conditions of the principle of double effect. The first condition allows for the injection of morphine because the action in and of itself is good, in that it effectively alleviates or manages the pain of the patient. While morphine may endanger the patient's life by suppressing respiration, the injection will not directly terminate the patient's life. The second condition allows for the injection of morphine because the good effect is not caused by means of the evil effect. The patient's pain is alleviated by the morphine not by the patient's death. The good effect and the evil effect happen simultaneously. The third condition allows for the injection of morphine because even though there is the possibility that the morphine may harm the patient, the intention of the physician is to alleviate or manage the patient's pain. Finally, the argument for the ethical justification of morphine for medical use by the principle of double effect focuses on whether there is a proportionately grave reason for allowing the foreseen but unintended possible consequences.

The specific value in using morphine and other pain analgesics is to relieve pain and suffering associated with treatment for specific illnesses. The premoral evil, which can come about by trying to achieve this value, is the foreseen but unintended possibility of the potential harmful effects of depressing the respiratory system and hastening death. The ethical question is: does the value of relieving pain and suffering outweigh the premoral evil of the potential harmful effects? To determine if a proper relationship exists

\footnotetext{
${ }^{37}$ Mangan J. “An Historical Analysis Of The Principle Of Double Effect," Theological Studies 10 (March 1949): at 41.

${ }^{38}$ Kelly, at 13-14.
} 


\section{THE JOURNAL OF HEALTHCARE ETHICS \& ADMINISTRATION}

Vol. 7 | No. 1 (Winter 2021)

between the specific value and the other elements of the act, ethicist Richard McCormick proposes three criteria for the establishment of proportionate reason:

1) The means used will not cause more harm than necessary to achieve the value.

2) No less harmful way exists to protect the value.

3) The means used to achieve the value will not undermine it. ${ }^{39}$

The application of McCormick's criteria to the use of morphine supports the argument that there is a proportionate reason for allowing physicians to prescribe it for palliative care. First, the use of morphine to control the pain and suffering in patients in certain situations does not cause more harm than necessary. With certain medical conditions, end-stage cancer, etc., physicians will prescribe the use of morphine because it is the only way to relieve the pain of the patients even knowing the unintentional side effects. Not treating the pain and suffering of these patients would violate their right to being treated with dignity and respect. Second, when a patient is clearly in pain and all other medications do not relieve said pain then the use of morphine is the only way to respect the value of the patient's life. Third, the use of morphine if intended for palliative care, gives these patients the dignity and respect they deserve under these desperate conditions. Palliative care is given to respect the value of the patient's life. All individuals, but especially the seriously ill, have the right to effective pain management. To deny them access to such therapies is to deny them the dignity and respect all persons deserve. The greater good is promoted in spite of the potential evil consequences.

Finally, the principle of justice recognizes that each person should be treated fairly, equitably, and be given his or her due. Every patient has the right to have his or her pain assessed and managed adequately. The fact that some physicians are doing this well and others are failing, whether it is because they lack the fundamental skills or essential clinical competencies, or because of fear of government scrutiny or because of misinformation should be no excuse. Ignorance is not an excuse or a defense because physicians have the responsibility to be adequately trained and up-to-date on medications that will benefit their patients. If this is not possible then these physicians have an ethical responsibility to consult those in the medical field who are trained to assess and manage pain effectively. To plead ignorance violates the very goals of medicine and the basic duty a physician has to his or her patients.

\section{Recommendations}

The issues surrounding pain assessment and management are here to stay. There is a need for immediate changes that will address the issues of pain assessment and management directly and concretely. If healthcare professionals honestly believe that one of the major goals of medicine is the relief of pain and suffering, then untreated and undertreated pain and unnecessary suffering must be alleviated. Finally, if we know that our failure to relieve pain and suffering is causing people to seek other methods such as physician-assisted suicide then we must do everything in our power to help individuals to deal with their pain and suffering in a way that benefits the good of the whole person. To accomplish this task the following recommendations are proposed:

First, each hospital should formulate a pain management policy that will address the assessment and management of all types of pain. Attached is the Pain Management Policy that has been formulated by a Catholic Health System in Philadelphia as a paradigm for other health care facilities [Appendix C]. This policy is grounded in the dignity and respect of every human person and the duty of health care professionals to relieve pain and suffering of patients.

\footnotetext{
${ }^{39}$ McCormick's criteria for proportionate reason first appeared in Richard McCormick, Ambiguity In Moral Choice (Milwaukee, WI.: Marquette University Press, 1973). He later reworked the criteria in response to criticism. His revised criteria can be found in Doing Evil To Achieve Good, eds. Richard McCormick and Paul Ramsey (Chicago, IL.: Loyola University Press, 1978).
} 


\section{THE JOURNAL OF HEALTHCARE ETHICS \& ADMINISTRATION}

Vol. 7 | No. 1 (Winter 2021)

Second, each hospital should also formulate a pain management team. This team would be interdisciplinary and would consist of a physician, nurse, social worker, physical therapist, pharmacist, anaesthesiologist, psychiatrist/psychologist, pastoral care member and someone skilled in alternative therapies. The purpose of this team would be to assist physicians who are unable to manage a patient's pain. Any health care professional could request a pain consult on a particular patient.

Third, there is a need for more education initiatives for healthcare professionals and the public regarding the way pain should be assessed and managed. This begins with medical schools instituting pain assessment and management curricula, residency programs that include practical experience in pain management--such as hospice, etc., and the education of attending physicians through continuing medical education courses. This education of medical professionals must include instruction about pain assessment and management, pharmacologic principles, the uses of analgesics, and nonpharmacologic methods. There should also be education initiatives for the public. The public needs to be educated to the fact that it can expect pain to be assessed and managed properly and that it too has a role to play in this process. Patients have the responsibility to report the nature, severity, and duration of their pain to their physicians and to expect that their pain be relieved. This can be accomplished by the regular charting of a patient's pain as the "fifth vital sign." It can also be accomplished by the staff instituting a simple assessment tool of a 0 to 10 scale or a "Faces" pain rating scale for those patients who are cognitively impaired or for children. ${ }^{40}$

Fourth, physicians should begin a grass-roots movement to challenge the out-dated regulations by medical boards and the federal government regarding opioid analgesics. If physicians are required to act in the best interest of their patients, then they should challenge the regulatory agencies that are hostile to effective pain management as both medical professionals and ethical persons.

Fifth, more research and testing needs to be done to augment the pain medications that are available today for patients experiencing the various types of pain. Researchers are trying to pinpoint more precise targets for pain therapy. The goal is to understand pain at a molecular level so that they can develop treatments aimed at specific molecules in pain pathways that relieve pain without causing adverse effects.

The issue of pain assessment and management is now a priority as it should always have been in the medical profession. Challenges still remain - to advance knowledge about the mechanisms of pain, develop new and better analgesic medications and methods of delivery, remove the obstacles that prevent physicians from using known effective means of relieving pain in the very young, and educate patients and surrogates about effective use of pain-relieving therapies. ${ }^{41}$ Reforms are needed from various aspects of society. It is both the professional and ethical responsibility of healthcare professionals to see that these reforms are initiated and carried out so that the best interest of the patient remains at the forefront of the medical profession. Pain management can be improved if it becomes a priority for all.

Post-Chapter Assessment Activity: Take a look back at the pain scale from the beginning of the lesson. What is an appropriate amount of pain for a patient to be in? When should a doctor intervene? Explain your answer.

\section{Discussion Questions:}

1. Pretend you are having a conversation with someone who only knows about the Opioid Epidemic from the television. Develop a strong argument that defends physicians and their prescribing practices of opioids. Then formulate a concise counterargument that illustrates why these practices may be outdated, dangerous to the patient, or a waste of resources.

\footnotetext{
${ }^{40} \mathrm{~A}$ simple 0-10 numeric scale that rates pain from "none" to "worst imaginable" and pain relief from "none" to "total" can be used with most patients over 7 years of age. Patients should be shown the scale and should be asked about pain intensity on admission, after each painful procedure, and at least once per shift. With children under 7 years of age and with the cognitively impaired the same type scale can be used but with faces.

${ }^{41}$ DeAngelis, at 2481.
} 


\section{THE JOURNAL OF HEALTHCARE ETHICS \& ADMINISTRATION}

Vol. 7 | No. 1 (Winter 2021)

2. What are the three types of pain? Contrast these pains, and explain why they are subjective.

3. Using Appendix $\mathrm{C}$ as a guide, critique the most important parts of a Pain Management Policy. Do you have anything to add to the policy?

4. Which of the five recommendations listed at the end of the chapter do you think should be the starting point to change the culture of pain in the medical profession? Why?

5.

Closure: Have groups report out

Exit Ticket: What number on the pain scale is acceptable to you for a family member? For yourself? Briefly explain your answer.

\section{Further Reading:}

1. The Center for Bioethics \& Human Dignity and Nash, Ryan R. Opioids and the Ethics of Pain Management and Addiction, YouTube, YouTube, 2 Sept. 2016, www.youtube.com/watch?v=WTG80hf96XM.

2. Payne, Richard. "Medical Professionalism and Responsibility in Pain Management." Practical Bioethics, vol. 3, no. 3, 2007, pp. 1-16. 


\section{Appendix A: Pediatric Pain Scale}

\section{PAIN SCALE}

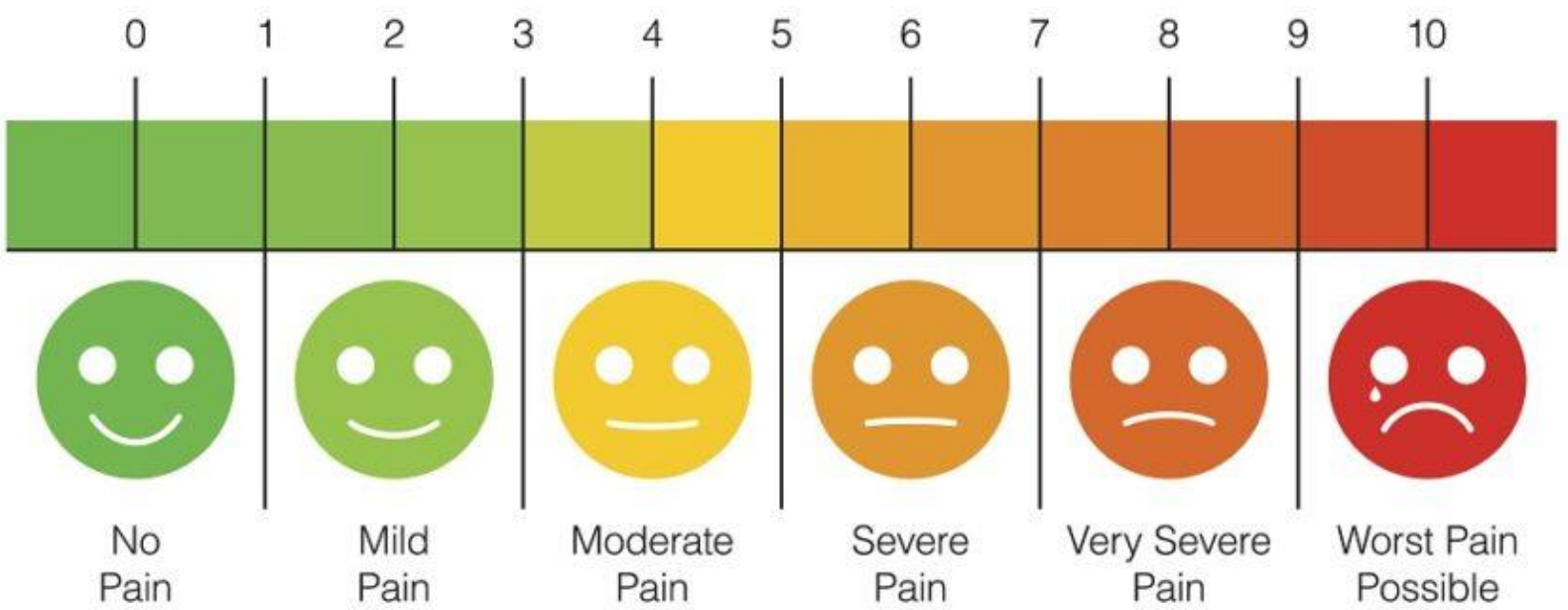




\section{Appendix B: Standard Doses of Commonly Used Opioids.*}

Generic Name (Trade Name)

Codeine

Oral

Parenteral

Fentanyl (Duragesic) **

Patch

Hydrocodone (Vicodin, Lorcet+)

Oral

Parenteral

Hydromorphone (Dilaudid)

Oral

Parenteral

Levophanol (Levo-Dromoran)

Oral

Parenteral

Meperidine (Demerol)

Oral

Parenteral

Methadone (Dolophine)

Oral

Parenteral

Morphine

Oral

Parenteral

Morphine SR (MSContin)

Oral

Parenteral

$30 \mathrm{mg}$ every 3-4 hr

$10 \mathrm{mg}$ every 3-4 hr

NA

NA

NA

Oral

NA
Typical First Dose

$30 \mathrm{mg}$ every 3-4 hr $10 \mathrm{mg}$ every 3-4 hr

25- $\mu$ g-per-hr patch every $72 \mathrm{hr} * *$

$10 \mathrm{mg}$ every 3-4 hr NA

2-4 mg every 3-4 hr $1.5 \mathrm{mg}$ every $3-4 \mathrm{hr}$

$4 \mathrm{mg}$ every 6-8 $\mathrm{hr}$ $2 \mathrm{mg}$ every $6-8 \mathrm{hr}$

$100 \mathrm{mg}$ every $3 \mathrm{hr}$ $100 \mathrm{mg}$ every $3 \mathrm{hr}$

$5 \mathrm{mg}$ every 8-12 hr $5 \mathrm{mg}$ every 8-12 hr

$15 \mathrm{mg}$ every 3-4 hr $10 \mathrm{mg}$ every 3-4 hr

$15 \mathrm{mg}$ every 8-12 hr NA

$15 \mathrm{mg}$ every 3-4 hr

NA 


\section{THE JOURNAL OF HEALTHCARE ETHICS \& ADMINISTRATION}

Vol. 7 | No. 1 (Winter 2021)

Oxycodone CR (OxyContin)

Oral

NA

$10 \mathrm{mg}$ every $8-12 \mathrm{hr}$

Parenteral

NA

$10 \mathrm{mg}$ every $8-12 \mathrm{hr}$

* The information is adapted from The Massachusetts General Hospital Handbook of Pain Management.[1] Equivalent doses of opioids vary markedly according to source. A low dose of an opioid should be used should be used to start and gradually increased until a dose is established that combines maximal analgesia with minimal adverse effects. A short-acting opioid should be used when the patient's pain is occasional, and a long -acting opioid when the pain is constant and frequent. A short-acting opioid can be added to a long-acting opioid to treat breakthrough or incidental pain, but in the treatment of chronic pain the use of nonmedical strategies to treat breakthrough pain is preferable. Rapid or frequent increases in dose should be avoided. Opioid rotation may be useful when dose escalation fails. The new opioid can be started at one half to one quarter of the calculated equivalent dose of the previously prescribed opioid.

NA denotes not applicable

** This is the lowest available dose. There is a risk of overdose in patients unaccustomed to opioid therapy.

+ These are combination formulations (with acetaminophen or aspirin), which have limited usefulness in the treatment of chronic pain.

Ballantyne J, ed. The Massachusetts General Handbook of Pain Management. $2^{\text {nd }}$ ed. Philadephia: Lippincott Williams \& Wilkins, 2002: 562. 


\section{THE JOURNAL OF HEALTHCARE ETHICS \& ADMINISTRATION}

Vol. 7 | No. 1 (Winter 2021)

\section{Appendix C: Pain Management Policy}

\section{PURPOSE:}

The purpose of this policy is to state the Health System's commitment to provide a dignified, comprehensive and collaborative approach to pain management consistent with the Ethical and Religious Directives for Catholic Health Care.

\section{POLICY}

The Health System believes that patients have the right to maximal pain relief at all stages of their acute and/or chronic disease processes. We recognize that appropriate pain management is critical in the care of patients and believe that all patients are entitled to a dignified, comprehensive and collaborative approach to pain management. While we realize that some medicines that alleviate pain in the dying patient may indirectly shorten the patient's life, our goal is to relieve pain and suffering as much as possible.

Although maximal pain relief is the right of all patients, some patients may choose to endure some aspects of their pain as an affirmation of their religious beliefs. The theological foundation of pain management for Christians is rooted in the passion of Christ. "Physical suffering is certainly an unavoidable element of the human condition; ... According to Christian teaching, however, suffering, especially during the last moments of life, has a special place in God's saving plan; it is in fact a sharing in Christ's Passion and a union with the redeeming sacrifice which he offered in obedience to the father's will. Therefore one must not be surprised if some Christians prefer to moderate their use of painkillers, in order to accept voluntarily at least part of their sufferings and thus associate themselves in a conscious way with the sufferings of Christ crucified (cf. Matthew 27:34)." ${ }^{42}$

Respect for the dignity of each patient creates a responsibility for the health care team to respect the free and informed decision by the patient to make medical treatment decisions, including the degree of pain relief desired. The emphasis of pain management should be on the prevention, evaluation and relief of pain. Comprehensive pain management is a multidisciplinary and collaborative effort that must address physical, psychological, spiritual and social effects of unrelieved pain.

\section{PRINCIPLES FOR PAIN MANAGEMENT}

A. The dignity of the human person creates a responsibility for medical professionals to relieve maximally the pain and suffering of patients.

B. Pain management must be tailored to the specific patient's needs and situation and include a comprehensive assessment of pain and an evaluation of the effectiveness of treatment.

C. Patients who possess decision-making capacity are the decision-makers for the course of their medical treatment, including the degree of pain desired. For patients who lack decision-making capacity, the appropriate surrogate, acting in a compassionate and ethical manner, should be the decision-maker.

D. Consistent with our policy of informed consent, placebos should not be used in the assessment and management of pain. However, complementary treatment modalities may be used.

E. All patients will have pain addressed as part of the plan of care and will be taught that pain management is an essential part of treatment.

F. Discharge instructions will include information about pain as it pertains to the patient's individual situation. This will include the cause(s) of pain, recognizing precipitating and relieving factors, available methods of relief and how to use them (including the importance of safe and effective use of medications), and communication to the physician relating to pain and its management

42 Congregation for the Doctrine of the Faith, "Declaration of Euthanasia”, 1980 


\section{PROCEDURE/GENERAL PAIN MANAGEMENT FOR PATIENTS}

\section{A. Assessment}

1. Each patient will be assessed by the nurse and the health care professional on admission for the presence /absence of pain.

2. Each patient will be reassessed for the presence/absence of pain prior to, during and/or following any intervention that may cause pain.

3. Each patient will be assessed for his/her previous experiences with pain, beliefs about and preferences for pain assessment.

4. Every patient will have pain addressed as part of the plan of care.

5. Every patient will be educated to inform the health care professionals when he/she experiences pain, recognizing that communication of unrelieved pain is essential in helping to manage its relief.

a. The staff will utilize one of the available pain scales in assessing a patient's pain. The scale used will be determined by the patient's age and cognitive function.

b. Staff will educate patients with regard to prevention of pain or reduction of pain rather than chasing and reducing pain once pain is established.

6. The patient will be assessed and reassessed for pain. The frequency of assessment and reassessment is based on how well each patient's pain is controlled.

7. Documentation will reflect assessment, reassessment, education, interventions and patient outcomes.

\section{B. Intervention}

1. Response to a patient's complaint of pain will be timely in an attempt to provide quick relief of pain.

2. If initial interventions are not effective to decrease the pain to a level acceptable to the patient, additional methods of pain relief will be sought. These may include other available pharmacologic methods as well as non-pharmacologic methods.

3. If pain relief is sub-optimal, the physician will be notified.

4. Documentation will reflect additional interventions, reassessments and patient outcomes.

\section{C.Pain Management Team Consultation ${ }^{43}$}

1. For hospitalized patients a Pain Management Consult is recommended in the following situations:

a. for any patient admitted with intractable pain

b. for any patient experiencing increasing pain or decreasing relief of pain by current methods utilized.

\footnotetext{
43 It is suggested that the Pain Management Team consist of a physician, registered nurse, social worker, case manager, physical therapist, pharmacist, a pastoral care member, hospice nurse, anesthesiologist, psychiatrist/psychologist, and someone skilled in alternative therapies.
} 


\section{THE JOURNAL OF HEALTHCARE ETHICS \& ADMINISTRATION}

Vol. 7 | No. 1 (Winter 2021)

c. For any patient situation in which the physician desires assistance with pain management for his/her patient.

\section{Patient Education}

1. Patient education is tailored to address the patient's needs, values, abilities, and assessed readiness to learn.

2. The goal of patient education is to include the patient in the management of his/her pain.

3. Education on pain management includes:

a. a general overview of the causes, a rating scale to communicate pain, as well as effectiveness of interventions, and the use of a diary to record occurrences, intensity, treatment and relief

b. pharmacological management

c. non-pharmacological management

\section{PROCEDURE/GENERAL PAIN MANAGEMENT FOR THE GERIATRIC PATIENT}

1. The health care professionals caring for the geriatric patient recognize that the geriatric patient:

a. May suffer from multiple, chronic, painful illnesses and may take several medications

b. Is at greater risk for drug-drug and drug-disease interactions

c. Presents unique problems when assessing for pain - these included physiologic, psychological, religious and cultural changes associated with aging

d. May believe that their pain cannot be relieved and are stoic in reporting their pain especially the elderly and frail elderly

e. May have cognitive impairment, delirium and dementia as well as sensory

problems, i.e. visual and hearing changes.

2. Health care professionals will adjust their assessments for the geriatric patient to include observations for behavioral cues to pain such as restlessness, agitation, or facial grimacing, recognizing that the absence of behaviors does not negate the presence of pain.

3. When appropriate, caregivers or family members will be included when assessment of pain is necessary and will be asked about pain history, interventions and patient outcomes.

\section{PROCEDURE/GENERAL PAIN MANAGEMENT FOR THE PEDIATRIC PATIENT}

1. The health care professionals caring for the pediatric patient recognize that the pediatric patient:

a. Determines pain by many factors including medical/surgical condition, developmental level, emotional and cognitive state, personal concerns, meaning of pain, family issues and attitudes, religion, culture and environment. b. Requires frequent assessment/reassessment of the presence, amount, intensity, quality and location of pain 


\section{THE JOURNAL OF HEALTHCARE ETHICS \& ADMINISTRATION}

Vol. 7 | No. 1 (Winter 2021)

c. Requires prevention or reduction of anticipated pain, and when prevention is not possible, needs prompt alleviation of pain

d. May require the use of a different format for measuring pain, e.g. a "Faces" pain rating scale, gestures, quality of cry or the use of special pain scales such as face scales

2. Health care professionals will adjust their assessments for the pediatric patient to include knowledge of the growth and development level of each individual child.

3. The assessment of the child will include a pain history, an evaluation of diagnoses such as infection that could cause the pain or an increase in the pain, evaluation of the pain severity and location, as well as observation of the child and his or her response to the environment.

4. When appropriate, patients, caregivers or other family members will be included when the assessment of a child's pain is necessary.

5. All interventions are tailored to the developmental level and personality of the child.

\section{PROCEDURE/GENERAL PAIN MANAGEMENT FOR THE DYING PATIENT}

1. Dying patients who possess decision-making capacity are the decision-makers for the course of their medical treatment, including the degree of pain relief desired in the final state of life.

2. It is incumbent on healthcare professionals to make every effort to relieve the pain and suffering of the dying patient even if this requires either intermittent or continued administration of progressively larger doses of opioids. The goal of treatment is to relieve pain and suffering to the fullest extent possible.

3. Dying patients should be assured the maximal possible comfort even in the fact of impending death as heralded by falling blood pressure, declining rate of respiration, or altered level of consciousness.

4. A variety of means for pain relief, including what the patient believes is effective, should be used.

5. Establish a relationship of trust with the patient, so that the patient will not feel abandoned.

\section{CONTINUOUS QUALITY IMPROVEMENT}

The process of managing pain in out patients and its effectiveness will be monitored, evaluated, and revised to continually Improve outcomes. 


\section{THE JOURNAL OF HEALTHCARE ETHICS \& ADMINISTRATION}

Vol. 7 | No. 1 (Winter 2021)

\section{APPENDIX 8 - CHAPTER 8: MEDICAL FUTILITY}

Quote: "Patients argue that if they have the right to withhold or withdraw certain medical treatments this also gives them the right to request certain medical treatments because they know what is in their best interest."

Chapter Objectives: (SWBAT= Students will be able to..)

- $\quad$ SWBAT identify the four categories of medical futility.

- SWBAT craft an argument that analyzes the subjective nature of futility.

- SWBAT define medical futility.

- SWBAT analyze the risks and benefits of a hospital's futility policy

Standards (derived from Common Core State Standards)

\section{CC.1.5.11-12.A}

Initiate and participate effectively in a range of collaborative discussions on grade-level topics, texts, and issues, building on others' ideas and expressing their own clearly and persuasively.

\section{CC.1.5.11-12.G}

Demonstrate command of the conventions of standard English when speaking based on Grades 11-12 level and content.

\section{CC.1.2.11-12.L}

Read and comprehend literary nonfiction and informational text on grade level, reading independently and proficiently.

\section{CC.1.4.11-12.G}

Write arguments to support claims in an analysis of substantive topics.

\section{Overarching Practical Goals of Curriculum:}

Step 1 - The Basics - This chapter serves as an introduction to medical futility; as such, it should help students realize that a balance between the expert opinions of physicians and the qualitative assessments of patients usually is sufficient to avoid legal litigation surrounding medical decisions.

Step 2 - Preparation Techniques - Like the previous chapters that discussed ordinary and extraordinary means, this chapter educates students on topics that strengthen opinions necessary to express opinions in living wills and the appointment of durable powers of attorney that will abide by the wishes of the patient. It is reiterated that students should appoint a durable power of attorney and draft a living will.

Step 3 - Communication - Upon completion of this chapter, students should have an idea of what they would consider qualitatively futile in their own opinions. They may want to consider informing older family members of their religion's stances on overtreatment and distributive justice.

Do Now: What are your thoughts and feelings around medical futility? What does that mean to you? 


\section{THE JOURNAL OF HEALTHCARE ETHICS \& ADMINISTRATION}

Vol. 7 | No. 1 (Winter 2021)

Pre-Chapter Assessment Activity: Each student will answer the following question: Do patients have the right to request any medical treatment that they think is in their best interests? Why? If there is a stark divide between the class, the instructor can moderate a debate.

\section{Sections:}

\section{Introduction}

In a previous chapter the right of a patient/surrogate to refuse medical treatment was examined under the principle of the ordinaryextraordinary means. This constitutional right to refuse medical treatment was extended to the decision maker's interpretation of the patient's wishes. While this settled the controversy surrounding a patient's rights to refuse medical treatment, it started another about whether a patient also has a corresponding right to demand medical treatment. ${ }^{1}$ For the past decade there has been a debate raging within the medical, ethical, and legal communities that has focused on the issue of medical futility. Despite these new concerns, the concept is not new.

Physicians at the time of Hippocrates recognized some medical conditions as futile and recommended no further treatment for the patient. ${ }^{2}$ What has re-fueled the fires of this debate is the patients' rights movement and the perception that the right of self-determination can be used to demand overtreatment. ${ }^{3}$ The patient's right movement began as a reaction to the paternalism of physicians who unilaterally overtreated patients and prolonged their lives against their wishes or the wishes of surrogates and family members. In the 1990's, patients and patient surrogates began to demand treatments that physicians believed were not in the best interest of the patient because they were medically futile and represented an irresponsible stewardship of health care resources. In many legal cases, the courts ruled in favor of the right of patients or their decision makers to request even those medical treatments from which physicians believed they would receive no medical benefit. ${ }^{4}$ This has caused a problem for judges in the court system because there is a lack of institutional policies on medical futility which would be used as a guide to monitor futility situations consistently. ${ }^{5}$ These complex cases have set the stage for the present debate over medical futility, which pits patient autonomy against physician beneficence and the allocation of social resources.

\section{The Debate}

Ethically, patients argue that if they have the right to withhold or withdraw certain medical treatments this also gives them the right to request certain medical treatments because they know what is in their best interest. Physicians argue that many of these

\footnotetext{
${ }^{1}$ Cruzan v. Director, Missouri Department of Health, 110 S. Ct. 2841 (1990); see also Jonsen A., Veatch R., Walters L. Source Book in Bioethics: A Documentary History (Washington, D.C.: Georgetown University Press, 1998): at 229-237.

${ }^{2}$ Hippocrates, “On The Art," in W.H.S. Jones, trans., Hippocrates Vol. II (Cambridge: Harvard University Press, 1981 ), at 193.

${ }^{3}$ In medical futility cases the patient or surrogate wants to pursue the goal of preserving life even if there is little chance or no hope of future improvement, while the other party, the physician, sees dying as inevitable and wishes to pursue the goal of comfort care. For a more detailed analysis, see Council of Ethical and Judicial Affairs, American Medical Association, "Medical Futility In End-Of-Life Care," Journal of the American Medical Association 281 (March 10, 1999): at 937-941.

${ }^{4}$ The two prominent cases here would be the Helga Wanglie case and the Baby K case. For a more detailed analysis of both cases, see In re Helen Wanglie. Fourth Judicial District (District Court Probate Court Division) PX-91-238. Minnesota, Hennepin County; and In re Baby K, 16 F. 3d 590, petition for rehearing en banc denied, no. 93-1899 (L), CA-93-68-A, 28 March 1994.It should be noted that in the Wanglie case the court never addressed the question of whether physicians or the medical center could refuse to provide requested treatment, and thus, the conflict between nonmafelicence and beneficence and autonomy was not resolved. The court ruled that Mr. Wanglie should be appointed his wife's conservator on the grounds that he could best represent his wife's interests. In the Baby K case physicians and ethics committees argued in Virginia that providing certain treatments such as mechanical ventilation to an anencephalic newborn was "futile" and "would serve no therapeutic or palliative purpose," and was "medically and ethically inappropriate." The courts ruled against them.

${ }^{5}$ Council of Ethical and Judicial Affairs, at 938.
} 


\section{THE JOURNAL OF HEALTHCARE ETHICS \& ADMINISTRATION}

Vol. 7 | No. 1 (Winter 2021)

interventions are burdensome for the patient and medically inappropriate. Doctors fear the treatments fail to achieve the proper physiological effect and result in a misuse of medical resources. Allowing these treatments compromises the physician's professional integrity; however, many physicians feel forced to comply with the patient's or surrogate's wishes. ${ }^{6}$

The ever-present fear of courtroom litigation has not only fueled this debate but has placed the very foundation of the physician-patient relationship in jeopardy. Extreme autonomy ignores the fact that the "best interest" standard is rooted in a strong connection between the patient, family, physicians, and community which builds the objective best interest standard. ${ }^{7}$ To address the concerns of both patients and physicians, a balance that avoids both the traditional physician driven overtreatment and recent patient or surrogate driven overtreatment must be found to protect the rights of all involved with care. ${ }^{8}$

From a legal and an ethical perspective, one way to foster this balance would be to analyze instances of possible medical futility on a case-by-case basis. The goal of this process-based approach would be a medical futility policy that protects the patient's right to self-determination, the physician's right of professional integrity, and society's concern for the just allocation of medical resources. This policy would be securely rooted in the moral tradition of promoting and defending human dignity.

\section{Legal Implications}

Futility policies are a relatively new initiative in health care. The state of Texas combined three preexisting laws in 1999 to establish a medical futility policy that can resolve disputes about end-of-life treatment. This law may be used in response to a surrogate, living will, or durable power of attorney's request to either 'do everything' or 'stop all treatment' if the physician feels ethically unable to agree to either request." ${ }^{\prime 9}$ The Texas law has become a model for individual hospitals and for other states that wish to adopt similar futility policies. It should be noted that when a hospital or state implements a futility policy it follows that the threat of litigation opens. This threat is for the benefit of both patients and physicians.

One of the goals in implementing a futility policy is to facilitate communication between the patient or surrogate and the health care staff so that all parties can come to an acceptable agreement regarding the proposed treatment. If agreement is not reached between the physician or hospital and the patient/surrogate either party may seek injunctive relief from the courts or the patient or surrogate may file medical malpractice action. Injunctive relief is when either party turns to an outside counsel to decide on the case.

As mentioned above, implementation of a futility policy may also lead to court injunction. The patient or surrogate may file an action asking a court to order that the "futile" treatment be administered. Likewise, a physician or institution may petition the court for an order that futile treatment not be initiated or if already initiated, that it be discontinued.

Futile treatment decisions today incorporate medical, ethical, social and legal components. The heart of the debate centers on the conflict between individual rights (patient autonomy) and the allocation of medical resources (social justice), but a central component of this debate must be what the physician believes is in the best interest of the patient. Futile treatment policies will not only benefit physicians legally by confirming that the standard of care was not breached, it will also be in the best interest of the patient and society as a whole.

For those physicians who are willing to risk litigation for the sake of preserving their professional integrity, a futility policy does offer legal benefits. Although a futility policy will not protect a physician from litigation, it should enable him or her to gather a strong defense against a medical malpractice claim. A futility policy requires consensus from other physicians and other

\footnotetext{
${ }^{6}$ Brody B. and Halevy A. "Is Futility A Futile Concept?" Journal of Medicine and Philosophy 20 (April 1995): 123-144 at 124.

${ }^{7}$ Drane J. and Coulehan J. "The Concept of Futility, Health Progress 74 (December 1993): 28-32 at 31. See also, Trau J.and McCartney J. "In The Best Interest Of The Patient," Health Progress (April 1993): 50-56.

${ }^{8}$ Schneiderman L., Jecker N. and Jonsen A. "Medical Futility: Its Meaning And Ethical Implications," Annals of Internal Medicine 112 (1990): at $949-$ 950.

9 Fine R. and Mayo T. "Resolution of Futility by Due Process: Early Experience with the Texas Advance Directive Act," Annals of Internal Medicine 138 (2003): 643-746, at 744. Texas Health and Safety Code 166.046 (a) (Vernon Supp 2002). Accessed at www.capitol.state.tx.us/statutes/he/he00116600.html\#he025.166.046 on 5 February 2007.
} 


\section{THE JOURNAL OF HEALTHCARE ETHICS \& ADMINISTRATION}

Vol. 7 | No. 1 (Winter 2021)

interdisciplinary committees within the institution that the proposed treatment is not beneficial to the patient. This consensus among physicians can then be submitted as evidence in any legal proceedings to demonstrate that the standard of care was not breached.

The physician who loses a malpractice claim risks damage to his or her professional reputation and the possibility of an increase in malpractice payment premiums. Even the physician who prevails in a malpractice suit spends substantial time defending himself by meeting with attorneys, answering interrogatories, appearing for deposition and testifying at trial. The threat of litigation alone will deter some physicians from ever invoking a futility policy.

\section{Ethical Analysis}

Futility is defined as "inadequacy to produce a result or bring about a required end; ineffectiveness." ${ }^{10}$ Medically, the concept of "futility," according to the American Medical Association, "cannot be meaningfully defined."11 Essentially, futility is a subjective judgment, but one that is realistically indispensable. ${ }^{12}$ This means that the concept of futility has a different interpretation in all medical cases but is critical in making the proper treatment decisions.

There is consensus within the medical community that at specific times during the course of an illness, some treatments are medically futile; consensus ends however, when attempts are made to create a fully objective and concrete definition. As a result, futility has been confused with interventions that are harmful, impossible, and ineffective.

Distinguishing futility from the concept of harmful and ineffective interventions has led to some clarity. In general, a medically futile treatment is "an action, intervention, or procedure that might be physiologically effective in a given case, but cannot benefit the patient, no matter how often it is repeated. A futile treatment does not have to be ineffective, but it is worthless, either because the medical action itself is futile (no matter what the patient's condition) or the condition of the patient makes it futile." ${ }^{13}$ This definition is great for a theoretical understanding of medical futility, but the challenge is applying this to the bedside of patients in hospitals. Until this happens, there will not be widespread agreement on definitions and implications of futility in general. ${ }^{14}$

\section{Categories of Futility}

Ethicists Baruch Brody and Amir Halevy have distinguished four categories of medical futility that help set futility apart from harmful or ineffective interventions. The first category is physiological futility, which is also known as quantitative futility. This category applies to treatments that fail to achieve their intended physiological effect. Deciding if a treatment is physiologically futile requires analyzing specific practical information about the outcome of the intervention from several perspectives. It is not a vague clinical impression.

The second category is imminent-demise futility which refers to instances in which despite the proposed intervention the patient will die in the very near future. Sometimes the phrase "in the very near future" is replaced with the claim that the patient would not survive past discharge from the hospital.

Brody and Halevy use the third category lethal-condition futility to describe those cases in which the patient has an underlying lethal condition which the medical intervention does not affect. This lethal condition will result in death in the not-toodistant future (weeks, perhaps months, but not years) even if the intervention is used.

\footnotetext{
10 "Futility," in The Oxford English Dictionary Vol. IV (Oxford: Oxford University Press, 1989), at 626.

${ }^{11}$ Council on Ethical and Judicial Affairs, Code Of Medical Ethics (Chicago, IL.: American Medical Association, 1998-1999), \#2.035 at 13.

${ }^{12}$ Council of Ethical and Judicial Affairs, "Medical Futility In End-Of-Life Care," at 938.

${ }^{13}$ Drane and Coulehan, at 29.

${ }^{14}$ Cranford RE. "Medical Futility: Transforming A Clinical Concept Into Legal And Social Policies," Journal of the American Geriatrics Society 42 (1994): 894-898 at 897.
} 


\section{THE JOURNAL OF HEALTHCARE ETHICS \& ADMINISTRATION}

Vol. 7 | No. 1 (Winter 2021)

Finally, qualitative futility refers to instances in which an intervention fails to lead to an acceptable quality of life for the patient. ${ }^{15}$ Obviously, this category is the most subjective because what is acceptable for one person may not be acceptable for another. When a treatment is judged to be qualitatively futile the claim being made is that, although the treatment may succeed in achieving an effect, the effect is not worth achieving from the patient's perspective. ${ }^{16}$ Medically, a consensus concerning the clinical features of medical futility remains elusive. Brody and Halevy's four categories emphasize that decisions on medical futility must be made on a case-by-case basis and must include both a practical component and a role for patient and surrogate input. Determining whether a medical treatment is futile basically comes down to deciding whether it passes the test of beneficence, that is, will this treatment be in the patient's "best interest."

Values, Rights, and Duties

Patients have the right of self-determination to control their own medical treatment, but this does not give patients the absolute right to demand any medical treatment. Physicians have the duty to practice medicine responsibly. They are expected to follow professional norms, standards, and values as guides to their judgments on the appropriateness of medical interventions for their patients. However, this does not mean that physicians can determine medical treatments for patients unilaterally. Ethically, the issue of medical futility focuses on the conflict between the values of the patient and surrogate and the values of the physician. In coming to the assessment of whether a treatment is medically futile, physicians must consider carefully not only the values and goals of the patient and surrogate, but physicians must also consider community and institutional standards. The question is how does the physician balance all these values so that the best interest of the patient is always the central focus? One can argue that the ethical principles of autonomy, beneficence and justice will provide a moral framework. In the following paragraphs these three terms will be defined and explained so you may better understand their importance.

\section{Autonomy}

Autonomy refers to the right of a person to exercise self-determination in making personal and informed choices. In the case of medical futility, autonomy refers to the right of a patient or surrogate to choose their preference of treatment from among certain medically justifiable options. The patient has the right to choose and refuse medical treatments. It is also true that the physician has the right to make choices based on his or her duty to practice medicine responsibly.

In the context of medical futility, both patient and physician have the right of autonomy in making these medical decisions. Legally and ethically, patients have been given the right to refuse medical treatments; however, this right does not imply that they also have the right of access to any medical treatment. Patients have the right to make medical decisions they believe are in their best interest, but at times these decisions may be destructive and irrational choices. It is at this point that patient autonomy conflicts with physician beneficence.

Physicians cannot be forced to make a decision concerning a medical treatment which they believe is not in the best interest of the patient or society as a whole. To do so would violate the professional norms of the physician. To initiate or continue medical interventions even though the patient is no longer able to appreciate any benefit from these interventions is not only an irrational act, but it is also morally irresponsible.

\section{Beneficence}

Beneficence involves the duty to prevent and remove harms and to promote the good of the person. This is done by minimizing the burdens the patient may face and maximizing the benefits. Beneficence includes nonmaleficence, which prohibits the infliction of harm, injury, or death upon others. In determining whether a particular treatment is beneficial to the patient it is important to distinguish between quantitative futility and qualitative futility. Remember, quantitative futility is an objective assessment of a

\footnotetext{
${ }^{15}$ Brody and Halevy, at 127-128.

${ }^{16}$ Griener GG. “The Physician's Authority To Withhold Futile Treatment," Journal of Medicine and Philosophy 20 (April 1995):207-223 at 209.
} 


\section{THE JOURNAL OF HEALTHCARE ETHICS \& ADMINISTRATION}

Vol. 7 | No. 1 (Winter 2021)

particular medical treatment that should be made by the physician. In judging futility, physicians must distinguish between an effect, which is limited to a part of the patient's body, and a benefit, which appreciably improves the person as a whole. ${ }^{17} \mathrm{~A}$ treatment that merely preserves permanent unconsciousness or cannot end dependence on critical care would be considered futile. Physicians have an ethical responsibility to provide those treatments to their patients which they believe will benefit them as a person and not harm them or be too burdensome for them.

In general, patients will make decisions that are rational and in their best interest, but situations arise when they may not be thinking rationally. Physicians need to take the time to communicate with their patients in order to get a better understanding of the physical, emotional, spiritual, and financial values that govern their lives. The values and goals of the patient should help to inform a physician's decisions, but they must be considered alongside the professional standards that reflect medical values. Physicians have the expertise to determine whether a medical treatment is quantitatively futile while patients and surrogates are in the best position to determine whether a medical treatment is qualitatively futile based on their interpretation of ordinary and extraordinary means. Physicians should never comply with a patient' or surrogate's request to offer a treatment that is clearly physiologically futile, burdensome, or certain only to prolong a seemingly meaningless life. Ideally, the physician and patient or surrogate should work together to come to a decision about the appropriateness of a particular medical treatment and whether such treatment will maximize the benefits and minimize the burdens for the patient.

Justice

The principle of justice recognizes that all people should be treated fairly and be given what they are due. The issue of medical futility focuses specifically on distributive justice, that is, the fair, equitable, and appropriate distribution of medical resources in society. One cannot remove the decision surrounding whether a particular medical treatment is futile from the realm of social justice. Medical treatments that are judged to be futile and inappropriate are inconsistent with the standards of society and violate the principle of distributive justice. Access to basic health care benefits for all Americans will never be realized if we continue to offer unreasonable medical care. Despite the important role distributive justice plays in the futility debate, it is rarely mentioned as a major factor. The mention of cost factors and scarce resources in discerning medical treatments brings the criticism that one is "putting a price tag on human life." For most people, this is unacceptable because human life cannot be assigned any monetary value.

As a matter of justice, patients and surrogates cannot be given the absolute right to demand any medical treatment. If patients were given this right it would create a system that "would irrationally allocate health care to socially powerful people with strong preferences for immediate treatment to the disadvantage of those with less power and less immediate needs." ${ }^{18}$ If patients and surrogates are given the absolute right to demand inappropriate and nonbeneficial medical treatments, then justice would be accomplished at the expense of the poor, the powerless, and the marginalized. Failure to consider the allocation of scarce resources in this debate would be a grave injustice.

Father Peter Clark S.J., Ph.D. is the bioethicist for several healthcare systems in the Mid-Atlantic region of the United States and internationally in Palestine. As the principle bioethicist for these major institutions, Clark played an integral part in developing futility policies for them. He writes that since there is no consensus on a definition of futility, a process-based approach for determining futility based on a case-by-case basis is most appropriate. He explains that in conjunction with a medical futility policy, a Palliative Care policy should be in effect so that it is very clear that even when a specific treatment is judged medically futile, care

\footnotetext{
${ }^{17}$ In recent years, a number of prognostic scoring systems have been developed to assist physicians in determining which patients are most likely to benefit from life-sustaining treatment. These systems, which include the Acute Physiology and Chronic Health Evaluation (APACHE) system, use databases to predict the hospital mortality of patients who receive critical care. Depending on the decision criteria used, the systems have positive predictive value of $80 \%$, and a negative predictive value of $90 \%$. These values correlate well with clinical judgment in most cases. Luce JM. "Physicians Do Not Have A Responsibility To Provide Futile Or Unreasonable Care If A Patient Or Family Insists," Critical Care Medicine 23 (1995): at 761. See also, Schneiderman LJ, Jecker NS. \& Jonsen AR. "Medical Futility: Its Meaning and Ethical Implications," Annals of Internal Medicine 112 (1990): 949-954.

${ }^{18}$ Luce, at 764.
} 


\section{THE JOURNAL OF HEALTHCARE ETHICS \& ADMINISTRATION}

Vol. 7 | No. 1 (Winter 2021)

will never be removed. There is a difference between treatment and care, and the Palliative Care policy ensure that a patient will never be abandoned.

To help patients, surrogates, and health care providers better understand medical futility, a copy of a futility policy is included at the end of this chapter (Appendix A). The basics of this policy, while grounded in the Catholic tradition, can serve as a paradigm for a medical futility policy in all hospitals. A sample case of medical futility will all be included at the end of this chapter so readers can apply the concepts explained in the chapter to an actual case seen in a Philadelphia area hospital (Appendix B). Lastly, a copy of a Palliative Care Policy will be attached that should go hand-in-hand with any futility policy (Appendix C). Hopefully, these policies can serve as a paradigm for physicians and hospitals to help resolve some of the medical futility questions that are confronting patients, surrogates, physicians and hospitals today.

Post-Chapter Assessment Activity: Read the steps laid out in the sample Adult Medical Futility

Policy provided in Appendix A. Then, reason why the litigation process is commonly avoided by physicians and patients. It is important to consider this from both perspectives to see how the policy protects the patient's rights and the physician's professional integrity.

OR

Read the case study in Appendix B. Which daughter do you agree with? Cite evidence from the chapter to support your answer.

Closure: Break into four groups, with each group discussing one of the following questions.

Pick one person to report out.

\section{Discussion Questions:}

1. In your own opinion, what is overtreatment? Provide two examples of something that you would deem overtreatment.

2. What advice would you give a patient who disagrees with his or her physician about the futility of a treatment? It may be helpful to include the concepts of "an effect" and a "benefit" in your advice.

3. There are four types of medical futility explained within the chapter. Why are doctors able to weigh their opinions more heavily on some of these decisions than others?

4. Construct the slippery slope argument that is eluded to in this chapter concerning the allocation of medical care to the socially powerful.

Exit Ticket: What are your thoughts and feelings around medical futility? Do these differ than what you thought before the beginning of the chapter? Are these in line with the research? Explain your answer.

\section{Further Reading:}

Please see attached futility policy and case study pertaining to medical futility. 


\section{THE JOURNAL OF HEALTHCARE ETHICS \& ADMINISTRATION}

Vol. 7 | No. 1 (Winter 2021)

\section{Appendix A: Adult Medical Futility Policy}

\section{PURPOSE:}

This policy supplements existing policies on limiting life-prolonging therapies by providing a conflict resolution mechanism to follow when a patient (or surrogate decision maker) requests an intervention that the attending physician assesses to be medically inappropriate.

\section{POLICY:}

In faithful imitation of Jesus Christ the healer, Catholic Health Care facilities have served the sick, the suffering, and the dying in various ways throughout history. This ministry of healing is rooted in the Christian belief that all people are created in the image and likeness of God (Genesis 1:26). Therefore, all human life is sacred and should be treated with dignity and respect from the moment of conception until death. Human life is a gift of God, but death is unavoidable. It is necessary therefore that we, without in anyway hastening the hour of death, should be able to accept it with full responsibility and dignity. It is true that death marks the end of our earthly existence, but at the same time it opens the door to eternal life. Therefore all people must prepare themselves for this event in the light of human values, and Christians even more so in the light of faith. ${ }^{19}$ The task of medicine is to care even when we cannot cure. Physicians and their patients must continually evaluate the use of the technology at their disposal. Reflections on the innate dignity of human life in all its dimensions and on the purpose of medical care is indispensable for formulating a true moral judgment about the use of technology to maintain human life. The use of life-sustaining technology must be judged in light of the Christian meaning of life, suffering, and death. ${ }^{20}$ Physicians, in imitation of Christ the healer, have the duty to make their skills available to all who are sick and dying; but should never forget that it is more important to provide them with comfort, kindness and charity. This service to the people of God is also a service to Christ, who said, "As you did to one of the least of these my brethren, you did to me" (Matthew 25:40).

The traditional goals of medicine, like the goals of Catholic Health Care, have been to heal and to relieve suffering and pain. In recent years, the goal of respecting autonomous patient choices has motivated the establishment of policies that permit patients (or surrogate decision makers) to exercise that autonomy by refusing or limiting an unwanted intervention. These policies are limited to situations in which patients (or surrogate decision-makers) refuse an intervention. This current policy, designed to supplement rather than to supplant currently existing policies on limiting life-prolonging therapies, provides a conflict resolution mechanism to follow when a patient (or surrogate decision maker) requests, rather that refuses, an intervention that the attending of record assesses to be medically inappropriate (commonly referred to medically futile).

This policy affirms both the traditional goals of medicine and the moral value of physician and institutional integrity in discerning the limits of medical interventions that are set forth in the "Ethical and Religious Directives for Catholic Health Care Services." Respect for this integrity provides the basis for the right to refuse to provide a medically inappropriate intervention. It complements the right of patient determination that must be given both voice and effect in any forum for medical decision-making. This appeal to integrity is generally rooted in a combination of concerns such as avoiding harm to patients, avoiding provision of unseemly care, just allocation and good stewardship of medical resources and the belief that human life is the basis of all good but not an absolute good. This policy affirms the value of integrity so long as appropriate institutional review supports the determination of medical inappropriateness.

After following the procedures set forth in this policy, a medically inappropriate intervention maybe withheld or withdrawn, without obtaining the agreement of the patient (or surrogate decision-maker).

\footnotetext{
${ }^{19}$ Congregation for the Doctrine of the Faith, "Declaration of Euthanasia," 1980.

${ }^{20}$ National Conference of Catholic Bishops, "Ethical and Religious Directives for Catholic Health Care Services" 1995 part 5.
} 


\section{THE JOURNAL OF HEALTHCARE ETHICS \& ADMINISTRATION}

Vol. 7 | No. 1 (Winter 2021)

\section{PROCEDURES}

1. When the attending of record determines that an intervention is medically inappropriate but the patient (or surrogate decision-maker) insists that it be provided, the attending of record should discuss carefully with the patient (or surrogate decision-maker) the nature of the ailment, the options - including palliative care and hospice care - the prognosis, and the reasons why the interventions are medically inappropriate. The attending of record should explain that not providing the intervention in question does not mean abandoning appropriate medically, humane care designed to promote comfort, dignity, emotional, and spiritual support.

2. The attending of record should address with the patient (or surrogate decision-maker) the options of patient transfer to another physician or to another institution and of obtaining an independent medical opinion concerning the medical inappropriateness or medical futility of the intervention in question. The attending of record should also provide the patient (or surrogate decision-maker)

3. The assistance of institutional resources (such as nursing, patient care representative, chaplain, social services,) must be made available to the patient (or the surrogate decision-maker) and the attending of record.

4. If, after reasonable effort by the attending of record using the available institutional resources, agreement is not reached between the attending of record and the patient (or surrogate decision-maker), the attending of record who still wishes to limit the intervention must request from the appropriate Department Director a second medical opinion from a physician who has personally examined the patient. The second opinion must be appropriately documented in the patient's chart. Within 48 hours of obtaining the second opinion, the attending of record must prepare the case for review and forward it to the Institutional Ethics Committee. The attending of record must provide to that body clinical and scientific information pertinent to the determination that the intervention is medically inappropriate. Within 48 hours after receipt of the case by the attending of record, the Institutional Ethics Committee must convene to hear the case. The attending of record and the patient (or surrogate decision maker) are requested to appear at the Institutional Ethics Committee meeting to represent their points of view. The Committee will render its recommendations no later than 24 hours after hearing the case. A representative of the Ethics Committee will meet with both parties together to review and discuss the recommendations of the Committee.

5. In the event that both parties cannot reach a consensus after the recommendations of the Institutional Ethics Committee all information will be forwarded by the Institutional Interdisciplinary Review Board (IIRB) ${ }^{21}$ for adjudication.

6. The attending of record must notify the patient ( or surrogate decision-maker) in writing that the case has been forwarded to the IIRB, what it involves, what are its possible outcomes, when and where the review will take place, and that the option of transfer before the meeting exists, but the arranging such a transfer is the responsibility of the patient or (surrogate decision-maker). Absent patient or (surrogate decision-maker) consent to an earlier time, the meeting cannot take place for at least forty-eight (48) hours after the patient or (surrogate decision-maker) is notified.

7. During the IIRB process, the attending of record and the patient or (surrogate decision-maker) are encouraged to be present together to express their views for consideration, including alternative plans of care. This meeting of the IIRB should occur at the acute care facility where the patient is currently hospitalized to facilitate access to the consent and the patient's record's.

8. If a finding of medical inappropriateness is affirmed by the IIRB, medically inappropriate intervention may be terminated and a plan of care established that addresses comfort care and the preservation of patient dignity. ${ }^{22}$ If, however, the IIRB does not concur with the attending of record's determination of medical inappropriateness, the orders to limit the intervention will not be recognized as valid without patient or (surrogate decision-maker) agreement.

\footnotetext{
${ }^{21}$ The Institutional Interdisciplinary Review Board will be a Health Care System Review Board that will be in acute care facilities within the system. The Board members will consist of a physician, a nurse, a social worker, a representative of mission services, a pastoral care member, the bioethicist and legal counsel. The Board will be appointed yearly by the Senior Vice President for Mission and Sponsorship or by the Senior Vice President for Medical Affairs for the system. In addition, the Senior Vice President of Mission and Sponsorship or the senior consultant to the IIRB when appropriate.

${ }^{22}$ Refer to the Palliative Care Policy.
} 


\section{THE JOURNAL OF HEALTHCARE ETHICS \& ADMINISTRATION}

Vol. 7 | No. 1 (Winter 2021)

9. If the IIRB agrees with the determination of medical inappropriateness, intrainstitutional system transfers of the care of the patient to another physician to provide palliative care are allowed. However, intrainstitutional system transfers to another physician to provide the intervention that has been judged by the IIRB to be medically inappropriate will not be allowed.

10. The procedures set forth in this policy may be invoked only by the attending of record or as otherwise authorized by the hospital's medical staff by-laws. Concerns on the part of other health care providers, hospital officials, or family members should be addressed through already existing institutional mechanisms.

\section{RESPONSIBILITY}

Hospital Administration at each facility is responsible for the effective implementation of this policy. 


\section{THE JOURNAL OF HEALTHCARE ETHICS \& ADMINISTRATION}

Vol. 7 | No. 1 (Winter 2021)

\section{Appendix B: Sample Case of Medical Futility}

To understand the issue of medical futility it might be helpful to look at the facts of a particular case. The case in question that convinced us of the need for a futility policy concerned "J.L.," an 87-year-old semi-comatose patient who was admitted several times from a local nursing home to one of our acute care facilities over the course of a few months. She had been ventilator depend ent, semi-comatose and in multiple system failure months before she was first admitted to our facility.

"J.L." did not have an Advance Directive and, therefore, her wishes regarding her medical care were unknown to her physicians. ${ }^{23}$ She appointed both of her daughters as her health care agents. Regrettably, the daughters had diametrically opposed viewpoints regarding their mother's medical treatment. One daughter, "S.A.," claimed that her mother wanted to die peacefully and never would have wanted to be ventilator dependent. The other daughter, "E.L.," contended that her mother valued life and would have wanted all available life-sustaining measures employed. Each time "J.L." was hospitalized in our facility the patient's daughters gave conflicting instructions regarding their mother's medical treatment leaving "J.L.'s" physicians in an unmanageable legal (as well as ethical) position. In one instance when "J.L." was admitted because her feeding tube had become dislodged, "E.L." insisted upon immediate insertion of a central line and hyperalimentation. "E.L." alleged that to do anything short of that would be tantamount to allowing her mother to starve to death. "S.A." refused to consent to insertion of a central line and requested comfort measures only. These conflicting instructions exposed "J.L.'s" physicians to a battery claim if a central line was inserted contrary to "S.A.'s" instructions and a claim of negligence if it withheld inserting the central line contrary to "E.L.'s" instructions.

"E.L." retained an attorney within 24 hours of "J.L.'s" feeding tube becoming dislodged and filed an emergency petition for injunctive relief in the county court asking that the court order "J.L.'s" physicians to insert a central line and begin hyperalimentation. The court entered the order requested by "E.L."

At her final admission to our facility, "J.L.'s" treating physicians diagnosed her with renal failure, possible bowel ischemia, sepsis and gastrointestinal bleeding. "E.L." instructed the treating physicians to proceed with an exploratory laparotomy and dialysis. "S.A.," on the other hand, would not consent to either procedure. The attending surgeon acknowledged that the patient stood less than a $1 \%$ chance of surviving the surgery. Nevertheless, the surgeon was willing to perform the surgery because he feared being sued by "E.L." Likewise, dialysis posed a serious risk to "J.L." because she was already dangerously hypotensive and dialysis would lower her blood pressure even more. Notwithstanding the high risks of surgery and dialysis, "E.L." insisted that both procedures be performed since her mother would certainly die without the interventions.

Once again "E.L." retained counsel who filed another emergency petition with the local court asking the court to order the hospital to "undertake any medical or other care that is necessary to try and preserve the life" of "J.L." Although the court declined to order surgery because to do so would almost certainly result in the patient's demise, the court did order dialysis and "full resuscitation." Less than a week after the court entered its order, "J.L." went into cardiac arrest. In accordance with the court order and "E.L.'s" wishes, "J.L.'s" physicians administered cardiopulmonary resuscitation for 45 minutes without success.

Although a futility policy would not have avoided any of the litigation in the "J.L." case, it would have afforded the treating physicians a venue in which to present the facts of "J.L.'s" medical condition and the likely outcome of the treatment requested by "J.L.'s" daughter. Assuming the review board, known as the Institutional Interdisciplinary Review Board, concluded that the laparotomy and dialysis were futile, "J.L.'s" physicians at least would then have had the endorsement of the Health Care System if they had decided to forego treatment. ${ }^{24}$ Perhaps the judge in the "J.L." case would have ruled differently had the hospital been able to introduce into evidence the fact that "J.L.'s" case had been reviewed by both the Institutional Ethics Committee and the

\footnotetext{
${ }^{23}$ At the time, under Pennsylvania's Advance Directive for Health Care Act, a health care provider must comply with a patient's Advance Directive or transfer the patient to another provider. See 20 Pa. C.S.A. 5401-et seq.

${ }^{24}$ The Institutional Interdisciplinary Review Board (IIRB) is the Health Care System Board that will serve all four acute care facilities within the system in determining medical futility cases. The Board will consist of a physician, nurse, social worker, a representative of Mission Services, a pastoral care member, the bioethicist and legal counsel. The Board will be appointed yearly by the Senior Vice-President for Medical Affairs for the system. In addition, the Senior Vice-President for Medical Affairs will also appoint ex officio a physician from each specialty to serve as a consultant to the IIRB when appropriate.
} 


\section{THE JOURNAL OF HEALTHCARE ETHICS \& ADMINISTRATION}

Vol. 7 | No. 1 (Winter 2021)

Institutional Interdisciplinary Review Board and that both had determined that the surgery and dialysis were medically futile treatments. 


\section{THE JOURNAL OF HEALTHCARE ETHICS \& ADMINISTRATION}

Vol. 7 | No. 1 (Winter 2021)

\section{Appendix C: Adult Palliative Care: Policy And Procedure}

\section{PURPOSE}

The purposes of this policy are to:

- Clarify the meaning of palliative care, often referred to as "comfort care."

- Promote comprehensive and consistent palliative care.

- Establish a process of determining appropriate palliative care for individual patients.

\section{POLICY}

The Health System recognized that in the care of patients with advanced disease it is medically appropriated and ethically acceptable to shift he primary goal of treatment of palliative care if this is judged to be medically appropriate by the patient's physician and consistent with the wishes of the patient or the patient's surrogate.

\section{Definition:}

Palliative care consists of all treatments and services aimed at alleviating physical symptoms and addressing the psychological, social and spiritual

Needs of the patients and their families so as to enhance patients' and families' quality of life to the greatest degree possible.

Palliative Care:

- affirms life and regards dying as a normal process;

- implies the cessation of all diagnostic measures and all life-sustaining and other therapeutic treatments that do not directly contribute to the patient's comfort or to patient and family goals;

- consists of active management of pain and other distressing symptoms. In the relief of pain, it is ethically permissible to administer analgesics, in sufficient amounts, to control the patient's pain even if this has the unintended effect of depressing the patient's respiratory function.

\section{Procedure:}

A. A discussion should be initiated between the attending physician and the patient and /or the patient's family about the appropriateness of shifting goals of treatment to palliative care.

B. The attending physician and other members of the healthcare team should develop a palliative care plan with the patient's family (usually in the context of a family conference), taking into account their particular goals and needs. Special attention should be given to:

- what therapies and procedures should be continued, discontinued or initiated;

- symptom control, especially the management of pain and anxiety;

- the most appropriate setting for the patient's death to occur, including the appropriateness of hospice care.

C. The physician should document the patient's and/or family's agreement with the plan in the medical record.

D. The physician should complete the "Palliative Care Order Form." A general order like "comfort care only" is not acceptable.

E. A regular review of the palliative care plan should occur and adjustments made as the patient's condition changes. 


\section{Appendix D: Adult Palliative Care Order Form}

DATE:

TIME:

\section{RESUSCITATION STATUS}

This patient is no-CPR. In the event of cardiac or respiratory arrest, cardiopulmonary resuscitation will not be attempted. No "code blue" should be called.

\section{INITIATE THE FOLLOWING ORDERS TO PROVIDE COMFORT:}

Pain/air hunger:

Anxiety/delirium:

Sleep:

Constipation:

Diarrhea:

Nausea/vomiting:

Thirst:

Fever:

Other:

3. The following therapies may not contribute to providing comfort. If this patient is currently receiving any of these, please indicate below if they are to be continued or discontinued.

$\begin{array}{lll}\text { IV hydration } & \text { Continue } & \text { Discontinue } \\ \text { Diagnostic procedures } & \text { Continue } & \text { Discontinue } \\ \text { ECG and O2 sat monitoring } & \text { Continue } & \text { Discontinue }\end{array}$




\section{THE JOURNAL OF HEALTHCARE ETHICS \& ADMINISTRATION}

Vol. 7 | No. 1 (Winter 2021)

$\begin{array}{lll}\text { Supplemental } \mathrm{O} 2 & \text { Continue } & \text { Discontinue } \\ \text { Parenteral and/or Enteral nutrition } & \text { Continue } & \text { Discontinue } \\ \text { Arterial lines } & \text { Continue } & \text { Discontinue } \\ \text { Central venous lines } & \text { Continue } & \text { Discontinue } \\ \text { Peripheral venous lines } & \text { Continue } & \text { Discontinue } \\ \text { PT/OT } & \text { Continue } & \text { Discontinue } \\ \text { Blood products } & \text { Continue } & \text { Discontinue } \\ \text { Radiation therapy } & \text { Continue } & \text { Discontinue } \\ \text { Dialysis (Please notify Nephrologist } & & \\ \text { Dr. } & & \text { Discontinue } \\ \text { Blood draws for standing laboratory } & & \\ \text { orders } & \text { Continue } & \text { Discontinue }\end{array}$

4. Please discontinue the following medications:

5. Consult Pastoral Care and Social Work Departments.

6. Hospice Department to evaluate patient appropriateness of hospice care.

Transfer Orders: 


\section{THE JOURNAL OF HEALTHCARE ETHICS \& ADMINISTRATION \\ Vol. 7 | No. 1 (Winter 2021)}

\section{APPENDIX - 9: CHAPTER 9: SPIRITUALITY AND END OF LIFE CARE}

Quote: "Why spend your money for what is not bread; your wages for what fails to satisfy?" (Isaiah 55:2).

Chapter Objectives: (SWBAT= Students will be able to..)

- SWBAT recognize the connection between spiritualty and outcomes in end of life care.

- SWBAT form opinions on spirituality and the significance of pray in end of life care.

- SWBAT identify useful conversational phrases for physicians and patients when discussing spirituality and end of life care.

- SWBAT express a basic understanding of the burial process after death has occurred.

Standards (derived from Common Core State Standards)

CC.1.2.11-12A

Determine and analyze the relationship between two or more central ideas of a Text, including the development and interaction of the central ideas; provide an objective summary of the text

\section{CC.1.5.11-12.C}

Integrate multiple sources of information presented in diverse formats and media (e.g., visually, quantitative, orally) in order to make informed decisions and solve problems, evaluating the credibility and accuracy of each source and noting any discrepancies among the data.

\section{CC.1.3.11-12.B}

Cite strong and thorough textual evidence to support analysis of what the text says explicitly, as well as inferences and conclusions based on and related to an author's implicit and explicit assumptions and beliefs.

\section{CC.1.2.11-12.L}

Read and comprehend literary non-fiction and informational text on grade level, reading independently and proficiently.

\section{Overarching Practical Goals of Curriculum:}

Step 1 - The Basics: Students should recognize the potential significance of spirituality and prayer for positive outcomes at the end of life.

Step 2 - Preparation Techniques: The Rite of Christian Commitment to the Terminally III is a resource students may find useful to use in full or part if they are dealing with sick loved ones. Reading over the Rite may provide solace in times of need.

Step 3 - Communication: Prayer is a powerful tool that students should not be embarrassed to use. Dialogues about the significance of prayer in their lives can help change the atmosphere of end of life care.

Do Now: What do you think happens after death?

Pre-Chapter Assessment Activity: Students will access a pdf copy of a summary of Elizabeth Kübler- 


\section{THE JOURNAL OF HEALTHCARE ETHICS \& ADMINISTRATION}

Vol. 7 | No. 1 (Winter 2021)

Ross's On Death and Dying and read the five stages of grief. Then, they will analyze how spirituality could aid individuals experiencing each stage. The summary can be found here:

https://hdsa.org/wp-content/uploads/2015/02/13080.pdf

\section{Sections:}

\section{Introduction}

For centuries, there has been a debate about the relationship between spirituality and health, specifically, between spirituality and end-of-life care. Despite countless studies on this topic, there is no definitive answer. We can only speculate if there will ever be a definitive answer or if this is one of those areas in life that an individual must determine for himself or herself. As patients and their families face diseases like cancer, Parkinson's, Alzheimer's, HIV/AIDS, etc. they are confronted with decisions about whether to seek aggressive treatment or if it is more appropriate to accept the inevitable and move toward palliative or even hospice care. Questions arise when considering experimental treatments, additional rounds of chemotherapy, further surgeries, tube feeding and hydration, and mechanical ventilation, all for the purpose of extending the patient's life. Issues of quality of life, quality of function, dignity, and respect seem to be pushed by the wayside as the emphasis is placed on quantity not quality of life.

In scripture, Isaiah writes: "Why spend your money for what is not bread; your wages for what fails to satisfy?" (Isaiah 55:2). In the context of medicine, one is left wondering if Isaiah was talking about end-of-life treatments. Death is inevitable and Judeo-Christian tradition has always attempted to walk a balanced path between medial vitalism (that preserves life at all cost) and medical pessimism (that kills when life seems frustrating, burdensome, or 'useless'). Both extremes are rooted in an identical idolatry of life, holding life as the absolute good and death as an absolute evil. ${ }^{1}$ Just because we have the technology to extend life for a prolonged period of time does not mean it should always be done. It is here that a patient faces a tough decision: should one continue aggressive treatment that is likely not beneficial, or does one accept the inevitability of his or her condition and move toward comfort measures. It is at this moment that a patient must face his or her own mortality and spiritual/religious values and concerns become intensified. Many of these spiritual and religious convictions will form the foundation by which many patients base their decision making when confronted about life-sustaining decisions. However, issues arise as many physicians and other healthcare professionals are either unskilled or uncomfortable discussing spiritual and religious values with their patients. This creates an unfortunate predicament as knowing a patient's religious and spiritual values and concerns can help physicians better understand a patient's need and provide them (the patient) with respectful, comprehensive, end-of-life care. ${ }^{2}$. However, to understand the role of spirituality in end-of-life decision making, one must understand the meaning of spirituality.

\section{What is Spirituality?}

Spirituality is word that is not easily defined. Some may even claim that 'spirituality' is a term that even though it is not easily defined, one knows what it means when it is heard or seen in writing. Bioethicist Danial Sulmasy, a Franciscan Brother and physician has written extensively on spirituality. Sulmasy claims that "spirituality is no more and no less than this: one's spirituality is a description of one's relationship with God. Ultimately, it is only God who can satisfy our deepest desires." ${ }^{3}$ Altogether, spirituality is our relationship to what we value most and with our commitment to live in a way that is consistent with what this value of love ultimately demands. ${ }^{4}$ Who we are and the decisions that we make should reflect what we value, believe, and love. Therefore,

\footnotetext{
${ }^{1}$ McCormick, R. "To Save or Let Die: The Dilemma of Modern Medicine," in How Brave A New World?: Dilemmas in Bioethics (Washington, D.C.: Georgetown University Press, 1981): 339-351 at 345.

${ }^{2}$ Lo, B., Ruston D., Kates L. et al. "Discussing Religious and Spiritual issues at the End of Life," Journal of the American Medical Association 287, 6 (February 13, 2002): 749-754 at 749.

${ }^{3}$ Sulmasy D. The Healer's Calling: A Spirituality for Physicians and Other Health Care Professionals (New York: Paulist Press, 1997): at 10.

${ }^{4}$ Gula, R. "Spirituality and Ethics in Healthcare," Health Progress 4 (July-August 2000): 17-19 at 17.
} 


\section{THE JOURNAL OF HEALTHCARE ETHICS \& ADMINISTRATION}

Vol. 7 | No. 1 (Winter 2021)

spirituality is essentially a relationship of love. ${ }^{5}$ Spirituality may name that love, God, Buddha, Allah, etc. or it may be called the "Holy Other." In Christianity, the ultimate love is God. It is important to note that this is not love in the sense marital love between a husband and wife, or brotherly love that one may have for friends and family. This love, from the Ancient Greek "agape", views love as the highest form of love and charity. This unconditional and unceasing love is what God has for man, and what man is called to have for God. Christian spirituality assumes a commitment to live our lives in a relationship with God, which is ultimately revealed in Jesus Christ as the source and end of all love, the One in whom all things have meaning and value. Therefore, spirituality is the experience of God's transcendent love, His overwhelming and universal concern for each individual person. ${ }^{6}$ This relationship of love means that we accept God's love and in turn, become dependent upon God. God loves us unconditionally and expects a response from us, a response of love towards ourselves, others, the world, and ultimately God. Spirituality is interpersonal and complex. "Spirituality takes time to develop. It waxes and wanes. It can grow warm, it can grow cold. It is a relationship that is sometimes in need of healing and forgiveness. It requires commitment despite day in and day out drudgery. It needs time alone for intimate sharing. It needs attention. It needs work." ${ }^{\prime 7}$ Spirituality, in essence, is no different from many of the other relationships one may have. Ultimately, spirituality is about the surrender to the "Voice" that calls you. It requires trust, opening oneself to the Other, allowing the self to be loved, and allowing the Other make demands of you. ${ }^{8}$ Spiritual beliefs are thus fundamental to the identity of many people. "Religious and spiritual variables have been associated with lower levels of mortality in prospective cohort studies, improved recovery from surgery, lower levels of substance abuse, coping with serious illness, immune function in HIV-infected patients, blood pressure control, and lower levels of health care utilization. Patients recognize the importance of these issues in their own lives, and many want physicians to consider these factors in their health care." ${ }^{9}$ Physicians and other healthcare professionals should appreciate the potentially beneficial role that religion and spirituality can play in lives of their patients. More importantly, they must realize how a patient's spiritual beliefs and values can impact their decision-making.

\section{Roles of Spirituality in End of Life Care}

It is difficult to argue that religious faith and spirituality do not play essential roles in dealing with illness and death for many patients and even physicians. It can affect not only the quality of a patient's life but the medical outcome of that patient's condition as well. "Virtually every human culture has prayed in one form or another during times of stress and the closing stages of life. Humans seem to be culturally coded to linking prayer with health and death. "From the early dynasties of China to the aboriginal empires of the Americas, holy men in ancient societies ministered not only to the spiritually fallen but to the physically ill as well. In western civilization, the earliest hospitals were built, staffed, and maintained by religious orders of various denominations. This tradition has endured as religiously affiliated hospitals currently account for $20 \%$ of inpatient care in community hospitals and are registered with the Centers for Medicare and Medicaid Services. ${ }^{10}$ As early as 100,000 years ago, humans began to employ rituals when burying their dead, presumably to aid their (the deceased's) well-being in the next life."11 Despite this, studies on prayer and spirituality's effect in medicine have been inconclusive over the years.

\footnotetext{
${ }^{5}$ Sulmasy, at 13.

${ }^{6}$ Sulmasy, at 12 .

${ }^{7}$ Sulmasy, at 13 .

${ }^{8}$ Sulmasy, at 13.

${ }^{9}$ Olive K. "Religion and Spirituality: Important Variables Frequently Ignored in Clinical Research," Southern Medical Association 97,12 (December 2004): 1152.

${ }^{10}$ Modjarrad K. "Medicine and Spirituality," Journal of the American Medical Association 291, 23 (January 16, 2004): 2880.

${ }^{11}$ O'Hara D. "Is There a Role for Prayer and Spirituality in Health Care?" Medical Clinics of North America 86, 1 (January 2002): 33-46 at 33. See also, Eliade M. The Sacred and the Profane (New York: Harper \& Brothers, 1957); Marrone R. "Dying, Mourning and Spirituality: A Psychological Perspective," Death Studies 23 (1999): 495-519.
} 


\section{THE JOURNAL OF HEALTHCARE ETHICS \& ADMINISTRATION}

Vol. 7 | No. 1 (Winter 2021)

\section{Spirituality's Benefits}

In 1872, Galton published a psychological analysis of the efficacy of prayer through a retrospective study of the effects of prayer on the health of clergy. He concluded that there were no benefits. Galton also cited an earlier study by an Englishman named Guy who concluded that the many prayers offered for the good health of British monarchs afforded them no increased longevity. ${ }^{12}$ However, other studies have concluded that spiritual well-being had a positive impact on an individual's general health. Early interest in the relationship between the spirituality and medicine highlights the legitimacy of the subject's research. However, this research is far from conclusive. A study by Gartner et al., in the 1990's found negative health consequences due to prayer. "They referred to several studies that found anxiety and fear of death to be higher in religious subjects and a tendency to have lower self-esteem. In other instances, studies of religious practice relative to health outcomes are inconclusive at best." ${ }^{13}$ In 1988 , Byrd's study on the efficacy of intercessory prayers (praying on the behalf of another) was recognized as one of the best-designed studies to date. "Byrd reported that during a 10-month period spanning 1982 to 1983, 393 patients who were admitted to the coronary care unit of San Francisco General Hospital and were assigned randomly to either a control group (201 patients) or to a group of 192 patients for whom intercessory prayers would be offered. These patients, the staff, and physicians did not know who were in either group, and the patients were not contacted again after they had given informed consent to be part of the study . . . Byrd concluded that the analysis of events after entry into the study showed the prayer group had less congestive heart failure, required less diuretic and antibiotic therapy, had fewer episodes of pneumonia, had fewer cardiac arrests, and were less frequently intubated and ventilated." ${ }^{14}$ In a randomized, double-blind study in 1994 by Wirth and Mitchell on the effect of healing therapy utilizing intercessory prayer on insulin dosage in type-1 diabetes patients, they found that although there was a reduction in insulin dosage over a period of two weeks in the treatment condition compared to the controlled condition, the difference was not statistically significant. $^{15}$

\section{Other Results of Prayer and Medical Outcomes}

Since 2000, nearly a dozen other studies on the effects of prayer have been done with varying results. These studies have been done at renowned research institutions such as the Mind/Body Medical Institute in Boston, Duke University, etc. ${ }^{16}$ A recent study is one by Herbert Benson et al. on the therapeutic effects of intercessory prayers in cardiac bypass patients. "Patients at 6 hospitals in the United States were assigned to one of three groups: 604 received intercessory prayer after being informed that they may or may not receive prayer; 597 did not receive intercessory prayer also after being informed that they may or may not receive prayer; and 601 received intercessory prayer after being informed that they would receive prayer. Intercessory prayer was done for 14 days starting the night before their Coronary Artery Bypass Grafting (CABG) procedure. The primary outcome was presence of any complication within 30 days of CABG. Secondary outcomes were any major event and mortality." ${ }^{17}$ Benson et al. found that intercessory prayer had no effect on complication-free recovery from CABG, but certainty of receiving intercessory prayer was

\footnotetext{
${ }^{12}$ O'Hare at 35-36. See also Galton F. "Statistical Inquiries Into the Efficacy of Prayer," Fortnightly Review 18 (1872): $125-135$.

13 O'Hara, at 36. See also, Gartner J., Larson DB, Allen, GD. "Religious Commitment and Mental Health: A Review of the Empirical Literature," Journal of Psychology and Theology 19 (1991): 6-25.

14 O'Hara, at 38-39. See also, Byrd RC. "Positive Therapeutic Effects of Intercessory Prayer in a Coronary Care Unit Population," Southern Medical Journal 81 (1988): 826-829.

${ }^{15}$ Wirth DP \& Mitchell BJ. “Complementary Healing Therapy for Patients with Type-1 Diabetes Milletus," Journal of Scientific Exploration 8 (1994): 367-377.

16 Carey B. "Can Prayer Heal? Critics Say Studies Go Past Science's Reach," New York Times (October 10, 2004$)$ : 1-4. http://www.nytimes.com/2004/10/10/health/10prayer.html.

${ }^{17}$ Benson H., Dusek J., Sherwood J. et al. "Study of the Therapeutic Effects of Intercessory Prayer in Cardiac Bypass Patients: A Multicenter Randomized Trial of Uncertainty and Certainty of Receiving Intercessory Prayer," American Heart Journal 151, 4 (April 2006$)$ : $934-942$.
} 


\section{THE JOURNAL OF HEALTHCARE ETHICS \& ADMINISTRATION}

Vol. 7 | No. 1 (Winter 2021)

associated with a higher incidence of complications. ${ }^{18}$ However, the study was limited in that it said little to nothing about the power of prayer or about the prayers of family members and friends. The largest obstacle to any prayer study is the unknown amount of prayers a patient may receive from family, friends, and those who intercede on behalf of the sick and dying daily. ${ }^{19}$ To date, the federal government has spent $\$ 2.3$ million on prayer research since $2000{ }^{20}$

\section{Integrating Prayer}

Despite Benson's study, there is still substantial evidence that prayer, religious values, and spirituality can positively impact health. However, there is reluctance to integrate elements of prayer and spirituality into health care. Instead, those elements are pushed aside, leaving a gap between the practice of prayer and spirituality and the practice of medicine. ${ }^{21}$ In a recent study on the effects of prayer on health McCaffrey et al., found that one third of adults used prayer for health concerns in 1998. However, most patients who responded to the study did not discuss prayer with their physicians. The prayer was most often directed toward wellness and used in conjunction with standard medical care. The study concluded that "physicians should consider exploring their patients' spiritual practice to enhance their understanding of their patients' response to illness and health." ${ }^{22}$ In a 2004 study on patients' views about discussing spiritual issues with their physicians, Ellis and Campbell found that "regardless of religious background, patients' willingness to discuss spiritual health issues may depend on their sense of the physician's qualities such as openness, nonjudgmental nature, respect for others' spiritual views, and attitudes toward spiritual health. The patients' views of how a physician ought to address spiritual issues may favor a direct, principle-based, patient-centered approach in the context of 'getting to know the patient." ${ }^{\prime 23}$ Spirituality, like health, must be viewed holistically, that is, how it is integrated into the vision of the whole person. Spirituality helps to define the purpose and meaning that people find in life and the goals they seek to achieve. Spirituality defines context; it is not content. In other words, spirituality is not just another factor or system that one must consider when treating a patient. To holistically treat a patient, spirituality must be a lens by which a physician must empathize with his or her patient. Research that reduces spirituality to another determining factor of human health misses the point. To bridge this evident gap between prayer and medical practice, research should be reconstructed within the horizon of a more holistic understanding of human health - an understanding that regards spirituality as context, and humans as integrated, multifactorial beings living within a complex social environment. ${ }^{24}$ Physicians need to be more knowledgeable and must change their attitudes toward the relationship between prayer, spirituality and medicine if they are going to understand and treat their patients with dignity and respect.

\section{Getting Physicians Onboard}

It is evident that society places a value on prayer and spirituality, despite the tendency to disregard both in the medical community. Studies have shown that individuals not only have engaged in prayer to improve their health or to overcome disease, but more than half of them would also welcome the opportunity to include their physicians in such endeavors. However, problems arise as physician perception and patient assertion on rarely on the same page. Most physicians are not well equipped to deal with matters of prayer and spirituality in health or the prayerful practices of patients as there is little mention of either in health care or social

\footnotetext{
${ }^{18}$ Benson et al., at 934 .

19 Carey B. "Long -Awaited Medical Study Questions the Power of Prayer," New York Times (March 31, 2006): 1-2 at 2. http://www.nytimes.com/2006/03/31/health/31pray.html.

${ }^{20}$ Carey B. "Long-Awaited Medical Study Questions the Power of Prayer," at 1.

${ }^{21} \mathrm{O}$ 'Hara, at 42.

${ }^{22}$ McCaffrey A., Eisenberg DM, Legedza R. et al. "Prayer For Health Concerns," Archives of Internal Medicine 164 (April 26, 2004 ): 858-862 at 861.

${ }^{23}$ Ellis MR \& Campbell JD. "Patients' Views About Discussing Spiritual Issues With Primary Care Physicians," Southern Medical Journal 97, 12 (December 2004): 1158-1164 at 1163.

${ }^{24} \mathrm{O}$ 'Hara at 42-43.
} 


\section{THE JOURNAL OF HEALTHCARE ETHICS \& ADMINISTRATION}

Vol. 7 | No. 1 (Winter 2021)

science literature. ${ }^{25}$ Additionally, most physicians see spirituality and prayer as the role of the pastoral care team. What these doctors fail to realize is that their pastoral care colleagues are part of the medical team caring for the patient. If the studies are correct, and religious and spiritual beliefs are essential to most people's identities, physicians are obliged to understand them. The physician-patient relationship is one built on trust, and as such, physicians have the responsibility to care for all the needs of their patients, medical and spiritual. This relationship is one that is deeply human and encompasses the whole person. "Healing requires a recognition of the human face of each person one sets out to heal and a communication of the message that both the healer and the healed share a bond that ties them to each other through their humanity, their morality, and the God-given spark of grace that lives in each of them." ${ }^{26}$ The physician-patient relationship is based on mutual trust, honesty, compassion, and communication. Mutuality means patients need to let their physicians know their values and how these values influence their decision making. On the other hand, physicians need to be able to listen and empathize with their patients, accepting their values that are based in religion and spirituality. These discussions can be initiated in various ways. In a study by Ellis and Campbell, "patients particularly valued physician initiation (on questions of spirituality) in cases of 'chronic illness that relates to death and dying' as opposed to less serious presentations. Conversely, one respondent observed that serious illness empowers patients to initiate discussions despite their preference for doctor initiation." ${ }^{27}$ The study also showed that patients felt when physicians talk about spirituality, they (the physicians) are acknowledging their limitation in their power to heal the patient. This reassures many patients that God has the ultimate power. Patients also expressed their concern that physicians know the difference between being an encouraging entity versus a spiritual advisor. Understanding the appropriate boundaries gives patients the feeling of being empowered to set the agenda of spiritual discussions. While patients appreciate physician openness, they distained the imposition of the physician's beliefs onto them. Patients also felt that physicians should know their limitations and utilize pastoral professionals when they need expertise in this area. ${ }^{28}$ This study clearly demonstrates that Americans draw on religious and spiritual beliefs when confronted with serious illness, especially those concerning end-of-life issues, and that physicians have the responsibility to be knowledgeable and sensitive about spirituality. Understanding these aspects is a crucial part of the physician-patient relationship.

\section{What Does Spirituality Do for Patients? Advice for Physicians}

In a recent cross-sectional survey of 2000 practicing U. S. clinicians in which $63 \%$ responded, $56 \%$ of clinicians believed that religion and spirituality had much or very much influence on health, but only $6 \%$ believed that religion and spirituality often changed "hard" medical outcomes. In contrast, most clinicians believed that religion and spirituality often helps patients cope (76\%), puts patients in a positive frame of mind (75\%), and provides emotional and practical support via the religious community (55\%). ${ }^{29}$ The major problem is that many physicians lack the skills and even feel uncomfortable discussing spiritual and religious concerns with patients. ${ }^{30}$ Lo et al. gave some practical suggestions on how to respond when patients and family raise spiritual and religious concerns. "First, some patients may explicitly base decisions about life-sustaining interventions on their spiritual or religious beliefs. Physicians need to explore those beliefs to help patients think through their preferences regarding specific interventions. Second, other patients may not bring up spiritual or religious concerns but are troubled by them. Physicians should identify such concerns and listen to them empathetically, without trying to alleviate the patient's spiritual suffering or offering premature reassurance.

\footnotetext{
${ }^{25}$ O'Hara at 34. See also, Poloma MM \& Pendleton BF. "The Effects of Prayer and Prayer experiences on measures of General Well-Being," Journal of Psychology and Theology 19 (1991): 71-93.

${ }^{26}$ Sulmasy, at 15.

${ }^{27}$ Ellis \& Campbell, at 1161

${ }^{28}$ Ellis \& Campbell, at $1162-1163$.

${ }^{29}$ Curlin F, Sellergren S, Lantos et al. "Physicians' Observations and Interpretations of the Influence of Religion and Spirituality on Health," Archives of Internal Medicine 167 (2007): 649-654 a6 649

${ }^{30}$ Lo et al., at 749. See also, Sloan RP, Bagiella E, Powell T. "Religion, Spirituality, and Medicine," Lancet 353 (1999): $664-667$ and Cohen CB, Wheeler SE, Scott DA. "Walking a Fine Line: Physician Inquiries Into Patient's Religious and Spiritual Beliefs," Hastings Center Report 31 (2001): 2939.
} 


\section{THE JOURNAL OF HEALTHCARE ETHICS \& ADMINISTRATION}

Vol. 7 | No. 1 (Winter 2021)

Third, some patients or families may have religious reasons for insisting on life-sustaining interventions that physicians advise against. The physician should listen and try to understand the patient's viewpoint. Listening respectfully does not require the physician to agree with the patient or misrepresent his or her own views. Patients and families who feel that the physician understands them and cares about them may be more willing to consider the physician's views on prognosis and treatment." ${ }^{\prime 31}$ When dealing with patients who are trying to make a decision about whether to initiate life-sustaining interventions Lo et al. believe the following phrases can be used to elicit the patient's concerns:

1) Use open-ended questions. Examples: Does your trust in God lead you to think about cardiopulmonary resuscitation in a particular way? Do you have any thoughts about why this is happening?

2) Ask the patient to say more. Examples: Tell me more about that. Can you tell me how you think your mother is suffering?

3) Acknowledge and normalize the patient's concerns. Examples: Many patients ask the same type of questions.

4) Use emphatic comments. Examples: I imagine I would feel pretty puzzled to not know. That sounds like a painful situation.

5) Ask about the patient's emotions. Examples: How do you feel about moving toward palliative care? How has it been for you with your wife in the intensive care unit for so long? $?^{32}$

There are also difficulties when a physician is having a discussion with a patient about spiritual and religious issues near the end of life. The following should be avoided:

1) Trying to solve the patient's problems or resolve unanswerable questions.

2) Going beyond the physician's expertise and role, or imposing the physician's religious beliefs on the patient.

3) Providing premature reassurance. ${ }^{33}$

Understanding the religious and spiritual beliefs of a patient can help physicians understand certain treatment decisions made by patients and can also give physicians the ability to provide the necessary support for patients and their families. The following are guidelines for physicians when discussing spiritual and religious issues with patients and families near the end of life:

1) Clarify the patient's concerns, beliefs, values, and needs and follow hints about spiritual and religious issues.

2) Make a connection with the patient by listening carefully, acknowledging the patient's concerns, exploring emotions, and using wish statements.

3) Identify common goals for care and reach agreement on clinical decisions.

4) Mobilize sources of support for the patient and the family. ${ }^{34}$

These guidelines can help physicians better understand their patients, especially their spiritual concerns as they are confronted with end-of-life decisions. By listening to and addressing these concerns, physicians may also help their patients find comfort and closure as they are near the end of life. ${ }^{35}$

\footnotetext{
${ }^{31}$ Lo et al., at 749 .

32 Lo et al., at 750 .

${ }^{33}$ Lo et al., at 751 .

${ }^{34}$ Lo et al., at 753.

${ }^{35}$ Lo et al., at 749
} 


\section{THE JOURNAL OF HEALTHCARE ETHICS \& ADMINISTRATION}

Vol. 7 | No. 1 (Winter 2021)

\section{Bringing it All Together}

After examining studies and listening to patients and physicians in acute care (shorter-term, but urgent care) facilities as they confront terminal illnesses together, it becomes clear that there is a connection between spirituality and health. However, the beneficial effects from spirituality and religion are neither universal nor reproducible, complicated by numerous confounding factors. ${ }^{36}$ Despite all the studies and recent literature in medical journals on this topic there is still a silence concerning how physicians and other healthcare professionals perceive spirituality in terms of health benefits. Until this silence is broken our desire to help patients die with dignity and respect will remain elusive. When many patients are faced with making end-of-life decisions, they do so based on their long-held values that are most times rooted in their religious and spiritual beliefs. Understanding a patient's religious values and initiating conversations about options that are available can help bridge the gap that is formed when a patient is informed further medical treatments are no longer beneficial, and hospice or palliative care is recommended. However, just understanding a patient's spiritual values is not enough. Physicians and healthcare professionals are called to walk with their patients and be present with them as their patients confront the inevitability of death. This is crucial since there is a void between the time a terminally ill patient is informed that additional medical treatment is futile and the initiation of palliative or hospice care. During this time, the potential exists for a patient to be presented with two distinct options. First, the patient can be overwhelmed by the fear of suffering and death, resulting in feelings of abandonment and despair. Second, the patient can, with the support of family and friends and understanding of healthcare professionals, accept the inevitability of suffering and death and grow in his or her dependence upon others and God. This is a time of transition for not only the patient but for family, friends, and even health care professionals. They too confront two options. They can avoid the inevitable by isolating the patient in the hospital, under the guise of what is best for the patient, which can lead to feelings of guilt and remorse after the death of the patient. On the other hand, they can support the terminally ill patient with their loving presence, which allows family and friends, and to a certain extent health care professionals, to face some of their deepest fears - embracing death as a part of the natural cycle of life.

For the patient as well as the family and health care professionals, this period of transition is critical, as it is during this time that the relationship between them is transformed. The transformation can manifest itself in either alienation and despair for the patient, or the essence of acceptance and hope. Unless the disparity between these two options is clearly understood, there is little hope that the patient will die with the dignity and respect that he or she deserves. Understanding these options from a spiritual framework of values and beliefs can help the patient find both comfort and peace of mind as their inevitable death approaches. However, for this to happen, family and health care professionals alike need to understand these two options that confront the patient.

\section{Fear of Abandonment}

Suffering and death are facts of life, yet American culture fosters a sense of denial in regards to these realities. Many Americans do not want to see anything relating to death let alone think or talk about it. We have become a "death-denying" society. As a result, American culture has created a "conspiracy of silence" when confronted with suffering and death. Those who are critically ill and suspected of being terminal tend to be separated from the healthy in society, including their families and friends. These patients are sent off to hospitals, with good intentions, where they enter the strange and often impersonal world of medical care. These patients are then barraged with innumerable medical tests and procedures, attached to the latest in medical technology, and for all intents and purpose, appear to be getting the best medical care insurance can provide. However, these patients are just beginning a long process that leaves some feeling dehumanized. They become just another patient in a particular room with a specific condition or disease. Who that patient is, what he or she has done, where he or she comes from, becomes lost in the world of clinical medicine. Often times, family and friends visit frequently in the beginning, and physicians remain positive and upbeat. Gradually, these visits

\footnotetext{
${ }^{36}$ Daly C. "Religion and the Attending Physician's Point-of-View," Southern Medical Journal 98, 8 (August 2005): 759.
} 


\section{THE JOURNAL OF HEALTHCARE ETHICS \& ADMINISTRATION}

Vol. 7 | No. 1 (Winter 2021)

become less frequent and attitudes become less positive when the diagnosis reveals that the patient is terminal and the prognosis gives the patient only a matter of months to live. For many families and even physicians, the first reaction is to give the patient a sense of false hope. This "conspiracy of silence" takes on a new form. Variations of chemotherapy, radiation therapy, experimental medications, and surgeries are attempted, but in the end, all prove to be nonbeneficial. Instead of facing the inevitability of death, through honest conversations, family members and physicians continue to cultivate the "conspiracy of silence" until they reach the point where the patient ought be told that further medical treatment is useless. It is at this point that loved ones and even physicians can begin to experience feelings of distance and detachment while the patient is confronted with feelings of abandonment and despair. The terminal patient begins to learn that suffering not only alienates one from others, but can also alienate one from self.

Instead of being sensitive to the needs of the terminally ill, talking about their condition and the time they have left, family, friends, and even physicians often distance themselves from the present issue, and their patient. Avoidance and artificiality become the norm at a time when honest, genuine, and loving conversation about death and dying would benefit all concerned. However, many today revert to denial. This avoidance of the inevitable has a profound impact on our culture. In the past, the elderly and the terminally ill died at home with the comfort of family and friends. Their physicians were often time even present at the bedside when they died. Today, many elderly and terminally ill patients end their earthly existence alone in a hospital, feeling useless and abandoned. The distance and silence that results from this insensitivity leads many terminally ill patients to dwell upon the negative aspects of life. They often fear becoming financial and emotional burdens on their families, and realize that many of their dreams and aspirations were never accomplished. As a result, their failures and disappointments become magnified. They begin to question the basic religious and spiritual values that dominated their lives, which now seem to offer little to no satisfaction. Finally, society has shown them firsthand how their impending loss of autonomy can lead to feelings of vulnerability, which only exacerbates feelings of fear and abandonment. These patients have witnessed the fear of isolation, degradation, and humiliation, which they know can lead to the possibility of exploitation, manipulation, and abuse. This sense of fear augments feelings of abandonment and loneliness, leading terminally ill patients to further despair. It is this sense of deep despair that is a driving force behind the ongoing debate over "dying well", that is, with "dignity and respect". As a result, physician-assisted suicide is on the horizon and it is becoming a startling reality. However, there is a viable option that can assist both the patient and loved ones, truly allowing patients to die with dignity and respect. That option is palliative and hospice care which allow patients to die comfortably, surrounded by loves, in peace, with dignity and respect. However, for this option to become a reality, family members, friends, even physicians must commit themselves to be present to the terminally ill patient, and the patient must allow himself or herself to become dependent on them as well.

\section{The Hope of Acceptance Through Dependence On Other And God}

With the initiation of palliative care and the emergence of hospice care, many terminally ill patients, family members, and physicians have the opportunity to face suffering and death together with a new sense of honesty and dignity. Suffering and death no longer need to be feared and avoided, but can be faced with courage and acceptance. The Christian tradition has always argued that pain and suffering have a special place in God's salvific plan. Without glorifying suffering, the Christian tradition has viewed suffering and death within a larger perspective, as part of the redemptive process. By suffering, Christians share in the Paschal mystery. Ethicist Richard McCormick claims that "suffering is not mere pain and confusion, dying is not merely an end. These must be viewed, even if mysteriously, in terms of a larger process: as occasions for a growing self-opening after Christ's example, as various participations in the paschal mystery. ${ }^{37}$ For Christians, pain is suffering must be seen as something more than that which is to be avoided at all costs.

Christians view life within the view of the Christian mysteries. McCormick believes, "just as Christ suffered and died for us to enter his glory, so we who are 'in the Lord,' who are inserted into the redemptive mystery, must expect that our growth 'to

${ }^{37}$ McCormick RA. Corrective Vision: Explorations In Moral Theology (Kansas City, KS.: Sheed and Ward, 1994$)$ : 145. 


\section{THE JOURNAL OF HEALTHCARE ETHICS \& ADMINISTRATION}

Vol. 7 | No. 1 (Winter 2021)

deeper life' will share the characteristics of God's engendering deed in Christ.." ${ }^{38}$ Grave illness is to be seen as an intensifying conformity to Christ. As the human body weakens, ravaged by disease and illness, the strength of Jesus Christ is shared by those who have been baptized into his death and resurrection. This conviction reinforces the view that human persons are completely dependent upon God's love. Christ manifested his supreme dignity by doing God's will - "Not my will but thine be done" (Luke 22:43). Christians are called to that same dependence on God's love as Christ showed on the Cross. This dependence on God manifests itself in our human dependence upon others. Therefore, suffering should not lead only to dependence on God, but to dependence on others. When a person is experiencing pain and suffering, that person needs the help and presence of others. Only through dependence on others and God can one become truly independent.

\section{Dependence}

To understand the full implications of being dependent on others and God, ethicist Drew Christiansen, S.J. developed a 'theology of dependence." Christiansen argues that being dependent on others is an inescapable part of being human. However, for most of our lives we ignore this sense of dependence that binds us to one another. We strive to be self-sufficient, but we will never reach our goal. As finite creatures, we only deceive ourselves by thinking we are in control and that we don't need to rely upon others and rely on God. Christiansen believes that our fear of dependence is misplaced if it is divorced from the Christian approach to it. "Our natural desire is to hold on as long as possible, to maintain our independence, to go it alone. From a faith stance, however, it is possible to let go, to accept support from others, and to find fulfillment in a community of care." ${ }^{\prime 39}$ Outside of faith, we fear that dependence threatens us from subjugation. But for the Christian, the promise hidden in dependence is a fuller communion with the Source of Life. ${ }^{40}$ In the mystery of suffering "we are invited to let go of certainties and trust that the mystery in which we have our being - God - is benevolent toward us." ${ }^{41}$ Letting go of our control and overcoming fear of dependence can only be accomplished if God is made present to the terminally ill patient through the love and presence of others.

Being present to another must occur in both word and action. It is not enough to tell a terminally ill patient to have courage because Christ is suffering with them. We must assume Christ's role for them by our loving presence. Family members, friends, and healthcare professionals must become "silent signs" of God's love and presence by entering into the suffering of the terminally ill patient, not peripherally, but in an intimate and loving way. Such presence allows the terminally ill patient to realize he or she is not alone. God is present to them in the presence of others. Through the loving presence of others, the terminally ill patient finds hope which challenges him or her to keep looking and listening because it now makes sense to hope. Why would God abandon them at such an important moment? The terminally ill patient is called to self-surrender, that is, to place his or her suffering before God, and to trust in God's unconditional love. This self-surrender can only be accomplished with the love and commitment of family, friends, and healthcare professionals. To foster this sense of loving presence and to bridge the transition that exists between termination of medical treatment and the beginning of palliative or hospice care, there is a need for a formal ritual that will strengthen the bond of Christian commitment between the patient and his or her and physicians. The ritual proposed is one called the "Rite of Commitment to the Terminally III." This ritual was designed to help not only the patient but family members, and healthcare professionals to understand the importance of a person's spiritual values and the responsibility we have toward one another as humans, especially as Christians.

\section{The Rite of Christian Commitment to the Terminally III}

During times of crisis and periods of transition, a ritual can play a significant role in the emergence and resolution of such phases. A ritual can be understood as a social, symbolic process which has the potential for communicating, creating, criticizing, and

\footnotetext{
${ }^{38}$ McCormick RA. Health And Medicine In The Catholic Tradition (New York: Crossroad, 1984): 116-117.

${ }^{39}$ Christiansen D. “The Elderly And Their Families: The Problems Of Dependence," New Catholic World 223 (1980): 102.

${ }^{40}$ Christiansen, at 104.

${ }^{41}$ Christiansen, at 102.
} 


\section{THE JOURNAL OF HEALTHCARE ETHICS \& ADMINISTRATION}

Vol. 7 | No. 1 (Winter 2021)

even transforming a specific meaning. It is a dynamic system of symbols, a process constituted by symbols and their significations. Ritual symbols can be any object, activity, relationship, word, gesture, or spacial arrangement which serves as a unit in the ritual process. The major benefit of a ritual is that new relationships may be formed and previous relationships among participants may be strengthened. ${ }^{42}$

The purpose of this particular ritual is for those who minister to the sick and dying to bring together the terminally ill person with family, friends and healthcare professionals at this moment of transition, so that the bond of relationship between them can be strengthened in the presence of God and one another. As a ritual symbol, family members, friends and healthcare professionals will commit themselves in both word and action to be present to the terminally ill patient throughout the remainder of his or her illness and when possible, the patient accepts their commitment. Just as Christ showed great concern for the bodily and spiritual welfare of the sick and dying by his presence to them, so family members, friends, and healthcare professionals, as fellow humans and sometimes Christians, will commit themselves in the "Rite of Christian Commitment to the Terminally III" to do the same. The following is an outline of the "Rite of Christian Commitment to the Terminally III":

\section{Rite of Christian Commitment to the Terminally III}

\section{Introductory Rites:}

\section{A. Greeting}

1. The peace of the Lord be with you always.

$R$. And also with you.

\section{B. Instruction:}

My dear brothers and sisters, the Lord Jesus, who went about doing good works and healing sickness and infirmity of every kind, commanded his disciples to lovingly care for the sick and dying, to pray for them, and to lay hands on them. In this celebration we shall entrust our sick brothers and sisters to the care of the Lord, asking that he will enable them to bear their pain and suffering in the knowledge that, if they accept their share in the pain of his passion, they will also share in its power to give comfort and strength. We ask this through Christ our Lord. Amen. $^{43}$

\section{Liturgy Of The Word}

\section{A. Suggested Readings:}

\section{Hebrew Scripture}

1. Psalm 23

2. Psalm 71

3. Job 7: 1-4, 6-11

\section{New Testament}

1. 2 Corinthians $1: 3-7$

2. Romans 8: 31b-35, 37-39

3. Romans 8: $18-27$

\footnotetext{
42 Kelleher MM. "Ritual," in The New Dictionary Of Theology eds. Joseph Komonchak, Mary Collins, and Dermot Lane (Collegeville, MN.: The Liturgical Press, 1987): 906-907.

${ }^{43}$ The Joint Commission of Catholic Bishops' Conferences, "Order For The Blessing Of Adults," Book Of Blessings, (New York, Catholic Book Publishing Co., 1989): No.383, at 165.
} 
4. Job 7: 12-21

5. Job 19: 23-27

6. Isaiah 35: 1-10

7. Isaiah 52: 13-53:12

8. Isaiah 61: 1-3

9. Wisdom 9: 1, 9-18
4. Colossians 1:22-29

5. Matthew 5: 1-12

6. Matthew 11: 28-30

7. Luke 12: 22-32

8. John 6: 35-40

9. John 6: 53-58

\section{Prayers of Christian Commitment}

The Pastoral Care member will begin by introducing the individual prayers of Christian commitment with a short prayer calling upon God to give comfort and care to the person who is ill. Then each person present will extemporaneously present a prayer for the person who is ill stating his/her intention to be present to the person who is ill throughout the remainder of their illness. The patient, if possible, will then state his/her intention to allow family, friends and healthcare professionals to be present to him/her.

Introduction:

Jesus came as healer of body and of spirit in order to cure all our ills. He chose to be like us in all things, in order to assure us of his compassion. He bore our weakness and carried our sorrows. He felt compassion for the crowd, and went about doing good and healing the sick. With trust let us pray to Jesus that he will comfort (N.) with his grace and that he will fill $(N$.) with new hope and strength.

Family, Friends \& Healthcare Professionals:

I pray that Christ will comfort you as you follow him on the path he has set before you. As your (family member) friend/healthcare professional) I promise to walk with you on your journey and that I will be present to you in both word and action. Just as Jesus felt compassion for the crowd, and went about doing good by caring for them, I promise that I will watch over you, that I will be there when you need me, and that I will show you the love of Christ by my very presence. (N.), in the presence of God and all present, I commit myself to you with the love of Jesus Christ.

Patient:

I accept your commitment to walk with me as I face my illness in the days ahead. I thank God for your love and your presence to me and acknowledge how blessed I am to have you all in my life.

\section{Prayer of Blessing}

All present will extend their hands over the person who is ill and pray the following prayer. At the conclusion of the prayer each person will trace the sign of the cross on the forehead of the person who is ill.

Lord, our God, you sent your only begotten Son into the world to bear our infirmities and to endure our sufferings. Look with compassion upon your servant (N.). Give (him/her) strength in body, courage in spirit, and patience in pain. Support (N.) with your grace, comfort (him/her) with your protection, and give (him/her) the strength to fight against all evil. Since you have given (N.) a share in your own passion, help (him/her) to find hope and consolation in suffering, for you are Lord for ever and ever. Amen

\section{All: Our Father}




\section{THE JOURNAL OF HEALTHCARE ETHICS \& ADMINISTRATION}

Vol. 7 | No. 1 (Winter 2021)

\section{Concluding Rite:}

God of mercy, look kindly on your servant $(N$.$) who has grown weak under the burden of illness. Strengthen$ ( $\mathrm{him} / \mathrm{her}$ ) by your grace and help (him/her) to remain close to you in prayer. Fill ( $\mathrm{him} / \mathrm{her}$ ) with the strength of your Holy Spirit. Keep (him/her) strong in faith and serene in hope, so that (he/she) may give us all an example of patience, and joyfully witness to the power of your love.

Lord, we ask you to soothe the hearts of the family members and friends of (N.) gathered here today. In your loving kindness enlighten their faith, give hope to their hearts, and peace to their lives. We ask this through Christ our Lord. Amen.

\section{Dismissal:}

Go in the peace of Christ to serve him in the sick and in all who need your love. ${ }^{44}$

This ritual may not be applicable for all patients who are terminally ill because of their specific faith beliefs. However, it can be modified to meet the needs of various other faiths. The main point is that all present-patient, family members, friends and healthcare professionals-commit themselves to be present to the patient during the illness and that they will walk with the patient to the conclusion. Such a process has the power to not only transform relationships but strengthen them for the good of all.

\section{$\underline{\text { Grief }}$}

Elizabeth Kübler-Ross's On Death and Dying was a breakthrough analysis of the dying process and the grief that accompanies the passing of a loved one. For both the terminally ill patient and the grieving family, there are stages of grief throughout the process. Kübler-Ross outlines these stages into five major categories. Though an individual may progress through these stages in the following order, it is not always the case. A person may skip stages, reverse, or never experience some. The five stages are denial, anger, bargaining, depression, and acceptance. It is very normal to experience these emotional states throughout the dying process. A more thorough analysis of these stages can be found in her book, and if you or a loved one needs to reach out to a professional counseling or psychiatric services your school has additional resources available.

\section{Conclusion}

Clinical medicine and religious and spiritual values and beliefs are from two distinct worlds and can represent two very different subcultures in our society. Medicine aspires to be objective and scientific; spirituality and religious beliefs are subjective and faithoriented. Healthcare professionals are taught to keep a professional distance; believers seek communion with the community and the world. Tension between these two ways of interpreting experience comes to the surface when confronting the ultimate decisions at the end of life. ${ }^{45}$ The gap between spirituality and medical practice can be bridged if there is an open, honest dialogue between patients, family members and healthcare professionals. Taking the time to understand the values and beliefs of a patient, helping patients think through their values and beliefs as they pertain to medical interventions, listening empathetically and respectfully to patients as they explain their viewpoints, and having a holistic understanding of human health can help alleviate many tensions that confront people at the end of life. Physicians can no longer remain silent when issues of spirituality and prayer surface nor can they fear exploring their patients' spiritual practices. Studies have shown that prayer and spirituality may improve

\footnotetext{
${ }^{44}$ Clark P. "The Transition Between Ending Medical Treatment And Beginning Palliative Care: The Need For A Ritual Response," Worship 72 (July, 1998): $345-354$ at 350-353.

${ }^{45}$ Kuczewski M. "Talking About Spirituality in the Clinical Setting: Can Being Professional Require Being Personal?" Address given at the University of Pittsburgh, Pittsburgh, Pennsylvania (March 2007): 1-22 at 18. http://www.pitt.edu/ cep/calendar.html
} 


\section{THE JOURNAL OF HEALTHCARE ETHICS \& ADMINISTRATION}

Vol. 7 | No. 1 (Winter 2021)

quality of life by enhancing a persons' subjective well-being by providing coping strategies, stress relief, and social support. ${ }^{46}$ Exploring a patient's spiritual and religious values and beliefs will only enhance a physician's understanding of their patients' response to illness and health. The debate within the medical profession about the appropriate place of spirituality in patient care will continue. Many will continue to require substantive evidence that there are objective health outcomes. Others will lower their defenses and begin to dialogue with their patients so that when decisions are made at the end of life, they will understand the basis of their decision-making and will be empathetic toward the ways spirituality allows patients to cope with suffering and death. When this dialogue occurs, then the true meaning of spirituality that is grounded in the love of God and others will transform the experience of dying and will allow patients to die with real dignity and respect.

\section{Post-Chapter Assessment Activity:}

Have students discuss what they found most surprising in the chapter. Once the class has come to a general consensus, have students explain why these were the most surprising findings.

\section{Discussion Questions:}

1. What is spirituality? What objective roles does it play in end of life care?

2. Analyze the difficulties physicians and patients face when discussions surrounding patient spirituality arise. Offer some suggestions to each side on how to handle these dialogues.

3. Do you agree with the information presented in the section titled "Dependence"? Why or why not?

Closure: Report out

Exit Ticket: What are the three most significant takeaways from what you have learned in this course?

\section{Additional Resources:}

1. Albom, Mitch. Tuesdays with Morrie: an Old Man, a Young Man, and Life's Greatest Lesson. New York: Broadway Books, 2017.

2. Hazeldine, Stuart, director. The Shack. Summit Entertainment, 2017

3. Kübler-Ross, Elisabeth. On Death and Dying. Macmillan, 1970.

4. Young, William P., et al. The Shack. Windblown Media, 2007.

\footnotetext{
${ }^{46}$ McCaffrey et al., at 861 .
} 